\title{
Phosphorus acquisition and yield gain in intercropping: empirical studies and meta-analyses
}

\section{Chunjie Li}

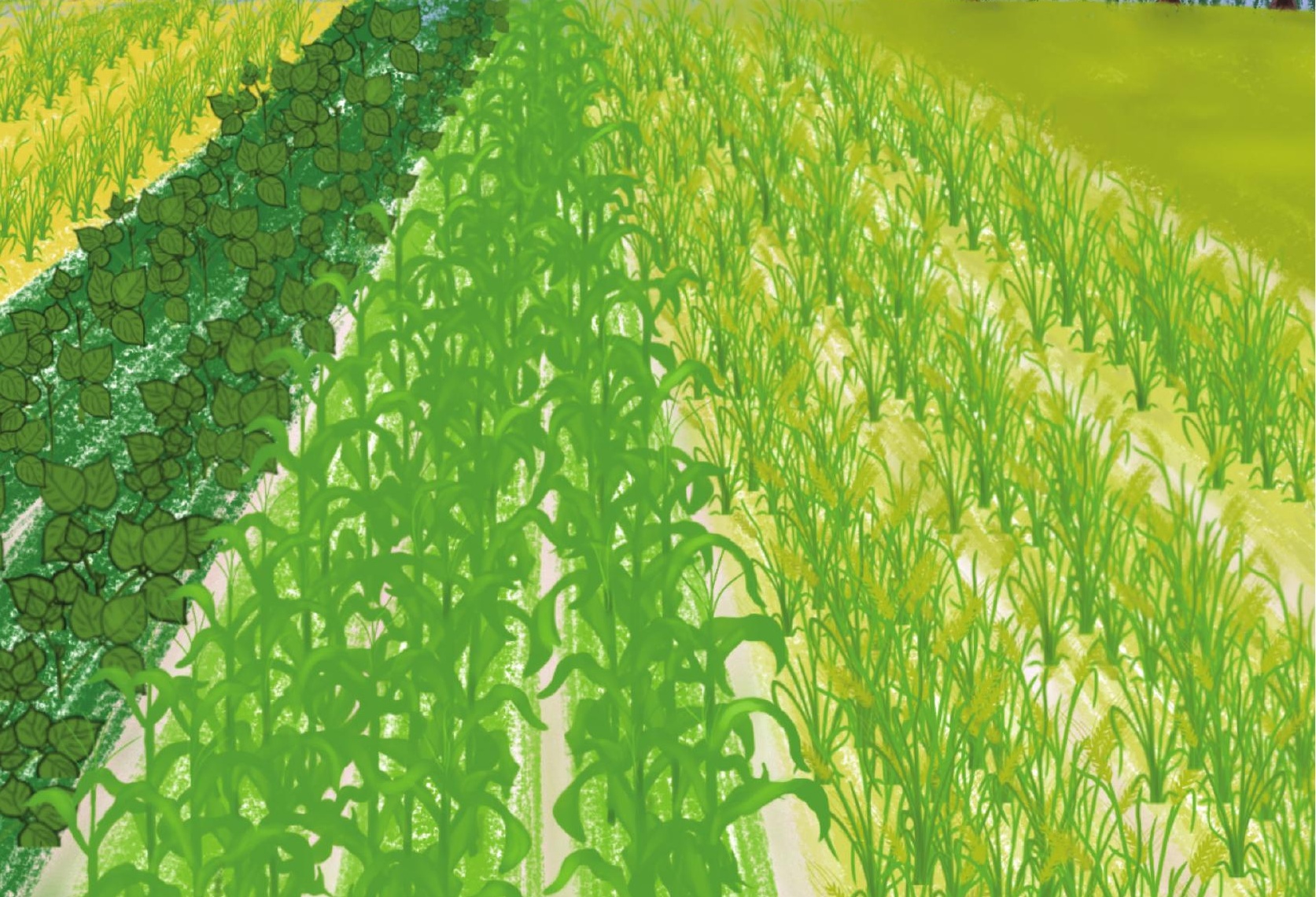




\section{Propositions}

1. Complementarity in P acquisition from different sources does not drive overyielding in intercropping (this thesis).

2. Overyielding by intercropping can be achieved under both high input and low input conditions (this thesis).

3. History of agriculture should be included in the agricultural science curriculum.

4. Social distancing between humans has similar effects on disease spread as plant diversity.

5. Gardening provides inspiration for novel crop combinations.

6. Ecological innovations are made by farmers, not by researchers.

Propositions belonging to the thesis entitled:

"Phosphorus acquisition and yield gain in intercropping: empirical studies and metaanalyses"

Chunjie Li

Wageningen, 16 September 2020 

Phosphorus acquisition and yield gain in intercropping: empirical studies and meta-analyses

Chunjie Li 


\section{Thesis committee}

\section{Promotors}

Prof. Dr E. Hoffland

Personal chair at the Soil Biology Group

Wageningen University \& Research

Prof. Dr Th.W. Kuyper

Personal chair at the Soil Biology Group

Wageningen University \& Research

\section{Co-promotors}

Dr W. van der Werf

Associate professor, Centre for Crop System Analysis

Wageningen University \& Research

Prof. Dr F.S. Zhang

Professor at the Department of Plant Nutrition

China Agricultural University, Beijing, China

\section{Other members}

Prof. Dr L. Mommer, Wageningen University \& Research

Dr D. Makowski, INRAE, AgroParisTech, Université Paris-Saclay, France

Dr A.G.T. Schut, Wageningen University \& Research

Dr A.M.D. van Rotterdam-Los, Nutriënten Management Instituut, Wageningen

This research was conducted under the auspices of the C.T. de Wit Graduate School for Production Ecology and Resource Conservation 


\section{Phosphorus acquisition and yield gain in intercropping: empirical studies and meta-analyses}

\section{Chunjie Li}

\section{Thesis}

submitted in fulfilment of the requirements for the degree of doctor at Wageningen University

by the authority of the Rector Magnificus

Prof. Dr A.P.J. Mol, in the presence of the

Thesis Committee appointed by the Academic Board to be defended in public on Wednesday 16 September 2020 at 11 a.m. in the Aula. 
Chunjie Li

Phosphorus acquisition and yield gain in intercropping: empirical studies and meta-analyses, 214 pages.

$\mathrm{PhD}$ thesis, Wageningen University, Wageningen, NL (2020)

With references, with summaries in English and Chinese

ISBN: 978-94-6395-477-8

DOI: https://doi.org/10.18174/528042 


\section{Abstract}

Intercropping, growing two or more crop species in the same field, is a practice that can contribute to ecological intensification of agriculture. Intercropping has been shown to increase productivity in low phosphorus $(\mathrm{P})$ soils compared to sole crops. The ecological mechanisms underlying these benefits mainly include complementarity and facilitation with respect to resource acquisition. The contribution of these mechanisms to the yield benefit of intercropping probably depends on crop species traits, soil nutrient availability and agronomic practices. This thesis aims to contribute to the design of intercropping systems for improved $\mathrm{P}$ acquisition and yield gain by testing the resource partitioning hypothesis (dissimilarity in $\mathrm{P}$ acquisition traits among plant species leads to enhanced $\mathrm{P}$ uptake by mixtures of crop species compared to sole crops), and by quantifying the absolute yield gain of intercrops and the effect of agronomic practices. It presents results from empirical studies and meta-analyses.

It appeared that the conditions under which the $\mathrm{P}$ resource partitioning hypothesis can be tested are limited. The tested crop species had inconsistent abilities to access the sparingly soluble Ca-bound P, phytate P, P-coated Fe(hydr)oxide, and competitive inequality between them largely determined the interaction. In a pot experiment with low P soils containing a mixture of organic and inorganic P sources, complementarity and facilitation did not result in increased $\mathrm{P}$ uptake by species mixtures, because $\mathrm{P}$ uptake was also affected by the competitive equality of species in the mixture. In a field experiment on a low $\mathrm{P}$ soil, complementarity and facilitation with respect to $\mathrm{P}$ uptake occurred in millet/chickpea relay strip intercropping, but they were not the main drivers for overyielding. In the subsequent meta-analysis on intercropping at the field level, the absolute yield gain of intercropping was mainly attributed to a positive complementarity effect, an outcome of any mechanism reducing competition. This positive complementarity effect was related to complementarity in using resources at different times caused by a relay sequence in the sowing and harvesting of intercropped species. The temporal complementarity in using resources plays an important role in competitive relaxation and hence overyielding. On a global level, there was a set of coordinated management factors rather than a single factor that drove the yield gain of intercropping, resulting in two contrasting syndromes of production in intercropping. The first syndrome was a high input - high output strategy that is maize-based with species arranged in relay strips and with high fertilizer input. The second syndrome was a low input low output strategy that is legume-based and arranged in simultaneous full mixtures or alternate row intercrops with low fertilizer input. Both intercropping strategies saved $16-29 \%$ land and $19-36 \%$ fertilizer compared to monocultures grown under the same management as the intercrop. 
To conclude, there was no evidence for the resource partitioning hypothesis for $\mathrm{P}$ sources in species mixtures. Designing intercropping systems for improved $\mathrm{P}$ acquisition cannot be through the mechanisms of complementarity in $\mathrm{P}$ acquisition from different $\mathrm{P}$ sources. Further research on designing intercropping systems could consider a set of management strategies such as using strip intercropping, a relatively short co-growth period of the two crop species, and including species with high productivity (e.g., maize). 


\section{Contents}

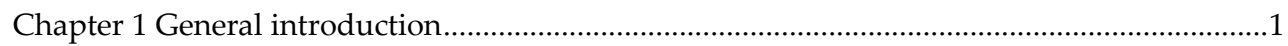

Chapter 2 Testing for complementarity in phosphorus resource use by mixtures of crop species.

Chapter 3 A conceptual framework and an empirical test of complementarity and facilitation with respect to $P$ uptake by species mixtures

Chapter 4 Complementarity and facilitation with respect to $\mathrm{P}$ acquisition do not drive overyielding by intercropping.

Chapter 5 Yield gain, complementarity and competitive dominance in intercropping in China; a meta-analysis of drivers of yield gain using additive partitioning.....

Chapter 6 Syndromes of production in intercropping impact yield gains 105

Chapter 7 General discussion 125

References 143

Appendix A .155

Appendix B 157

Appendix C 161

Appendix D .169

Appendix E .193

Summary (English) .199

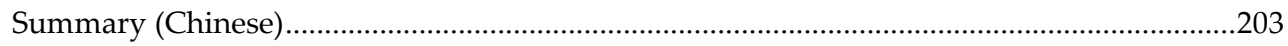

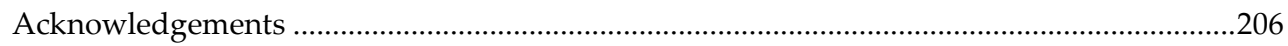

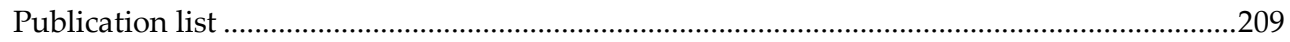

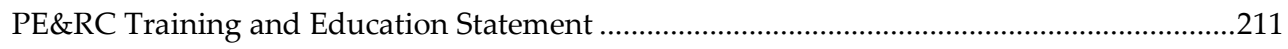

Funding 

Chapter 1 General introduction 


\subsection{Intercropping as a sustainable cropping system}

Increasing crop production is a major challenge for agriculture to meet food requirements of the growing world population (Godfray et al. 2010; Tilman et al. 2011). However, intensive agriculture provides high yields but comes with environmental risks, such as soil erosion and degradation, greenhouse gas emission, and reduced biodiversity in agroecosystems (Matson et al. 1997; Tilman et al. 2002; Foley et al. 2011). Increasing on-farm biodiversity through diversified farming systems is considered to be a key strategy for sustainable agriculture (Bommarco et al. 2013; Raseduzzaman and Jensen 2017; Renard and Tilman 2019).

Intercropping is an ancient agronomic practice that increases productivity by exploring on-farm biodiversity (Bommarco et al. 2018; Martin-Guay et al. 2018). Intercropping is defined as the mixed cultivation of crop species (or varieties of the same species) on the same field (Willey 1979; Vandermeer 1989; Willey 1990). Various crop combinations have been recognized and practiced around the world for centuries (Lithourgidis et al. 2011a; Li et al. 2013). The most obvious advantage of intercropping is to produce a greater yield on a given piece of land compared to sole crops (Willey 1979; Vandermeer 1989; Zhang and Li 2003; Bedoussac et al. 2015). Intercropping also has the potential to make better use of light, water, nitrogen (N), and phosphorus (P) (Zhang et al. 2008; Bedoussac and Justes 2010; Li et al. 2014), suppress pests, diseases (Trenbath 1993; Zhu et al. 2000; Zhang et al. 2019) and weeds (Liebman and Dyck 1993; Banik et al. 2006).

Although intercropping is commonly used by small-scale farmers in developing countries (Machado 2009), it is gaining more attention nowadays in developed countries, especially in organic farming (Wezel et al. 2014; Bedoussac et al. 2015). The benefits of intercropping for nutrient acquisition and yield depend on the species interactions, which can be affected by agronomic managements. To achieve high nutrient acquisition and yield gain, it is essential to design intercropping systems by characterizing crop species' nutrient uptake abilities, selecting appropriate species combinations and management in intercropping.

\subsection{P acquisition and productivity in intercropping}

Cereal/legume intercropping has proven effective for $\mathrm{N}$ use, with complementary $\mathrm{N}$ uptake through $\mathrm{N}_{2}$-fixation by legumes and mineral $\mathrm{N}$ uptake by cereals (Hauggaard-Nielsen and Jensen 2001; Corre-Hellou et al. 2006). In comparison, research into the benefits of intercropping for $\mathrm{P}$ acquisition is in its infancy. $\mathrm{P}$ is a major growth-limiting factor for crop yield. Applied P fertilizer often ends up into P pools (Fig. 1.1) in the soil (Holford 1997; Sattari et al. 2012). Plant roots can only take up $P$ as orthophosphate (ortho-P) anions from the soil solution. Depending on the soil $\mathrm{pH}$, ortho-P exists in several ionic forms, with $\mathrm{H}_{2} \mathrm{PO}_{4}^{-}$and $\mathrm{HPO}_{4}{ }^{2-}$ as the dominant ortho-P forms (Fig. 1.1). The ortho-P concentrations in the soil 
solution are mostly low due to its strong adsorption to soil (Hinsinger 2001). For instance, P is adsorbed to $\mathrm{Fe}$ or $\mathrm{Al}$ (hydr)oxides in acid soils, or is precipitated as sparingly soluble calcium $\mathrm{P}$ in alkaline soils. Some studies have observed that cereal/legume intercrops can achieve an enhanced P uptake and yield compared to sole crops under field conditions, e.g., maize/faba bean intercrop, maize/chickpea intercrop (Li et al. 2003b; Li et al. 2007; Mei et al. 2012; Xia et al. 2013; Li et al. 2018), maize/common bean intercrop (Latati et al. 2014; Latati et al. 2016), maize/soybean intercrop (Wang et al. 2017), barley/pea intercrop (Hauggaard-Nielsen et al. 2009). Intercropping appears a promising way to exploit soil P sources to increase P uptake and sustain yield production on P-deficient soils.

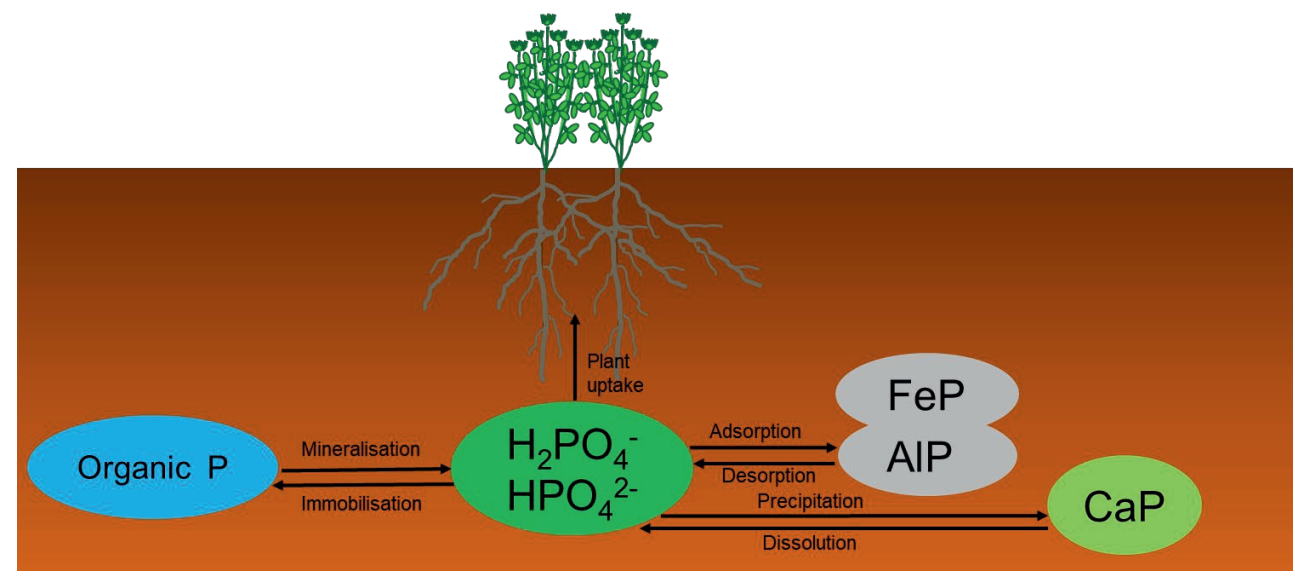

Fig. 1.1 Simplified overview of different phosphorus $(P)$ pools in soil.

The land equivalent ratio (LER) is one of the most commonly used measures to compare the performance of intercrops to that of the corresponding sole crops. It is calculated as the sum of relative yields of component crops in intercropping compared to sole crops (Mead and Willey 1980) (Box 1.1). LER represents the relative land area needed under sole crops to obtain the same yields as are obtained on a unit area of intercrop. The land use efficiency of intercropping averages $1.22 \pm 0.02$ (Yu et al. 2015) or $1.30 \pm 0.01$ (Martin-Guay et al. 2018) in previous meta-analyses. However, LER is a dimensionless ratio and the relative yield can be high if the absolute yields in the intercrop and the sole crop(s) are low. Thus, the LER is not an indicator for the productivity of intercrops but rather for the comparative land use efficiency of intercrops and sole crops. Loreau and Hector (2001) proposed additive partitioning as a statistical method to analyze productivity benefits in plant species mixtures (Box 1.1), which can be applied to quantify the absolute yield gain of intercrops compared to sole crops. 


\subsection{Possible mechanisms for high $P$ use efficiency of intercropping}

\subsubsection{Facilitation and complementarity with respect to $P$ acquisition}

The mechanisms underlying improved $\mathrm{P}$ acquisition by intercropping are mainly due to two processes: facilitation and complementarity. These two mechanisms often occur simultaneously and are difficult to tease apart empirically (Loreau and Hector 2001; Hinsinger et al. 2011; Li et al. 2014). However, they are different conceptually, i.e., facilitation is unidirectional, and complementarity is bidirectional (Fig. 1.2 b, c).

(a)

Competition

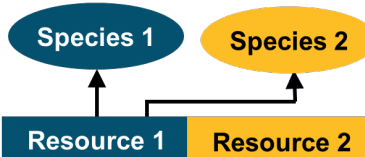

(b)

\section{Facilitation}

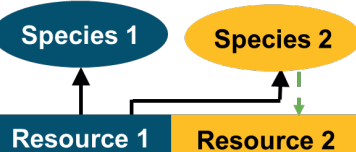

(c) Complementarity

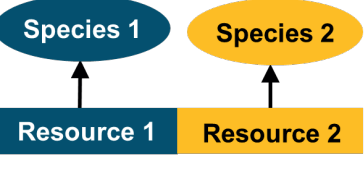

Fig. 1.2 Competition (a), facilitation (b), and complementarity (c) between two species in a mixture. Resources represent different forms of a single resource (e.g., nutrient). Solid arrows indicate uptake of the resource by the species. Dashed arrows indicate mechanisms by which species 2 can alter the resource availability. The increased available resource is available for both species, thereby improving uptake of the resource by the neighboring species 1 (facilitation). This can give rise to changes in competition between both specie (Modified from Hinsinger et al. 2011).

Facilitation and complementarity are contrasted with competition between two species for exploiting a single resource (Fig. 1.2a). Facilitation is defined as the positive interaction by which one species increases the growth, reproduction or survival of the other species through modifying the biotic or abiotic environment (Callaway 1995). Facilitation occurs when a species can modify the resource availability, ultimately benefiting the neighboring species as well (Hinsinger et al. 2011) (Fig. 1.2b). Complementarity refers to a decrease in competition through resource partitioning (Fridley 2001) (Fig. 1.2c). Resource partitioning is roughly synonymous with the term niche partitioning but is more specific to include only resources (Jesch et al. 2018). Resource partitioning includes a variety of biological processes, for instance, species might specialize on different resources (e.g., different $\mathrm{N}$ forms) (McKane et al. 2002) or take up the same resources at different times or from different spatial locations (Hooper and Vitousek 1998; Fargione and Tilman 2005).

The ortho-P pool is the only available P form to plants (Fig. 1.1). There is still no credible evidence that plants can take up organic $\mathrm{P}$. In the case of $\mathrm{P}$ as the resource in the model, the mobilized P through root exudates always ends up into a common ortho-P pool, which is available to both species. The more competitive species may outcompete the other species, and this competition for ortho-P could further promote root exudation by the facilitating 
plant species (Wang et al. 2017). Therefore, to better understand the effect of species interactions on P uptake, a framework is needed to illustrate species interaction, including root exudates and species competitive balance.

Facilitation of $\mathrm{P}$ uptake is hypothesized to be the main mechanism underlying enhanced $\mathrm{P}$ uptake by intercrops ( $\mathrm{Li}$ et al. 2014; Xue et al. 2016). For instance, P-mobilizing species (e.g., legumes) can mobilize P through root exudates (e.g., protons, carboxylates, phosphatases), which then facilitates enhanced $P$ uptake by the cereals when the roots of the intercropped cereals and legumes are close to each other (Fig. 1.2b). Under field conditions, previous studies showed that rhizosphere $\mathrm{P}$ mobilization by legumes facilitated $\mathrm{P}$ uptake by intercropped maize in maize/soybean (Wang et al. 2017) and maize/alfalfa intercropping (Sun et al. 2019a). Rhizosphere acidification and acid phosphatase activity increased in maize/soybean intercropping with root contacts compared to intercrop roots separated with a barrier (Wang et al. 2017). Rhizosphere acidification, carboxylate exudation, and acid phosphatase activity increased in both intercropped maize and alfalfa compared to that in their corresponding sole crops, although maize and alfalfa had similar abilities to exude protons and carboxylates (Sun et al. 2019a). Some pot studies also have reported increased P acquisition by cereals when growing together with legumes, for instance, wheat and maize took up more P when they were mixed with faba bean ( $\mathrm{Li}$ et al. 2016; Zhang et al. 2016), chickpea ( $\mathrm{Li}$ et al. 2003a; Li et al. 2004; Wang et al. 2007), or white lupin (Cu et al. 2005; Dissanayaka et al. 2015). However, other pot studies did not show enhanced P acquisition by either species in the mixture (Wang et al. 2007; Li et al. 2008; Li et al. 2010; Betencourt et al. 2012), although the abilities of legumes to release root exudates are higher than cereals in those studies ( $\mathrm{Li}$ et al. 2008; Li et al. 2010). These variations in results suggest more research is needed to reveal the mechanisms of species interactions and the contribution of root exudates to $P$ uptake by species mixtures.

The mechanism of complementarity in P uptake occurs in species mixtures if two species can tap into distinct $\mathrm{P}$ pools (Hinsinger et al. 2011) (Fig. 1.2c). Plant species have developed different $\mathrm{P}$ acquisition strategies to access sparingly soluble $\mathrm{P}$ sources in soil (Vance et al. 2003; Shenoy and Kalagudi 2005). For instance, in response to P deficiency, rice showed increased root growth to acquire soil P (Dissanayaka et al. 2016), and rape enhanced exudation of malate and citrate to mobilize the sparingly soluble calcium P (Hoffland et al. 1989). Faba bean had a stronger ability to acidify the rhizosphere and hence had a higher ability to access calcium P than soybean and maize (Zhou et al. 2009). Pigeon pea enhanced P uptake in low-P tropical soil by producing piscidic acid that chelates Fe from Fe phosphates (Ae et al. 1990). Chickpea also secreted large amounts of acid phosphatase to hydrolyze organic $\mathrm{P}$ in soil (Li et al. 2004). However, no plant species is superior in accessing all sparingly soluble $\mathrm{P}$ pools 
(Pearse et al. 2007), because the P mobilizing strategies (e.g., increasing root growth, exudation of protons, carboxylates, and phosphatases) require energy and hence carbon (Bais et al. 2006; Preece and Peñuelas 2020), which causes trade-offs between P mobilization strategies (Gao et al. 2007; Ryan et al. 2012).

Dissimilarity in plant traits is an important driver of increased nutrient uptake in diverse agroecosystems (Faucon et al. 2017). According to the resource partitioning hypothesis proposed by Turner (2008), competition for P would be alleviated by tapping different organic $\mathrm{P}$ forms by different species in the mixtures. However, experimental evidence for this hypothesis on the mechanism of complementarity in accessing different $\mathrm{P}$ sources by species mixtures is ambiguous compared to the well-known complementarity in accessing $\mathrm{N}$ sources (soil mineral $\mathrm{N}$ and atmospheric $\mathrm{N}_{2}$ ) by cereal/legume mixtures (Hauggaard-Nielsen and Jensen 2001; Corre-Hellou et al. 2006).

Several studies have reported potential difference in accessing different $\mathrm{P}$ sources between species in a species mixture. To demonstrate that different species can tap into different $\mathrm{P}$ pools, the depletion of soil $\mathrm{P}$ fractions was determined after plant growth in previous studies (Cu et al. 2005; Li et al. 2008). However, the legumes hardly took up any P in those studies, which did not provide the evidence for accessing different $\mathrm{P}$ sources by different species in the mixture. Ahmad-Ramli et al. (2013) showed that two species (an arbuscular mycorrhizal grass and an ericoid mycorrhizal plant) had different abilities to access P sources and this study tested the reduction in competition for $\mathrm{P}$ uptake by species mixtures growing with a mixture of $\mathrm{P}$ sources compared to growing on single $\mathrm{P}$ source. However, $\mathrm{P}$ was not the limiting factor, and the results did not demonstrate that the enhanced $\mathrm{P}$ uptake was due to complementarity in acquiring $\mathrm{P}$ resources. The lack of evidence for complementarity in $\mathrm{P}$ uptake suggests that further research is needed to test complementarity in acquiring different P sources.

\subsubsection{Species dominance}

In addition to the mechanisms of complementarity and facilitation with respect to resource use, increased nutrient uptake and yield of intercrops may also be due to species dominance. For instance, species dominance occurs in intercropping if one species takes up the most of the nutrient in monoculture and has a higher nutrient uptake at the expense of the other species in the mixture. This effect is known as the selection effect, and the complementarity and facilitation with respect to resource use are often collectively referred as the complementarity effect (Loreau and Hector 2001). Complementarity and selection effects are two components of net effect in plant species mixtures based on the additive partitioning method proposed by Loreau and Hector (2001) (Box 1.1). The complementarity and selection effects are mathematical derivations, which can inform hypotheses on the ecological 
mechanisms underlying the net effect of biodiversity (or intercropping). The complementarity effect is the overall average relative change in yield or biomass in a mixture, scaled by the average yield or biomass of the sole crops (Box 1.1). A positive complementarity effect indicates the occurrence of mechanisms of complementarity or facilitation concerning resource acquisition in a species mixture (Loreau and Hector 2001). The selection effect measures the association between relative yield gain and the sole crop yield of a species (Loreau and Hector 2001). The value of the selection effect characterizes to which extent the dominance of the more productive species in terms of nutrient uptake, biomass production or space occupancy is responsible for the absolute yield gain of the mixture.

The additive partitioning method has been widely applied in biodiversity studies (Cardinale et al. 2007; Turnbull et al. 2013) and has also been applied in a few intercropping studies (Malezieux et al. 2009; Zhang et al. 2014; Li et al. 2018) to quantify the contribution of complementarity effect and selection effect to the increased nutrient acquisition or increased growth of intercrops. Zhang et al. (2014) showed that the increased biomass production of maize/bean/squash intercropping was largely associated with a positive complementarity effect rather than a selection effect. Li et al. (2018) reported that enhanced P acquisition in maize/faba bean intercropping was almost entirely due to positive complementarity effect, but the increased $\mathrm{P}$ acquisition by maize/chickpea intercrops was due to a large contribution of a positive selection effect. However, no overarching analysis on multiple studies has been made to quantify the contribution of complementarity effect and selection effect to yield gain by intercrops.

\subsection{Agronomic practices impact intercropping performance}

To take advantage of the complementary aspects of species' niches, component species in intercropping systems are often combined based on species' functional traits, for instance, combinations of tall and short species, cereal and legume species, or C3 and C4 species. The contributions of the complementarity effect and selection effect to the increased P acquisition by intercrops depend on species combinations (Li et al. 2018).

Crop species can be grown simultaneously or partly so, and in no distinct row arrangement (mixed) or in alternate rows or strips on the same field (Li et al. 2013). In northwest China, the temperature sum is not enough to grow two consecutive crops in a growing season but enough to grow two crops that partly overlap in a growing season as relay intercropping. For instance, in maize/soybean (Yan et al. 2010; Yan et al. 2015) and maize/pea intercropping (Tan et al. 2020b), maize is sown in strips of several rows, alternating with several rows of the other species (C3 species). Because of its late growing season, maize is usually sown and harvested after the $\mathrm{C} 3$ species. The alternate-row intercropping and mixed intercropping are popular in organic farming with low input in Europe. Mixed intercropping is also widely practiced in 
tropical areas with limited use of resources and machinery (Vandermeer 1989). These intercropping systems include a legume and a C3 species grown and harvested at the same time (Bedoussac et al. 2015). An index for temporal niche differentiation (TND) was proposed by $\mathrm{Yu}$ et al. (2015) to quantify the relative non-overlap in growing period of the two species on a scale of 0 (simultaneous growth) to 1 (the first species is harvested before the second is sown) (Box 1.1). Yu et al. (2015) showed that LER increases with TND.

The stress gradient hypothesis (Maestre et al. 2009; He et al. 2013a) assumes that facilitative interactions between species dominate in unfavorable environments, but competitive interactions dominate in favorable environments. For instance, the relative yield advantage of maize/common bean intercropping was greater under P-deficient conditions than under P-sufficient conditions (Latati et al. 2016). However, the stress gradient hypothesis has not always been confirmed in previous studies. The relative yield increase of intercropping was shown to be independent of the $\mathrm{P}$ fertilizer application rate under field conditions (Mei et al. 2012; Tang et al. 2016; Li et al. 2018). The relative advantages of P uptake and yield of maize/alfalfa intercropping were greater under high $\mathrm{P}$ than low $\mathrm{P}$ conditions (Sun et al. 2019b).

Therefore, species trait combination, temporal and spatial arrangement, and fertilizer input might influence the effect of interspecific interactions on resource use and the absolute yield gain of intercrops. How the interactive effects of these management factors impact yield gain and the contribution of the complementarity effect and selection effect to yield gain is not clear.

\subsection{Knowledge gaps and research objectives of this thesis}

Based on the above, I identified the following knowledge gaps in improving $\mathrm{P}$ acquisition and yield gain in intercropping.

1) The resource partitioning hypothesis assumes that dissimilarity in species' capabilities to access $\mathrm{P}$ sources leads to enhanced $\mathrm{P}$ uptake by species mixtures. However, there is a shortage of empirical evidence for this hypothesis compared to the well-known complementarity in accessing $\mathrm{N}$ sources by cereal/legume mixtures;

2) Previous meta-analyses have shown the land use efficiency of intercrops. However, the absolute yield gain of intercrops and the drivers of yield gain are still unknown;

3) Agronomic practices (e.g., selection of species, temporal and spatial arrangement, and fertilizer input) impact species interactions in intercropping, but it is still unknown how combinations of these factors affect yield gain of intercrops.

The research objectives of this thesis are:

1) to test for complementarity in $P$ acquisition from different sources by intercrops;

2) to quantify the absolute yield gain of intercrops and the drivers of yield gain; 
3) to study the effect of species trait combination, temporal niche differentiation, spatial arrangement, and $\mathrm{N}$ and $\mathrm{P}$ fertilizer input on yield gain of intercrops.

\subsection{Research approach}

In this thesis, to achieve the above research objectives, I investigated crop species $\mathrm{P}$ uptake traits and species interactions concerning $\mathrm{P}$ acquisition, and management factors in intercropping, using a combination of empirical studies and meta-analyses (Fig. 1.3).

In the empirical chapters, I characterized species' capabilities to access sparingly soluble $\mathrm{P}$ sources (i.e., Ca-bound P (CaP); phytate (PhyP); P-coated Fe (hydr)oxide (FeP)) and selected species combinations that have different capabilities to access two different P sources (Table 1.1). Then I tested whether there were absolute increases in $P$ uptake and biomass by comparing the P uptake and biomass of species mixtures to that expected from sole species.

I carried out a sequence of studies under conditions with different levels of complexity (Chapters 2-4, Fig. 1.3): using quartz sand (an inert substrate without interaction between $P$ ions and the mineral phase), or soil as substrate, or growing a species combination in the field. Pot experiments with quartz sand were the simplest conditions that allow for the application of a single P source or a mixture of two P sources. The pot experiment with soil provided a more complicated condition than pot experiments using sand as a substrate. I selected four different soils and mixed them with a mixture of two P sources, respectively, where both complementarity and facilitation with respect to P uptake could occur simultaneously. In the field experiments, the conditions were the most complex among these studies because both the mechanisms of complementarity and facilitation with respect to $\mathrm{P}$ uptake and temporal complementarity in resource use could occur simultaneously. In these empirical studies, the mechanism of complementarity in P uptake referred to the reduced competition for P uptake by species mixture through accessing different $\mathrm{P}$ sources by different species in a species mixture.

I conducted meta-analyses to quantify the net effect of intercropping on yield (i.e., the absolute yield gain) extracted from field intercropping studies and investigated how management affects the outcomes of species interactions (Chapters 5 and 6, Fig. 1.3). The complementarity in resource use could not be specifically quantified because of the lack of studies about complementarity in accessing resources, especially the studies on complementary $\mathrm{P}$ acquisition in field experiments. Thus, I applied the additive partitioning method (Loreau and Hector 2001) in intercropping to quantify the complementarity effect and selection effect, which represent the outcomes of species interactions and can inform hypotheses on the mechanisms of species interactions underlying the net effect of intercropping. 


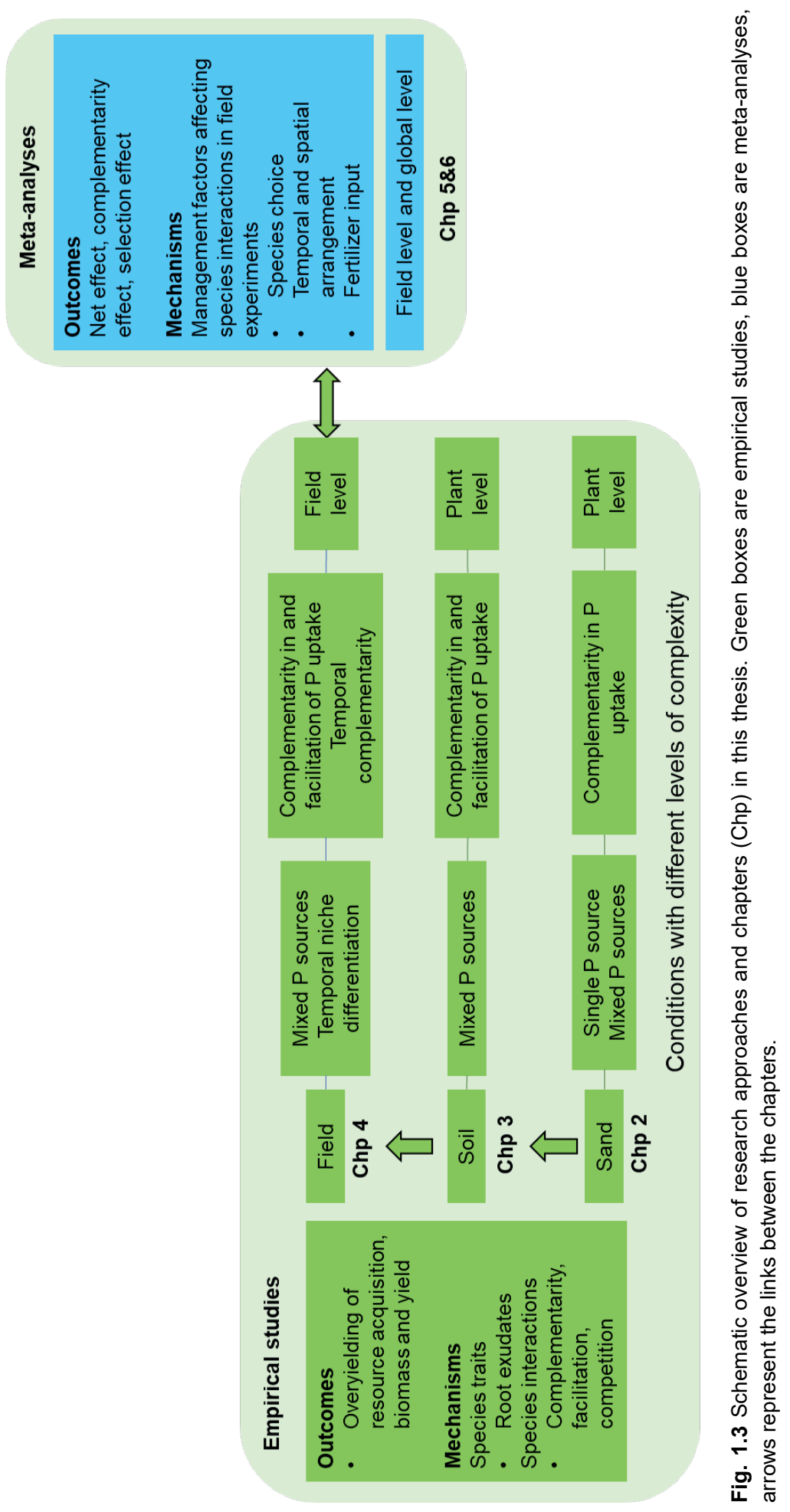


Many field studies on intercropping have been done in China over the past thirty years. That has resulted in ample data on intercropping from China. The first meta-analysis focused on the data from intercropping field studies conducted in China. To test whether the conclusions on intercropping in China hold for intercropping worldwide, a second meta-analysis focused on data from intercropping on a global scale. The net effect of intercropping (measured in $\mathrm{Mg}$ $\mathrm{ha}^{-1}$ ) depends on yield level of intercrops, and the yield of forage crops is often determined as the total biomass, which is substantially higher than the grain yield of grain intercrops. Therefore, the meta-analyses in this thesis were only on grain intercrops (e.g., cereals, legumes, and oilseed crops).

Table 1.1 Overview of resource sources and crop combinations used in empirical studies and the datasets used in the meta-analyses.

\begin{tabular}{|c|c|c|c|}
\hline Approaches & Substrate/dataset & Resource sources & Species combinations \\
\hline \multirow[t]{3}{*}{$\begin{array}{l}\text { Empirical } \\
\text { studies }\end{array}$} & $\begin{array}{l}\text { Pot experiments } \\
\text { with inert } \\
\text { substrate (quartz } \\
\text { sand) }\end{array}$ & $\begin{array}{l}\text { Single P source (CaP; PhyP; } \\
\text { FeP); mixed P sources } \\
\text { (CaP/PhyP; FeP/PhyP) }\end{array}$ & $\begin{array}{l}\text { Millet (Setaria italica)/chickpea } \\
\text { (Cicer arietinum); Cabbage } \\
\text { (Brassica oleracea)/faba bean } \\
\text { (Vicia faba); Wheat (Triticum } \\
\text { aestivum)/maize (Zea mays) }\end{array}$ \\
\hline & $\begin{array}{l}\text { Pot experiment } \\
\text { with soil }\end{array}$ & $\begin{array}{l}\text { Mixed P sources } \\
\text { (calcareous soils mixed with } \\
\text { CaP/PhyP; acid and neutral } \\
\text { soils mixed with FeP/PhyP) }\end{array}$ & $\begin{array}{l}\text { Millet/chickpea; Cabbage/faba } \\
\text { bean; Wheat/maize }\end{array}$ \\
\hline & Field experiments & $\begin{array}{l}\text { Mixed } P \text { sources } \\
(\text { CaP/Phy } P)\end{array}$ & Millet/chickpea \\
\hline \multirow[t]{2}{*}{ Meta-analyses } & $\begin{array}{l}\text { Field studies in } \\
\text { China }\end{array}$ & Light and soil resources & 19 grain intercrops from literature \\
\hline & $\begin{array}{l}\text { Global field } \\
\text { studies }\end{array}$ & Light and soil resources & 50 grain intercrops from literature \\
\hline
\end{tabular}

Note: CaP: Ca-bound P, PhyP: phytate-P, FeP: P-coated Fe (hydr)oxide.

\subsection{Outline of the thesis}

In Chapter 2, I tested the mechanism of complementarity in acquiring different $\mathrm{P}$ sources by species mixtures under the simplest conditions in pot experiments with an inert substrate (quartz sand), which allows for the addition of a single P source and mixed P sources. The hypothesis was that if two species had different capabilities to access two P sources, their mixture would acquire more $\mathrm{P}$ from the mixed $\mathrm{P}$ sources than the average $\mathrm{P}$ uptake from 
single $\mathrm{P}$ sources, due to reduced competition for a single $\mathrm{P}$ source. First, I tested the capabilities of twelve species to access different sparingly soluble P sources. Then I selected species combinations with and without complementarity in acquiring $\mathrm{P}$ sources based on species' dissimilar or similar capabilities to access different $\mathrm{P}$ sources.

In Chapter 3, I tested whether dissimilarity in $\mathrm{P}$ uptake from different $\mathrm{P}$ sources led to improved $\mathrm{P}$ uptake and growth of species mixtures compared to sole species under a complex condition: soils mixed with a mixture of $\mathrm{P}$ sources, where both mechanisms of complementarity and facilitation with respect to $\mathrm{P}$ uptake could occur together. I determined root exudates (e.g., carboxylate concentration and acid phosphatase activity), P uptake, and biomass of plants, and I developed a conceptual framework to determine the relative role of co-occurring mechanisms of complementarity and facilitation with respect to $\mathrm{P}$ uptake by species mixtures.

In Chapter 4, I investigated the occurrence of the mechanisms of complementarity and facilitation with respect to $P$ uptake and their role in overyielding of $P$ uptake and yield of millet/chickpea relay strip intercropping on a low P soil in the field. The root exudates and depletion of $\mathrm{P}$ pools were determined to characterize the differential P uptake traits of the component species. Overyielding of P uptake, biomass, and yield were assessed under low and high $\mathrm{P}$ levels to test the hypothesis that the mechanisms of complementarity and facilitation with respect to P uptake more likely occur at low P level than at high P level, in agreement with the stress gradient hypothesis.

In Chapter 5, I synthesized the field studies on intercropping in China to quantify the absolute yield gain of intercrops and the contributions of the complementarity effect (informs the occurrence of complementarity and facilitation with respect to resource use in intercropping) and the selection effect (informs species dominance in intercropping) to the yield gain. I also investigated the effect of species trait combination, temporal niche differentiation, and nutrient availability on the yield gain, complementarity effect, and selection effect.

In Chapter 6, I conducted a global meta-analysis based on two datasets, which include data from field intercropping studies in China (Chapter 5) and outside China (Yu et al. 2015). I also studied how combinations of management factors such as species choice, spatial and temporal arrangement, and fertilizer input impact yield gain.

In Chapter 7, I integrate the results of the above chapters and discuss the implications for understanding the mechanisms and relevance of the mechanisms of complementarity and facilitation with respect to $\mathrm{P}$ uptake underlying overyielding and the effect of management factors on yield gain. Besides, I derive suggestions for the future design of intercropping systems. 


\section{Box 1.1 Calculation of index}

\section{Land equivalent ratio (LER)}

The land equivalent ratio (LER) is calculated as the sum of relative yields of component crops in intercropping compared to sole crops (Mead and Willey 1980). It is numerically the same as the relative yield total (RYT; De Wit 1960).

$L E R=\frac{Y_{1}}{M_{1}}+\frac{Y_{2}}{M_{2}}$

where $Y_{1}, Y_{2}$ are the yields (per unit of total area of the intercrop) of species 1 and 2 in intercropping, $M_{1}, M_{2}$ are the yields (per unit area of the respective sole crop) of species 1 and 2 in monoculture. A LER of 1 means the same land use efficiency for intercrops and sole crops, while a LER greater than 1 means that, to produce the same sole crops yield as in a unit area of intercrop, more land area of sole crops would be needed.

\section{Additive partitioning method}

The net effect (NE) is defined as the difference between the observed yield and the expected yield (Loreau and Hector 2001).

$N E=\left(Y_{1}+Y_{2}\right)-\left(E Y_{1}+E Y_{2}\right)$

$Y_{1}$ and $Y_{2}$ are the observed yields of species 1 and 2 in intercrop, $E Y_{1}$ and $E Y_{2}$ are the expected yields $(E Y)$ of two species.

$N E=\mathrm{CE}+\mathrm{SE}=N * \overline{\Delta R Y} * \bar{M}+N * \operatorname{cov}(\Delta R Y, M)$

Here, $\overline{\Delta R Y}$ is the average relative yield gain of the two species, $\bar{M}$ is the average yield of sole crops, and $\operatorname{cov}(\Delta R Y, M)$ is the covariance between the relative yield gain in the intercrop and the sole crop yield. $N$ is the number of species, which is in all cases of this thesis $N=2$.

\section{An index for temporal niche differentiation (TND)}

An index for temporal niche differentiation was calculated using sowing dates and harvest dates of each species in the intercrop (Yu et al. 2015):

$\mathrm{TND}=\frac{P_{\text {system }}-P_{\text {overlap }}}{P_{\text {system }}}=1-\frac{P_{\text {overlap }}}{P_{\text {system }}}$

Where $P_{\text {overlap }}$ represents the period of overlap between the growing periods of the intercropped species, while $P_{\text {system }}$ represents the duration of the whole intercrop. TND $=0$ means both species are sown and harvested at the same time. TND $=1$ means no overlap, i.e., double cropping (the second species is sown after the first is harvested). 



\section{Chapter 2 Testing for complementarity in phosphorus resource use by mixtures of crop species}

Chunjie Li, Thomas W. Kuyper, Wopke van der Werf, Junling Zhang, Haigang Li, Fusuo Zhang, Ellis Hoffland

This chapter is published as:

Li C, Kuyper TW, van der Werf W, Zhang J, Li H, Zhang F, Hoffland E (2019) Testing for complementarity in phosphorus resource use by mixtures of crop species. Plant and Soil 439:163-177. https://doi.org/10.1007/s11104-018-3732-4 


\begin{abstract}
The phosphorus $(\mathrm{P})$ resource partitioning hypothesis assumes that dissimilarity in $\mathrm{P}$ acquisition traits among plant species leads to enhanced $\mathrm{P}$ uptake by crop combinations compared with their sole crops. We developed and implemented a test for this hypothesis.

Two pot experiments were conducted with quartz sand. In Experiment 1, the ability of the crop species to acquire $\mathrm{P}$ from sparingly soluble sources (Ca phosphate (CaP), phytate (PhyP) and P-coated Fe (hydr)oxide (FeP)) was tested. In accordance with the species performances in Experiment 1, combinations of millet/chickpea and cabbage/faba bean (which have dissimilar P acquisition traits) and wheat/maize (which have similar traits) were selected for Experiment 2. The biomass production and P uptake were compared between the sole crops and species combinations as well as between the single and mixed P sources.

A dissimilarity in $\mathrm{P}$ acquisition traits enhanced $\mathrm{P}$ uptake by millet/chickpea on CaP/PhyP (as expected) but not by cabbage/faba bean on FeP/PhyP. Despite their similar P acquisition traits, we found enhanced $\mathrm{P}$ uptake by wheat/maize on $\mathrm{CaP} / \mathrm{PhyP}$.

Because of complicating factors such as unstable $\mathrm{P}$ acquisition traits and competitive inequality between species, the conditions under which the $\mathrm{P}$ resource partitioning hypothesis can be tested are limited. This challenge complicates designing for complementarity in soil $\mathrm{P}$ pools by intercrops.
\end{abstract}

Keywords: complementarity, intercrop, phosphorus, resource partitioning, competition 


\subsection{Introduction}

Phosphorus $(\mathrm{P})$ is an essential macronutrient that limits crop production in many agroecosystems. Most soils contain sufficient amounts of $\mathrm{P}$ to sustain multiple crops, but only a small proportion of the total amount of $\mathrm{P}$ is potentially available to plants due to its strong binding to the solid phase of the soil. In acid soils, a major fraction of $\mathrm{P}$ is adsorbed to metal(hydr)oxides, while it is found in the form of sparingly soluble Ca phosphates in calcareous soils. Organic P is a major component of many soils (Stutter et al. 2015), especially in soils in which the $\mathrm{pH}$ is low (Holford 1997; Hinsinger 2001). Due to these interactions, the $\mathrm{P}$ applied to agricultural soils tends to become unavailable, resulting in large $\mathrm{P}$ reserves in arable soils (Shenoy and Kalagudi 2005; Sattari et al. 2012; Faucon et al. 2015; George et al. 2016).

Plants with an efficient $\mathrm{P}$ acquisition strategy can access these soil $\mathrm{P}$ reserves. Several plant traits promote $\mathrm{P}$ acquisition, namely, expanding soil-root contact by increasing the root surface area (e.g., by growing thinner roots or by enhancing root-hair production), symbioses with mycorrhizal fungi and/or the exudation of P-solubilizing organic compounds such as phosphatases and carboxylates and/or protons (Vance et al. 2003). Some P acquisition traits are plant species-specific and/or solubilize specific forms of P. For instance, faba bean (Vicia $f a b a)$ can acidify the rhizosphere and thereby mobilize Ca phosphate (CaP) relatively well compared with other insoluble P forms (Zhou et al. 2009). Pigeon pea (Cajanus cajan) mobilizes Fe phosphates in low-P tropical soils by producing piscidic acid (Ae et al. 1990). Rape (Brassica napus) can effectively utilize CaP by exuding malate and citrate (Hoffland et al. 1989). Chickpea (Cicer arietinum) secretes larger amounts (per root fresh weight or per g of soil) of acid phosphatase into the rhizosphere than maize (Zea mays) to mobilize organic P (Li et al. 2004).

All P acquisition strategies require energy and carbon (Bais et al. 2006); therefore, there are trade-offs between them. For example, inoculating with arbuscular mycorrhizal fungi (AMF) reduces the quantity of carboxylates in the rhizosphere (Gao et al. 2007; Ryan et al. 2012), and there is an inverse relationship between root phosphatase activity and mycorrhizal colonization in plants (Nasto et al. 2017). This is probably why one plant species usually does not combine two $P$ acquisition strategies.

It is generally accepted that dissimilarity in functional traits promotes complementarity in nutrient acquisition (e.g., soil P) (Crème et al. 2016; Faucon et al. 2017), and increases productivity in natural and agricultural ecosystems (Lambers et al. 2008; Marquard et al. 2009; Garnier et al. 2016; Wagg et al. 2017). These variations in functional traits are thought to form the cornerstone of reduced competition through niche partitioning and to promote facilitation and ecological complementarity (Loreau et al. 2001; Grime 2006). Facilitation is defined as the 
beneficial effect of one plant species on another (Callaway 1995), which occurs in stressful environments (Michalet et al. 2006). The most obvious examples of facilitation in agricultural ecosystems come from intercropping, as reviewed by Li et al. (2014), Faucon et al. (2015) and Xue et al. (2016). P-mobilizing crops can improve P availability for themselves and neighboring non-P-mobilizing species through the exudation of protons, carboxylates and phosphatases, as in the case of wheat or maize intercropped with faba bean (Li et al. 1999; Li et al. 2016), chickpea (Li et al. 2003; Li et al. 2004; Wang et al. 2007), white lupin (Cu et al. 2005; Dissanayaka et al. 2015), or shrubs mixed with Proteaceae species (Muler et al. 2014).

Complementarity refers to niche differentiation, the rationale being that species with different traits may occupy different space (e.g., rooting depth) or time (e.g., sowing time or growth dynamics and species phenology), or use different resources (e.g., $\mathrm{N}$ or $\mathrm{P}$ forms), and they will compete less intensely than species with similar traits (Adler et al. 2013; Brooker et al. 2015). Turner (2008) hypothesized that partitioning for different forms of soil organic $P$ would alleviate competition for $\mathrm{P}$ among coexisting plant species with different abilities to access these organic P compounds. Hinsinger et al. (2011) extended Turner's hypothesis to intercropping systems (the cultivation of multiple crop species in a single field), in which two intercropped species would tap into distinct pools of soil P resources, e.g., inorganic and organic P. They referred to it as complementarity in soil P pools. In intercropping, there is ample evidence for the complementary use of light (Zhang et al. 2008; Zhu et al. 2015), water (Morris and Garrity 1993) and $\mathrm{N}$ sources (mineral soil $\mathrm{N}$ and atmospheric $\mathrm{N}_{2}$ ) (Hauggaard-Nielsen et al. 2001; Fan et al. 2006). However, unlike N, the differential acquisition of $\mathrm{P}$ sources by various plant species is difficult to determine because of the absence of stable isotopes that may be used in experiments to distinguish between P pools.

To test Turner's and Hinsinger's hypotheses, the following four criteria must be fulfilled within the experimental design: (1) P is the unique factor limiting plant growth; (2) the species have differential access to different $P$ sources (trait dissimilarity); (3) there is overyielding in the species combination, which indicates that the total $\mathrm{P}$ uptake by the plant species combination is higher than the mean P uptake by the sole species; and (4) there is overyielding by the plant species combination on the mixed $P$ sources compared to the single $\mathrm{P}$ sources, which indicates that the total $\mathrm{P}$ uptake by the plant species combination from the mixed $\mathrm{P}$ sources is higher than the mean $\mathrm{P}$ uptake from the two single $\mathrm{P}$ sources. A comparison of sole plant species and their mixtures (3) is needed to demonstrate overyielding. We designate this occurrence "general overyielding" because it can be due to any interaction between the two plant species, including complementarity in the time and location of $\mathrm{P}$ uptake, complementarity in soil $\mathrm{P}$ pools, and shifts in the balance between intraspecific and interspecific competition. No distinction can be made among these mechanisms on the basis 
of the observed overyielding. The comparison of both single and mixed P sources (4) is the ultimate test for "specific overyielding" due to complementarity in soil P pools. This analysis is imperative, because mechanisms other than P partitioning could cause general overyielding in plant species combinations as well and thereby result in the false attribution of causality.

Several studies have reported (the potential for) $\mathrm{P}$ source partitioning and its effect on plant interactions in mixtures, but they did not fulfil the four criteria and hence did not allow for a test of Turner's and Hinsinger's hypotheses. Steidinger et al. (2015) investigated the abilities of tropical montane tree species to use different organic $\mathrm{P}$ forms, and therefore, they provided only the conditions for P use complementarity in species mixtures (criterion 2). Ceulemans et al. (2017) proposed that partitioning for P resources by grassland species contributed to the biodiversity in low-P ecosystems. However, these researchers doubled the amount of $\mathrm{P}$ in mixtures of inorganic and organic P compared to the treatment with a single P source, which could be the reason why the competition between the grassland species was relaxed. Ahmad-Ramli et al. (2013) included both a species mixture (an arbuscular mycorrhizal grass and an ericoid mycorrhizal plant) and a P mixture, but the low plant biomass (only 2-3 $\mathrm{mg}$ for the ericoid mycorrhizal plant), large size differences (the grass biomass was two orders of magnitude larger) and $\mathrm{N}$ limitation of their experimental system rather than P-limitation (based on foliar N:P ratios between 1 and 4) hamper the interpretation as a demonstration of complementary P source uptake as the driving factor for overyielding.

An alternative approach is to study the performance of sole crop species and their combination on soils with the subsequent fractionation of various $\mathrm{P}$ forms in the rhizosphere of these species to demonstrate the depletion of different P sources. $\mathrm{Cu}$ et al. (2005) investigated the depletion of soil P pools (i.e., citric acid-leachable and water-leachable P) by white lupin (Lupinus albus) and wheat (Triticum aestivum) separately and in combination. This study showed that white lupin alone selectively depleted the citric acid-leachable $\mathrm{P}$ and wheat depleted water-leachable P (complying with criterion 2), whereas their mixtures depleted both P pools. However, the white lupin in this study did not actually take up any $\mathrm{P}$ from the substrate, because the total $\mathrm{P}$ content of the lupin $(0.75 \mathrm{mg}$ in the sole crop or mixtures) was less than the seed P, which was estimated as $1.2 \mathrm{mg}$ (Watt and Evans 2003). Therefore, criterion 1 (P is plant growth-limiting) was not met. The same applies to Li et al. (2008), who investigated the depletion of the soil P fractions by monocrops of common bean (Phaseolus vulgaris) and wheat (Triticum turgidum subsp. durum (Desf.) Husn.) and their intercrops and demonstrated significant differences in various $\mathrm{P}$ pools in the soil after plant growth. However, neither plant species took up any $\mathrm{P}$, and the reported overyielding was due to $\mathrm{P}$ dilution effects rather than to differential uptake from different $\mathrm{P}$ sources. 
We aimed to design a test for complementarity in $\mathrm{P}$ resource use with combinations of crop species. We used a pot experiment with quartz sand as the substrate to be able to supply mixed and single P sources (criterion 4, above). We first grew twelve plant species (commonly used in intercropping) that were supplied with three different single P sources to test their abilities to take up P from sparingly soluble P sources. We then combined two selected species with or without complementary abilities to access two different $\mathrm{P}$ sources (criterion 2) and then supplied these species with a single P source or mixed P sources. We hypothesized that if two crop species differ in their abilities to access two P sources, their combination acquires more $\mathrm{P}$ from mixed $\mathrm{P}$ sources than from a single $\mathrm{P}$ source (criterion 4), due to the alleviation of competition for a single P source. We also tested the null hypothesis: if two crop species do not differ in their abilities to access two P sources, then their mixture does not acquire more $\mathrm{P}$ from mixed $\mathrm{P}$ sources than from a single $\mathrm{P}$ source. Note that increased $\mathrm{P}$ acquisition by species mixtures from mixed $\mathrm{P}$ sources in comparison with expectations based on sole species can only yield data that comply with criterion 3 and do not constitute a proper test for our hypothesis related to specific overyielding.

\subsection{Materials and Methods}

This study included two pot experiments, both of which used acid-washed quartz sand (grain size $\pm 1 \mathrm{~mm})$ as the substrate $\left(0.78 \mathrm{mg} \mathrm{kg}^{-1} \mathrm{P}\right.$-Olsen, $\mathrm{pH} 6.4$ in water (1:2.5)). Each pot $(160 \times$ $210 \mathrm{~mm}$ ) was filled with $2 \mathrm{~kg}$ of quartz sand and nutrient solution. The experiments were conducted in the greenhouse of China Agricultural University, Beijing.

\subsubsection{Experiment 1: $P$ acquisition ability of crop species}

The aim of the first experiment, conducted from October through December 2015, was to test the ability of different species to access sparingly soluble P sources. Heating was applied to maintain the temperature in the greenhouse range from a minimum of $13{ }^{\circ} \mathrm{C}$ at night to a maximum of $25^{\circ} \mathrm{C}$ during the day.

The design was full factorial with five $\mathrm{P}$ sources $\times$ twelve crop species $\times$ three replicates (blocks). The five $\mathrm{P}$ treatments included no $\mathrm{P}\left(\mathrm{P}_{0}\right)$ and four $\mathrm{P}$ sources, which were supplied as $\mathrm{KH}_{2} \mathrm{PO}_{4}(\mathrm{KP})$, hydroxyapatite $\left(\mathrm{Ca}_{5}\left(\mathrm{PO}_{4}\right)_{3}(\mathrm{OH})\right.$, Shanghai National reagents; CaP), phytate $\mathrm{P}$ $\left(\mathrm{C}_{6} \mathrm{H}_{6} \mathrm{O}_{24} \mathrm{P}_{6} \mathrm{Na}_{12}\right.$, Sigma; PhyP) or Fe hydroxide coated with $\mathrm{P}(\mathrm{FeP})$, all (except $\mathrm{P}$ ) at a rate of $50 \mathrm{mg} \mathrm{kg}^{-1} \mathrm{P}$.

Except for the FeP treatments, the sand was mixed with the various P sources, after which it was mixed with $170 \mathrm{~mL} \mathrm{~kg}^{-1}$ of P-free nutrient solution (at 75\% water-holding capacity). The nutrient solution consisted of (in $\mathrm{mmol} \mathrm{L}^{-1}$ ) $\mathrm{NH}_{4} \mathrm{NO}_{3}$ (5), $\mathrm{K}_{2} \mathrm{SO}_{4}$ (4.75), $\mathrm{CaCl}_{2} .2 \mathrm{H}_{2} \mathrm{O}$ (5), $\mathrm{MgSO}_{4} .7 \mathrm{H}_{2} \mathrm{O}(2)$ and (in mg L-1) Fe (9.2) as EDTAFe-Na, Mn (0.5) as $\mathrm{MnSO}_{4} \cdot \mathrm{H}_{2} \mathrm{O}$, Zn (0.1) as $\mathrm{ZnSO}_{4} .7 \mathrm{H}_{2} \mathrm{O}, \mathrm{Cu}(0.02)$ as $\mathrm{CuSO}_{4} .5 \mathrm{H}_{2} \mathrm{O}, \mathrm{B}(0.5)$ as $\mathrm{H}_{3} \mathrm{BO}_{3}$, and $\mathrm{Mo}(0.01)$ as $\left(\mathrm{NH}_{4}\right)_{6} \mathrm{Mo}_{7} \mathrm{O}_{24} \cdot 4 \mathrm{H}_{2} \mathrm{O}$. 
A full nutrient solution without $\mathrm{P}$ was selected to make sure that $\mathrm{P}$ was the only growth-limiting factor, which is a prerequisite for Experiment 2.

In the FeP treatment, the substrate was a mixture of $2 \mathrm{~kg}$ of sand with $340 \mathrm{~mL}$ of a suspension containing iron sludge $(\mathrm{Fe}(\mathrm{OH}) 3)$ coated with $\mathrm{P}(\mathrm{pH}$ 7.1). This suspension was prepared by shaking (180 $\left.\mathrm{min}^{-1}\right) 12 \mathrm{~g}$ of Fe sludge ( $\mathrm{pH} 7.4$ in water (1:2.5), a by-product of Brabant Water Ltd, the Netherlands) in $340 \mathrm{~mL}$ of nutrient solution for 2 days at $25{ }^{\circ} \mathrm{C}$ (modified from Chardon et al. (2012)). The $340 \mathrm{~mL}$ of nutrient solution contained $100 \mathrm{mg}$ of $\mathrm{P}_{\text {as }} \mathrm{KH}_{2} \mathrm{PO}_{4}(294$ $\mathrm{mg} \mathrm{P} \mathrm{L}{ }^{-1}$ ) plus the other nutrients as indicated above. To check whether phosphate was bound to the iron sludge, ortho-P was analyzed in the suspension after centrifugation at $17,400 \times g$ and subsequent filtering $(0.45 \mu \mathrm{m})$, using the phosphorus-molybdate blue color reaction (Murphy and Riley 1962). The equilibrium P concentration was $1.30 \mathrm{mg} \mathrm{L}^{-1}$, indicating that $99.6 \%$ of the phosphate from the $\mathrm{KH}_{2} \mathrm{PO}_{4}$ was bound to the iron sludge.

The seeds (Table 2.1) were surface-sterilized with $10 \% \mathrm{H}_{2} \mathrm{O}_{2}$ for $30 \mathrm{~min}$, rinsed thoroughly in deionized water and pre-germinated on filter paper. On 3 October 2015, four germinated seeds of maize (Zea mays L. cv. Zhengdan-958), potato (Solanum tuberosum L. cv. Zhongshu-3), capsicum (Capsicum annuum L. cv. Tixian-8819), cabbage (Brassica oleracea L. cv. Sulv), pea (Pisum sativum L. cv. Longwan-1), chickpea (Cicer arietinum L. cv. Longying-1), peanut (Arachis hypogaea L. cv. Luhua-11), soybean (Glycine max (L.) Merrill cv. Zhonghuang-13) and faba bean (Vicia faba L. cv. Yundou-324) were sown. They were thinned to two plants per pot 7 days after sowing. Germinated seeds of wheat (Triticum aestivum L. cv. Kenong-9204), upland rice (Oryza sativa L. cv. Handao-502) and millet (Setaria italica L. cv. Huangjingu) were sown at six, eight and sixty plants per pot and thinned to three, four or forty plants, respectively, per pot, also at 7 days after sowing. All the legume seedlings were inoculated with an appropriate strain of Rhizobium provided by the Culture Collection of Beijing Agricultural University, as listed in Table 2.1. The pots were watered to $75 \%$ of the water holding capacity every 2 days and supplied with $50 \mathrm{~mL}$ of the above nutrient solution every 3 days. The plants were harvested when the plant size differences between the $\mathrm{P}_{0}$ and $\mathrm{KP}$ treatments were obvious and the $\mathrm{P}_{0}$ plants were still vital. Millet and maize were harvested 40 days after sowing; wheat, pea, and faba bean were harvested 53 days after sowing; rice, cabbage and chickpea were harvested 58 days after sowing; potato, soybean, peanut and capsicum were harvested 63 days after sowing. The pots within each block were arranged randomly in the greenhouse, and their positions were re-randomized every 2 weeks. 
Table 2.1 List of plant species used in Experiment 1

\begin{tabular}{|c|c|c|c|}
\hline Species & $\begin{array}{l}\text { Average } \\
\text { seed dry } \\
\text { mass } \\
\text { (mg/seed) }\end{array}$ & $\begin{array}{l}P \text { content of } \\
\text { one seed }(\mathrm{mg})\end{array}$ & $\begin{array}{l}\text { Rhizobium strain } \\
\text { of legumes }\end{array}$ \\
\hline Wheat (Triticum aestivum L. cv. Kenong-9204) & 47.0 & 0.14 & \\
\hline Maize (Zea mays L. cv. Zhengdan-958) & 350 & 0.43 & \\
\hline Rice (Oryza sativa L. cv. Handao-502) & 31.0 & 0.06 & \\
\hline Potato (Solanum tuberosum L. cv. Zhongshu-3) & 340 & 0.80 & \\
\hline Capsicum (Capsicum annuum L. cv. Tixian-8819) & 5.70 & 0.03 & \\
\hline Cabbage (Brassica oleracea L. cv. Sulv) & 3.49 & 0.02 & \\
\hline Millet (Setaria italica L. cv. Huangjingu) & 3.41 & 0.01 & \\
\hline Pea (Pisum sativum L. cv. Longwan-1) & 146 & 0.70 & R. anhuiense \\
\hline Chickpea (Cicer arietinum L. cv. Longying-1) & 350 & 1.11 & M. muleiense \\
\hline Peanut (Arachis hypogaea L. cv. Luhua-11) & 924 & 3.16 & B. arachidis \\
\hline $\begin{array}{l}\text { Soybean (Glycine } \max \\
\text { Zhonghuang-13) }\end{array}$ & 246 & 1.19 & B. daqingense \\
\hline Faba bean (Vicia faba L. cv. Yundou-324) & 1164 & 4.60 & R. leguminosarum \\
\hline
\end{tabular}

\subsubsection{Experiment 2: Complementary $P$ uptake by mixtures of crop species}

To test for the complementary use of $\mathrm{P}$ sources, we selected combinations of the two crop species and P sources. Two criteria were used to select the crop species (mixtures); 1) the two species should differ (or not - to test the null hypothesis) in their ability to access sparingly soluble P sources; and 2) they can potentially be grown together as an intercrop in the field. Based on the results of Experiment 1, we selected three plant species combinations, millet/chickpea, cabbage/faba bean and wheat/maize. Each combination included three plant treatments (each sole crop species and their combination). There were two mixtures of $\mathrm{P}$ sources, PhyP/CaP and PhyP/FeP. The millet/chickpea combination was supplied with $\mathrm{CaP}$ or PhyP or their mixture, cabbage/faba bean with FeP or PhyP or their mixture, and wheat/maize with both mixtures of $\mathrm{P}$ sources and their components. With four replicates, this experiment resulted in 144 pots in total.

This experiment was conducted from April to June 2016. The temperatures ranged from $18{ }^{\circ} \mathrm{C}$ to $28^{\circ} \mathrm{C}$ in the glasshouse. The cultivars of the selected species, planting densities of sole crop species, P sources, nutrient supply and water management were the same as they were in the first experiment. The planting densities of the mixture component species were half those of the sole species. The $\mathrm{P}$ rate of the single $\mathrm{P}$ sources was $50 \mathrm{mg} \mathrm{kg}^{-1}$. For the mixtures of $\mathrm{P}$ sources, $25 \mathrm{mg} \mathrm{kg}^{-1}$ of each P source was used. Millet, chickpea, wheat and maize growing on 
$\mathrm{CaP}$, PhyP and mixed CaP/PhyP were grown for 40 days; Cabbage, faba bean, wheat and maize growing on FeP, PhyP and mixed FeP/PhyP were grown for 50 days.

\subsubsection{Plant analyses}

At harvest, the shoots were cut off just above the sand surface and washed. All the roots were carefully collected and washed with deionized water. The shoots, roots and seeds were dried at $70{ }^{\circ} \mathrm{C}$ for $72 \mathrm{~h}$, weighed and ground. The subsamples were digested with concentrated $\mathrm{H}_{2} \mathrm{SO}_{4}$ and $\mathrm{H}_{2} \mathrm{O}_{2}$ for $\mathrm{P}$ determination using the vanadomolybdate method (Westerman 1990).

\subsubsection{Data analysis}

The $P$ uptake in Experiment 1 by each species per pot was calculated by subtracting the seed $P$ content from the plant $\mathrm{P}$ content (shoot + root). The capacity of each plant species to use the sparingly soluble $\mathrm{P}$ sources was expressed as the $\mathrm{P}$ uptake ratio, which was defined as the $\mathrm{P}$ uptake from the sparingly soluble $\mathrm{P}$ sources compared to the $\mathrm{P}$ uptake from $\mathrm{KH}_{2} \mathrm{PO}_{4}\left(P_{\mathrm{KP}}\right)$.

$P$ uptake ratio $=\left(P_{\mathrm{i}}-P_{0}\right) /\left(P_{\mathrm{KP}}-P_{0}\right)$

with $P_{\mathrm{i}}$ representing the $\mathrm{P}$ uptake when supplied with $\mathrm{CaP}$, PhyP or FeP, and the $P_{\mathrm{KP}}$ representing the $\mathrm{P}$ uptake when supplied with $\mathrm{KP}$, and the $P_{0}$ representing the $\mathrm{P}$ uptake without $\mathrm{P}$ addition. A $\mathrm{P}$ uptake ratio of 1 indicates that this plant species can use the specific sparingly soluble $\mathrm{P}$ source as efficiently as $\mathrm{KH}_{2} \mathrm{PO}_{4}$; a $\mathrm{P}$ uptake ratio of 0 indicates that the plant species cannot access the sparingly soluble P source at all.

The design of Experiment 2 was full factorial. For each species combination, there were two crop species grown alone and combined, and the plants were supplied with two single $\mathrm{P}$ sources (CaP or PhyP; FeP or PhyP) and the mixture of two P sources (Fig. 2.1). To test for interactions between crop species, we first tested for general overyielding by comparing the observed P uptake (or biomass) by the plant species mixtures (treatments $d$, e or $\mathrm{f}$ in Fig. 2.1) with the expected $\mathrm{P}$ uptake (or biomass) per pot by sole plant species $((\mathrm{a}+\mathrm{g}) / 2,(\mathrm{~b}+\mathrm{h}) / 2$ or $(\mathrm{c}+\mathrm{i}) / 2)$, respectively; "horizontal comparisons" in Fig. 2.1). No difference between the observed and expected $\mathrm{P}$ uptake (or biomass) per pot (i.e., $\mathrm{d}=(\mathrm{a}+\mathrm{g}) / 2$, or $\mathrm{e}=(\mathrm{b}+\mathrm{h}) / 2$, or $\mathrm{f}=$ $(\mathrm{c}+\mathrm{i}) / 2)$ would indicate an absence of general overyielding. Overyielding, i.e., a higher observed P uptake (or biomass) than expected $(\mathrm{d}>(\mathrm{a}+\mathrm{g}) / 2$, etc.), can be caused by the complementarity effect and the selection effect (Loreau and Hector 2001). The complementarity effect indicates positive interactions between the two plant species including facilitation or the complementary use of $\mathrm{P}$ or other resources such as water, $\mathrm{N}$ or light, and the selection effect is due to the competitive dominance of the more productive species in the mixture (Yachi and Loreau 2007). 


\begin{tabular}{|c|c|c|c|c|}
\hline & & \multicolumn{3}{|c|}{ Plant species } \\
\hline & & $\mathrm{S}_{1}$ & $\mathrm{~S}_{1}+\mathrm{S}_{2}$ & $\mathrm{~S}_{2}$ \\
\hline \multirow{3}{*}{ 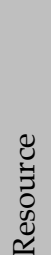 } & $\mathrm{R}_{1}$ & A & d & $\mathrm{g}$ \\
\hline & $\mathrm{R}_{1}+\mathrm{R}_{2}$ & B & $\mathrm{e}$ & $\mathrm{h}$ \\
\hline & $\mathrm{R}_{2}$ & $\mathrm{C}$ & $\mathrm{f}$ & $\mathrm{i}$ \\
\hline
\end{tabular}

Fig. 2.1 Framework for evaluating results of species mixtures growing on two resources and distinguishing the complementary resource use (specific overyielding) from any reason for overyielding (general overyielding). There is general overyielding when the total biomass (or resource use) produced by the species combination is significantly higher than the mean biomass (or resource use) of the sole species due to any positive interaction between two plant species. There is specific overyielding when the total biomass (or resource use) of the species combination growing on mixed $\mathrm{P}$ sources is significantly higher than expected based on the performance of the species combination growing on single $P$ sources. The table shows sole plant species $1\left(S_{1}\right)$ and $2\left(S_{2}\right)$ and their combination $\left(S_{1}+S_{2}\right)$, which were supplied with single resource $1\left(R_{1}\right)$, or $2\left(R_{2}\right)$ and mixed resources $\left(R_{1}+R_{2}\right)$. The planting density of each species in the combination is half in the density of sole crops, and the amount of each mixed resource is half the amount of the single resource. a-i: values of response variable; for example, the biomass or uptake of a nutrient supplied by the resources. General overyielding: Overyielding for any reason, but not necessarily complementarity in the use of the considered resources at Resource 1 if $\mathrm{d}>(\mathrm{a}+\mathrm{g}) / 2$; at Resource 2 if $\mathrm{f}>(\mathrm{c}+\mathrm{i}) / 2$; Overyielding for any reason, including complementarity in use of resource $R$ : if $e>(b+h) / 2$. Specific overyielding: Overyielding due to complementarity: if $e>(d+f) / 2$.

We demonstrated overyielding due to complementary P source use (specific overyielding) by comparing the P uptake by the plant combination on the P mixture (treatment e, Fig. 2.1) with the single $\mathrm{P}$ sources (treatments $\mathrm{d}, \mathrm{f}$ ): e $>(\mathrm{d}+\mathrm{f}) / 2$ ("vertical comparison" in Fig. 2.1). This comparison required three treatments $(\mathrm{d}$, e and $\mathrm{f})$, with the four "corner" treatments $(\mathrm{a}, \mathrm{c}, \mathrm{g}$ and i) to check if the prerequisites of the differential $\mathrm{P}$ source used by the two plant species (criterion 2) is met.

\subsubsection{Statistics}

Both Experiments 1 and 2 had completely randomized block designs. The P uptake ratios in Experiment 1 were log-transformed and analyzed by two-way ANOVA with plant species and $\mathrm{P}$ sources as the main factors. In Experiment 2, data on the P uptake were analyzed by one-way ANOVA with the $\mathrm{P}$ sources as an independent variable. Data on $\mathrm{P}$ uptake by cabbage, faba bean, wheat and maize from FeP and PhyP were log-transformed. We performed ANOVA and Tukey's HSD test using R (R version 3.1.2, R Core Team, 2014). 


\subsection{Results}

\subsubsection{P uptake ratio of sole crop species (Experiment 1)}

In the treatment without added $\mathrm{P}\left(\mathrm{P}_{0}\right)$, very little or no $\mathrm{P}$ was taken up by all the tested plant species (Fig. 2.2a), because the quartz sand contained only minor amounts of available P (0.78 $\mathrm{mg} \mathrm{kg}{ }^{-1}$ ). The P uptake was significantly higher in the KP treatment than in the $\mathrm{P}_{0}$ treatment for all the species except soybean. The uptake of $\mathrm{P}$ from sparingly soluble $\mathrm{P}$ sources was mostly in between that of the KP and $\mathrm{P}_{0}$ treatments. As a result, the $\mathrm{P}$ uptake ratios ranged from 0 to 1 for all the species except soybean.

The $\mathrm{P}$ uptake ratio varied among the plant species and $\mathrm{P}$ sources. The primary effects of the crop species and $\mathrm{P}$ source as well as their interactions on the $\mathrm{P}$ uptake ratio were significant $(P$ $<0.01$, Table 2.2), indicating a species-specific ability to mobilize $\mathrm{P}$ from sparingly soluble $\mathrm{P}$ sources. When supplied with $\mathrm{CaP}$, the $\mathrm{P}$ uptake ratios of millet and faba bean were higher (3-5-fold) than those of cabbage, chickpea, peanut and soybean (Fig. 2.2b). There was less differentiation among the species in their capacities to use PhyP, though the P uptake ratios of potato, capsicum, chickpea, soybean and faba bean were higher than those of other species. When supplied with FeP, the P uptake ratios of capsicum, cabbage and millet were relatively high. Those of maize, rice, pea, chickpea, soybean and faba bean were relatively low. Peanut had the lowest $\mathrm{P}$ uptake ratio when grown on FeP.

The abilities of wheat, maize and rice to acquire $\mathrm{P}$ from $\mathrm{CaP}$ or PhyP were similar. FeP was less accessible than PhyP for maize and rice. Potato, capsicum, chickpea, peanut, soybean and faba bean had better access to PhyP than to CaP or FeP (Fig. 2.2). All these species (except peanut) could use PhyP as efficiently as KP. The cabbage accessed PhyP and FeP equally well, but took up less $\mathrm{P}$ from CaP. Millet accessed to CaP and PhyP equally well but had less access to $\mathrm{FeP}$.

Table 2.2 ANOVA results with $P$ uptake ratio as the dependent variable, with the $P$ source and species as independent variables.

\begin{tabular}{llll}
\hline Independent Variable & df & $\mathrm{F}$ & $P$ value \\
\hline P source & 2 & 53.78 & $<0.001$ \\
Species & 11 & 3.73 & $<0.001$ \\
P source $\times$ Species & 22 & 2.52 & $<0.01$ \\
\hline
\end{tabular}




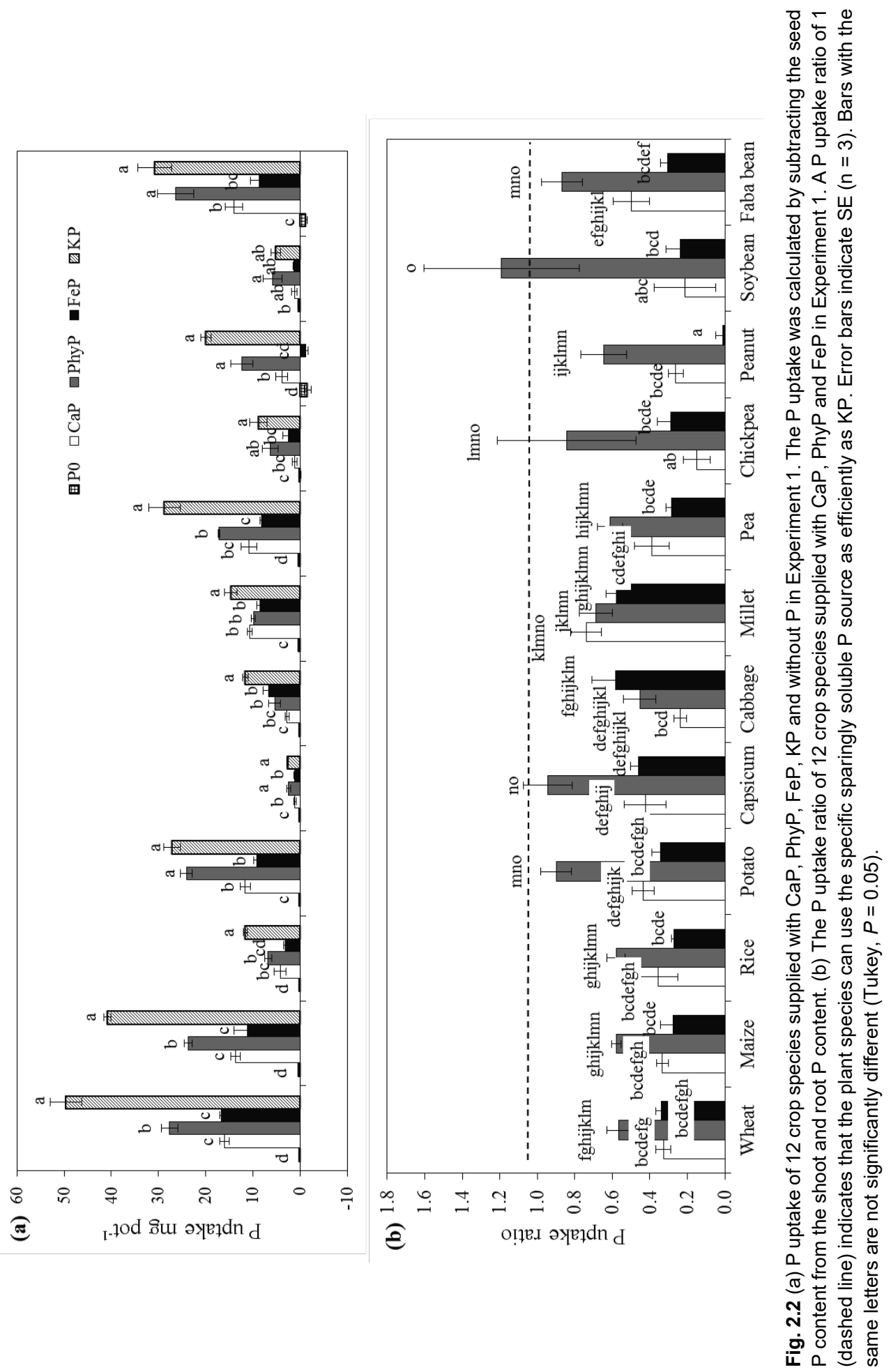




\subsubsection{P uptake and biomass by sole crop species on single P sources (Experiment 2)}

Consistent with the criteria for selecting species combinations for Experiment 2, millet was selected in combination with chickpea, because millet was better able to take up P from CaP than chickpea (Fig. 2.2a), whereas PhyP was the most accessible P source for chickpea (Fig. 2.2b). Cabbage and faba bean were selected because cabbage was able to mobilize FeP relatively well (Fig. 2.2b), whereas faba bean could more effectively use PhyP as a P source (Fig. 2.2a). Mixtures of wheat and maize were selected to test the null hypothesis, because they had similar abilities to access the three sparingly soluble P sources. Therefore, no partitioning of $\mathrm{P}$ sources and specific overyielding were expected for this crop species combination.

The results of the relative $\mathrm{P}$ uptake by the selected plant species from the different sparingly soluble P sources (four "corner" treatments - a, c, g and i in Fig. 2.1) were mostly consistent with those from Experiment 1 (Table 2.3). In all the single-species treatments, millet took up more P from CaP than chickpea. Chickpea took up more P from PhyP than from CaP $(P<$ 0.05). Cabbage took up 3.5 times more $P$ from FeP than faba bean. Faba bean took up approximately 2.5 times more P from PhyP than from FeP. In contrast to Experiment 1, both cabbage and faba bean took up more $\mathrm{P}$ from Phy than from $\mathrm{FeP}$ which compromised a proper test for complementarity in $\mathrm{P}$ uptake from FeP/PhyP.

\subsubsection{Crop species mixtures with expected complementary P uptake (Experiment 2)}

The observed P uptake by the millet/chickpea mixtures growing on all the P sources was significantly higher than expected from the sole crop species (Table 2.3; horizontal comparisons in Fig. 2.1), indicating general overyielding. On average, the P uptake by the plant mixtures was 1.5 times higher than expected. This finding was primarily due to higher $\mathrm{P}$ uptake by mixed millet, largely at the expense of chickpea (Table 2.3, Table S2.1, Appendix A); mixed millet and sole millet took up similar amounts of $\mathrm{P}$ per pot, despite the $50 \%$ reduced sowing density of the mixed millet. This finding indicates the competitive dominance of millet in the mixture when it was grown with chickpea.

Consistent with the P uptake, the observed biomass of the millet/chickpea mixture was 1.6-fold higher than expected on average (Table 2.3; horizontal comparisons in Fig. 2.1), confirming that $\mathrm{P}$ was also the plant growth-limiting factor in the mixture.

To test whether the above positive net effect on $\mathrm{P}$ uptake by the millet/chickpea combination was (partly) related to the complementarity in $\mathrm{P}$ uptake from $\mathrm{CaP} / \mathrm{PhyP}$, we compared the observed $\mathrm{P}$ uptake by the plant mixture growing on $\mathrm{CaP} / \mathrm{PhyP}\left(26.3 \mathrm{mg}^{\mathrm{p}} \mathrm{pot}^{-1}\right)$ with the expected $\mathrm{P}$ uptake (i.e., the average $\mathrm{P}$ uptake on $\mathrm{CaP}\left(22.5 \mathrm{mg} \mathrm{pot}^{-1}\right)$ and $\mathrm{PhyP}\left(22.3 \mathrm{mg} \mathrm{P}\right.$ pot $\left.^{-1}\right)$; (vertical comparison e versus $(\mathrm{d}+\mathrm{f}) / 2$ in Fig. 2.1)). The observed $\mathrm{P}$ uptake by the 
millet/chickpea combination from the mixed $P$ sources was 1.2-fold higher $(P=0.03)$ than expected (Table 2.3; Fig. 2.3a). The reason was that the $\mathrm{P}$ uptake by mixed millet from $\mathrm{CaP} / \mathrm{PhyP}\left(25.0 \mathrm{mg} \mathrm{pot}^{-1}\right)$ was higher than that from PhyP alone (21.4 $\mathrm{mg} \mathrm{pot}^{-1} ; P=0.04$, Table 2.3). Mixed chickpea also took up more $P$ from the mixed $P$ source than from the single $P$ sources, but this increase was not statistically significant. Mixed chickpea took up relatively small amounts of $\mathrm{P}$ regardless of the $\mathrm{P}$ source. These results confirm the partitioning of the $\mathrm{P}$ sources (specific overyielding), which is consistent with Turner's and Hinsinger's hypotheses. The observed biomass of the millet/chickpea combination on mixed P sources did not differ from its expected value based on the single P sources (Fig. 2.3c).

Unexpectedly, no overyielding by the cabbage/faba bean combination was observed when the plants were grown on FeP/PhyP (Table 2.3, 2.4). The P uptake by this combination was higher than expected when supplied with PhyP $(P=0.03$, Table 2.3; horizontal comparison in Fig. 2.1) but not on FeP and FeP/PhyP, indicating that there was no general overyielding. The observed total P uptake from PhyP by cabbage/faba bean was higher than that from FeP or FeP/PhyP $(P<0.001$, Table 2.3), indicating a relatively high ability to use PhyP as the P source. The observed biomass of the cabbage/faba bean combination did not differ from the expected value $(P=0.85$, Table 2.4, horizontal comparison in Fig. 2.1), regardless of the $\mathrm{P}$ source. Accordingly, there was no difference between the observed biomass of the cabbage/faba bean combination growing on $\mathrm{FeP} / \mathrm{PhyP}$ and the expected biomass based on the two single $\mathrm{P}$ sources ( $P=0.07$; Fig. 2.3d, vertical comparison in Fig. 2.1). 


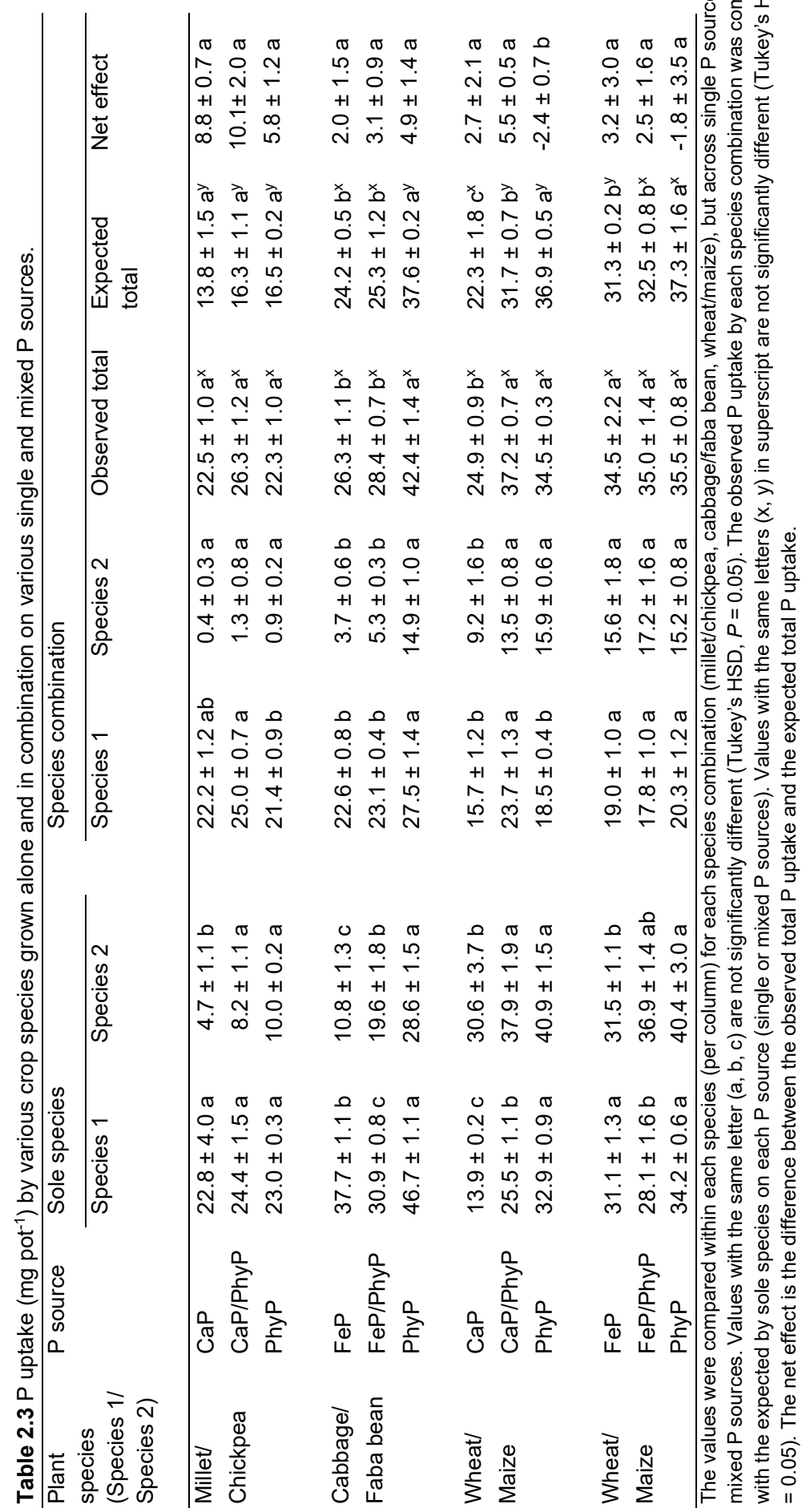



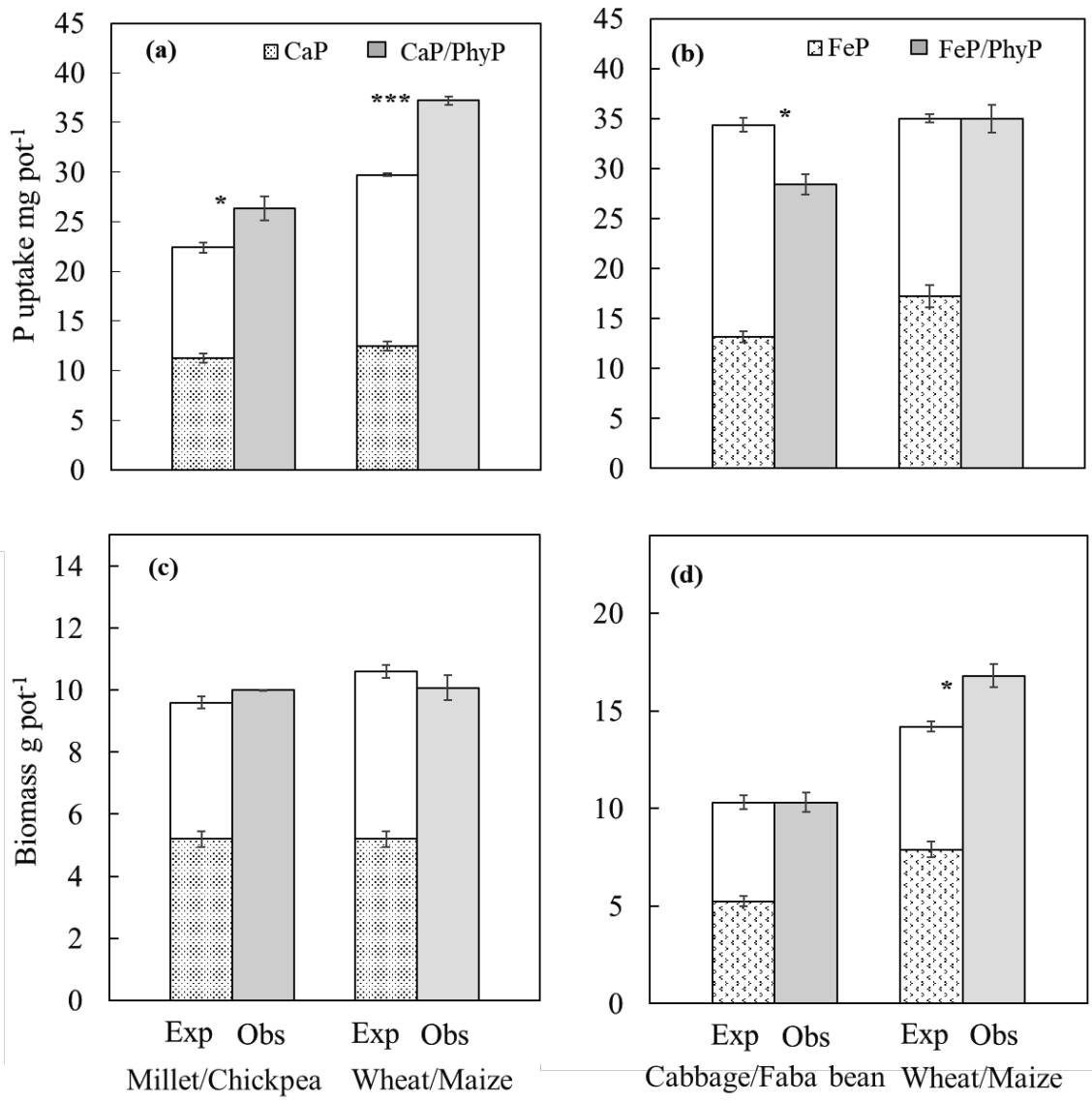

Fig. 2.3 Expected (Exp) and observed (Obs) P uptake (a, b) and biomass (c, d) of crop species combinations growing on mixed $P$ sources. The expected $P$ uptake (or biomass) is the average of the $P$ uptake (or biomass) of the same species combinations growing on the corresponding single $\mathrm{P}$ sources. Asterisks refer to significant differences between observed and expected $\mathrm{P}$ uptake (or biomass) ${ }^{* * *} P<$ $0.001,{ }^{*} P<0.01$, and ${ }^{*} P<0.05$.

Nevertheless, we compared the performance of the cabbage/faba bean mixture on mixed $\mathrm{P}$ sources to that on single $\mathrm{P}$ sources (vertical comparison in Fig. 2.1) to test for any complementary P use component in the general overyielding. The observed P uptake from the mixed $\mathrm{P}$ sources by the plant mixture was lower than expected based on their P uptake from FeP and PhyP $(P=0.01$, Fig. 2.3b; $<<(d+f) / 2$ in Fig. 2.1). This finding contrasts with the resource partitioning hypotheses. Both mixed cabbage and faba bean took up more $\mathrm{P}$ from PhyP than from FeP $(P=0.01)$ or FeP/PhyP $(P<0.001$, Table 2.3$)$. This result is indicative of the competition for PhyP rather than the P partitioning on the FeP/PhyP. Cabbage dominated over faba bean in that the biomass of mixed cabbage was 2-6 times higher than that of mixed faba

bean. 


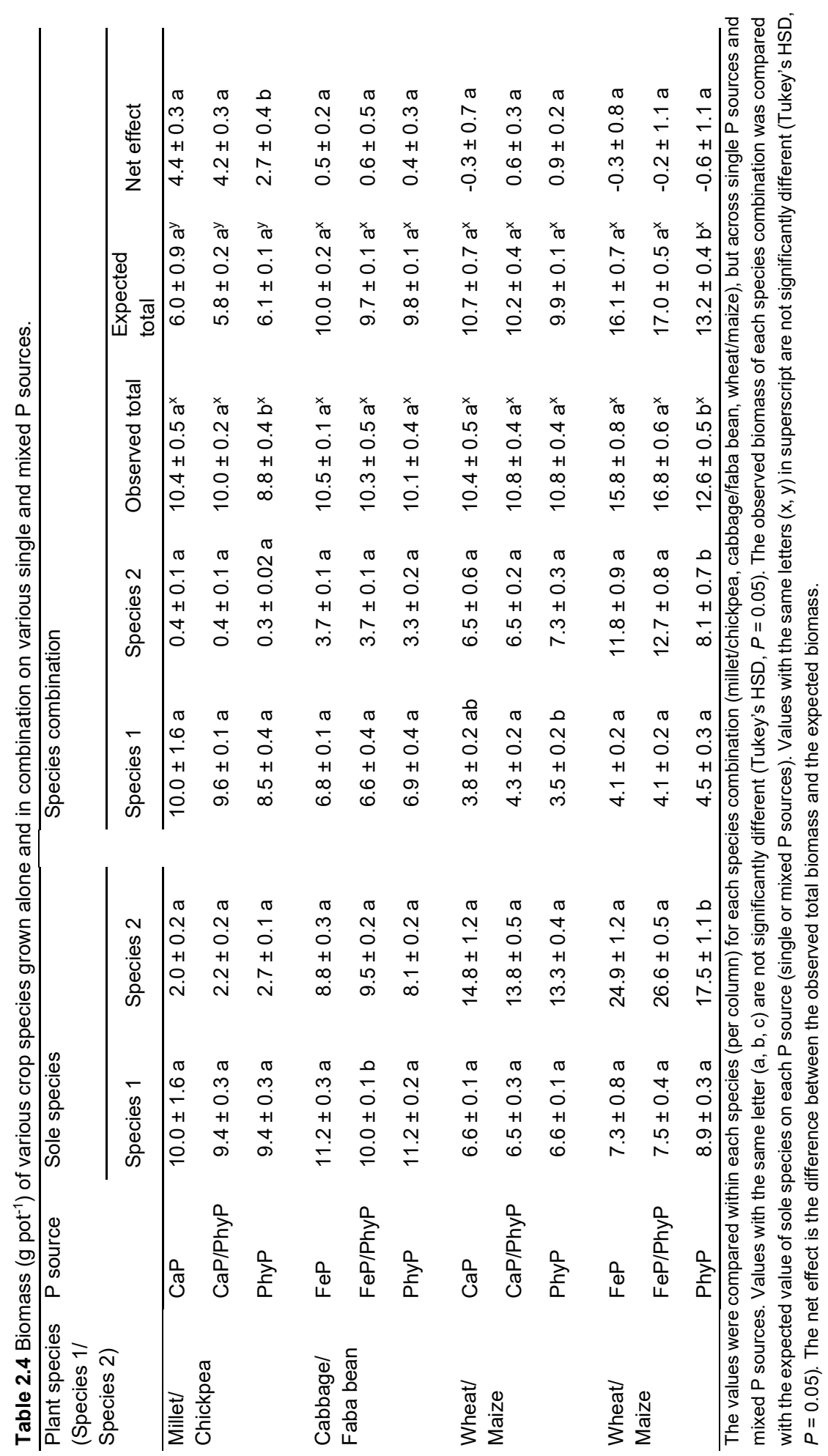




\subsubsection{Crop species mixture with no expected complementary P uptake}

When grown on $\mathrm{CaP} / \mathrm{PhyP}$, wheat/maize combination took up 1.2-fold more $\mathrm{P}$ than expected based on their sole plant species $(P<0.01$, Table 2.3, horizontal comparison in Fig. 2.1). This result was due to an unexpectedly high $\mathrm{P}$ uptake by wheat from $\mathrm{CaP} / \mathrm{PhyP}$. When growing on PhyP, the observed P uptake by the wheat/maize combination decreased slightly compared with the expected uptake based on the sole plant species $(P<0.01$, Table 2.3$)$; on CaP, the expected and observed P uptakes were similar. The observed biomass of the wheat/maize mixture did not differ from the expected biomass, regardless of the P source (Table 2.4).

The observed $\mathrm{P}$ uptake by the wheat/maize combination from $\mathrm{CaP} / \mathrm{PhyP}$ was 1.2-fold higher $(P<0.001)$ than expected based on the $P$ uptake from the single $P$ sources (Fig. 2.3a; vertical comparison $\mathrm{e}>(\mathrm{d}+\mathrm{f}) / 2$ in Fig. 2.1). This result occurred because both wheat and maize took up more P from the mixed P sources than from the single P sources; the mixed wheat took up approximately 1.3-fold more $\mathrm{P}$ from $\mathrm{CaP} / \mathrm{PhyP}$ than from the single $\mathrm{P}$ sources, and the mixed maize took up 1.5-fold more P from CaP/PhyP than from CaP $(P<0.01$, Fig. 2.3a, Table 2.3).

The result of this comparison suggests the occurrence of specific overyielding. The observed biomass of the wheat/maize combination growing on $\mathrm{CaP} / \mathrm{PhyP}$ did not differ from the expected biomass based on the single P sources ( $P=0.10$, Fig. 2.3c). Apparently, the positive interaction on the P uptake (Fig. 2.3a) did not translate into overyielding in terms of biomass. When supplied with FeP, the wheat/maize mixture took up more $\mathrm{P}$ than expected based on their sole crop species $(P=0.03$, Table 2.3; horizontal comparison in Fig. 2.1). There was no overyielding on the PhyP, or on the FeP/PhyP. The observed biomass was not different from the expected biomass across all the P sources (Table 2.4).

The observed P uptake of the wheat/maize combination from FeP/PhyP did not differ from the expected P uptake from FeP and PhyP (Fig. 2.3b; $=(d+f) / 2$ in Fig. 2.1). Mixed wheat and mixed maize took up similar amounts of $\mathrm{P}$, independently of the $\mathrm{P}$ source (Table 2.3). Therefore, this vertical comparison (Fig. 2.1) of the $\mathrm{P}$ uptake does not confirm the $\mathrm{P}$ partitioning hypotheses, similar to the above horizontal comparison.

Surprisingly, the observed biomass of the wheat/maize mixture on the mixed P sources was higher than expected from FeP and PhyP $(P=0.02$, Fig. 2.3d). The reason was that there was a higher biomass for mixed maize when grown on FeP or on FeP/PhyP than when grown on PhyP $(P<0.01$, Table 2.4$)$. 


\subsection{Discussion}

We have found mixed evidence at best for the conceptual model of resource partitioning for soil P proposed by Turner (2008) and extended by Hinsinger et al. (2011). Our hypothesis that combinations of plant species with different abilities to access sparingly soluble $\mathrm{P}$ forms would take up more P from P mixtures than expected was confirmed in only one of the two tests, with millet/chickpea on $\mathrm{CaP} / \mathrm{PhyP}$ but not with cabbage/faba bean on $\mathrm{FeP} / \mathrm{PhyP}$. Additionally, the test of the null hypothesis (a combination of two crop species with similar access to two $\mathrm{P}$ sources do not acquire more $\mathrm{P}$ from mixed $\mathrm{P}$ sources than from a single $\mathrm{P}$ source) yielded mixed evidence; it was confirmed by the results from wheat/maize on $\mathrm{FeP} / \mathrm{PhyP}$ but had to be rejected based on wheat/maize on $\mathrm{CaP} / \mathrm{PhyP}$.

Similar to what others reported before, we found trait dissimilarities among the species acquiring $\mathrm{P}$ from different $\mathrm{P}$ sources (Fig. 2.2). The lack of correlation between the $\mathrm{P}$ uptake ratios of CaP and PhyP, or between FeP and PhyP (Fig. S2.1, Appendix A), was consistent with the concept of a trade-off between P-mobilizing strategies (Gao et al. 2007; Ryan et al. 2012; Nasto et al. 2017). This trade-off provided the conditions for a test on complementarity in P resource use by crop species mixtures. However, there was overlap among the species' abilities to use $\mathrm{P}$ resources, which makes testing for soil $\mathrm{P}$ partitioning more difficult than for $\mathrm{N}$ partitioning between legumes (that can use $\mathrm{N}_{2}$ ) and non-legumes (that cannot use $\mathrm{N}_{2}$ ). Variations in $\mathrm{P}$ acquisition traits (as shown as discrepancies between Experiment 1 and Experiment 2) or P-status-dependent P acquisition traits (Wen et al. 2017) may further complicate a proper test of the P resource partitioning hypotheses.

Based on these trait dissimilarities on acquiring $\mathrm{P}$ from sparingly soluble $\mathrm{P}$ sources, we expected higher $\mathrm{P}$ uptake by the millet/chickpea combination from $\mathrm{CaP} / \mathrm{PhyP}$ and by cabbage/faba bean from $\mathrm{FeP} / \mathrm{PhyP}$ than from single $\mathrm{P}$ sources. We found evidence for complementary P uptake only in the first combination (Fig. 2.3a). However, competition between millet and chickpea (somewhat similar to Ahmad-Ramli et al. (2013)) complicated the interpretation of the results in terms of $\mathrm{P}$ partitioning; mixed millet took up more P (Fig. 2.3a) and grew larger than millet grown as the sole crop (Table 2.4), at the expense of chickpea (Table 2.3, Table S2.1). The general overyielding was due to this selection effect, and the magnitude of this effect was much larger than that of specific overyielding. Even when resulting in enhanced $\mathrm{P}$ acquisition and overyielding, a large selection effect and a small complementarity effect might not necessarily be desirable for the design of intercropping systems. Chickpea may have facilitated P uptake by millet, a strong competitor with a well-developed root system and a high degree of plasticity (Rostamza et al. 2013). Our results are similar to those of Montazeaud et al. (2018), who reported that trait dissimilarity led to the dominant genotypes gaining more in the mixture than the subdominant genotypes lost, 
compared with sole crops. This selection effect (Loreau and Hector 2001) is not consistent with the suggestion that partitioning for $\mathrm{P}$ sources would minimize competition between coexisting plant species (Turner 2008).

In the cabbage/faba bean combination on FeP/PhyP, we found the opposite of what was hypothesized by the $\mathrm{P}$ partitioning hypothesis, in that the cabbage/faba bean combination took up less $\mathrm{P}$ from the mixed $\mathrm{P}$ sources than expected based on the P uptake from the single $P$ sources (Fig. 2.3b). In this case, the $P$ acquisition traits varied between Experiments 1 and 2. Both cabbage and faba bean acquired more P from PhyP than from FeP in Experiment 2, whereas in Experiment 1, the P uptake by cabbage from PhyP and FeP were similar. This discrepancy compromises a proper test of the P partitioning hypotheses, because criterion 2 is not met. The higher temperature in Experiment 2 may have increased the acid phosphatase activity and released $\mathrm{P}$ into the rhizosphere and, consequently, increased the $\mathrm{P}$ uptake from organic P by cabbage (Pulgar et al. 2000). As a result, the cabbage and faba bean could both use PhyP as a P source better than FeP, such that the absence of any overyielding would not oppose the P partitioning hypothesis.

Contrary to our null hypothesis, we found higher P uptake by the wheat/maize combination when it was supplied with CaP/PhyP (Fig. 2.3b), although wheat and maize had similar P acquisition capabilities. In both Experiments 1 and 2, maize and wheat took up more P from PhyP than CaP (Fig. 2.2, Table 2.3, Fig. 2.3a). The reason for the unexpected increase in P uptake from the $\mathrm{CaP} / \mathrm{PhyP}$ by the species combination is not clear. The model on complementarity in soil $\mathrm{P}$ pools implicitly assumes that plant species do not change their $\mathrm{P}$ acquisition strategy when they are combined. However, in reality, they may respond to each other's presence by adapting their P acquisition strategies (Zhang et al. 2016). Strong plasticity in $\mathrm{P}$ acquisition strategies and hence P-source-dependent competitive inequalities would ultimately cause the testing of the resource partitioning hypothesis to be problematic. Wheat is more competitive than maize during the co-growth stages because of its high root length density and phenotypic plasticity (Li et al. 2001a; Liu et al. 2015). Therefore, wheat gained more $\mathrm{P}$ than maize lost when grown on mixed $\mathrm{CaP} / \mathrm{PhyP}$, which contains only half the preferred PhyP for wheat and maize.

As far as we are aware, we are the first to present a true test for complementary P uptake, avoiding the problems of previous papers that claimed to confirm Turner's and Hinsinger's hypotheses. At the same time, we demonstrated that testing for complementarity in soil $\mathrm{P}$ pools is complicated by many factors, namely, that competitive relationships may change when plant species are combined, and their $\mathrm{P}$ acquisition traits present high phenotypic and intraspecific variation because they are known to depend on the P supply (and may change in the presence of a neighbor) and on other soil properties (Hoffland et al. 1989; Lambers et al. 
2008; Zemunik et al. 2015). Altogether, the conditions under which the hypothesis on soil P partitioning can be tested are very limited. Real soils will always contain a combination of at least two P pools. Regardless of how attractive Turner's and Hinsinger's hypotheses are, it may be difficult if not impossible to design for complementarity in $\mathrm{P}$ source acquisition for intercrops. This conclusion is consistent with the opinion of Montazeaud et al. (2018) in that matching diversity and productivity in agroecosystems might be more complicated than simply promoting the trait differences in crop species, because the promotion of trait differences can both enhance the complementarity effect and the selection effect (through changes in competition), depending on the environmental context.

Our test allowed us to separate specific overyielding from general overyielding. First, the four "corner" treatments in Fig. 2.1 can support the rational basis for the resource partitioning hypothesis, i.e., two plant species have different abilities to access two P sources. The specific overyielding can be tested by comparing the $\mathrm{P}$ uptake by plant mixtures on mixed $\mathrm{P}$ sources with that on single P sources (the middle column in Fig. 2.1), but we also need the test for general overyielding to make sure that there are no other forms of overyielding. The test for general overyielding was similar to those in previous studies (Li et al. 2004; Dissanayaka et al. 2015); for example, by comparing the performance of plant species mixtures with their expected performances in sole crops when supplied with a single $\mathrm{P}$ source (horizontal comparisons in Fig. 2.1). We found high $P$ uptake by some plant species mixtures, on single $P$ sources as well as on mixed $\mathrm{P}$ sources (Table 2.3), due to the release from intraspecific competition by growing species mixtures. Therefore, the enhanced overyielding of crop species combinations on mixed P sources compared with the single P sources would not necessarily indicate the partitioning of $\mathrm{P}$ resources because the selection effect (e.g., the millet/chickpea combination and wheat/maize combination on $\mathrm{CaP} / \mathrm{PhyP}$ ) rather than the complementarity in $\mathrm{P}$ source use complicates the results. Therefore, only if all nine treatments in Fig. 2.1 are included and the above three tests are executed can complementarity in P source use be tested.

Trait-based ecology (Violle et al. 2007; Garnier et al. 2016; Shipley et al. 2016) has emphasized the link between complementary resource use and plant trait divergence. Our results show that species combinations with slightly higher $\mathrm{P}$ uptake than the sole crops can be designed by combining different $\mathrm{P}$ acquisition traits, but they require strict conditions.

\subsection{Conclusions}

We proposed the first proper test that requires the separate addition of $\mathrm{P}$ sources. This test is impossible to perform with soils in which the P sources are inherently mixed. Our test could be used to design for complementarity in intercropping systems. However, although our treatments were designed to test for complementarity, it occurred in only one of the two 
combinations where we expected it to occur. Competition can override the designed complementarity in P uptake when species with different $\mathrm{P}$ use abilities are combined, and thus, competitive inequality should be controlled when designing P-use-efficient intercropping systems. Altogether, the conditions under which the hypothesis about soil $\mathrm{P}$ partitioning can be tested are very limited, especially in soils in which the P sources are inherently mixed.

\section{Acknowledgements}

We thank the three anonymous reviewers for helpful comments on this manuscript. The authors gratefully acknowledge funding from National Key R \& D Program of China (2017YFD0200200/2017YFD0200202), projects of International Cooperation and Exchanges NSFC (31210103906), the Innovative Group Grant of the National Natural Science Foundation

of China (31421092). The financial support of the Wageningen University Sandwich Scholarship and China Scholarship Council (CSC, grant number: 201606350142) are gratefully acknowledged. 


\section{Chapter 3 A conceptual framework and an empirical test of complementarity and facilitation with respect to $\mathbf{P}$ uptake by species mixtures}

Chunjie Li, Thomas W. Kuyper, Wopke van der Werf, Junling Zhang, Haigang Li, Fusuo Zhang, Ellis Hoffland 


\begin{abstract}
We aimed to test whether differential phosphorus $(\mathrm{P})$ uptake from different $\mathrm{P}$ sources in soils leads to the mechanisms of facilitation and complementarity with respect to P uptake and whether such mechanisms contribute to increased P uptake and growth of plant species mixtures compared to pure stands.
\end{abstract}

Millet/chickpea mixtures were grown in pots on two calcareous soils mixed with CaP (calcium-bound P) and PhyP (Phytate-P). Cabbage/faba bean mixtures were grown on both acid and neutral soils mixed with FeP (P-coated Fe(hydr)oxide) and PhyP. Wheat/maize mixtures were grown in all four soils. Carboxylate concentration, acid phosphatase activity, $\mathrm{P}$ uptake and biomass were determined in sole and mixed species. To determine the occurrence of the mechanisms of complementarity and facilitation, we utilized a conceptual framework that describes both mechanisms and outcomes depending on species' competitive ability for $\mathrm{P}$ uptake.

The mechanism of facilitation of $\mathrm{P}$ uptake occurred in millet/chickpea mixtures in one calcareous soil, but the mechanism of complementarity in $\mathrm{P}$ acquisition from different $\mathrm{P}$ sources was not found in millet/chickpea or cabbage/faba bean mixtures. Cabbage and faba bean showed differences in acid phosphatase activity and carboxylate concentration in the neutral soil, but those did not lead to overyielding. Wheat and maize showed no differences in root exudates, but there was overyielding of $\mathrm{P}$ uptake in one calcareous soil.

The differences in root exudates provide the conditions for the mechanisms of complementarity and facilitation with respect to $\mathrm{P}$ uptake in some species mixtures. The conditions for complementarity and facilitation do not necessarily result in increased $\mathrm{P}$ uptake by species mixtures, because this also depends on the relative $\mathrm{P}$ acquisition gains by one species in the mixture compared to monocultures.

Keywords: complementarity, facilitation, phosphorus uptake, species mixture, carboxylate, phosphatase activity 


\subsection{Introduction}

Available phosphorus $(\mathrm{P})$ is often inadequate to support crop yield because a large proportion of $\mathrm{P}$ is adsorbed to metal (hydr)oxides, precipitated as calcium phosphates or bound in organic matter. Intercropping could help to better use these P resources (Zhang et al. 2010; Faucon et al. 2015; Faucon et al. 2017). For instance, intercropping, the mixed cultivation of crop species in the same field (Vandermeer 1989; Willey 1990), can increase P uptake and yields compared to sole cropping (Song et al. 2007; Latati et al. 2014). The improved acquisition of $\mathrm{P}$ has been explained by two main mechanisms: facilitation and complementarity (Hinsinger et al. 2011).

In intercropping systems, facilitation involves belowground processes where a nutrient-mobilizing species increases the nutrient availability both for itself and for its non-mobilizing neighbor ( $\mathrm{Li}$ et al. 2014). For instance, facilitation occurs when legumes increase $\mathrm{P}$ availability to the benefit of the cereals through rhizosphere modification (e.g., acidification, secretion of carboxylate or phosphatases) when the roots of the intercropped species are close together (Li et al. 2014; Faucon et al. 2015; Xue et al. 2016; Wang and Lambers 2019). Enhanced P acquisition has been reported in cereal/legume intercropping, such as wheat/faba bean (Song et al. 2007), maize/chickpea (He et al. 2013b; Xia et al. 2013), maize/faba bean ( $\mathrm{Li}$ et al. 2007) in field experiments. It is unclear whether the outcome of enhanced $\mathrm{P}$ acquisition by intercrop is caused by the mechanism of facilitation of $\mathrm{P}$ uptake, since that mechanism does not necessarily lead to overyielding by species mixtures (Barry et al. 2019).

Complementarity refers to a decrease in competition through resource partitioning (e.g., temporal, spatial and chemical partitioning of resources) (Fridley 2001; Brooker et al. 2016; Duchene et al. 2017). Complementary acquisition of different forms of the same nutrient has been well demonstrated for $\mathrm{N}$ in cereal/legume intercropping. The unique capacity of legumes to access the atmospheric $\mathrm{N}_{2}$ through symbiotic fixation relaxes competition for soil N with cereals (Hauggaard-Nielsen et al. 2001; Bedoussac et al. 2015). Turner (2008) hypothesized resource partitioning for different forms of soil organic $\mathrm{P}$ in species mixtures. Hinsinger et al. (2011) extended this hypothesis to intercropping systems, in which two component species would tap into distinct soil $\mathrm{P}$ pools. Only a few empirical studies have investigated the hypothesis by investigating the depletion of different $\mathrm{P}$ pools by species $(\mathrm{Cu}$ et al. 2005; Li et al. 2008), however, P was not the limiting factor in these studies. Therefore, there is scarce evidence for complementarity in $\mathrm{P}$ acquisition from different sources in species mixtures.

We have tested complementarity in $\mathrm{P}$ acquisition from different sources in pot experiments with inert quartz sand. In such a system $P$ resources could be added separately, there is no 
native $\mathrm{P}$ supply from the sand itself, and there is no interaction of $\mathrm{P}$ with the mineral phase (Chapter 2). Increased P uptake was observed in one species mixture (millet/chickpea) on mixed P sources compared to the average P uptake by the species mixture on a sole P source (Chapter 2). That outcome suggested differential $\mathrm{P}$ acquisition from mixed $\mathrm{P}$ sources by species mixture and reduced competition for P. Compared to this inert quartz sand, soils always contain a mixture of multiple $\mathrm{P}$ sources and the desorption of $\mathrm{P}$ is essential for plant $\mathrm{P}$ acquisition in soil. So, whether there is complementarity in $\mathrm{P}$ acquisition from different sources in soil in species mixture is still unclear.

Facilitation and complementarity often occur simultaneously and cannot easily be distinguished experimentally (Loreau and Hector 2001). They are often contrasted with competition between two species that exploit a single resource. According to the conceptual scheme outlined by Hinsinger et al. (2011), only one species in species mixture improves $\mathrm{P}$ availability through P-mobilizing strategies under the mechanism of facilitation. Both species improve the $\mathrm{P}$ availability by mobilizing different $\mathrm{P}$ sources through different $\mathrm{P}$-mobilizing strategies under the mechanism of complementarity. Facilitation is therefore unidirectional and complementarity is bidirectional. Hinsinger's framework of complementarity in tapping into different resource pools applies to complementarity in $\mathrm{N}$ acquisition, because plant species have different direct access to ammonium, nitrate, organic $\mathrm{N}$ or atmospheric $\mathrm{N}_{2}$. Unlike $\mathrm{N}$, there is no $\mathrm{P}$ form exclusively available to one species, because $\mathrm{P}$ can only be taken up in the orthophosphate form. Once an unavailable form of $\mathrm{P}$ has been made available as ortho-P, all species can take it up. This common increased ortho-P pool for all species makes a change in the competitive balance between species a further possibility, something that was not indicated in the model proposed by Hinsinger et al. (2011).

Based on the mechanistic difference between complementarity and facilitation, we modified the conceptual framework of Hinsinger et al. (2011). The modified framework also includes competition for ortho-P. It describes the underlying mechanisms involving rhizosphere modifications, and illustrates the outcomes of $\mathrm{P}$ uptake in species mixture depending on the competitive ability of two mixed species (Fig. 3.1). Our model assumes that organic P is mobilized through exudation of phosphatase, while sparingly soluble inorganic $\mathrm{P}$ sources are mobilized through exudation of carboxylates. Under the mechanism of complementarity, 1) two species have different abilities to mobilize different $P$ sources, so the sole species have different abilities to exude phosphatase and carboxylate; 2) both species in the mixture can mobilize more $\mathrm{P}$ than when growing solely and hence both species would differentially increase root exudation compared to sole species. Under the mechanism of facilitation, 1) only one of the two species has a higher ability to mobilize the P sources than the other species, so in monoculture, one species has higher ability to exude than the other species; 2) one of the 
two species increases root exudation, while the other species (also) benefits from the P mobilization in the mixture.

To test whether the mechanism of complementarity or facilitation of $\mathrm{P}$ uptake lead to increased $\mathrm{P}$ uptake by species mixture, we selected four low $\mathrm{P}$ soils and three species combinations. The soil selection comprised two high $\mathrm{pH}$ soils, containing Ca-bound $\mathrm{P}$ (Ca-P) and organic $\mathrm{P}$ (sodium phytate $\mathrm{P}, \mathrm{PhyP}$ ), and two neutral/acid soils containing metal(hydr)oxide-sorbed $\mathrm{P}(\mathrm{FeP})$ and organic $\mathrm{P}$ (PhyP). We selected millet/chickpea because they differed in their abilities to acquire $\mathrm{P}$ from $\mathrm{CaP}$ and PhyP and cabbage/faba bean because of their different abilities to mobilize P from FeP and PhyP (Chapter 2). The millet/chickpea and cabbage/faba bean mixtures were expected to take up more $\mathrm{P}$ than the average of their monocultures caused by differential $\mathrm{P}$ acquisition from different sources. Wheat and maize had similar abilities to acquire $\mathrm{P}$ from different sources (Chapter 2), so we expected no increase in $\mathrm{P}$ uptake by mixtures caused by similar $\mathrm{P}$ acquisition from different $\mathrm{P}$ sources.

\subsection{Materials and Methods}

\subsubsection{Conceptual framework}

Based on a previous model by Hinsinger et al. (2011), we expanded their conceptual framework (Fig. 3.1) to assess the mechanisms underlying the contribution of species interactions (competition, complementarity or facilitation) to P uptake by species mixtures after addition of different sparingly available $\mathrm{P}$ sources. Competition dominates the interaction when both species in the mixture effectively mobilize one and the same sparingly available $\mathrm{P}$ source and hardly mobilize the other $\mathrm{P}$ source, or when both species hardly mobilize both $\mathrm{P}$ sources and only compete for ortho-P in the soil solution (Fig. 3.1a, d). Complementarity in accessing $\mathrm{P}$ from different sources dominates when each of the two species effectively mobilize $P$ from only one source, and have a weak capacity to mobilize the alternative P source (Fig. 3.1b, e). Facilitation dominates when one species in the mixture has a higher capability to mobilize one or both sparingly available P sources than the other, while the other species has low capability to mobilize both P sources but (also) benefits from the P mobilization by the first species (Fig. 3.1c, f). This conceptual framework only describes the mechanisms of complementarity and facilitation. These mechanisms can result in two different outcomes - depending on whether the mixed species are equally strong competitors for ortho-P (Fig. 3.1a, b, c) or whether one species is a stronger competitor (Fig. 3.1d, e, f). In the latter case there can both be overyielding and underyielding of $\mathrm{P}$ uptake and growth, depending on relative $\mathrm{P}$ acquisition gains by one species and $\mathrm{P}$ acquisition losses by the other. Our conceptual framework differs from that of Hinsinger et al. (2011) in three major respects. (1) It states that there is always competition for ortho- $\mathrm{P}$, the only form of $\mathrm{P}$ that plants can take 
up, while competition under the mechanisms of complementarity and facilitation is not mentioned in the framework of Hinsinger et al. (2011); (2) It assumes plants can mobilize both P sources to some extent, although they may differ in the extent to which they can mobilize them, while in the framework of Hinsinger et al. (2011) differential mobilization is absolute in that each species mobilizes only one $\mathrm{P}$ source in the case of complementarity or that one species accesses two sources while the other accesses one; (3) It separates the mechanism from the outcome - in all cases addition of sparingly soluble P sources can equalize competitive ability or can result in competitive superiority (as competitive ability in a P-limiting soil is determined by acquisition of ortho-P, not directly by mobilization of sparingly soluble $\mathrm{P}$ ).

Competition

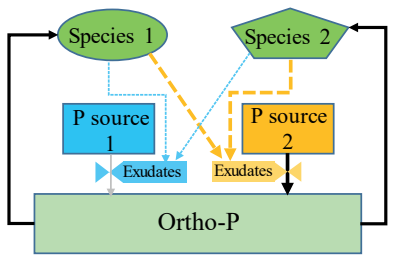

(a)

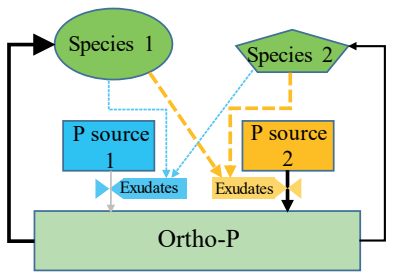

(d)
Complementarity

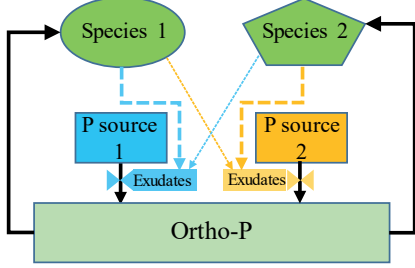

(b)

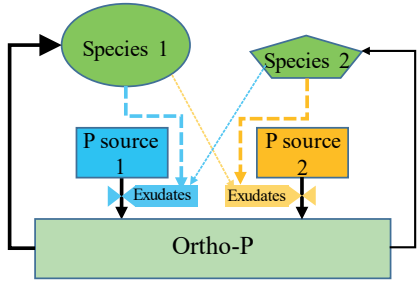

(e)
Facilitation

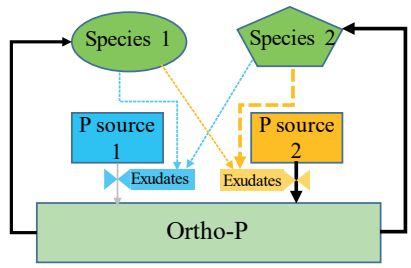

(c)

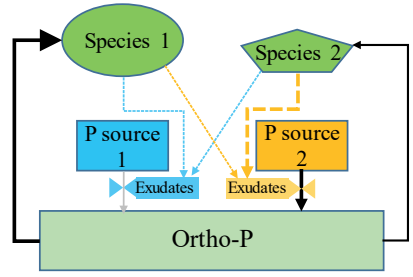

(f)

Fig. 3.1 Conceptual framework of competition, complementarity and facilitation with respect to $P$ acquisition. Two plant species ( 1 and 2 ) acquire, and compete for $P$ in the soil solution orthophosphate pool. They have a weak (thin dashed line) or strong (thick dashed line) ability to mobilize sparingly available $\mathrm{P}$ sources 1 and/or 2 through exudation of $\mathrm{P}$ mobilizing compounds (carboxylates, phosphatases) and protons (different colors represent different root exudates). The thickness of the black arrows indicates the relative uptake of $P$ from the soil solution. The relative sizes of the ellipses and pentagons indicate overyielding. $(a, d)$ Competition. Both species effectively mobilize the same sparingly available $\mathrm{P}$ source and can hardly mobilize the $\mathrm{P}$ source (or both species can hardly mobilize both $\mathrm{P}$ sources and can only compete for ortho P); (b, e) Complementarity. Species 1 and 2 effectively mobilize $P$ source 1 and 2 , respectively, and have a weak capacity to mobilize the alternative $P$ source. (c, f) Facilitation. Species 2 can effectively mobilize $P$ source 2 , while species 1 has low capability to mobilize either $P$ source. $(a, b, c)$ Two species have equal competitive strength for $P$ uptake, (d, e, f) Species 1 outcompetes species 2 . 


\subsubsection{Soils}

Low P soils were collected from the top $20 \mathrm{~cm}$ of plots at experimental stations at four locations in China: Beijing (Changping district, $\left.39^{\circ} 59^{\prime} \mathrm{N}, 116^{\circ} 17^{\prime} \mathrm{E}\right)$, Zhangye city in Gansu province $\left(38^{\circ} 85^{\prime} \mathrm{N}, 100^{\circ} 38^{\prime} \mathrm{E}\right)$, Guangzhou city in Guangdong province $\left(23^{\circ} 10^{\prime} 48^{\prime \prime} \mathrm{N}\right.$, $\left.114^{\circ} 16^{\prime} 48^{\prime \prime} \mathrm{E}\right)$ and Kunming city in Yunnan province $\left(25^{\circ} 2^{\prime} \mathrm{N}, 102^{\circ} 42^{\prime} \mathrm{E}\right)$ in China. The Changping and Zhangye soils are calcareous and their texture is loam and silt loam, respectively. The Guangzhou soil is a typical acid red soil, and the Kunming soil is a neutral red soil. Texture of the Guangzhou and Kunming soils is clayey. The P pools of each soil were determined using the method of Tiessen and Moir (1993) (Methods S3.1). Properties of the four soils are listed in Table 3.1. After the soils were collected, they were air-dried and sieved to $2 \mathrm{~mm}$ prior to potting.

Table 3.1 Physical and chemical properties of four types of soils used in the experiment.

\begin{tabular}{ccccc}
\hline Soil property & \multicolumn{4}{c}{ Soils } \\
\cline { 2 - 5 } & Changping & Zhangye & Guangzhou & Kunming \\
\hline Texture & Loam & Silt loam & Clay & Clay \\
$\mathrm{pH}\left(1: 2.5\right.$ soil: $\left.\mathrm{CaCl}_{2}\right)$ & 7.90 & 7.41 & 4.50 & 6.78 \\
Olsen-P $\left(\mathrm{mg} \mathrm{g}^{-1}\right)$ & 2.6 & 6.5 & 2.1 & 2.9 \\
Total N $\left(\mathrm{mg} \mathrm{kg}^{-1}\right)$ & 69 & 157 & 40 & 68 \\
Total $\mathrm{C}\left(\mathrm{g} \mathrm{kg}^{-1}\right)$ & 0.52 & 1.72 & 0.21 & 0.47 \\
\hline
\end{tabular}

\subsubsection{Plant growth}

A pot experiment was conducted from the end of September to December 2016 in the glasshouse with natural light of China Agricultural University, Beijing. The temperature in the glasshouse ranged from minimally $13^{\circ} \mathrm{C}$ at night to maximally $25{ }^{\circ} \mathrm{C}$ during the day. Plants were grown in pots (height: $160 \mathrm{~mm}$, diameter: $170 \mathrm{~mm}$ ) with $1 \mathrm{~kg}$ air-dried soil. The calcareous soils (Changping and Zhangye) were supplemented with hydroxyapatite $\left(\mathrm{Ca}_{5}\left(\mathrm{PO}_{4}\right)_{3}(\mathrm{OH})\right.$, Shanghai National reagents; $\left.\mathrm{CaP}\right)$ and sodium phytate $\mathrm{P}\left(\mathrm{C}_{6} \mathrm{H}_{6} \mathrm{O}_{24} \mathrm{P}_{6} \mathrm{Na}_{12}\right.$, Sigma; PhyP), both at a rate of $50 \mathrm{mg} \mathrm{P} \mathrm{kg}^{-1}$ soil as sparingly soluble $\mathrm{P}$ substrates under alkaline conditions. The Kunming and Guangzhou soils were mixed with quartz sand (2:1 $w / w)$ to prevent soil compaction. They were supplemented with PhyP and P-coated iron sludge (FeP) both at $50 \mathrm{mg} \mathrm{P} \mathrm{kg}^{-1}$ soil as sparingly soluble $\mathrm{P}$ substrates under acid conditions. The FeP was prepared by shaking $\left(180 \mathrm{~min}^{-1}\right) 6 \mathrm{~g}$ Fe sludge (a by-product of Brabant Water Ltd, Netherlands) in $170 \mathrm{~mL}$ of nutrient solution for 2 days at $25^{\circ} \mathrm{C}$ (Chardon et al. 2012). To support the initial growth of plants, $40 \mathrm{mg} \mathrm{P} \mathrm{kg}^{-1}$ soil as $\mathrm{KH}_{2} \mathrm{PO}_{4}$ was applied to each pot. 
Other nutrients were mixed in the soils at the following rates (mg per pot): $200 \mathrm{~N}$ as $\mathrm{NH}_{4} \mathrm{NO}_{3}$, $226 \mathrm{~K}_{\text {as K}} \mathrm{SO}_{4}, 126 \mathrm{Ca}$ as $\mathrm{CaCl}_{2} .2 \mathrm{H}_{2} \mathrm{O}, 39 \mathrm{Mg}$ as $\mathrm{MgSO}_{4} .7 \mathrm{H}_{2} \mathrm{O}, 5.5 \mathrm{Fe}$ as EDTAFe- $\mathrm{Na}, 6.7 \mathrm{Mn}$ as $\mathrm{MnSO}_{4} . \mathrm{H}_{2} \mathrm{O}, 10 \mathrm{Zn}$ as $\mathrm{ZnSO}_{4} .7 \mathrm{H}_{2} \mathrm{O}, 2 \mathrm{Cu}$ as $\mathrm{CuSO}_{4} .5 \mathrm{H}_{2} \mathrm{O}, 0.68 \mathrm{~B}$ as $\mathrm{H}_{3} \mathrm{BO}_{3}, 0.12 \mathrm{Mo}$ as $\left(\mathrm{NH}_{4}\right)_{6} \mathrm{Mo}_{7} \mathrm{O}_{24} \cdot 4 \mathrm{H}_{2} \mathrm{O}$.

The crop species were millet (Setaria italica L. cv. Longgu-11) and chickpea (Cicer arietinum L. cv. Longying-1); cabbage (Brassica oleracea L. cv. Sulv) and faba bean (Vicia faba L. cv. Yundou-324); wheat (Triticum aestivum L. cv. Kenong-9204) and maize (Zea mays L. cv. Zhengdan-958).

Monocultures and mixtures of millet/chickpea and wheat/maize were sown in the Changping and Zhangye soils. Monocultures and mixtures of cabbage/faba bean and wheat/maize were sown in the Guangzhou and Kunming soils. There were 24 treatment combinations in total, with four replicates arranged in a completely randomized design.

Before sowing, seeds of each species were surface-sterilized with $10 \% \mathrm{H}_{2} \mathrm{O}_{2}$ for $30 \mathrm{~min}$, rinsed thoroughly in deionized water and pre-germinated on filter paper. The germinated seeds of millet were sown two weeks later than chickpea to prevent competition for light with chickpea caused by fast growth of millet. The seedlings of monocultures were thinned to four individuals for millet and chickpea, two for cabbage and faba bean, six for wheat and two for maize, seven days after sowing. There were two seedlings of each species in the millet/chickpea mixture, one seedling of each species in the cabbage/faba bean mixture, three seedlings of wheat and one of maize in the wheat/maize mixture. The seedlings of chickpea and faba bean were inoculated with Mesorhizobium muleiense and Rhizobium leguminosarum, respectively (provided by Culture Collection of Beijing Agricultural University). The germinated chickpea and faba bean seeds were soaked in a bacterial suspension for $30 \mathrm{~min}$ before sowing, and $5 \mathrm{~mL}$ inoculum was also added to each pot. No nodules were formed on chickpea and faba bean in the experiment, most likely because we provided ample amounts of $\mathrm{N}$ to ensure that $\mathrm{P}$ is the unique limiting factor. Pots were watered with deionized water to $75 \%$ of water holding capacity every 2 days.

\subsubsection{Harvest and sample analysis}

Millet and chickpea were harvested 51 days after sowing chickpea. Wheat and maize were harvested 47 days after sowing and cabbage/faba bean 65 days after sowing when plant growth was slow. The shoots were cut at the soil surface, and roots were collected carefully. The roots with tightly adhering rhizosphere soil were immersed in $50 \mathrm{~mL} 0.2 \mathrm{mM} \mathrm{CaCl}$ solution and shaken carefully to extract rhizosphere soil. To prevent the degradation of carboxylates, we added the microbial inhibitor Micropur (Sicheres Trinkwasser, Germany) at $0.01 \mathrm{~g} \mathrm{~L} \mathrm{~L}^{-1}$ and also three drops of concentrated phosphoric acid to a subsample of the rhizosphere extract (approximate $8 \mathrm{~mL}$ ) before storing at $-20^{\circ} \mathrm{C}$ for HPLC analysis in which 
six carboxylates were identified (tartrate, malate, citrate, succinate, fumarate and trans-aconitate) (Li et al. 2010). Another subsample was stored at $4{ }^{\circ} \mathrm{C}$ for determination of acid phosphatase (APase) activity. The remaining rhizosphere suspension was air-dried to determine rhizosphere soil dry weight.

Because the solution: rhizosphere soil ratios differed depending on root size and the amounts of rhizosphere soil, we could not directly compare the absolute carboxylate concentrations in the extracts of different treatments. We therefore calculated exudate ratios (of the same species when grown in mixture compared to when grown alone) under two extreme assumptions: 1) The soil solid phase is inert and does not buffer the carboxylate concentration. Under this assumption the carboxylate concentration in the extract is a dilution of the rhizosphere solution concentration, and the carboxylate concentration can be expressed in $\mu \mathrm{mol} \mathrm{g}^{-1}$ rhizosphere soil $\mathrm{dw}$. 2) The soil solid phase completely buffers the carboxylate concentration, such that the carboxylate concentration in the extract is the same as the concentration in the rhizosphere soil solution (expressed in $\mu \mathrm{mol} \mathrm{L}^{-1}$ ). We then tested whether the ratio, calculated under both assumptions, showed increase (if both ratios $\pm 2 \times \mathrm{SE}>1$ ) or decrease (if both ratios $\pm 2 \times \mathrm{SE}<1$ ) of exudation as a response to a heterospecific neighbor. In other cases, we refer to the outcome as no increase/no decrease. We also calculated the ratio of carboxylates in the rhizosphere of one species over that of the other species to test for differences between the two species in a mixture.

We also determined rhizosphere $\mathrm{pH}$, but because of different solution: rhizosphere soil ratios and different $\mathrm{pH}$ buffering capacities of the four soils, measured $\mathrm{pH}$ values were not necessarily representative of the rhizosphere $\mathrm{pH}$ and were not shown.

The determination of rhizosphere APase activity was performed as described by Neumann (2006). The analysis involved colorimetric estimation of the $p$-nitrophenol released by phosphatase activity after incubation of soil with $4 \mathrm{~mL}$ of $0.04 \mathrm{M}$ sodium maleate buffer $(\mathrm{pH}$ 5.3) at $28{ }^{\circ} \mathrm{C}$ for 30 minutes. The reaction was stopped by $0.5 \mathrm{M} \mathrm{NaOH}$, and the absorbance was measured spectrophotometrically at $405 \mathrm{~nm}$. One unit of APase activity was defined as the activity per gram soil that produced $1 \mu \mathrm{mol} p$-nitrophenol (PNP) per hour. A similar procedure as for carboxylates was followed for APase activity to decide whether there was an increase or a decrease.

All harvested shoots and roots after washing with deionized water were oven-dried at $70{ }^{\circ} \mathrm{C}$ for $72 \mathrm{~h}$ before weighing. The shoot and root samples were ground and digested with $\mathrm{HNO}_{3}-\mathrm{H}_{2} \mathrm{O}_{2}$ in a microwave accelerated reaction system (CEM, Matthews, NC, USA). The P concentrations in the digests were determined by inductively coupled plasma optical emission spectroscopy (ICP, OPTIMA 7300 DV, Perkin-Elmer, USA). 


\subsubsection{Data analysis and statistics}

Phosphorus uptake per plant was calculated by subtracting seed P content from the sum of shoot $\mathrm{P}$ content and root $\mathrm{P}$ content.

One-way ANOVA was performed on biomass, $\mathrm{P}$ uptake and tissue $\mathrm{P}$ concentration. We performed the above analysis using $R$ ( $R$ version 3.1.2) ( $R$ Core Team 2014). All data were checked for normality and homogeneity of variances prior to ANOVA, and data were transformed when necessary. Data on maize root biomass on the Kunming soil, and wheat shoot and root biomass on the Guangzhou soil were log-transformed.

\subsection{Results}

\subsubsection{P fractionation of the selected soils}

Phosphorus concentrations of the different $\mathrm{P}$ fractions varied among the four soils. Total $\mathrm{P}$ was relatively high in the calcareous Zhangye soil and the neutral Kunming soil. The two calcareous soils contained similar $\mathrm{P}$ fractions. The largest $\mathrm{P}$ fractions of both calcareous soils were $1 \mathrm{M} \mathrm{HCl}-\mathrm{P}_{\mathrm{i}}$ (Table 3.2), representing Ca-bound P. The Guangzhou and Kunming soils mainly contained occluded $\mathrm{P}$ and $\mathrm{P}$ held within Fe or $\mathrm{Al}$ (hydr)oxides (such as residual $\mathrm{P}$, $\mathrm{NaOH}-\mathrm{P}_{\mathrm{i}}$, conc. $\mathrm{HCl}-\mathrm{P}_{\mathrm{i}}$ ) and recalcitrant organic $\mathrm{P}$.

\subsubsection{Species combinations on the calcareous soils}

\section{Millet/chickpea}

On the Changping soil, both the carboxylate exudation and APase activity in the rhizosphere of sole chickpea were higher than sole millet (Table 3.3). There was an increase in carboxylate exudation of mixed millet (the main carboxylates were malate, citrate and succinate, Fig. S3.1, Appendix B) compared to sole millet (the main carboxylates were malate and citrate, Fig. S3.1) (Table 3.4), but the carboxylates were predominantly produced by chickpea (Table 3.3).

Plant P content of chickpea was not significantly different from seed P (Fig. 3.2a), hence no net uptake of $\mathrm{P}$ could be demonstrated. Shoot and root biomass were similar in sole and mixed chickpea (Fig. 3.3a, e). P uptake (Fig. 3.2a), shoot and root biomass (Fig. 3.3a, e) of mixed millet were higher than sole millet. However, the increase in P uptake and biomass of mixed millet did not result in overyielding by millet/chickpea combinations (Fig. 3.4a, e). The much higher root exudation of chickpea than millet indicates the mechanism of facilitation (Fig. 3.1f). The outcome of increased $\mathrm{P}$ uptake and biomass of mixed millet in the mixture compared to sole millet indicates enhanced competitive inequality potentially due to the increased ortho-P availability and fast root growth by millet (Fig. 3.3e). 
On the Zhangye soil, APase activity of sole chickpea was higher than of sole millet, but no difference in carboxylate exudation was found between sole millet and sole chickpea (Table 3.3). The carboxylate exudations of both millet and chickpea were similar when grown in monoculture and in mixture (Table 3.4). Only APase activity of mixed millet was lower compared to sole millet (Table 3.4). P uptake (Fig. 3.2a) and biomass of millet and chickpea (Fig. 3.3a, e) were not affected by mixing on this soil. None of the mechanisms represented in Fig. 3.1 matches these results.

\section{Wheat/maize}

On the Changping soil, there was no difference in carboxylate exudation between sole wheat and sole maize (Table 3.3), and there was no increase in the rhizosphere of mixed wheat in response to mixing with maize (Table 3.4). The results did not allow for any conclusion on modification of root exudation by maize when mixed with wheat (Table 3.4). P uptake and shoot biomass of mixed wheat were $56 \%$ and $29 \%$ higher than sole wheat (both $P<0.01$, Fig. 3.2c; Fig. 3.3c). In contrast, P uptake and shoot biomass of mixed maize were $89 \%(P<0.05$, Fig. 3.2c) and $31 \%(P<0.05$, Fig. 3.3c) lower than sole maize, respectively. There was no overyielding of the biomass of wheat/maize mixture (Fig. 3.4g). Observed P uptake, however, was higher than expected (Fig. 3.4c). The outcome of mixing wheat and maize indicates unequal competitive ability (Fig. 3.1d).

On the Zhangye soil, there was no difference in exudation between sole wheat and sole maize (Table 3.3) and in carboxylate concentrations between both wheat and maize grown in monoculture or in a mixture (Table 3.4). Decrease in APase activity was found in the rhizosphere of only wheat in response to mixing with maize (Table 3.4). P uptake of mixed wheat increased by $56 \%$ compared to sole wheat $(P<0.01$, Fig. $3.2 \mathrm{c})$, while P uptake of mixed maize decreased by $44 \%$ compared to sole maize $(P<0.01$, Fig. $3.2 \mathrm{c})$. The shoot and root biomass of wheat and maize were not affected by mixing (Fig. $3.3 \mathrm{c}, \mathrm{g}$ ). No overyielding was found in P uptake or biomass of wheat and maize mixture (Fig. 3.4). The outcome of mixing wheat and maize on the Zhangye soil is in line with what we expect in case of unequal competitive abilities (Fig. 3.1d). 

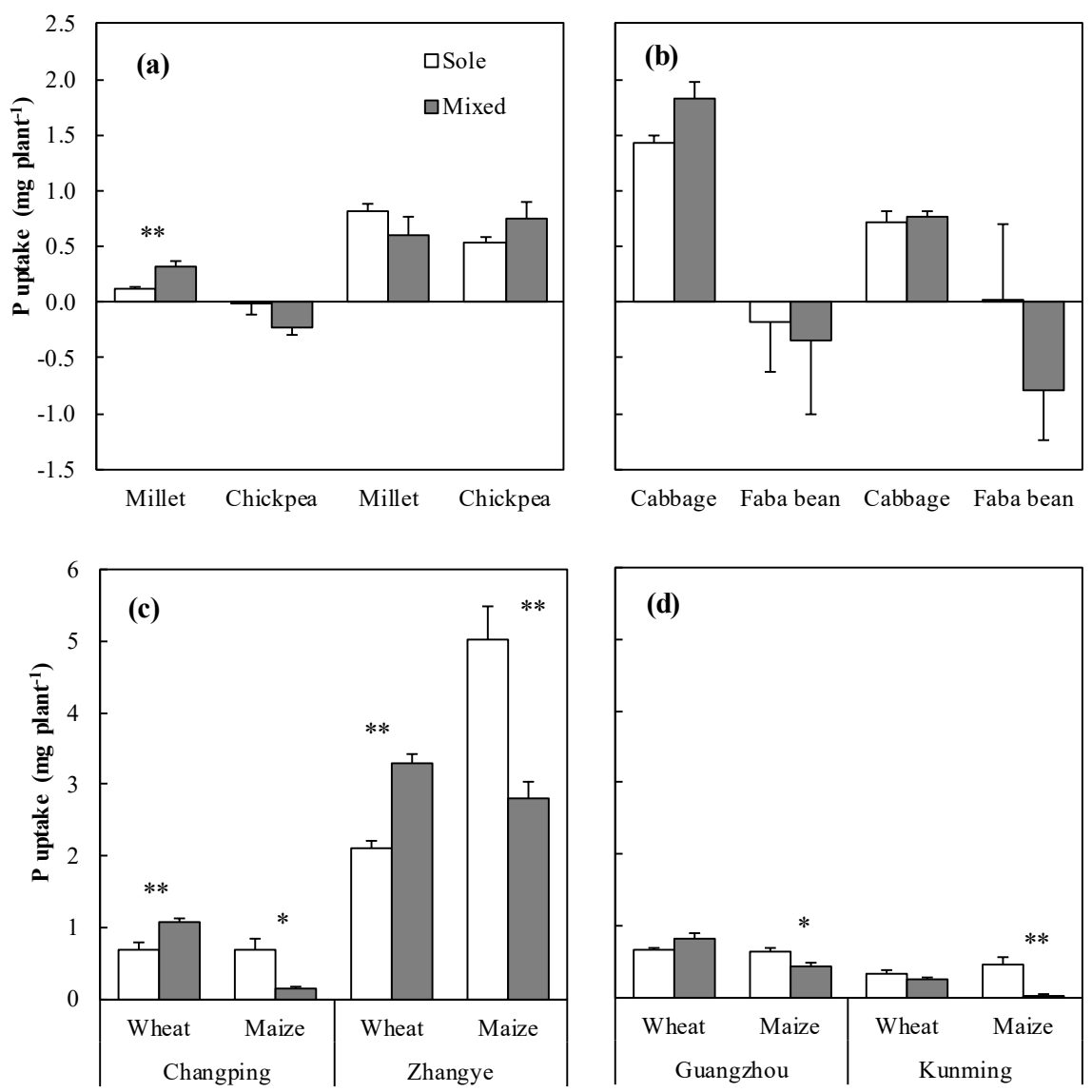

Fig. 3.2 $\mathrm{P}$ uptake of species in monocultures and mixtures on four soils. (a) millet and chickpea on Changping and Zhangye soils; (b) cabbage and faba bean in Guangzhou and Kunming soils; (c) wheat and maize on Changping and Zhangye soils; (d) wheat and maize on Guangzhou and Kunming soils. Asterisks refer to significant differences between monocultures and intercrops ${ }^{* *} P<0.01,{ }^{*} P<0.05$. Sole and Mixed represent species grown in monoculture or in mixture. 


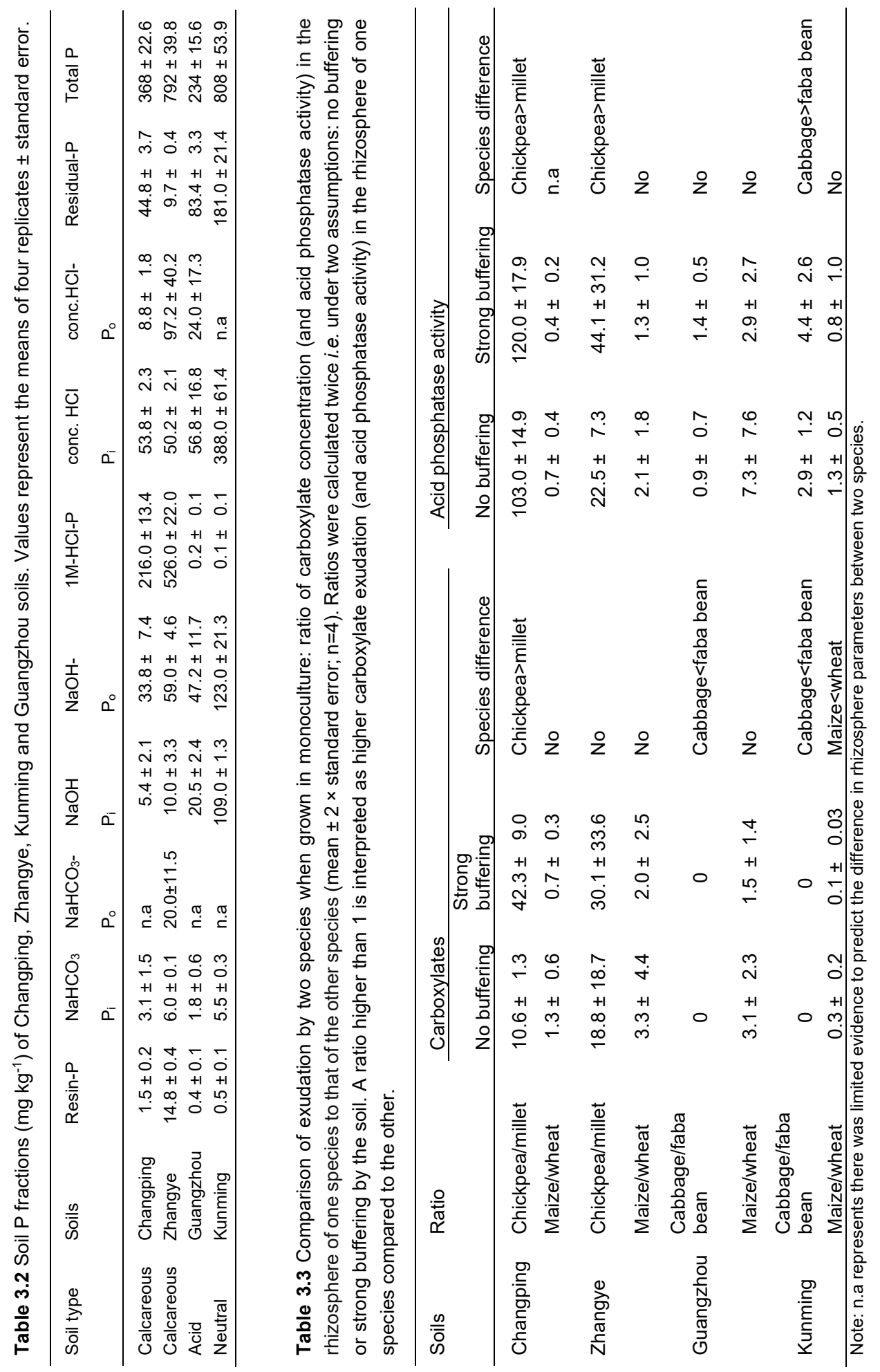




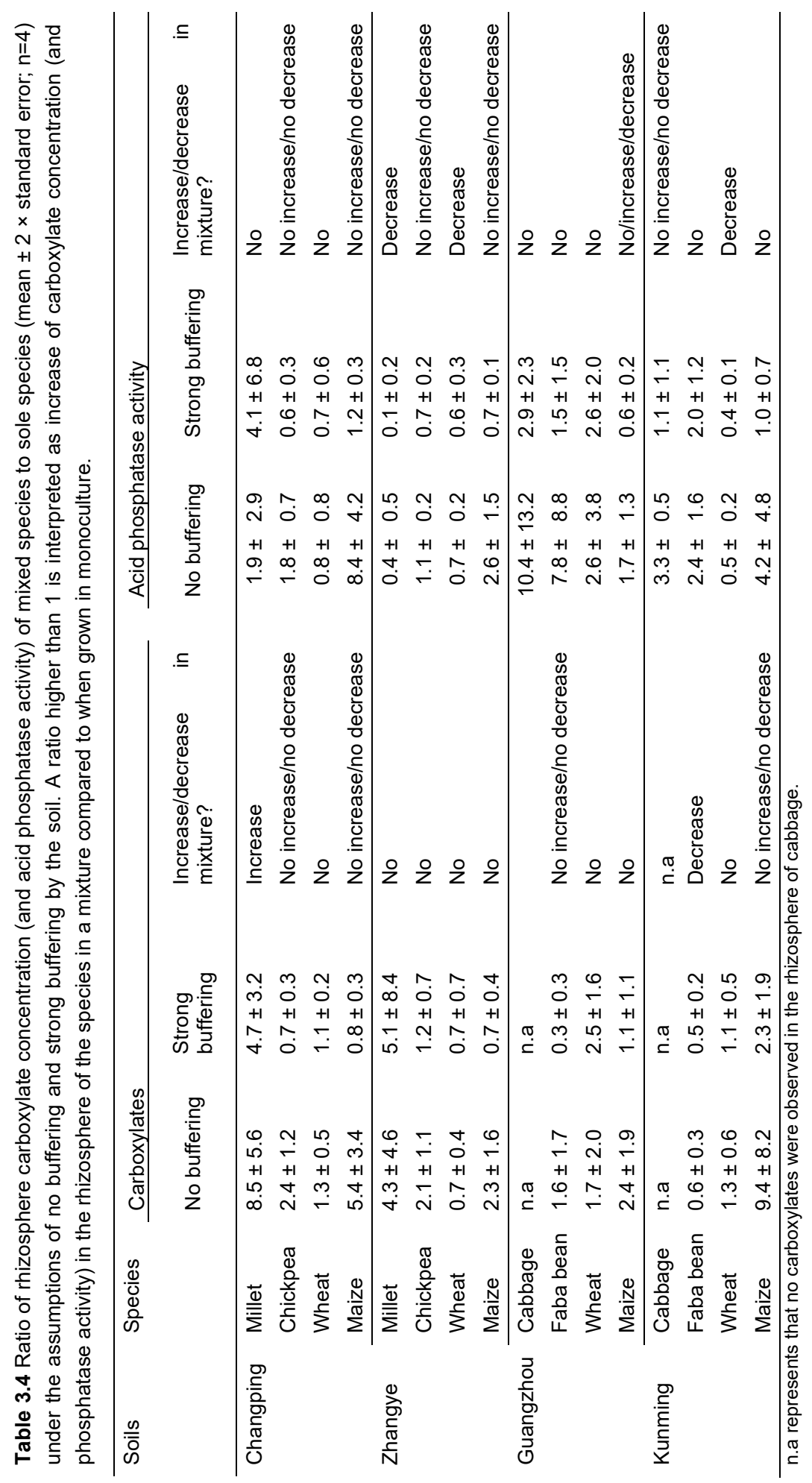




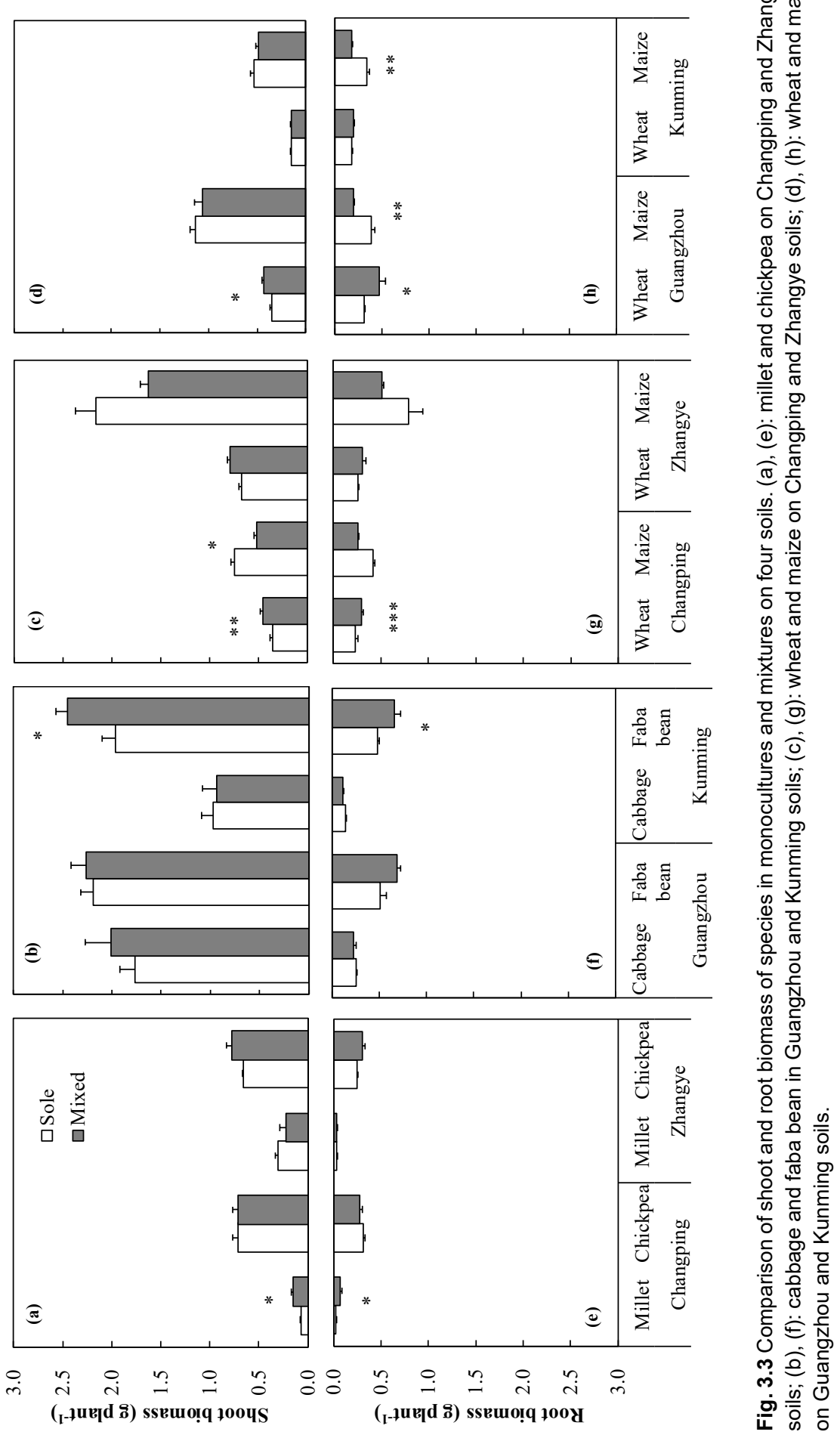



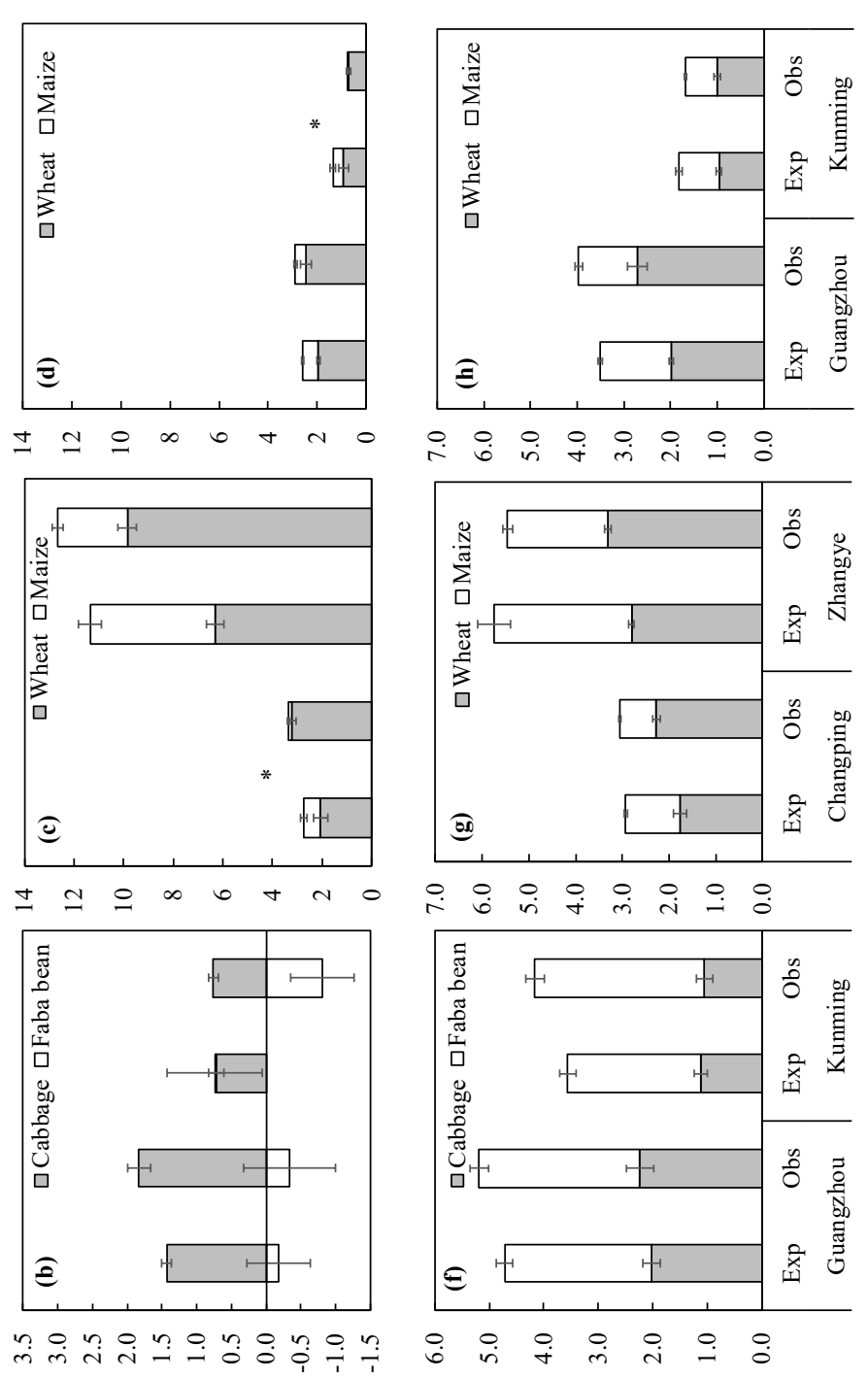

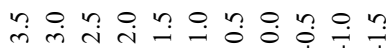
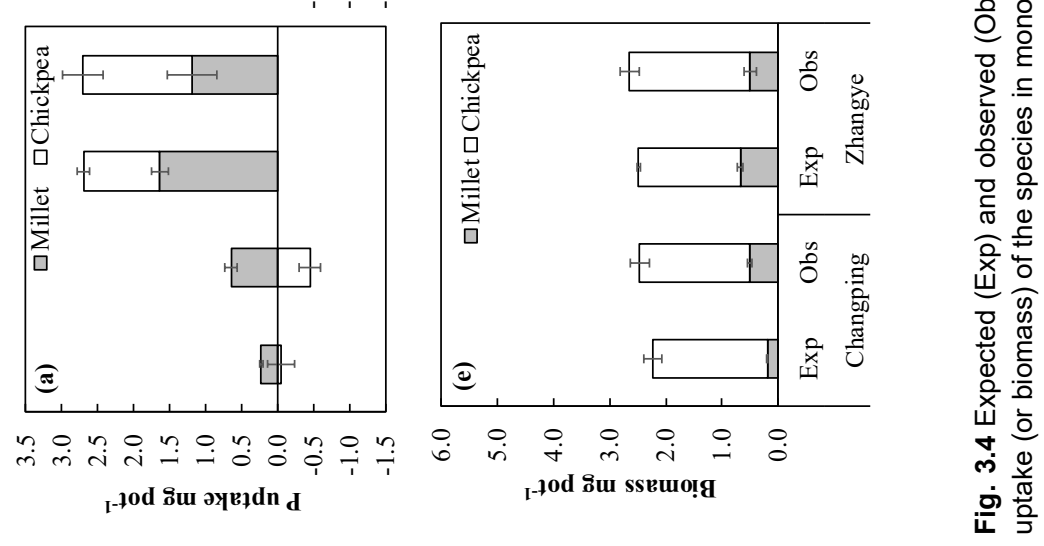


\subsubsection{Species combinations on the acid and neutral soils}

\section{Cabbage/faba bean}

On the acid Guangzhou soil, carboxylate exudation of faba bean was higher than that of cabbage, but APase activity was similar for the two species (Table 3.3). No carboxylates were observed in the rhizosphere of either sole or mixed cabbage (Table 3.4). Mixing cabbage and faba bean had no effect on APase activity of either species (Table 3.4). There was no difference in P uptake or biomass between sole and mixed cabbage or faba bean (Fig. $3.2 b$, Fig. 3.3b). The difference in carboxylate exudation between cabbage and faba bean was consistent with the potential mechanisms of facilitation (Fig. 3.1c), however, there was no increase in carboxylate exudation by faba bean in the mixture.

On the neutral Kunming soil, the rhizosphere carboxylate concentration of sole faba bean was higher than that of sole cabbage, while APase activity of faba bean was lower than that of cabbage (Table 3.3). There was decrease in carboxylate exudation by faba bean in the mixture (Table 3.4). However, APase activity was similar for mixed and sole faba bean (Table 3.4). Carboxylate exudation was hardly observed in the rhizosphere of mixed or sole cabbage (Table 3.4), and the response of APase activity of cabbage to mixing with faba bean was not clear (Table 3.4). P uptake by both species was not affected by mixing (Fig. 3.2b; Fig. $3.3 \mathrm{~b}, \mathrm{f})$. Shoot and root biomass of mixed faba bean were respectively $24 \%(P<0.05$, Fig. $3.3 b)$ and $36 \%(P<0.05$, Fig. 3.3f) higher compared to sole faba bean. Biomass of cabbage was not affected by mixing. The differences in rhizosphere parameters between two species met the prerequisite for the mechanism of complementarity (Fig. $3.1 \mathrm{~b}$ or c).

On both soils, mixing cabbage and faba bean did not result in any additional $\mathrm{P}$ uptake or biomass by species mixtures (Fig. 3.4b, f).

\section{Wheat/maize}

On the acid Guangzhou soil, rhizosphere parameters were similar for wheat and maize (Table 3.3), and not affected by mixing (Table 3.4). P uptake was similar for mixed and sole wheat (Fig. 3.2c). Shoot and root biomass of mixed wheat increased by $23 \%$ and $52 \%$ respectively (both $P<0.05$, Fig. 3.3d, h) compared to sole wheat. For maize, P uptake and root biomass of mixed maize were $33 \%(P<0.05$, Fig. $3.2 \mathrm{~d})$ and $50 \%(P<0.01$, Fig. $3.3 \mathrm{~h})$ respectively lower than for sole maize. There was no difference in the observed and expected P uptake or biomass of wheat/maize (Fig. 3.4h) on the Guangzhou soil. These results indicate competitive inequality (Fig. 3.1d).

On the neutral Kunming soil, APase activity was similar between sole wheat and sole maize, but carboxylate exudation of wheat was higher than that of maize (Table 3.3). Only decrease in APase activity was found in the rhizosphere of mixed wheat but not of mixed 
maize (Table 3.4). Biomass was similar for sole and mixed wheat (Fig. 3.3d). In contrast, P uptake decreased by $97 \%(P<0.01$, Fig. 3.2d) and root biomass of mixed maize decreased by $46 \%(P<0.01$, Fig. $3.3 g)$ due to mixing. There was no difference in the observed and expected biomass of wheat/maize (Fig. 3.4d) on the Kunming soil, but the observed P uptake by wheat/maize was significantly lower than expected (Fig. 3.4d). The results indicate competitive inequality (Fig. 3.1d).

\subsection{Discussion}

We expanded a conceptual framework, originally proposed by Hinsinger et al. (2011), to test for rhizosphere mechanisms of complementarity in accessing different $\mathrm{P}$ sources or facilitation of $\mathrm{P}$ acquisition which could subsequently cause enhanced $\mathrm{P}$ uptake and overyielding as an outcome. In addition to Hinsinger et al. (2011), our framework takes into account that an increased pool of available ortho-P, due to complementarity and facilitation, could shift the competitive balance between both species. We then tested the mechanism of complementarity in P uptake from mixed P sources by mixing two species with differential $P$ uptake traits. We expected to find enhanced P uptake by a species mixture based on the species' different abilities to solubilize the different $P$ forms in the soil. But we did not find evidence for complementarity in P acquisition from different sources in any of the species combinations. However, based on our conceptual framework, we found that the mechanism of facilitation could occur in millet/chickpea combination on one calcareous soil (Changping soil). We found the prerequisite for complementarity in accessing P sources to occur because of differences in root exudates between cabbage and faba bean on the neutral soil (Kunming soil). But the potential mechanisms of complementarity and facilitation did not lead to overyielding. The acid phosphatase activity and carboxylate concentration of wheat and maize were similar, but there was overyielding of $\mathrm{P}$ uptake by wheat/maize mixture on one calcareous soil.

A prerequisite for testing our conceptual model is that plant growth is limited by $\mathrm{P}$ and not by other factors. In all soils, P-Olsen levels ranged between 2.1 and $6.5 \mathrm{mg} \mathrm{P} \mathrm{kg}^{-1}$, well below $10 \mathrm{mg} \mathrm{P} \mathrm{kg}^{-1}$, and this criterion is often used to assess $\mathrm{P}$ deficiency. Plants were fertilized with all other essential nutrients in adequate amounts, further maintaining the status of the soils as P-limited. Further evidence for P limitation is found in the (very) low shoot $\mathrm{P}$ concentrations (mostly $<2 \mathrm{mg} \mathrm{P} \mathrm{g}^{-1}$ plant $\mathrm{dw}$ ), which were lower than the approximate critical shoot $\mathrm{P}$ concentration of these plant species ( $\mathrm{mg} \mathrm{P} \mathrm{g}^{-1}$ plant $\mathrm{dw}$, wheat, 5.5; cabbage, 2.9; chickpea, 2.4; faba bean, 4.0 (Pearse et al. 2006); maize, 2.7 (Wen et al. 2017)).

In the current literature, complementarity is often used both as a cause of enhanced ecosystem functioning and as a consequence of some community processes (Barry et al. 
2019). The complementarity effect, calculated with additive partitioning method (Loreau and Hector 2001), land equivalent ratio (LER) or relative yield total (RYT), represent the consequences but not the underlying mechanisms. LER calculated on the basis of plant $\mathrm{P}$ content is often used to demonstrate complementarity and facilitation with respect to $\mathrm{P}$ uptake and overyielding, however, several kinds of species interactions often occur simultaneously and result in enhanced resource acquisition and yield gain of intercrops. To avoid confusion, we separated mechanisms and outcomes in our framework. Complementarity and facilitation with respect to $\mathrm{P}$ uptake from different chemical forms in the present study were referred to as mechanisms, i.e., complementarity means complementarity in $\mathrm{P}$ acquisition from different sources by species mixture (Hinsinger et al. 2011) and facilitation of $P$ uptake means one species facilitates the $P$ uptake by its neighbor through root exudates ( $\mathrm{Li}$ et al. 2014).

Our hypothesis on complementarity in $\mathrm{P}$ acquisition from different sources and enhanced $\mathrm{P}$ uptake by species mixtures was not confirmed. We only found species differences in root exudates in one of the four hypothesized cases. On the Kunming soil, faba bean carboxylate concentrations were higher than those of cabbage, while cabbage APase activity was higher. This would suggest differential access to metal(hydr)oxide bound $\mathrm{P}$ and organic $\mathrm{P}$, which is according to the mechanism of complementarity (as shown in Fig. 3.1b, e) as both species are able to mobilize different $\mathrm{P}$ sources. However, the expected differential access to different $P$ sources by cabbage and faba bean did not result in extra $P$ uptake by the species mixture. The high APase activity of cabbage was probably a response to $\mathrm{P}$ deficiency (Tadano et al. 1993). We hardly found carboxylates in the cabbage rhizosphere in response to $\mathrm{P}$ deficiency, which was not consistent with a previous study (Dechassa and Schenk 2004). The lack of enhanced $P$ uptake by cabbage/faba bean mixture compared to sole species could be due to low exudation of carboxylates, which did not release the phytate from FeP and other metal oxides in this strongly buffering soil (Methods S3.2). Therefore, the efficiency of phosphatase may have been limited, as mineralization of $\mathrm{P}$ from organic sources is not limited by the concentration of phosphatases but by the availability of organic $\mathrm{P}$ in the soil solution for which effective desorption through carboxylates and / or acidification is essential (Tinker and Nye 2000; George et al. 2005; Gerke 2015).

On the Changping soil with a mixture of $\mathrm{CaP}$ and PhyP, we expected the mechanism of complementarity and enhanced $P$ uptake by millet/chickpea mixture based on differential $\mathrm{P}$ uptake traits in our previous study (Chapter 2). However, there was neither enhanced $\mathrm{P}$ uptake nor overyielding by millet/chickpea mixture; only millet benefited in the mixture. The results are consistent with previous studies that cereals benefited from mixing with legumes without any effect on legumes ( $\mathrm{Li}$ et al. 2004; Cu et al. 2005; Dissanayaka et al. 2015). In line with previous studies (Tadano and Sakai 1991; Hayes et al. 1999; Neumann 
and Romheld 1999), both APase activity and carboxylate concentrations were higher in the rhizosphere of chickpea compared to millet (Table 3.3). This is consistent with the fact that enhanced phosphatase activity is only effective in combination with enhanced dissolution or desorption of P (Hayes et al. 2000; Tinker and Nye 2000; George et al. 2004). The rhizosphere of millet and chickpea likely overlapped in the mixture, which might have allowed facilitation of $\mathrm{P}$ acquisition by mixed millet. One of the two species (chickpea) was better able to mobilize sparingly soluble P sources and the other species (millet) benefited. That matches the mechanism of unidirectional facilitation of millet by chickpea, followed by increased competitive ability by millet (Fig. 3.1f). There was a small but significant increase in carboxylates of mixed millet compared to sole millet, indicating that millet could mobilize Ca-bound P in the mixture. However, as the amount of carboxylates exuded in the mixture by chickpea was much higher than that of millet (Table 3.3), we consider upregulation of carboxylates by mixed millet as quantitatively not very important. Because of the relatively poor growth of millet at low P availability on the Changping soil (Methods S3.3), the increased P uptake by millet did not lead to significant overyielding by the millet/chickpea mixture. On the Zhangye soil, however, millet and chickpea performed differently in terms of rhizosphere modifications, and there was no positive mixing effect on P uptake by each species. The immediately available P (Resin-P) of the Zhangye soil was 10 times higher than the Changping soil (Table 3.2). Shoot P concentrations (Fig. S3.2), P uptake (Fig. 3.2a) and shoot biomass (Fig. 3.3a) of both millet and chickpea were higher on the Zhangye soil than that on the Changping soil. Lack of facilitation of $\mathrm{P}$ uptake in millet/chickpea mixture in the Zhangye soil compared to the Changping soil is therefore likely due to the higher soil $\mathrm{P}$ availability in the Zhangye soil.

Consistent with our hypothesis, mechanism of complementary P uptake did not occur in wheat/maize mixture on the calcareous soils. There was almost no difference in rhizosphere parameters between wheat and maize (Table 3.3). So, wheat and maize should have similar capacities to access the two P sources, consistent with our previous study (Chapter 2). On the Changping soil, the wheat/maize mixture took up more $\mathrm{P}$ than expected based on their monocultures. This may be caused by competitive inequalities. Wheat is a stronger competitor for $\mathrm{P}$ than maize, because the root length density and phenotypic plasticity of wheat are larger than maize in intercropping (Li et al. 2001b; Li et al. 2006; Liu et al. 2015). Assuming low soil buffering capacity, there could have been an increase in root exudation by mixed maize (Table 3.4), which increased P availability and enhanced competition for $\mathrm{P}$ by mixed wheat at the expense of maize. These enhanced competitive inequalities caused by increased $\mathrm{P}$ availability could happen in the field as well. They can be reduced by arranging the species with temporal niche differentiation in the 
mixture (Chapter 5). In the Zhangye soil with higher available P (Table 3.2), we did not observe higher $\mathrm{P}$ uptake by wheat/maize mixture compared to monocultures.

In line with our hypothesis, the mechanism of complementary P uptake also did not occur in wheat/maize mixture on the acid and neutral soils. On these soils, the growth and P uptake of wheat and maize were highly limited by P. The outcomes of mixing wheat and maize on these soils are consistent with the mechanism of competition since wheat and maize showed similar rhizosphere exudation. Field studies often showed overyielding by wheat/maize intercropping ( $\mathrm{Li}$ et al. 2001b; Gou et al. 2016). However, the overyielding by wheat/maize intercropping is probably mainly due to temporal niche differentiation as a result of differences in sowing and harvesting time (Chapter 5).

In the present pot experiment, there was little evidence for complementarity in $\mathrm{P}$ acquisition from different sources or facilitation of $\mathrm{P}$ uptake in species combinations where facilitation or complementarity was predicted. In our experiment we studied only one mechanism, related to differential acquisition of $\mathrm{P}$ from various sparingly available $\mathrm{P}$ sources. Several other mechanisms also drive overyielding, including temporal and spatial complementarity in P uptake. In field studies with relay strip intercropping ( $\mathrm{Li}$ et al. 2007; Song et al. 2007; Xia et al. 2013), temporal complementarity in resource acquisition (e.g., light, water, $\mathrm{N}$ and $\mathrm{P}$ ) is the dominant mechanism responsible for enhanced $\mathrm{P}$ uptake compared to that in sole crops.

Our expanded conceptual framework provides a tool to assess the potential role of co-occurring mechanisms contributing to the outcome of root interactions in species mixtures. Separating physiological mechanisms from outcomes (also driven by other root traits like root morphologies) helps to better understand the variable results on the contribution of rhizosphere modifications to $\mathrm{P}$ uptake by mixtures in previous studies. The mobilized P from sparingly soluble P pools goes into the same ortho-P pool, which is available to both species (Fig. 3.1). The increased P availability could enhance P uptake by the dominant species, thus increased resource availability caused by facilitation promotes species' competition for resources (Holmgren et al. 1997; Maestre et al. 2009; O'Brien et al. 2017).

It may be incorrect to infer mechanisms from outcomes because absence of overyielding may coincide with facilitation. Alternatively, it may be incorrect to infer outcomes from mechanisms because overyielding can occur in case of competitive inequality (selection effect sensu Loreau and Hector (2001)). Our study therefore serves as a reminder that physiological root traits (exudation, the underlying mechanism for complementarity and facilitation) might be insufficient to result in overyielding, as the final outcome can also be influenced by morphological and architectural traits like root length, diameter or biomass 
(Sun et al. 2019b) through which thin-rooted species may have the larger benefit of enhanced P mobilization.

\subsection{Conclusions}

We did not find conclusive evidence of the mechanism of complementarity in P acquisition from different sources by species mixtures. Our conceptual framework based on the mechanisms associated with rhizosphere modification helps to better understand the relative roles of mechanisms of complementarity in accessing $\mathrm{P}$ from different sources and facilitation of $\mathrm{P}$ uptake by species mixture. The rhizosphere modifications supported circumstantial evidence for access to certain $\mathrm{P}$ sources and facilitation of $\mathrm{P}$ uptake in some species mixtures. However, under the low $\mathrm{P}$ conditions in our experiment, the increased $\mathrm{P}$ availability through root exudation likely enhanced rather than decreased the competition for $\mathrm{P}$ by the dominant species in the mixture. Therefore, mechanisms of complementarity and facilitation do not necessarily result in increased $\mathrm{P}$ uptake by species mixtures, because this also depends on the relative $\mathrm{P}$ acquisition gains of species in the mixture compared to sole species.

\section{Acknowledgements}

This research was supported by projects of National Key R \& D Program of China (2017YFD0200200/2017YFD0200202), International Cooperation and Exchanges NSFC (31210103906), and by the Wageningen University Sandwich PhD Fellowship. 


\section{Chapter 4 Complementarity and facilitation with respect to $P$ acquisition do not drive overyielding by intercropping}

Chunjie Li, Ellis Hoffland, Wopke van der Werf, Junling Zhang, Haigang Li, Jianhao Sun,

Fusuo Zhang, Thomas W. Kuyper 


\begin{abstract}
Complementarity in phosphorus $(\mathrm{P})$ acquisition from different sources and facilitation of $\mathrm{P}$ uptake have been implicated in yield advantages of intercropping. These beneficial interactions between crop species are expected to be particularly relevant on low P soils.

Millet and chickpea have previously been found to differ in their ability to access different chemically bound forms of P. Here, we conducted a two-year field experiment on a low-P soil with or without $\mathrm{P}$ fertilization to determine whether the resulting potential for complementarity and facilitation with respect to $\mathrm{P}$ acquisition is associated with increased $\mathrm{P}$ uptake and yield of an intercrop as compared to sole crops.

Alkaline phosphatase activity and carboxylate concentration differed between millet and chickpea, indicating potential complementarity in access to different P sources. Comparison of aboveground $\mathrm{P}$ content in the intercrop and the pure stands showed a positive net effect for $\mathrm{P}$ uptake (NEp $>0$ ) when no $\mathrm{P}$ fertilizer was applied, but this positive net effect for $\mathrm{P}$ acquisition was not associated with yield increase $(\mathrm{NEY}=0)$. When $\mathrm{P}$ fertilizer was applied, there was no significant net increase in $\mathrm{P}$ uptake by the intercrop compared to sole crops (NEP $=0)$, but there was a significant yield gain $(\mathrm{NEy}>0)$.

Species trait dissimilarities for $\mathrm{P}$ acquisition from different sources supported complementary in, and facilitation of P uptake by millet and chickpea in the field on a low P soil, but this did not result in yield increase. The finding does not support the notion that complementarity in $\mathrm{P}$ acquisition from different sources and facilitation of $\mathrm{P}$ uptake are key drivers for overyielding by intercropping on low-P soil.
\end{abstract}

Keywords: intercropping, complementarity, facilitation, phosphorus, root exudates, stress gradient hypothesis, temporal niche differentiation 


\subsection{Introduction}

Phosphorus $(\mathrm{P})$ is an essential nutrient for plants. Agricultural crops are commonly fertilized with $\mathrm{P}$ fertilizer, but a large part of the applied $\mathrm{P}$ fertilizer accumulates in the soil (Faucon et al. 2015; George et al. 2016) because the $\mathrm{P}$ ions are adsorbed to $\mathrm{Al}$ or $\mathrm{Fe}$ (hydr)oxides or precipitated as calcium-P (Ca-P) and converted into sparingly soluble forms of $\mathrm{P}$ (Hinsinger 2001; Vance et al. 2003). These sparingly soluble P sources are relatively inaccessible to plants. Plants can access sparingly soluble soil $\mathrm{P}$ reserves by the formation of thinner roots, symbioses with mycorrhizal fungi and/or the production of P-mobilizing root exudates (Richardson et al. 2011). Plant species vary widely in their capabilities to mobilize or access sparingly soluble P sources (Pearse et al. 2007). Legumes are in general better able than cereals to mobilize theses sparingly soluble $\mathrm{P}$, converting theses $\mathrm{P}$ forms into soluble orthophosphate that can be readily taken up (Li et al. 2014). Cereal/legume intercropping (the cultivation of two or more crop species in the same field (Vandermeer 1989; Willey 1990)) is therefore considered an efficient way to optimize the use of poorly available P sources in the soil. Improved acquisition of $\mathrm{P}$ and increased yield (overyielding) have been observed in intercrops of maize with legumes, e.g., maize/faba bean (Li et al. 2007), maize/common bean (Latati et al. 2016) and maize/soybean (Wang et al. 2017). These increases in P uptake and yield of intercrops represent an outcome of species interactions in intercropping but the mere observation of greater than expected $\mathrm{P}$ uptake by intercropping is not a proof that complementarity in or facilitation of $\mathrm{P}$ uptake is the underlying mechanism of the increased $\mathrm{P}$ uptake. The literature mentions both complementarity and facilitation with respect to $\mathrm{P}$ uptake as mechanisms enabling the outcomes of increased P uptake and yield gain of intercrops.

Complementarity in $\mathrm{P}$ uptake is defined as the reduced competition for $\mathrm{P}$ between intercropped species as due to their differential accesses to different $P$ sources (Hinsinger et al. 2011), i.e., P partitioning in species mixtures (Turner 2008). Facilitation is defined as a belowground process where a nutrient-mobilizing species increases the nutrient availability both for itself and for a non-mobilizing neighbour (Li et al. 2014; Brooker et al. 2015).

Most of the studies on $\mathrm{P}$ acquisition by intercrops have focused on facilitation of a P-non-mobilizing species by a P-mobilizing species (Li et al. 2014; Faucon et al. 2015; Xue et al. 2016). Studies on facilitation usually concerned intercropped legumes, which, through exudation of P-mobilizing compounds, facilitate P uptake by other crop species, often cereals, especially on P-deficient soils (Li et al. 2007; Latati et al. 2014; Wang et al. 2017). P-mobilizing compounds include carboxylates, phosphatases and protons. Carboxylates can compete with phosphate for the same sorption sites on metal (hydrox)ides and therefore bring P into the soil solution. Phosphatases hydrolyse organic P (Richardson et al. 2009). The release of 
protons can acidify the rhizosphere and improve the dissolution of Ca-P in alkaline soil (Hinsinger 2001). Li et al. (2014) hypothesized that mobilization of sparingly soluble P sources plays an important role in overyielding by cereal/legume intercrops. However, Evers et al. (2018) argue the connectedness of acquisition of light, water and nutrients by plants in mixed stands and the difficulty of identifying causes and effects in increased resource capture and overyielding. While it is possible that complementarity or facilitation with respect to $\mathrm{P}$ uptake would drive yield increases in agriculture, particularly on $\mathrm{P}$ deficient soils, it is likewise possible that complementarity of other factors, e.g., light or water, would drive an increase in biomass that - as a consequence - would drive increased $\mathrm{P}$ acquisition by intercrops without complementarity in $\mathrm{P}$ acquisition from different sources being initial driver of the yield increase. There is therefore uncertainty regarding the importance of complementarity in or facilitation of $\mathrm{P}$ uptake as a driver for, or a result of, yield increase of intercrops. This is unlike the situation with respect to $\mathrm{N}$, where ample evidence has been collected demonstrating that complementarity in $\mathrm{N}$ acquisition (through $\mathrm{N}_{2}$-fixation by legumes and mineral $\mathrm{N}$ uptake by the other species) is the main driver for yield increase on soils where $\mathrm{N}$ is the yield-limiting element (Hauggaard-Nielsen and Jensen 2001; Corre-Hellou et al. 2006).

Previous studies have shown that crop species differ in their ability to access various $\mathrm{P}$ forms (e.g., Ca-bound P or organic P) (Pearse et al. 2007). If two species with diverging P uptake traits are combined in a mixture, this would enlarge the ways in which the mixture can access $\mathrm{P}$, which could result in a reduction of competition for $\mathrm{P}$, and hence allow complementarity and overyielding. Several field studies tested for such complementarity by measuring the depletion of different $P$ pools by species mixtures (Crème et al. 2016; Liao et al. 2020). Lucerne (legume species) depleted more the available $\mathrm{P}$ fraction (extracted by $\mathrm{NaHCO}_{3}$ ) than grass cocksfoot and tall grass fescue (Crème et al. 2016). Sole maize and maize/faba bean intercropping depleted the sparingly available organic $\mathrm{P}$ fraction (extracted by $\mathrm{NaOH}$ and concentrated $\mathrm{HCl}$ ), and sole faba bean was found to deplete the labile and moderately labile organic $\mathrm{P}$ fractions (extracted by $\mathrm{NaHCO}_{3}$ and $\mathrm{NaOH}$ ) (Liao et al. 2020). However, these results of depletion of $\mathrm{P}$ fractions by cereals and legumes in intercropping in the field are contrary to the general notion that legumes are better than cereals able to mobilize sparingly soluble P.

Previously, I tested for complementarity in P uptake between two species with differing ability to take up different chemical forms of $\mathrm{P}$ by growing them as mixtures on single or mixed $\mathrm{P}$ sources in quartz sand (Chapter 3). If the mixture took up more $\mathrm{P}$ from mixed sources than from a single source, this was interpreted as evidence that the different ability to acquire different chemical forms of $\mathrm{P}$ resulted in greater $\mathrm{P}$ uptake from mixed sources as compared to single P sources. We found that millet was better able to access Ca-bound $\mathrm{P}$ than phytate-P, while chickpea could better acquire P from phytate than from Ca-bound P. This 
trait divergence indeed resulted in increased $\mathrm{P}$ uptake from mixed $\mathrm{P}$ sources by a millet/chickpea mixture (Chapter 3). In follow-up pot experiments with soils containing a natural mixture of different $\mathrm{P}$ sources, there was, however, no increased $\mathrm{P}$ uptake by millet/chickpea mixture, but we did find that chickpea facilitated P uptake by millet as a result of greater ability of chickpea to exudate carboxylates and acid phosphatase to mobilize sparingly soluble P sources (Chapter 3). A pot experiment, however, does not address all possible forms of complementarity or facilitation. For instance, in pot experiments, species are grown simultaneously, while, in the field, there may be a difference in sowing date, as in relay intercropping (Yu et al., 2015). As a C4 species, millet is more adapted to high temperatures than chickpea (C3 species), enabling later sowing and harvesting compared to chickpea. In the field, complementarity may exist if root systems of different species differentially extract $P$ from the soil in space or time. It is unknown whether complementarity and facilitation with respect to $\mathrm{P}$ uptake contribute to the overyielding by intercrops during the whole growing period when there is substantial temporal niche differentiation. This is best studied in the field.

Designing for complementarity in P uptake from different sources by intercrops not only requires an appropriate species choice based on species traits, but it also depends on the soil $\mathrm{P}$ condition. According to the stress-gradient hypothesis, competitive interactions between plants dominate in favourable environments, but positive interactions dominate in unfavourable environments (e.g., low nutrient availability) (Callaway et al. 2002; He et al. 2013a). We can use P fertilization of a low P soil as an experimental manipulation to test whether complementarity in $\mathrm{P}$ acquisition is a driver for yield increase. If complementarity in or facilitation of $\mathrm{P}$ acquisition drives yield increase, we expect that the yield increase is reduced or disappears if sufficient $P$ fertilizer is added, thus effectively removing limitation of growth by P uptake.

Facilitation of $\mathrm{P}$ uptake via root exudates requires root proximity (Hinsinger et al. 2011; Vengavasi and Pandey 2018). In strip intercropping, where one species is sown in strips of several rows alternated with several rows of the other species, facilitative nutrient uptake (e.g., $\mathrm{Fe}$ ) was only observed for plants in border rows but not for plants in inner rows that were not making root contact with the other species (Zuo et al. 2000). Complementarity in accessing $P$ sources is likely to be more pronounced for border row plants than for inner row plants in intercrops that are grown in multi-row strips, because of the difference between the two in proximity to the companion species. Therefore, comparing performance of outer and inner row plants is a way to gauge the role of interspecific vs intraspecific interactions. A previous study showed an increase in releases of protons and phosphatases in maize/soybean intercropping compared to sole crops, that could be responsible for the increased soil $\mathrm{P}$ concentration in the rhizosphere of intercrops (Wang et al. 2017). Therefore, comparing the 
root exudates of intercrops and sole crops is useful to determine whether root exudates are responsible for increased $\mathrm{P}$ uptake by intercrops compared to sole crops.

In the present study, we conducted a field experiment with millet/chickpea relay strip intercropping during two growing seasons to test for complementarity and facilitation with respect to $\mathrm{P}$ acquisition by intercropping on a low $\mathrm{P}$ soil. We hypothesized that

(1) there is overyielding of P uptake, aboveground biomass and yield of millet/chickpea intercropping: intercrops acquire more $\mathrm{P}$ and produce more biomass and yield than expected based on sole crops.

(2) overyielding is caused by complementarity and facilitation with respect to P uptake because (a) millet and chickpea have different root exudates; (b) millet and chickpea deplete different P pools; (c) there is an increase in root exudates in intercrops compared to sole crops; (d) millet and chickpea plants take up more $\mathrm{P}$ in border rows than in inner rows.

(3) overyielding of P uptake and yield of intercrops is more pronounced at a lower P level if complementarity and facilitation with respect to P uptake are drivers of overyielding.

\subsection{Materials and methods}

\subsubsection{Site description}

The field experiment was conducted in 2017 and 2018 at Zhangye Experimental Station $\left(38^{\circ} 85^{\prime} \mathrm{N}, 100^{\circ} 38^{\prime} \mathrm{E}\right)$ at the Institute of Soils, Fertilizers and Water-Saving Agriculture, Gansu Academy of Agricultural Sciences. The experimental site is located in northwest China, $10 \mathrm{~km}$ southwest of Zhangye City, Gansu Province, at an altitude of $1555 \mathrm{~m}$ above sea level. The area has a typical arid climate and the soil type is an Aridisol. The experimental field was used to grow maize without $\mathrm{P}$ fertilizer in the previous three years. Soil $\mathrm{pH}$ was 7.41 (1:2.5 soil: $\left.\mathrm{CaCl}_{2}\right)$, and the soil contained $6.5 \mathrm{mg} \mathrm{kg}^{-1}$ Olsen-P, $0.11 \mathrm{~g} \mathrm{~kg}^{-1}$ total $\mathrm{N}, 0.83 \mathrm{~g} \mathrm{~kg}^{-1}$ total $\mathrm{P}, 140 \mathrm{mg} \mathrm{kg}^{-1}$ exchangeable $\mathrm{K}$ and $1.14 \mathrm{~g} \mathrm{~kg}^{-1}$ organic carbon. The monthly total precipitation (mm), mean temperature $\left({ }^{\circ} \mathrm{C}\right)$ and monthly total sunshine duration $(\mathrm{h})$ during the two growing seasons are presented in Table 4.1. 
Table 4.1 Temperature, precipitation and sunshine during the growing seasons of 2017 and 2018 at Zhangye experimental site.

\begin{tabular}{llrrrrrc}
\hline Year & Month & April & May & June & July & August & September \\
\hline 2017 & Average temperature $\left({ }^{\circ} \mathrm{C}\right)$ & 13 & 16 & 23 & 24 & 22 & 18 \\
& Precipitation $(\mathrm{mm})$ & 8 & 13 & 4 & 14 & 57 & 3 \\
& Sunshine duration $(\mathrm{h})$ & 301 & 280 & 330 & 299 & 206 & 282 \\
2018 & Average temperature $\left({ }^{\circ} \mathrm{C}\right)$ & 12 & 18 & 23 & 24 & 22 & 15 \\
& Precipitation $(\mathrm{mm})$ & 12 & 11 & 10 & 44 & 31 & 31 \\
& Sunshine duration $(\mathrm{h})$ & 280 & 295 & 269 & 277 & 240 & 263 \\
\hline
\end{tabular}

\subsubsection{Experimental design and crop management}

The treatments comprised three cropping systems: sole millet (Setaria italica L. cv. Longgu 11), sole chickpea (Cicer arietinum L. cv. Longying 1), millet/chickpea intercropping (Fig. 4.1), and two P fertilizer levels: P0 (without addition of inorganic P) and P100 (with $100 \mathrm{~kg} \mathrm{P} \mathrm{ha-1}$ applied each year as triple superphosphate). The experiments were laid out according to a random block design with two factors and five replicates.
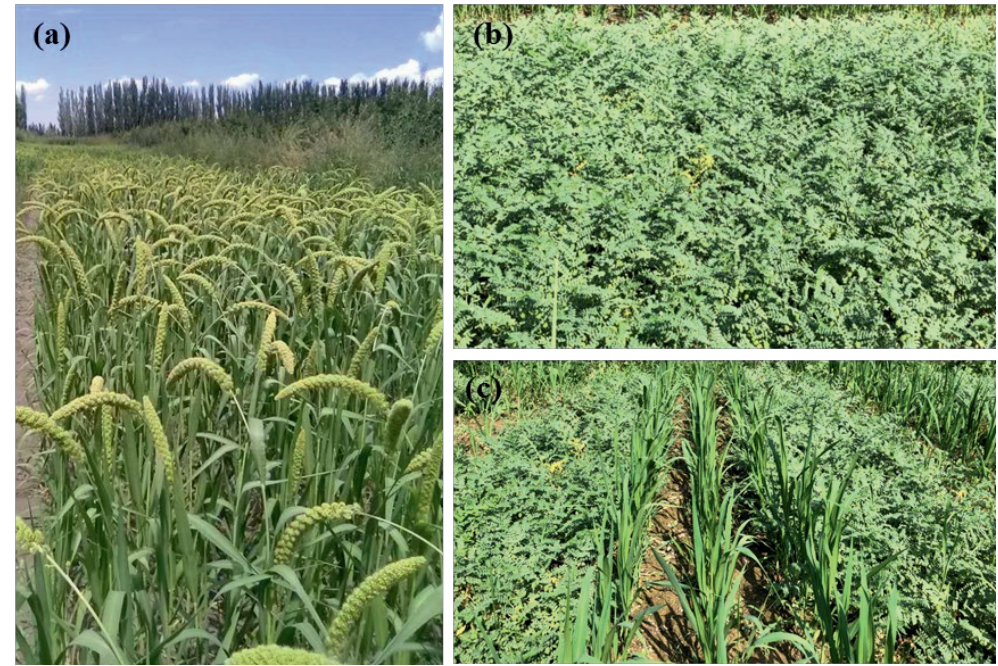

Fig. 4.1 The three cropping systems in this study. (a) sole millet (at grain filling stage), (b) sole chickpea (at podding stage), (c) millet/chickpea intercropping with alternating strips of three rows of millet and four rows of chickpea (at podding stage of chickpea).

The experiment was done in a single field in two subsequent years. Sole crops were grown as rotations (one year millet, the other year chickpea) while intercropped species swapped 
position within the plot in the second year (small rotation) in accordance with local practice to avoid problems associated with continuous cultivation of a crop species. Individual plots were $4.75 \mathrm{~m}$ long and $6.80 \mathrm{~m}$ wide. Each intercropping plot consisted of four strips of $1.70 \mathrm{~m}$ width. Four rows of chickpea alternated with three rows of millet (Fig. 4.2). Row distance was $20 \mathrm{~cm}$ in chickpea and $30 \mathrm{~cm}$ in millet, with $25 \mathrm{~cm}$ between adjacent chickpea and millet rows in intercropping. Plant distance in the row was $20 \mathrm{~cm}$ in chickpea and $10 \mathrm{~cm}$ in millet. Millet and chickpea occupied $53 \%$ and $47 \%$ of the intercropped area, respectively. Crop rows were oriented east-west.

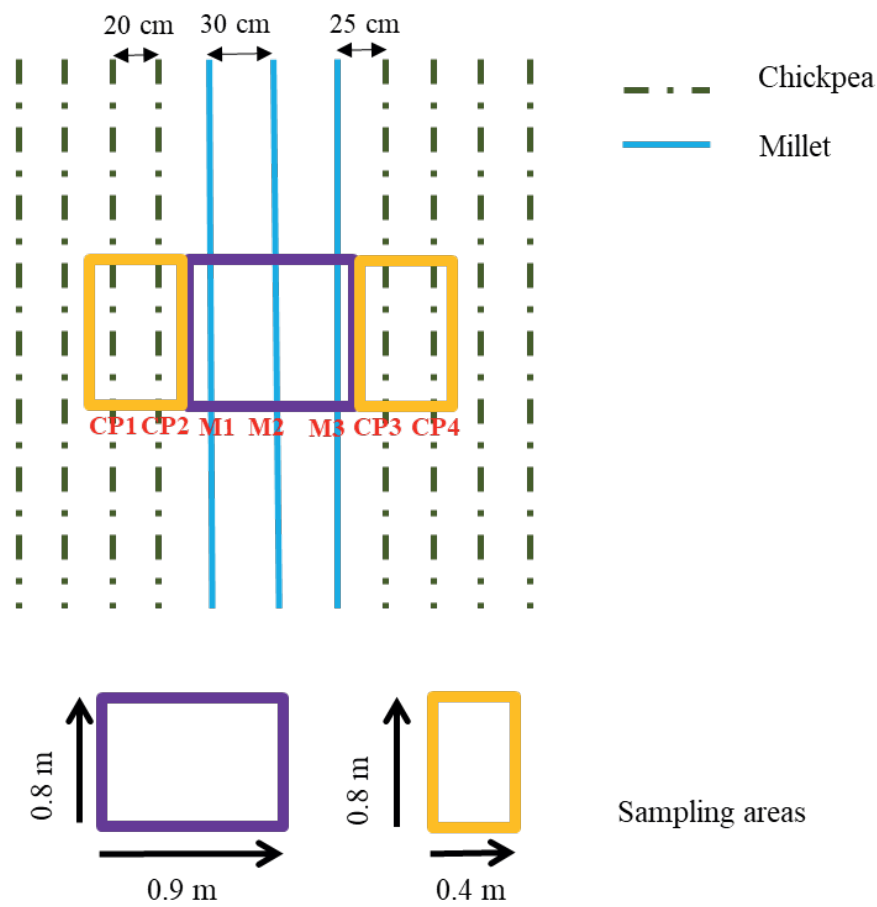

Fig. 4.2 Diagrammatic representation of the millet/chickpea intercropping strips. CP1-4 represent intercropped chickpea (border rows CP2 and CP3, inner rows CP1 and CP4). M1-3 represent intercropped millet (border rows M1 and M3, inner row M2) in the strip.

Sixty-one percent of the total soil $\mathrm{P}$ was Ca-bound $\mathrm{P}, 21 \%$ was organic $\mathrm{P}$, and the remaining $18 \%$ were $\mathrm{P}$ adsorbed to $\mathrm{Al}$ or Fe (hydr)oxides and residual $\mathrm{P}$ that is hardly available for plants. To increase the possibility for intercrops to access different $\mathrm{P}$ sources, each plot received an extra $40 \mathrm{~kg} \mathrm{ha}^{-1} \mathrm{P}$ as sodium phytate (Anhui Huainan Biological Development Co., LTD, China) as a form of sparingly available organic P. N fertilizer was supplied at a rate of $225 \mathrm{~kg} \mathrm{ha}^{-1}$ pure N as urea. All P fertilizer and $112.5 \mathrm{~kg} \mathrm{ha}^{-1}$ of the $\mathrm{N}$ fertilizer were evenly broadcast and 
incorporated into the upper $20 \mathrm{~cm}$ of the soil before sowing. Another $112.5 \mathrm{~kg} \mathrm{ha}^{-1}$ of N was applied in the form of urea in early July. No K or organic fertilizer was applied. All plots were irrigated and weeded manually. Crops were temporarily flooded on 15 June 2017 (flowering stage of chickpea) due to a break of the irrigation canal.

In 2017, chickpea was sown on 2 April and harvested on 10 August, and millet was sown on 29 April and harvested on 5 September (Fig. 4.3). In 2018, chickpea was sown on 23 March and harvested on 2 August, while millet was sown on 27 April and harvested on 21 September. At chickpea sowing, a $25 \mathrm{~cm}$-long PVC pipe of $15 \mathrm{~cm}$ diameter was inserted between plant rows in each monoculture plot to prevent root in growth and to allow collecting reference soil samples at harvest.

\subsubsection{Final harvest and $P$ uptake}

At final harvest of each crop species, in 2017, we harvested three adjacent rows of sole millet and four adjacent rows of sole chickpea over a length of $3.15 \mathrm{~m}$, avoiding the outer $80 \mathrm{~cm}$ of the rows nearest to the edge of the plot. In 2018, sole millet and chickpea were harvested over an area of $7.2 \mathrm{~m}^{2}$ per plot. In both years, three rows of millet and four rows of chickpea were harvested in one central strip in each intercropping plot. A sub-sample was randomly taken to determine dry weight $\left(70{ }^{\circ} \mathrm{C}\right.$ for $72 \mathrm{~h}$ ) of straw and grain separately. P concentration of straw and grain was determined using the vanado-molybdate method (Westerman 1990) after wet digestion with a mixture of concentrated $\mathrm{H}_{2} \mathrm{SO}_{4}$ and $\mathrm{H}_{2} \mathrm{O}_{2}$. Total $\mathrm{P}$ content was calculated as the sum of the P contents of straw (stems plus leaves) and grain.

\subsubsection{Periodic samples during co-growth to measure biomass and P uptake and collect rhizosphere soil samples}

Above- and belowground plant samples were collected from both the sole crops and the intercrop during the co-growth period of millet and chickpea to measure the aboveground biomass and $\mathrm{P}$ uptake and determine carboxylate concentration and enzyme activities in the rhizosphere. There were three sampling occasions during the co-growth period in 2017 (Fig. 4.3). The sampling I was on 1 June (the $33^{\text {rd }}$ day of co-growth when chickpea started flowering and millet was at seedling stage), the sampling II was on 6 July (the $68^{\text {th }}$ day of co-growth when chickpea was at podding stage and millet was at stem elongation), and the sampling III was on 9 August (the $102^{\text {nd }}$ day of co-growth when chickpea was at maturity and millet was at grain filling stage). Samples were taken twice during the co-growth period in 2018. The sampling I was on 28 June (the $62^{\text {nd }}$ day of co-growth when chickpea was at podding stage and millet was at stem elongation), and the sampling II was on 2 August (the $97^{\text {th }}$ day of co-growth when chickpea was at maturity and millet was at grain filling stage). 


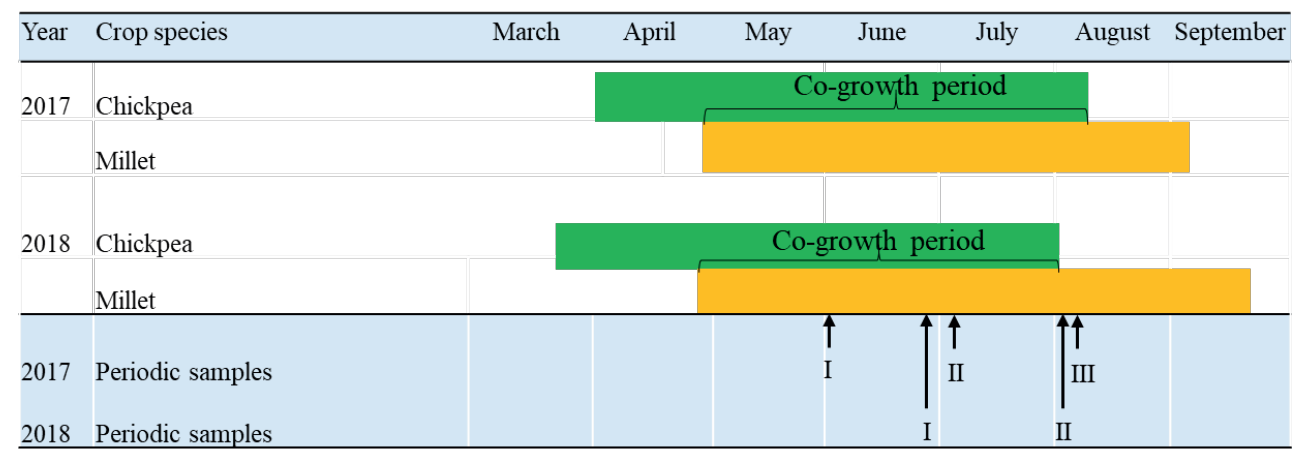

Fig. 4.3 Diagrammatic representation of the time of sampling during the co-growth period of millet and chickpea in two years; The green and yellow bars represent the period that the chickpea and millet are growing in the field respectively. The short arrows represent the three periodic samples in 2017, and the long arrows represent the two periodic samples in 2018.

At each sampling, the aboveground biomass was collected in $0.80 \mathrm{~m}$ row length of three millet rows (M1, M2, M3 in Fig. 4.2), and 0.80 m row length of four chickpea rows (CP1, CP2, CP3, CP4) in intercropping plots. The samples were processed separately for each row to determine differences between inner and outer rows of the species strips. In pure stands, the aboveground biomass was collected in $0.80 \mathrm{~m}$ row length of millet or chickpea. All sampled shoots were oven-dried at $70{ }^{\circ} \mathrm{C}$ for $72 \mathrm{~h}$ to estimate above-ground biomass.

Roots of sole millet, sole chickpea, intercropped millet (M1, M2, M3) and intercropped chickpea (CP1, CP2) were excavated at each sampling occasion $(0-20 \mathrm{~cm}$ depth). Roots of two sampled plants were shaken to remove the loosely adhering soil, then the roots with tightly adhering rhizosphere soil were immersed in $50 \mathrm{~mL}$ of $0.2 \mathrm{mM} \mathrm{CaCl}_{2}$ solution and shaken carefully to collect the rhizosphere soil solution. A subsample of the rhizosphere soil solution was stored at $-20{ }^{\circ} \mathrm{C}$ prior and six types of carboxylates were identified (tartrate, malate, citrate, succinate, fumarate and trans-aconitate) and their concentrations were determined using HPLC. The sediment in the rhizosphere soil solution was dried to determine dry weight of rhizosphere soil. After shaking the roots of the other two sampled plants, the rhizosphere soil was collected by brushing the roots carefully. The collected rhizosphere soils were stored at $4{ }^{\circ} \mathrm{C}$ for determination of enzyme activity. Subsamples of the rhizosphere soils were dried to determine $\mathrm{P}$ fractions.

The solution:rhizosphere soil ratios differed depending on root size and the amounts of rhizosphere soil. We cannot exclude that the carboxylate concentration in the solution is buffered by the soil, hence we calculated exudate ratios (of the same species when grown in mixture compared to when grown alone) under two extreme assumptions: 1) The soil solid phase is inert and does not buffer the carboxylate concentration. Under this assumption the carboxylate concentration in the extract is a dilution of the rhizosphere solution concentration, 
and the carboxylate concentration can be expressed in $\mu$ mol $\mathrm{g}^{-1}$ soil $\mathrm{dw}$, based on the measured dry weight of the rhizosphere soil. 2) The soil solid phase completely buffers the carboxylate concentration, such that the carboxylate concentration in the extract is the same as

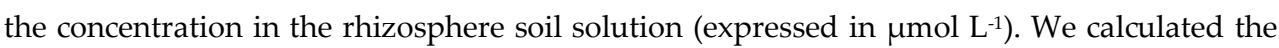
ratio of (mixed plant):(sole plant) under both assumptions to see if there is a significant increase (both ratios $\pm 2 \times \mathrm{SE}>1$ ) or decrease (both ratios $\pm 2 \times \mathrm{SE}<1$ ) of exudation as a response to a heterospecific neighbour (Table S4.1, Appendix C). In other cases, we refer to the outcome as no increase/no decrease. A similar procedure was followed for the comparison of carboxylate concentration between two species, the ratios were calculated as the ratio of (chickpea):(millet) under these two extreme assumptions (Table S4.2). The carboxylate concentration of chickpea was significantly higher (both ratios $\pm 2 \times \mathrm{SE}>1$ ) or lower (both ratios $\pm 2 \times \mathrm{SE}<1$ ) than that of millet if. In other cases, we refer to the outcome as undecided.

The enzyme activities were determined within one week after sampling. Soil solution for the determinations of enzyme activities were obtained by gently shaking $2 \mathrm{~g}$ moist rhizosphere soils with $8 \mathrm{ml}$ of deionized water for $1 \mathrm{~min}$. After settling, the suspension was collected for the determinations of enzyme activities and the sediment was dried at $90{ }^{\circ} \mathrm{C}$ for $24 \mathrm{~h}$ to determine dry weight as a reference base.

Phytase activity was assessed according to Richardson et al. (2000): $0.5 \mathrm{~mL}$ of soil solution was mixed with $2 \mathrm{~mL}$ of $30 \mathrm{mM}$ MES [2-(N-morpholino) ethanesulfonic acid] buffer ( $\mathrm{pH}$ 5.5), 0.5 $\mathrm{mL}$ of $2 \mathrm{mM}$ EDTA (ethylenediaminetetraacetic acid) and $0.5 \mathrm{~mL}$ of $20 \mathrm{mM}$ Na-phytate (Sigma, St. Louis, MO, USA). The mixture was incubated for $1 \mathrm{~h}$ at $37^{\circ} \mathrm{C}$ and the reaction was terminated by addition of $1 \mathrm{~mL}$ of $25 \%$ trichloroacetic acid (TCA). Solutions were subsequently centrifuged at $12,000 \times g$ for $10 \mathrm{~min}$ to remove soil particles. A control was determined in parallel for each soil sample and TCA was added prior to incubation. The orthophosphate concentration in the supernatant was determined by measuring absorbance at $882 \mathrm{~nm}$ using the molybdenum-blue reaction (Murphy and Riley 1962). Phytase activity was expressed as $\mu \mathrm{g}$ released $\mathrm{P}$ per hour per gram soil.

Alkaline phosphatase activity was assayed according to (Neumann 2006): $0.5 \mathrm{~mL}$ of soil solution was transferred into $2 \mathrm{~mL}$ Eppendorf reaction vials, then $0.4 \mathrm{~mL}$ of $100 \mathrm{mM}$ Trizma buffer ( $\mathrm{pH} 7.4$ ) and $0.1 \mathrm{~mL}$ of $150 \mathrm{mM}$ substrate [ $p$ NPP ( $p$-nitrophenyl phosphate); Sigma St. Louis, MO, USA] was added. The mixture was incubated for $30 \mathrm{~min}$ at $30{ }^{\circ} \mathrm{C}$, after that the reaction was terminated by addition of $0.5 \mathrm{~mL}$ of $0.5 \mathrm{M} \mathrm{NaOH}$ and centrifuged for $10 \mathrm{~min}$ at $12,000 \times g$ to remove soil particles. A control was determined in parallel for each soil sample to correct for background coloration. The supernatant was measured spectrophotometrically at $405 \mathrm{~nm}$ to determine the absorbance. Alkaline phosphatase activity was measured from the release of $p$-nitrophenol (PNP) and expressed as $\mu$ mol PNP per hour per gram soil. 


\subsubsection{Soil P fractionation}

At final harvest of each species, the soil in the PVC columns was collected as reference soil. P fractions of rhizosphere soils in monoculture plots of $\mathrm{P} 0$ treatments and $\mathrm{P}$ fractions of reference soils were determined using the method described by Tiessen and Moir (1993) (Methods S3.1, Appendix B).

\subsubsection{Data analysis}

Observed grain yield (or aboveground biomass, P content) is the sum of the grain yields (aboveground biomass, or P content) of millet $\left(Y_{\mathrm{I}, \mathrm{M}}\right)$ and chickpea $\left(\mathrm{Y}_{\mathrm{I}, \mathrm{CP}}\right)$ in intercropping:

Observed yield $=Y_{\mathrm{I}, \mathrm{M}}+Y_{\mathrm{I}, \mathrm{CP}}$

In strip intercropping systems, the expected yield is calculated from the land shares ( $L S_{\mathrm{M}}$ and $\left.L S_{\mathrm{CP}}\right)$ and crop yields ( $\Upsilon_{\mathrm{M}, \mathrm{M}}$ and $\left.Y_{\mathrm{M}, \mathrm{CP}}\right)$ of each species in monoculture.

Expected yield $=L S_{\mathrm{M}} \times Y_{\mathrm{M}, \mathrm{M}}+L S_{\mathrm{CP}} \times Y_{\mathrm{M}, \mathrm{CP}}$

Where $L S_{\mathrm{M}}=0.53, L S_{\mathrm{CP}}=0.47$.

The net effect is the difference between observed yield and expected yield (Loreau and Hector 2001):

Net effect $(\mathrm{NE})=$ Observed yield - Expected yield

In a two-species mixture, the NE is equal to the sum of two components, which have been coined the complementarity effect (CE) and the selection effect (SE) (Loreau and Hector 2001):

$\mathrm{NE}=\mathrm{CE}+\mathrm{SE}=2 * \overline{\Delta R Y} * \bar{M}+2 * \operatorname{cov}(\Delta R Y, M)$

The CE is calculated by multiplying $\overline{\Delta R Y}$, the average relative yield gain of the two species, and $\bar{M}$, the average sole crop yield of the two species. The SE is equal to twice the covariance of relative yield gain and monoculture yield, $\operatorname{cov}(\Delta R Y, M)$.

Relative yield gain is defined as the difference between actual and expected relative yield:

$\Delta R Y_{i}=R Y_{i}-R Y_{i}^{0}$

where $R Y_{i}$ is the actual relative yield of a species and $R Y_{i}^{0}$ is the expected relative yield. Actual relative yield is the yield in the intercrop (per unit area of the whole crop) divided by the yield in the sole crop. It is for each species defined as (De Wit 1960):

$R Y_{i}=Y_{i} / M_{i}$

Expected relative yield is based on the land share of a species in the intercrop (e.q. (4.2)) (Chapter 5). 
We applied two-way ANOVA with cropping system and P level as fixed factors and block as a random effect to compare biomass, yield and $\mathrm{P}$ content for millet and chickpea within each year. We applied three-way ANOVA for data at each sampling date with crop species, cropping system and $\mathrm{P}$ level as fixed factors and block as a random effect to compare alkaline phosphatase activity, phytase activity of millet and chickpea within each year ( $R$ package nlme, (R Core Team 2014)). T-test was used to compare the harvest index of millet or chickpea between P levels.

\subsection{Results}

\subsubsection{Aboveground biomass, grain yield and aboveground P content}

$\mathrm{P}$ uptake responded positively to fertilization with $\mathrm{P}$ in both years (Tables 4.2, 4.3). However, the biomass and yield of both species in the pure stands and intercropping did not respond to application of $\mathrm{P}$ fertilizer in 2017, while the biomass but not the yield of both species responded positively to the application of P fertilizer in 2018 (Tables 4.2, 4.3). Significant net effects of intercropping were found for P uptake (NEP>0) at P0 in 2017 and for grain yield $(\mathrm{NEr}>0)$ in the P100 treatment in 2018, but no significant net effects were recorded in other cases. The harvest indices of both millet and chickpea were on average $55 \%$ and $39 \%$ lower in 2017 than in $2018(P<0.0001$, Fig. S4.1).

The observed aboveground biomass in intercropping was similar to the expected biomass based on monocultures at both $\mathrm{P}$ levels in both growing seasons (Fig. 4.4a). There was, however, significant overyielding of grain yield at the high $\mathrm{P}$ level and overyielding of $\mathrm{P}$ content at low P level in 2018: the observed grain yield of intercrop was $0.6 \pm 0.2 \mathrm{Mg} \mathrm{ha}^{-1}$ higher than expected from sole crops at the high $P$ level in $2018(P<0.05$, Fig. 4.4b). This net effect was entirely due to the complementarity effect $\left(0.6 \pm 0.2 \mathrm{Mg} \mathrm{ha}^{-1}\right)$ (Table 4.2). The observed aboveground P content in the intercrop was $2.4 \pm 0.8 \mathrm{~kg} \mathrm{ha}^{-1}$ higher than expected at the low $\mathrm{P}$ level in 2018 ( $P<0.05$, Fig. 4.4c). This net effect was entirely due to the complementarity effect $\left(2.7 \pm 0.8 \mathrm{Mg} \mathrm{ha}^{-1}\right.$, Table 4.2$)$ while the selection effect was not significantly different from zero (-0.3 $\pm 0.3 \mathrm{Mg} \mathrm{ha}^{-1}$, Table 4.2). In 2017, the observed yield and $\mathrm{P}$ content of intercrops were similar to expected (Fig. 4.4b, c). 
음 तิ

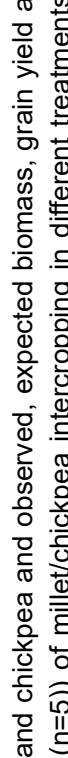

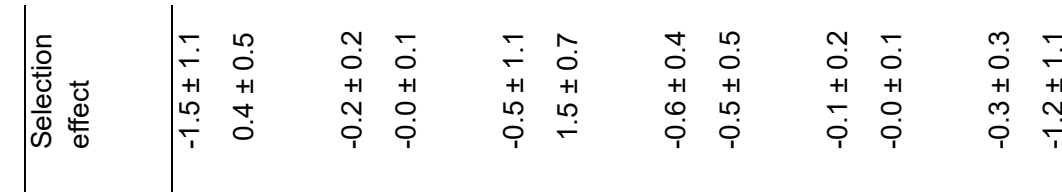

产

4 은

ล

$\frac{\pi}{\frac{\pi}{0}}$

훙+1

으 $\frac{\omega}{\sqrt{2}}$

उँ है

密

$\div$

잉

을

तั

응 $\frac{\mathrm{c}}{2}$

包

. $\frac{\sqrt{6}}{4}$

하

i

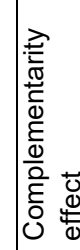

$\stackrel{+1}{+\infty}$

$\stackrel{-1}{\infty}$

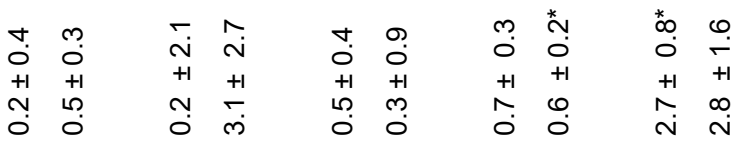

N

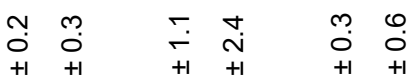

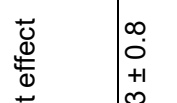

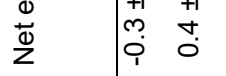

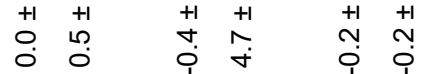

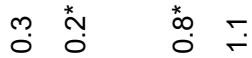

$\begin{array}{llll}+1 & +1 & +1 & + \\ +0 & 0 & + & 0 \\ 0 & 0 & 0 & -1\end{array}$

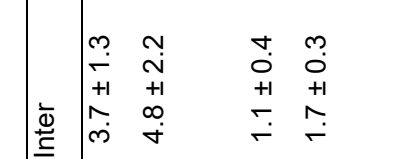

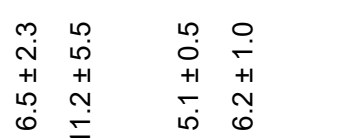

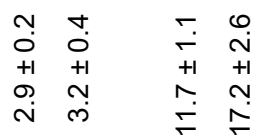

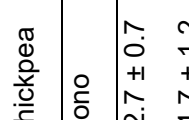

+1

்ֻ

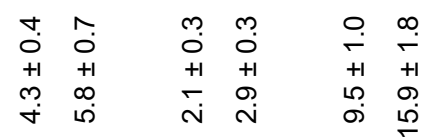

है

응 잉

을 잉

ㅎํำ

ชั

ก ฮ

พั

U $\frac{\bar{c}}{\Sigma}$

$\stackrel{+1}{+1} \stackrel{+1}{\circ} \stackrel{?}{\circ}$

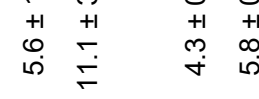

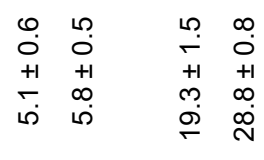

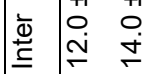

$\begin{array}{cc}m & m \\ 0 & 0 \\ +1 & +1 \\ \dot{v} & 0 \\ \stackrel{N}{N} & 0\end{array}$

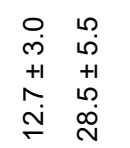

$\begin{array}{lll} & + \\ 0 & + \\ +1 & +1 \\ 0 & 0\end{array}$

mำ

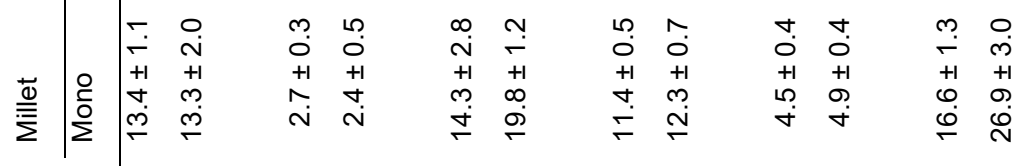

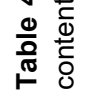

웅

웅

웅

음

음

웅 음
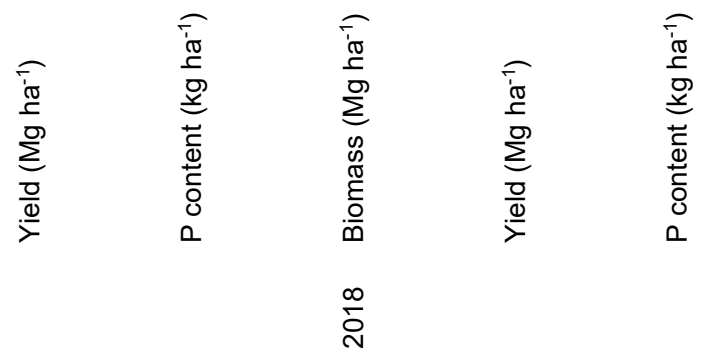


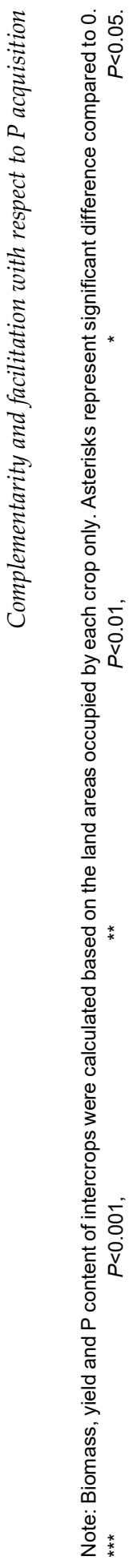


Table 4.3 $P$ values of two-way ANOVA (P level $\times$ cropping system) on aboveground biomass, grain yield and $P$ content (straw $P+$ grain $P$ ) of millet and chickpea.

\begin{tabular}{|c|c|c|c|c|c|}
\hline \multirow[b]{2}{*}{ Year } & \multirow[b]{2}{*}{$\begin{array}{l}\text { Dependent } \\
\text { variable }\end{array}$} & \multirow[b]{2}{*}{ Species } & \multicolumn{3}{|c|}{ Significance level ( $P$ value $)$} \\
\hline & & & $P$ level $(P)$ & Cropping $(\mathrm{C})$ & $\mathrm{C} \times \mathrm{P}$ \\
\hline \multirow[t]{6}{*}{2017} & Biomass & Millet & 0.10 & 0.21 & 0.19 \\
\hline & & Chickpea & 0.20 & 0.84 & 0.95 \\
\hline & Yield & Millet & 0.48 & 0.48 & 0.08 \\
\hline & & Chickpea & 0.14 & 0.76 & 0.51 \\
\hline & P content & Millet & $0.001^{* *}$ & 0.67 & 0.13 \\
\hline & & Chickpea & $0.04^{*}$ & 0.52 & 0.57 \\
\hline \multirow[t]{6}{*}{2018} & Biomass & Millet & 0.06 & 0.11 & 0.69 \\
\hline & & Chickpea & 0.07 & 0.08 & 0.70 \\
\hline & Yield & Millet & 0.14 & $0.04^{*}$ & 0.56 \\
\hline & & Chickpea & 0.11 & 0.15 & 0.60 \\
\hline & P content & Millet & $<0.003^{* *}$ & 0.31 & 0.80 \\
\hline & & Chickpea & $0.005^{\star *}$ & 0.34 & 0.84 \\
\hline
\end{tabular}

Note: The two-way ANOVA was carried out for 2017 and 2018 separately, and for millet and chickpea separately, with biomass, grain yield or $\mathrm{P}$ content as the dependent variables, with the $\mathrm{P}$ levels and cropping systems as the fixed independent variables and with block as the random effect.
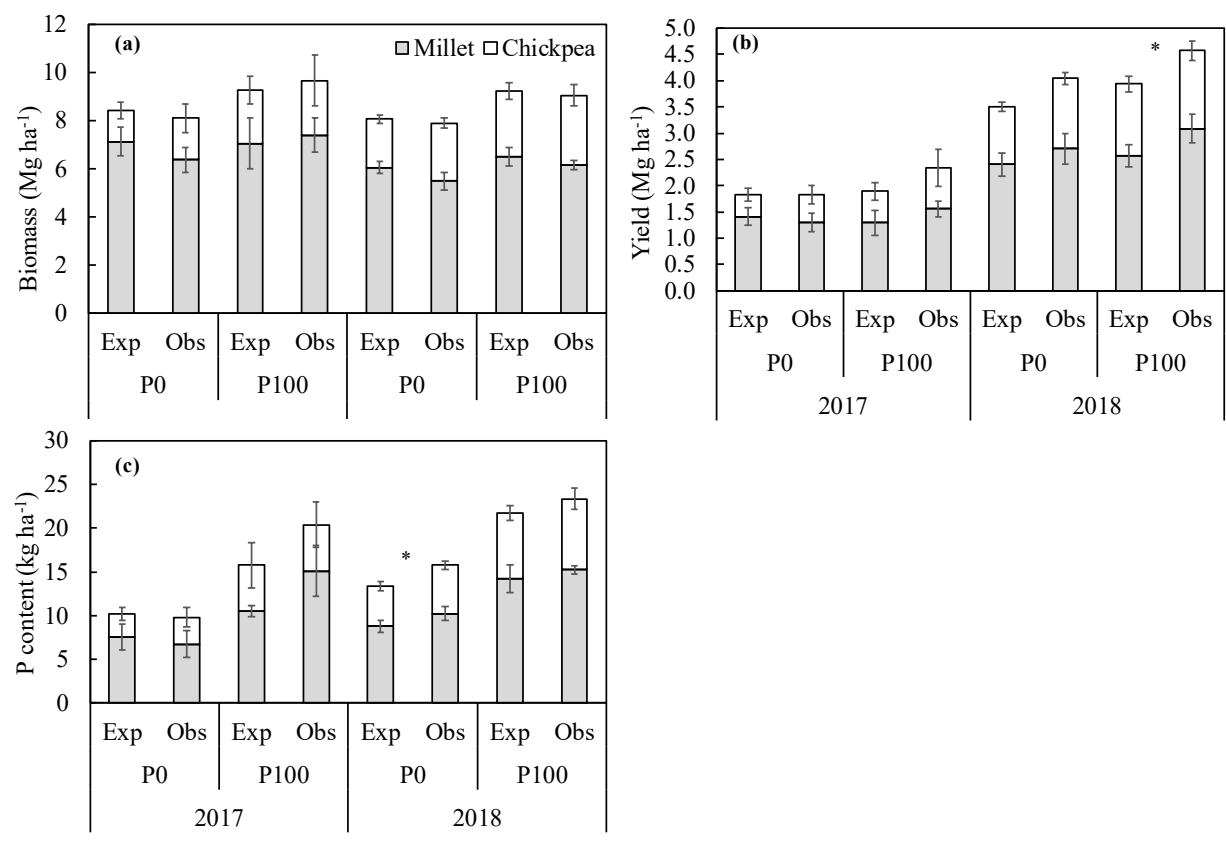

Fig. 4.4 Expected (Exp) and observed (Obs) aboveground biomass (a), grain yield (b), aboveground $P$ content (c) of millet/chickpea intercropping in two growing seasons and at two P levels (P0 and $P 100)$. Error bars represent standard errors $(n=5)$. Asterisks represent significant difference between $\begin{array}{llll}\text { observed and } \text { expected } & P<0.05 \text {. }\end{array}$ 

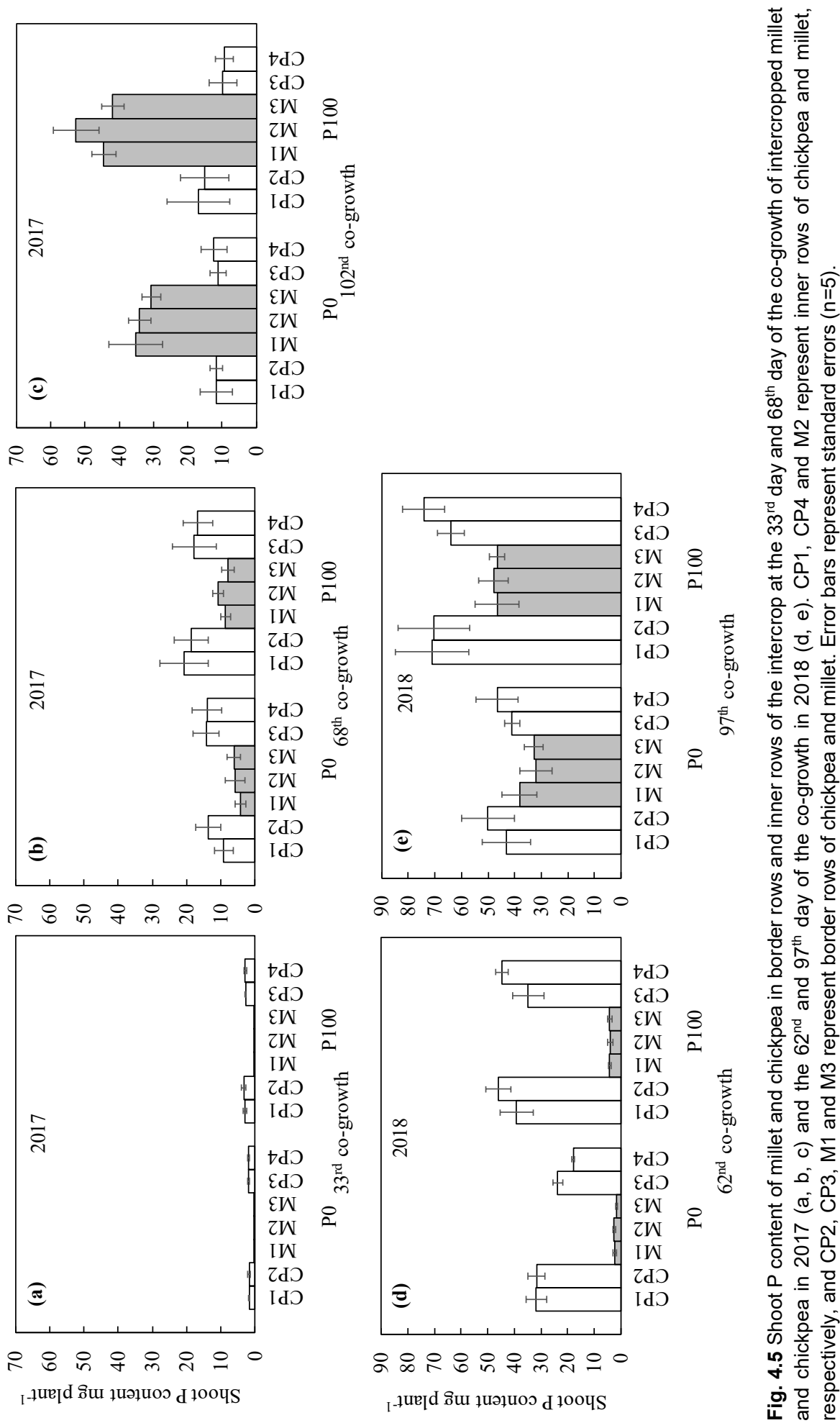

용ํㅇ 유응
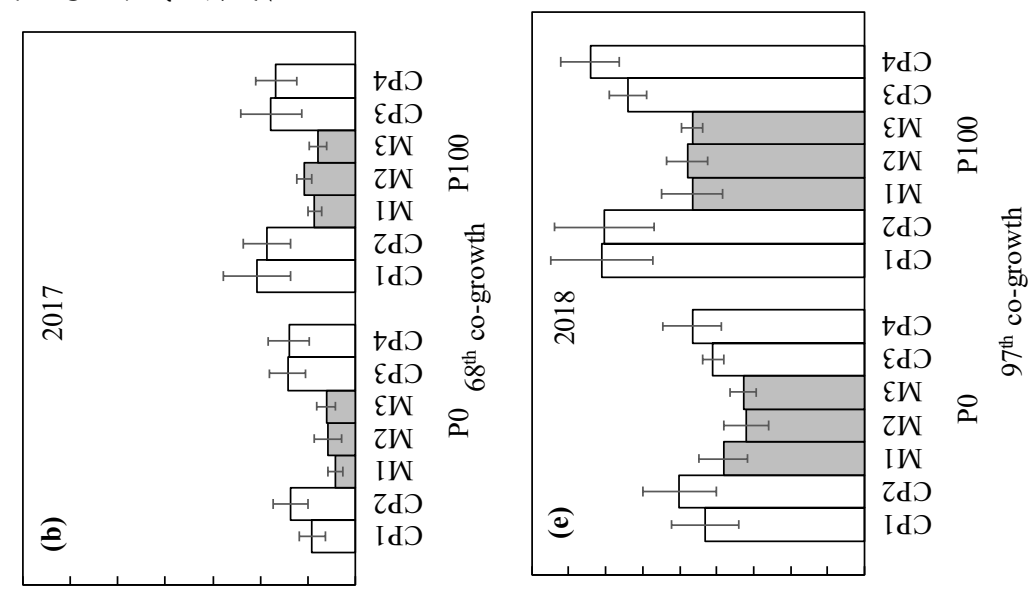

요유아유으.
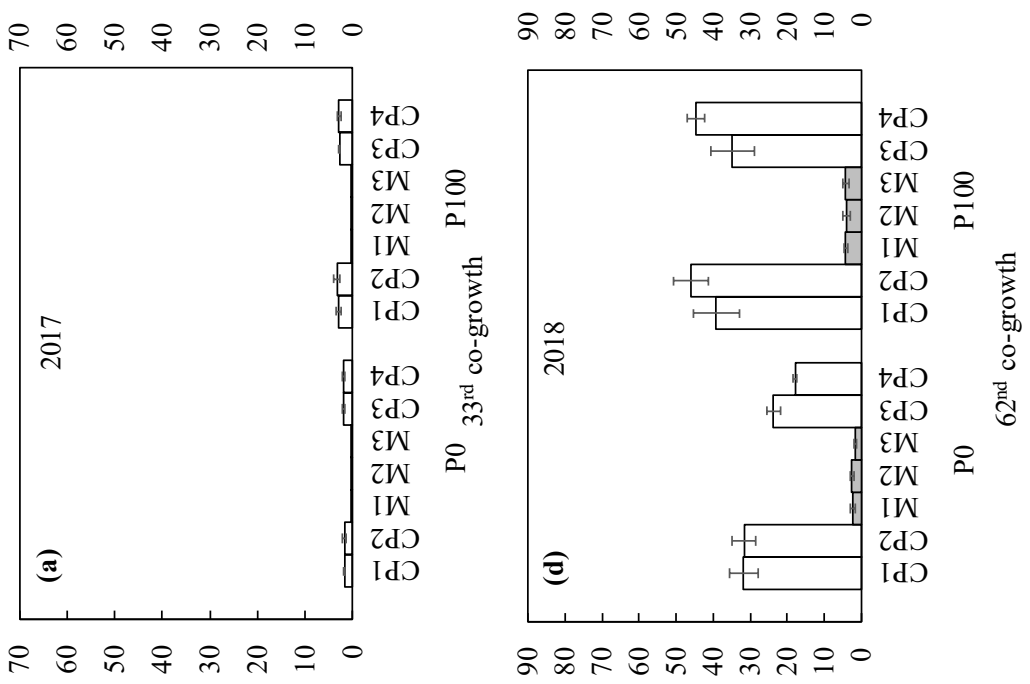

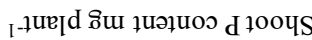

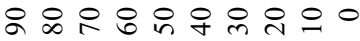
I † 
There was no difference in shoot P content (Fig. 4.5), shoot biomass (Fig. S4.2) and shoot P concentration (Fig. S4.3) of millet and chickpea between inner rows and border rows in intercropping at any sampling date in any of the two seasons. The lack of border row effects indicates absence of relevant interspecific interactions between millet and chickpea.

\subsubsection{Root exudates}

On the $33^{\text {rd }}$ day of the co-growth period in 2017, phytase activity was on average four times higher in intercrops than in pure stands, irrespective of species, P level or their interactions (Table S4.3; Fig. 4.6). At the $68^{\text {th }}$ day of co-growth in 2017, phytase activity was 2.2 times higher at the high $\mathrm{P}$ level than at the low $\mathrm{P}$ level, independent of species or cropping system or their interactions (Table S4.3; Fig. 4.6a). In 2018, on the contrary, there was no difference in phytase activity between millet and chickpea, or between intercrops and monoculture, or between high $\mathrm{P}$ and low $\mathrm{P}$ (Table S4.3).
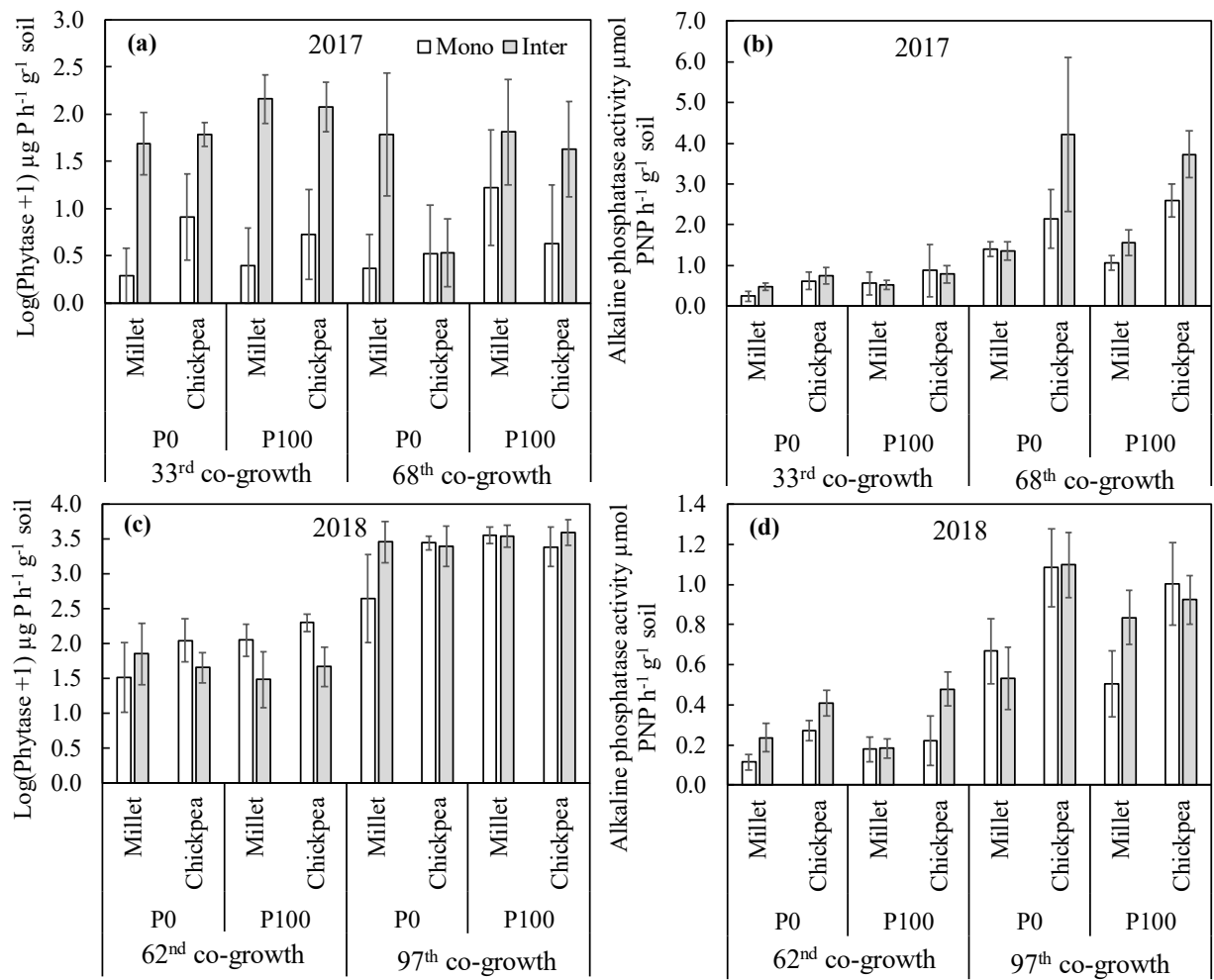

Fig. 4.6 Enzyme activities in the rhizospheres of millet and chickpea grown in monoculture or intercropping. (a, c) Phytase activity and (b, d) alkaline phosphatase activity: at the $33^{\text {rd }}$ day and $68^{\text {th }}$ day of the co-growth in $2017(\mathrm{a}, \mathrm{b})$ and the $62^{\text {nd }}$ and $97^{\text {th }}$ day of the co-growth in $2018(\mathrm{c}, \mathrm{d})$. Error bars represent standard errors $(n=5)$.

Alkaline phosphatase activity of chickpea was higher than that of millet at each sampling date in both years (Table S4.3; Fig. 4.6b, d). At the $62^{\text {nd }}$ day of co-growth in 2018, the alkaline 
phosphatase activity was 1.7 times higher in intercrops than in monocultures regardless of species and $\mathrm{P}$ levels. There was no difference in both phytase and alkaline phosphatase activity between millet or chickpea plants in different rows (Fig. S4.4).

The main carboxylate components of millet and chickpea were malate, succinate and citrate, and the fractional contribution of these carboxylates varied over time (Fig. S4.5). The difference in carboxylate concentration between millet and chickpea also varied over time. The carboxylate concentration in the rhizosphere was higher in sole millet than in sole chickpea at the low P level on the $62^{\text {nd }}$ day of the co-growth period in 2018 but not at any other sampling moment (Table S4.1). The rhizosphere carboxylate concentration was higher in intercropped millet than in sole millet at the $33^{\text {rd }}$ day of co-growth period at high P level in 2017 (Table S4.1), while intercropped chickpea had a lower rhizosphere carboxylate concentration than sole chickpea at the $97^{\text {th }}$ day of co-growth at the high P level in 2018.

\subsubsection{Depletion of $P$ pools by sole crops}

The organic P extracted by $\mathrm{NaHCO}_{3}\left(\mathrm{NaHCO}_{3}-\mathrm{P}_{0}\right)$ was depleted (compared to the control soil in the PVC tubes without roots) by both sole millet (38\%) and sole chickpea (32\%) in 2018 (Fig. 4.7c). None of the other P fractions was depleted. There was more residual P (i.e. the least available P for plants, determined in the last step of P fractionation), in the millet rhizosphere than in the control soil in both years. 

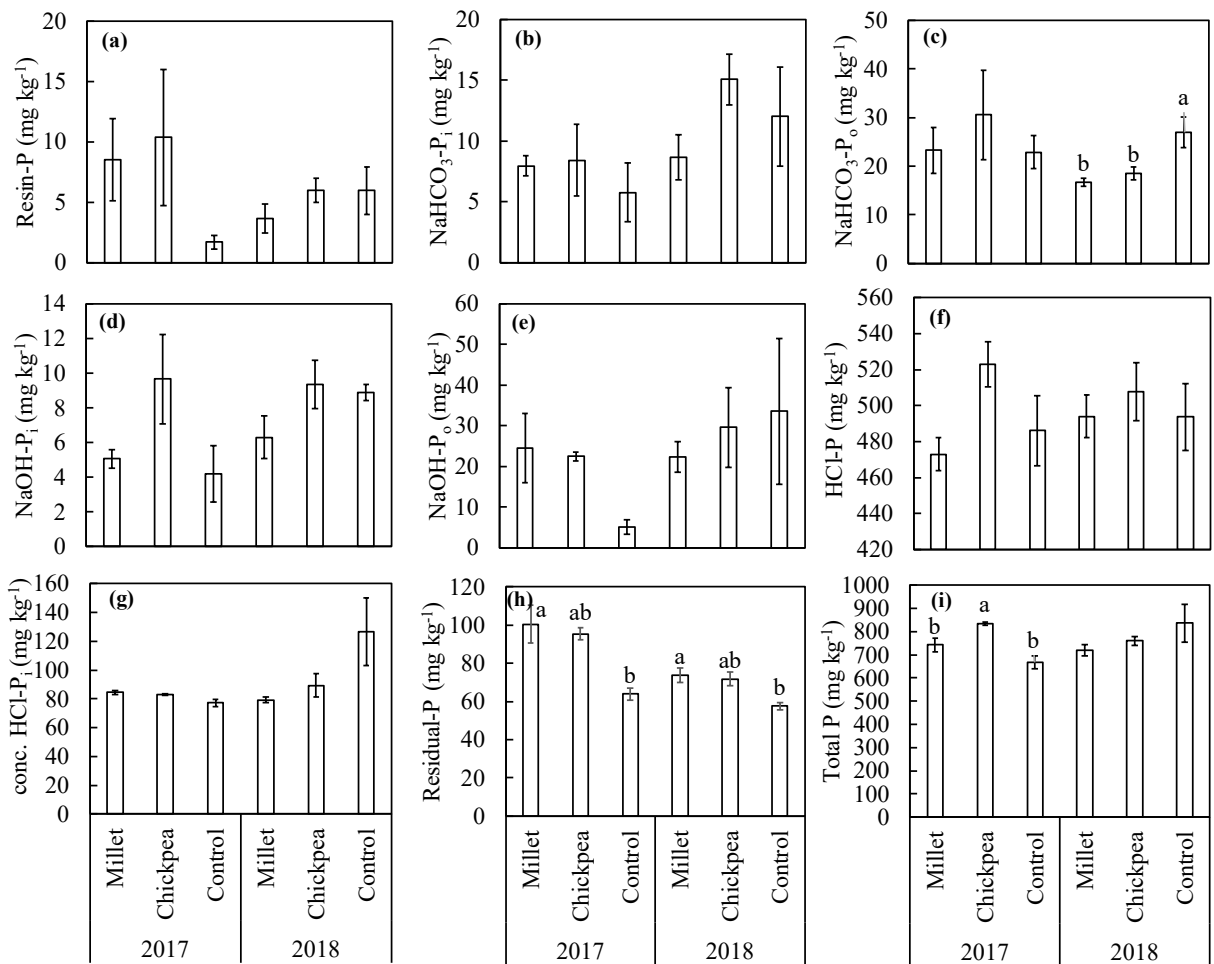

Fig. 4.7 $\mathrm{P}$ fractions in the rhizosphere soil of millet and chickpea in monocultures and in bulk soil (control) without $P$ fertilizer (P0 treatment) at harvest. Error bars represent standard errors $(n=4)$. Values with the same letters are not significantly different. No letters were shown for bars of treatments within each growing season without significant differences.

\subsection{Discussion}

This study addressed three questions: (1) is there a positive net effect of millet/chickpea relay strip intercropping on $\mathrm{P}$ uptake, biomass and yield; (2) is there evidence for complementarity and facilitation with respect to P uptake; (3) do complementarity and facilitation with respect to $P$ uptake drive a positive net effect of intercropping. The first question did not receive a straightforward "yes or no" answer: We observed a positive net effect of intercropping on aboveground $\mathrm{P}$ content $(\mathrm{NEP}>0)$ at zero $\mathrm{P}$ input, and there was a positive net effect for grain yield ( $\mathrm{NEY}>0$ ) with $\mathrm{P}$ fertilizer input in 2018. However, neither effect was consistent across the two years, and the positive net effect for yield at high $\mathrm{P}$ in 2018 occurred without a positive net effect for P uptake, whereas the positive net effect for P uptake at low P in 2018 occurred without a positive net effect for biomass or yield at low P. Measurement of root exudates indicated that the experimental conditions and choice of species provided an opportunity for the realization of $\mathrm{P}$ partitioning and facilitation of $\mathrm{P}$ 
uptake: at certain sampling dates, there were differences in rhizosphere alkaline phosphatase activity and carboxylate concentrations between millet and chickpea. We furthermore observed increased alkaline phosphatase activity in intercrops compared to sole crops in both species at both P levels, but decreased carboxylate concentration in intercropped chickpea compared to sole chickpea. Rhizosphere parameters hinted at potential complementarity and facilitation. But $\mathrm{P}$ uptake was similar in different rows of intercrop strips, negating a potentially positive effect of interspecific plant-plant interactions on P uptake. We also did not find a difference in depletion of different pools between millet and chickpea. The third question was answered negatively: while some mechanisms for complementary $\mathrm{P}$ uptake were found, and intercropping was characterized by some positive net effects, compared to sole crops, no evidence was found that the net effect of intercropping was driven by complementarity and facilitation with respect to $\mathrm{P}$ uptake. Yield and $\mathrm{P}$ uptake were uncoupled. The increased $\mathrm{P}$ uptake by intercrops at low $\mathrm{P}$ level did not result in a yield increase of intercrops, and the yield increase of intercrops at high P level was not associated with an increased P uptake by intercrops compared to sole crops.

The requirement for a proper test for complementarity and facilitation with respect to $\mathrm{P}$ uptake is that $\mathrm{P}$ is at least an important growth-limiting factor. The biomass and shoot $\mathrm{P}$ content of both species responded positively to the application of $P$ fertilizer (Table 4.3) in 2018, so this condition was fulfilled in 2018. However, because of a flooding event in 2017, the grain yields of both millet and chickpea were low (Table 4.2), resulting in lower harvest indices in 2017 compared to that in 2018 (Fig. S4.1). Consequently, the results in the first season did not justify to test complementarity and facilitation with respect to $\mathrm{P}$ uptake by intercrops. The results in 2018 are considered representative for the potential for complementarity in this intercropping system.

We found overyielding by millet/chickpea intercropping compared to their sole crops in 2018: there was a positive net effect of intercropping on aboveground P content at low $\mathrm{P}$ level, and on yield at high P level (Fig. 4.4b, c). The former was not associated with extra biomass and yield (Table 4.2). Yield of millet was higher in intercropping than in the sole cropping regardless of P level (Table 4.2, Table 4.3). This indicates reduced competition for resources in intercropping compared to sole cropping, as reflected by the positive complementarity effect of yield of intercrop under high $\mathrm{P}$ level, and positive complementarity effect of P content of intercrop under low P level (Table 4.2).

Root exudates differed between species and cropping systems. The higher alkaline phosphatase activity of chickpea than millet suggests higher ability of chickpea to access organic P. Carboxylate concentration of millet was mostly similar to that of chickpea except 
at the last sampling in 2018 when carboxylate concentration of millet was higher than chickpea (Table S4.2). This means that both millet and chickpea exuded carboxylates, which promote the desorption of organic $P$ in the soil for hydrolysis by phosphatase (Tinker and Nye 2000; George et al. 2005; Gerke 2015). In our previous pot experiment (Chapter 3), both carboxylate concentration and enzyme activities were higher in chickpea than in millet. Temporal fluctuations of root exudates at different plant growth stages could be related to this discrepancy (Mimmo et al. 2011; Li et al. 2016). At the first sampling in 2018, the higher alkaline phosphatase activity in the rhizosphere of intercrops compared to the sole crops, regardless of species and $\mathrm{P}$ levels, indicates potential $\mathrm{P}$ mobilization by intercrops. However, during the co-growth period in 2018, the rhizosphere carboxylate concentrations of intercrops were mostly similar to or lower than in sole crops. Lower carboxylate concentrations could limit the efficiency of higher phosphatase activity in intercropping. Similar P content (Fig. 4.5) and biomass (Fig. S4.2) of plants in different rows of intercropping strips suggest no increased $\mathrm{P}$ uptake in response to a heterospecific neighbour in intercropping, although there were differences in root exudates between millet and chickpea.

Contrary to our hypothesis, we did not observe any difference in depletion of $\mathrm{P}$ pools by millet and chickpea. Both millet and chickpea depleted the labile organic $\mathrm{P}$ in $\mathrm{NaHCO}_{3}$ extracts ( $\mathrm{NaHCO}_{3}-\mathrm{P}_{\mathrm{o}}$ ) in 2018 (Fig. 4.7c). The lack of species difference could be related to the exudation of phytase and alkaline phosphatase by both species (Richardson et al. 2009). There was no significant depletion of other P fractions. This lack of depletion could be due to the large stocks of $\mathrm{P}$ in the soil, and depletion is difficult to measure over the short term, especially under field conditions. Showing depletion requires long term studies. For instance, Liao et al. (2020) showed that sole maize, sole faba bean, and their intercrops mainly depleted the Ca bound $\mathrm{P}\left(1 \mathrm{M} \mathrm{HCl}-\mathrm{P}_{\mathrm{i}}\right)$, and differed in depletion of organic $\mathrm{P}$ fractions over four years.

Thus, based on the estimation of $\mathrm{P}$ depletion, we did not find evidence that the two species tap into different $\mathrm{P}$ pools or that one species facilitates $\mathrm{P}$ acquisition by the other species. Complementarity (or facilitation) is often used as both a cause of enhanced ecosystem functioning in diverse communities and a consequence of some community processes (Barry et al. 2019). The measurements at the plant level (biomass, yield and P uptake) represent the outcomes but not the underlying mechanisms. The differences in rhizosphere enzyme activities provided the potential to cause complementarity or facilitation, but they did not result in increased yield or $\mathrm{P}$ uptake. These results were similar to those of a pot experiment reported by Phoenix et al. (2020) who provided some evidence for P partitioning without any impact on $\mathrm{P}$ uptake by, and growth of mixtures compared to monocultures. That means the mechanism of complementarity in or facilitation of $\mathrm{P}$ uptake 
was not the only cause of the positive net effect that we found. The net effect was independent of P level. Previous studies likewise reported no change in overyielding by intercropping in response to a P fertilizer gradient on low P soil (Tang et al. 2016; Li et al. 2018). This indicates that overyielding can be achieved at both high and low P levels, and that $\mathrm{P}$ partitioning in intercropping is a phenomenon that is not highly related to overyielding, and cannot be regarded as the main driver of overyielding.

In the present study, the identified positive complementarity effects at high and low $\mathrm{P}$ levels may have been caused by other factors than complementarity in or facilitation of $\mathrm{P}$ uptake. Chickpea, a C3 species was sown and harvested earlier than millet (C4 species), resulting in temporal complementarity between two species. A previous meta-analysis showed that intercrops of $\mathrm{C} 3 / \mathrm{C} 4$ combination and temporal niche differentiation allow temporal and spatial complementarity in acquiring light or soil resources between intercropped species (Chapter 5). The later sown species may benefit from $\mathrm{N}$ mineralization from decomposing roots of the earlier sown species (Cong et al. 2015). Moreover, fertilizer input increases the net effect of relay strip intercropping (Chapter 5) because sufficient nutrient availability promotes the recovery growth of the later-sown species (e.g., millet in the present study) after harvest of the early-sown species (e.g., chickpea).

\subsection{Conclusions}

Millet and chickpea are species with complementary traits for acquisition of sparingly soluble P. We selected these species to test in the field whether complementary traits for P acquisition and resulting $\mathrm{P}$ partitioning can drive agronomically relevant levels of overyielding. The two species differed in carboxylate concentrations and alkaline phosphatase activity in the rhizosphere. Consistent with this difference in $\mathrm{P}$ acquisition traits, we found an increase in P uptake by the intercrop in the low P treatment (no P added) in one of the two experimental years. This increase in $\mathrm{P}$ uptake was, however, not associated with overyielding. On the other hand, in the same year, overyielding occurred in the high $\mathrm{P}$ treatment in which $\mathrm{P}$ fertilizer was added to supplement the low $\mathrm{P}$ soil at the site. This overyielding by intercropping was not associated with increased P uptake by intercropping. In the first year, a flooding event affected all experimental treatments, potentially nullifying the potential for complementarity and facilitation. Results in the second year provide evidence for complementary traits for $\mathrm{P}$ acquisition from different sources, but no evidence for agronomically relevant overyielding as a result of related $\mathrm{P}$ partitioning. On the other hand, complementarity of other factors associated with differences in other species traits, e.g., growing period, resulted in positive overyielding in the high P treatment. Results clearly show that complementary traits (e.g., differences in root exudates) do not guarantee overyielding at the crop level. 


\section{Acknowledgements}

This research was supported by projects of National Key R \& D Program of China (2017YFD0200200/2017YFD0200202), International Cooperation and Exchanges NSFC (31210103906), and the Wageningen University Sandwich PhD Fellowship. 


\section{Chapter 5 Yield gain, complementarity and competitive dominance in intercropping in China; a meta-analysis of drivers of yield gain using additive partitioning}

Chunjie Li, Ellis Hoffland, Thomas W. Kuyper, Yang Yu, Haigang Li, Chaochun Zhang, Fusuo Zhang, Wopke van der Werf

This chapter is published as:

Li C, Hoffland E, Kuyper TW, Yu Y, Li H, Zhang C, Zhang F, van der Werf W (2020) Yield gain, complementarity and competitive dominance in intercropping in China: A meta-analysis of drivers of yield gain using additive partitioning. European Journal of Agronomy 113:125987. https://doi.org/10.1016/j.eja.2019.125987 


\begin{abstract}
Intercropping is known to increase the efficiency of land use, but no meta-analysis has so far been made on the yield gain of intercropping compared to sole cropping in terms of absolute yield per unit area. Yield gain could potentially be related to a relaxation of competition, due to complementarity or facilitation, and/or to the competitive dominance of the higher yielding species. The contributions of competitive relaxation and dominance were here estimated using the concepts of complementarity effect (CE) and selection effect (SE), respectively. We compiled a dataset on intercropping of grain-producing crops from China, a hotspot of strip intercropping in the world. We quantified the yield gain and its components and analyzed the contribution to yield gain of species traits (C3, C4, legume, non-legume), complementarity in time and nutrient input. Total yield in intercrops exceeded the expected yield, estimated on the basis of sole crop yields, by $2.14 \pm 0.16 \mathrm{Mg} \mathrm{ha}^{-1}$ (mean \pm standard error). Ninety percent of this yield gain was due to a positive CE while the remaining $10 \%$ was due to SE. The net yield gain increased with temporal niche differentiation (TND) which is the proportion of the total growing period of the crop mixture during which species grow alone. The mechanism underlying yield gain shifted from competitive dominance of the higher yielding species when there was more overlap in growth period between the two species, to competitive relaxation when there was less overlap, while competitive relaxation remained the major component of the yield gain. The yield gain was substantially greater in intercrops with maize than in intercrops without maize, but there was no difference in yield gain between systems with and without legumes. The yield gain increased with nitrogen $(\mathrm{N})$ input in maize/C3-cereal intercrops but not in cereal/legume intercrops, illustrating the ability of legumes to compensate for low $\mathrm{N}$ input, and highlighting the need for $\mathrm{N}$ input for high productivity in intercropping systems without legumes. Yield gain did not respond to phosphorus $(\mathrm{P})$ input. We conclude that competitive relaxation is the main contributing factor to yield gain in the investigated Chinese intercropping systems, which were mostly relay strip intercropping systems. The underlying drivers of yield gain were related to presence of maize and species complementarity in time, but we did not find strong evidence for the selection effect.
\end{abstract}

Keywords: meta-analysis, intercropping, species traits, complementarity effect, selection effect, temporal niche differentiation, nutrient input 


\subsection{Introduction}

Biodiversity is a major determinant of productivity, functioning and stability in natural ecosystems (Tilman et al. 2014). Likewise, on-farm biodiversity can contribute to more sustainable agro-ecosystems (Loreau et al. 2012; Bommarco et al. 2013; Geertsema et al. 2016). Intercropping is the planned combination of multiple crop species in one field (Willey 1990). It aims to increase yields, improve resource capture, and lower production risks (Vandermeer 1989; Lithourgidis et al. 2011a). Intercropping results in natural suppression of pests and diseases (Zhu et al. 2000; Zhang et al. 2019) and it increases soil nitrogen and carbon due to increased biomass input into the soil and better nutrient retention (Cong et al. 2015). Intercropping has been practiced in China for over 2000 years, and there are contemporary hotspots of intercropping in the southwest and northwest of China, e.g., in the provinces Sichuan, Yunnan and Gansu (Zhang and Li 2003; Hong et al. 2017).

The land equivalent ratio (LER) is a commonly used index to assess yields in intercropping compared to sole crops (Mead and Willey, 1980). It is numerically the same as the relative yield total (RYT; De Wit, 1960; Weigelt and Jolliffe, 2003). The LER represents the relative land area needed under sole crops to obtain the same yields as are obtained on a unit area of intercrop (Mead and Willey 1980). Yu et al. (2015) found an average LER of $1.22 \pm 0.02$ in a database of 100 intercropping studies while Martin-Guay et al. (2018), using an independent selection of 126 papers from the literature, found an average LER of $1.30 \pm 0.01$. The LER does not directly relate to absolute yield levels because it is defined as the sum of relative yields of component crops in the intercrop as compared to the sole crops. LER is an indicator for the comparative land use efficiency of intercrops and sole crops as it represents the area of sole crops that is required to produce the yield that are obtained from a unit area of intercropping. LER is not a suitable indicator for productivity.

Here we present an analysis focusing on the yield advantage in intercropping in absolute terms (grain yield per unit area). Loreau and Hector (2001) proposed additive partitioning as a statistical method to analyze productivity benefits in plant species mixtures. This method defines the net effect (NE) as the difference in yield or biomass between the mixture and the (weighted) average of the sole crops, and partitions the NE into two components: a complementarity effect (CE) and a selection effect (SE). The CE is the overall gain in relative yield in a mixture (RYT-1) multiplied by the average yield or biomass of the sole crops (Loreau and Hector 2001). The SE measures the association between sole crop yield of species and their change in relative yield in the mixture (Loreau and Hector 2001). It is a measure for how much of the yield gain is due to overyielding of component species with high versus low sole crop yield. A positive CE can arise if species are complementary or facilitative with respect to resource acquisition in the mixture such that the total resource capture in the 
mixture is greater than expected from the sole crops (Loreau and Hector 2001). Complementarity results in competitive relaxation and increased production according to what Vandermeer (1989) called the "competitive production principle". The value of SE characterizes to which extent the dominance of the more productive species in terms of biomass or space occupancy is responsible for overyielding in the mixture. Additive partitioning can be used to assess whether intercropping advantage is achieved in a situation where, on average, the species do relatively better in the mixture than in sole crop (high CE) or, alternatively, this advantage is achieved by competitive dominance of the species with the highest sole crop yield (high SE), or a combination of high CE and SE. (Malezieux et al. 2009) pointed out that the additive partitioning method could be used to analyze the yield increases that might be obtained by cultivating $N$ species as a polyculture instead of cultivating them on $N$ separate fields. However, only few empirical studies have been made to date on how the complementarity and selection effects contribute to overyielding in intercrops (Zhang et al. 2014; Giles et al. 2016; Li et al. 2018), and no overarching analysis of data from multiple studies has so far been made.

LERs of intercrops can be increased by combining species with different functional traits, e.g., a C3 with a C4 species (Yu et al. 2015). Moreover, cereal/legume intercropping is popular in low-input agriculture because of functional complementarity for $\mathrm{N}$ uptake (Bedoussac and Justes 2010; Pelzer et al. 2012). C3 and C4 species differ in photosynthesis-light response, water use efficiency and N use efficiency (Li 1993; Vogan and Sage 2011), growing period and temperature response. These trait differences between $\mathrm{C} 3$ and $\mathrm{C} 4$ species may synergize to maximize canopy functioning (Anten and Hirose 1999; Chimonyo et al. 2015). Because of their differences in adaptation to climate factors, C3 and C4 species are suitable for combining in relay intercropping where each species is sown at an appropriate time to optimize its performance. In China, widely used relay intercropping are wheat/maize (Hong et al. 2019), maize/soybean (Yan et al. 2010; Yan et al. 2015) and maize/pea (Hu et al. 2016). Relay intercropping allows for niche partitioning and competitive relaxation between component species due to time differences in resource capture. An index for temporal niche differentiation (TND) was first defined by Yu et al. (2015). This index is the proportion of the total growing period of an intercropping system that species are growing alone, without the companion (competitor) crop.

Maize is a commonly cultivated C4 species in intercrops. The peak of its growth rate is later in the season than that of C3 crops such as small grains (e.g., wheat) and legumes (e.g., soybean or peanut). Sowing maize later reduces shading of the less competitive C3 species by maize but also reduces maize performance early in the growing season when it is shaded by an earlier sown C3 species (Li et al. 2001b; Gou et al. 2016). However, maize can continue to grow 
after harvest of the C3 species and compensate for the early-season growth reduction (Li et al. 2001b; Gou et al. 2016). Our first hypothesis is that C3/C4 intercrops show a greater NE and $\mathrm{CE}$ than intercrops with only $\mathrm{C} 3$ species, because greater differences in functional traits allow greater complementarity in resource capture. We also expect a greater SE in C3/C4 intercrops than in $\mathrm{C} 3 / \mathrm{C} 3$ intercrops due to the tendency of tall C4 species to be competitively dominant and high yielding which could result in a positive SE.

Cereal and legume species differ in $\mathrm{N}$ acquisition and rhizosphere-related traits: Legumes are able to fix $\mathrm{N}_{2}$ from air, hence cereal/legume intercrops can show a complementary use of $\mathrm{N}$ sources (Jensen 1996; Fan et al. 2006). Therefore our second hypothesis is that CE is greater in intercrops including legumes than in intercrops without legumes, especially under low $\mathrm{N}$ conditions. Legumes are furthermore expected to facilitate $\mathrm{P}$ acquisition of intercropped cereals through exudation of phosphatases and carboxylates in the rhizosphere (Li et al. 2014). This would also lead to a positive contribution of mixing cereals and legumes to the CE.

Yu et al. (2015) showed that the LER of intercropping increases with TND. Therefore, our third hypothesis is that CE increases with TND, but the SE may decrease with TND because the $\mathrm{SE}$ is driven by competitive interactions which may be mitigated by niche differentiation in time, as characterized by TND.

There has been no meta-analysis on the occurrence of CE in intercropping in relation to nutrient availability. The stress gradient hypothesis (Maestre et al. 2009; He et al. 2013a) predicts that positive interactions between species (associated with high CE) are more common under conditions with higher abiotic stress (Roscher et al. 2016). In agreement with this hypothesis, the yield advantage (as measured by LER) of cereal/legume intercrops was greatest with no $\mathrm{N}$ fertilization and was reduced when $\mathrm{N}$ fertilizer was applied (Hauggaard-Nielsen and Jensen 2001). However, overyielding of cereal/cereal intercrops can also be attained with adequate $\mathrm{N}$ fertilizer input (Li et al. 2011c) and the level of $\mathrm{P}$ fertilization did not affect the LER of cereal/legume intercrops such as durum wheat/faba bean intercrop (Tang et al. 2016). Our last hypothesis is that species complementarities between cereals and legumes are greatest at low nutrient availability $(\mathrm{N}$ and $\mathrm{P}$ ) while sole crop yields are greater at high nutrient availability. With CE being the product of average relative yield gain and average sole crop yield, CE could then show a quadratic response to nutrient input. The SE quantifies the dominance of species with high yield in sole cropping because of their capacity to capture more light and nutrients. Competitive dominance for light is related to leaf growth, which is promoted by high nutrient input, hence we expect a greater selection effect at higher nutrient input.

Intercropping is still prevalent in China (Hong et al. 2017), and many studies on productivity of intercrops have been done in China over the past 30 years. This has resulted in a wealth of 
suitable data from China, both in the international and Chinese literature. We therefore focus this meta-analysis on data from intercropping studies conducted in China. In summary, we did a meta-analysis to address three research questions: (1) How large is the yield gain of intercropping in units of grain yield per hectare? (2) What is the contribution of the CE and SE to the yield gain in various intercropping systems, and (3) What are the effects of species trait combination, TND, and $\mathrm{N}$ and $\mathrm{P}$ input on the NE, CE and SE?

\subsection{Materials and Methods}

\subsubsection{Data collection}

A literature search was conducted on the Chinese National Knowledge Infrastructure. We used the search terms "intercrop" and "yield" in the topic field and "field experiment" in the full text. An additional literature search was conducted on Web of Science using the search terms "intercrop" and "yield" and "field experiment" in the topic field and "China" in the author address. The two datasets were combined and doubles were removed. The papers were then checked on extractable data on crop yields in intercrops and sole crops, information to calculate the land shares of species in the intercrop, sowing dates and harvest dates, and information on management, based on original field experiments (Table 5.1; see also Methods S5.1). A total of 69 publications (24 in English and 45 in Chinese, Methods S5.2) were retained during this selection. Data were extracted from tables or from figures using GetData software (http://getdata-graph-digitizer.com/).

The final dataset included data from 100 experiments, i.e., 100 unique combinations of site and year, and 426 data records. Each data record contained yield data on the intercrop and the corresponding sole crops at the same management such as fertilizer input, sowing dates and harvest dates. If an experiment reported data on intercropping and sole crops at different levels of fertilizer input, the data at each nutrient input level was recorded in separate records. If the $\mathrm{N}$ and $\mathrm{P}$ fertilizer in the intercrop were given separately for each species, the total $\mathrm{N}$ and $P$ fertilizer input in intercropping was calculated according to the land share of each species in the intercrop (Methods S5.3).

In this database, most of the experiments concerned strip intercropping (414 out of 426 records), in which two species were cultivated in alternative strips and at least one strip includes more than one row. (Of those, 14 records had one of the species in single strips while the other species was arranged of multiple rows in strips.) There were only 12 records of row intercropping (1 record of maize (Zea mays)/peanut (Arachis hypogaea), 4 records of wheat (Triticum aestivum)/faba bean (Vicia faba), 7 records of maize/soybean (Glycine max)), in which two species were cultivated in alternate rows. There were three main groups of species combinations (Table 5.2): C4-cereal/C3-cereal (118 records), C4-cereal/legume (252 records) 
and C3-cereal/legume intercrops (36 records). The C4-cereal/C3-cereal intercrops were dominated by maize/wheat and maize/barley (Hordeum vulgare), while the C4-cereal/legume intercrops comprised maize intercropped with a variety of legume species, such as soybean, faba bean, peanut and pea (Pisum sativum). If a C4 cereal was present, it was almost always maize. There were two data records on maize/millet (Setaria italica) (Fig. 5.1).

Table 5.1 Variables extracted from publications

\begin{tabular}{|c|c|c|}
\hline Variable & Definition & Data type/Unit \\
\hline Title & Title of publication & Text \\
\hline Authors & Authors of publication & Text \\
\hline Journal name & The name of the journal & Text \\
\hline $\begin{array}{l}\text { Year of } \\
\text { publication }\end{array}$ & Year & Text \\
\hline $\begin{array}{l}\text { Latitude and } \\
\text { longitude }\end{array}$ & Latitude and longitude of experimental site & Decimal Degrees \\
\hline Species & Name of crop species & Text \\
\hline Plant density & Density of each species in sole crops and in the intercrop & Plants ha ${ }^{-1}$ \\
\hline $\begin{array}{l}\text { Row numbers, } \\
\text { row distance and } \\
\text { plant distance in } \\
\text { intercropping }\end{array}$ & $\begin{array}{l}\text { Number of rows, row distance and plant distance of each } \\
\text { species in the sole crop and intercropping, and row distance } \\
\text { between two species in intercropping or strip width of each } \\
\text { species in intercropping, to calculate the strip width, relative } \\
\text { density and land share }\end{array}$ & Number/cm \\
\hline $\begin{array}{lr}\text { Sowing } & \text { dates } \\
\text { and } & \text { harvest } \\
\text { dates } & \end{array}$ & $\begin{array}{l}\text { Sowing dates and harvest dates of intercropped species or } \\
\text { information on total period and overlap period of intercrops to } \\
\text { calculate TND }\end{array}$ & Dates \\
\hline $\begin{array}{l}\text { Functional-trait } \\
\text { species } \\
\text { combinations }\end{array}$ & 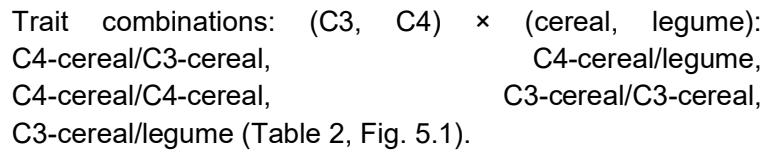 & Categorical \\
\hline Yield & $\begin{array}{l}\text { Grain yield (dry grain weight) of both sole crops and } \\
\text { intercrops }\end{array}$ & $\mathrm{Mg} \mathrm{ha}^{-1}$ \\
\hline $\begin{array}{l}\text { Amount of } \mathrm{N} \text { and } \\
\mathrm{P} \text { fertilizer }\end{array}$ & $\begin{array}{l}\text { Amount of } \mathrm{N} \text { and } \mathrm{P} \text { fertilizer applied to sole crops and to } \\
\text { intercrops }\end{array}$ & $\mathrm{kg} \mathrm{ha}^{-1}$ \\
\hline
\end{tabular}


Table 5.2 Contingency table for frequency (data records) of intercrops including $\mathrm{C} 3$, $\mathrm{C} 4$, cereal, legume or other species.

\begin{tabular}{lllllll}
\hline & Cereal/cereal & Cereal/legume & Cereal/others & $\begin{array}{l}\text { Legume/l } \\
\text { egume }\end{array}$ & $\begin{array}{l}\text { Legume/o } \\
\text { thers }\end{array}$ & Total \\
\hline C3/C3 & 0 & 36 & 0 & 1 & 5 & 42 \\
C3/C4 & 118 & 252 & 12 & 0 & 0 & 382 \\
C4/C4 & 2 & 0 & 0 & 0 & 0 & 2 \\
Total & 120 & 288 & 12 & 1 & 5 &
\end{tabular}

Note: The three main combinations are C3-cereal/legume, C4-cereal/C3-cereal and C4-cereal/legume.

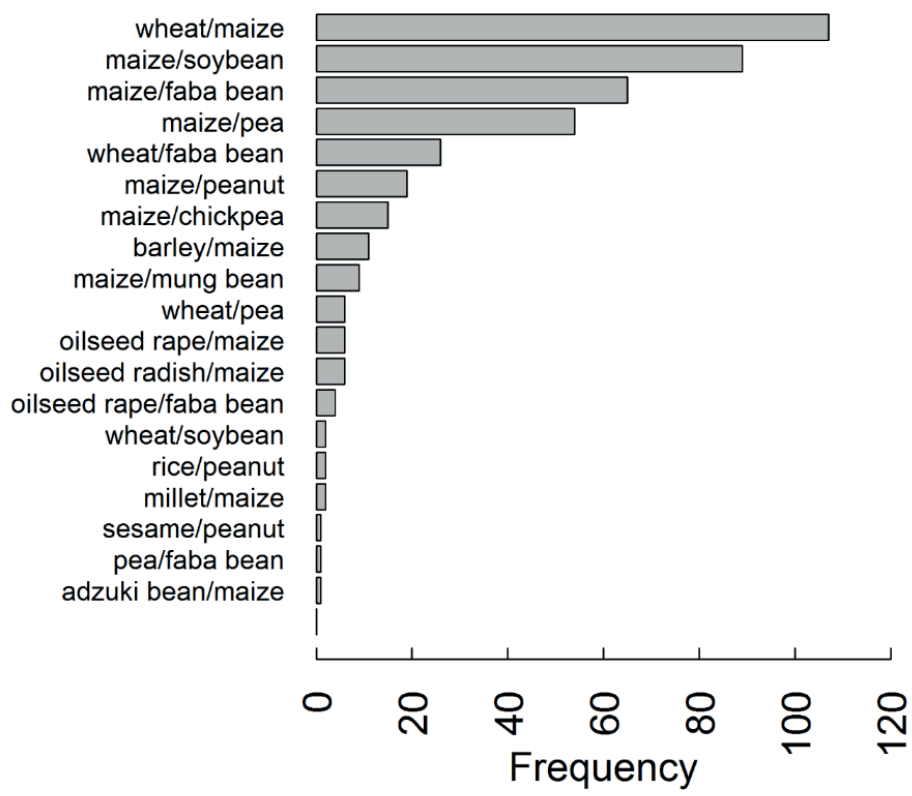

Fig. 5.1 Frequency of occurrence (data records) of species combinations in the dataset.

\subsubsection{Calculation of an index for temporal niche differentiation (TND)}

An index for temporal niche differentiation was calculated using sowing dates and harvest dates of each species in the intercrop (Yu et al. 2015):

$\mathrm{TND}=\frac{P_{\text {system }}-P_{\text {overlap }}}{P_{\text {system }}}=1-\frac{P_{\text {overlap }}}{P_{\text {system }}}$

Where $P_{\text {overlap }}$ represents the period of overlap between the growing periods of the intercropped species, while $P_{\text {system }}$ represents the duration of the whole intercrop. TND $=0$ means simultaneous intercropping, with full overlap of two species (both species are sown 
and harvested at the same time). TND $=1$ would mean no overlap, i.e., double cropping (the second species is sown after the first is harvested). Double cropping was not included in our analysis. Most of the intercrops in the dataset had a value of TND greater than zero (296 out of 326 data records with TND $>0$ ), and only 30 data records had TND $=0$. Thus, most of the intercrops were relay intercrops.

\subsubsection{Additive partitioning method to calculate net effect, complementarity effect and selection effect}

The net effect (NE) is defined as the difference between the observed yield and the expected yield (Loreau and Hector 2001).

$\mathrm{NE}=\left(Y_{1}+Y_{2}\right)-\left(E Y_{1}+E Y_{2}\right)$

$Y_{1}$ and $Y_{2}$ are the observed yields of species 1 and 2 in intercrop, $E Y_{1}$ and $E Y_{2}$ are the expected yields ( $E Y$ ) of two species, which were calculated as the products of the yield of each sole crop and its land share (see Methods S5.4).

The NE is equal to the sum of two components, which have been coined the complementarity effect (CE) and the selection effect (SE) (Loreau and Hector 2001):

$\mathrm{NE}=\mathrm{CE}+\mathrm{SE}=N \times \overline{\Delta R Y} \times \bar{M}+N \times \operatorname{cov}(\Delta R Y, M)$

Here, $\overline{\Delta R Y}$ is the average relative yield gain of the two species, $\bar{M}$ is the average yield of sole crops, and $\operatorname{cov}(\Delta R Y, M)$ is the covariance between the relative yield gain in the intercrop and the sole crop yield. $N$ is the number of species, which is in all cases of the dataset $N=2$.

Relative yield gain is mathematically defined as:

$\Delta R Y_{i}=R Y_{i}-R Y_{i}^{0}$

where $R Y_{i}$ is the actual relative yield of a species and $R Y_{i}^{0}$ is the expected relative yield. Actual relative yield is the yield in the intercrop (per unit area of the whole crop) divided by the yield in the sole crop. It is for each species defined as (De Wit 1960):

$R Y_{i}=Y_{i} / M_{i}$

Expected relative yield is based on the land share of a species in the intercrop. This land share can be calculated on the basis of the densities of a species in the intercrop and the sole crop or on the basis of row or plant arrangement (Methods S5.4).

For a two-species intercropping system, CE can be written as

$\mathrm{CE}=(\mathrm{RYT}-1) \times \bar{M}$.

Thus, CE is equal to the relative yield total (or LER) minus 1, multiplied by the average yield of sole crops. SE can be written as (Methods S5.5): 
$\mathrm{SE}=2 \times \operatorname{cov}(\Delta R Y, M)=\frac{1}{2} \times\left(\Delta R Y_{1}-\Delta R Y_{2}\right) \times\left(M_{1}-M_{2}\right)$

SE is positive if the species with the highest sole crop yield (presumably a competitive species) is overyielding more strongly (greater $\Delta R Y$ ) in intercropping than the species with the lowest sole crop yield. SE is negative if the species with the lowest sole crop yield has a higher relative yield gain. Therefore, the sign of SE indicates whether the high or low-yielding species profits most (in terms of relative yield gain) from intercropping. Positive SE would arise if the more productive species dominates the mixture in terms of biomass or space occupancy (Barot et al. 2017).

The additive partitioning method was proposed for multi-species systems with $N$ species (Loreau and Hector 2001; Malezieux et al. 2009). However, all components in the additive partitioning formula (Eq. 5.3), including the covariance term (Eq.5. 7), can be readily calculated with only two species in the mixture, as is well known from analyses of grassland biodiversity studies, where the species number $N=2$ represents one of the levels of biodiversity that is considered (Loreau and Hector 2001).

\subsubsection{Statistical analysis}

All analyses were conducted in R (R Core Team, 2014). Linear regression with mixed effects models (R package nlme; Pinheiro et al. 2015) was used to quantify the relationships of NE, CE, and SE with the explanatory variables (species trait combinations, TND, N and P input). We assumed normal error structure and homoscedasticity and validated the model assumptions by checking residuals (Zuur et al. 2009). We used publication and experiment within publication as random effects to account for differences between the studies (publications) and between experiments (sites * years) within studies. The best random effects structure was identified by fitting different structures and comparing them using Akaike's information criterion (R functions anova( ) and AIC( )) (Bolker 2008). We finally selected eight mixed effects models to present in this paper (Table 5.3).

We used the anova( ) function to check the significance of quadratic or linear effects (e.g., nutrient input) or interactions between TND or nutrient input and a categorical variable for functional-trait species combinations (Three levels: maize/C3-cereal, maize/legume, and C3-cereal/legume intercrops (Table 5.1)). The AICs of models with the same or different intercept or slope among the three groups were compared (Methods S5.6). The best models were presented in Table 5.3, and only the regression lines of the models with $\mathrm{P}$ values lower than 0.05 are shown in the figures. 
Table 5.3 List of final best models fitted to the data. The indices, $i, j$ and $k$ represent publication, experiment and treatment, respectively. In all mixed models, $a_{i}$ is a random publication effect and $b_{i j}$ is a random experiment effect. $a_{i}$ and $b_{i j}$ are assumed normally distributed with constant variances. $\varepsilon_{i j k}$ is a residual random error assumed normally distributed with constant variance. The variance terms $a_{i}, b_{i j}$ and $\varepsilon_{i j k}$ were all assumed independent.

\begin{tabular}{|c|c|c|}
\hline Model & Equations & Data \\
\hline 1 & $(\mathrm{NE}, \mathrm{CE}, \mathrm{SE})_{i j k}=\beta_{0}+a_{i}+b_{i j}+\varepsilon_{i j k}$ & All data \\
\hline 2 & $(\mathrm{NE}, \mathrm{CE}, \mathrm{SE})_{i j k}=\beta_{\mathrm{TC}}\left(T C_{i j k}\right)+a_{i}+b_{i j}+\varepsilon_{i j k}$ & $\begin{array}{l}\text { Only for maize/C3-cereal, maize/legume } \\
\text { and C3 cereal/legume intercrops }\end{array}$ \\
\hline 3 & $(\mathrm{NE}, \mathrm{CE}, \mathrm{SE})_{i j k}=\beta_{\mathrm{TND}} T N D_{i j k}+a_{i}+b_{i j}+\varepsilon_{i j k}$ & All records with information on TND \\
\hline 4 & $\begin{array}{l}(\mathrm{NE}, \mathrm{CE})_{i j k}=\beta \mathrm{TC}\left(T C_{i j k}\right)+\beta_{\mathrm{TND}}\left(T C_{i j k}\right) T N D_{i j k}+a_{i}+ \\
b_{i j}+\varepsilon_{i j k}\end{array}$ & $\begin{array}{l}\text { Only for maize/C3-cereal, maize/legume } \\
\text { and C3 cereal/legume intercrops }\end{array}$ \\
\hline 5 & $\begin{array}{l}\mathrm{SE}_{i j k}=\beta_{\mathrm{DV} 1}\left(D V 1_{i j k}\right)+\beta_{\mathrm{TND}}\left(D V 1_{i j k}\right) T N D_{i j k}+a_{i}+b_{i j} \\
+\varepsilon_{i j k}\end{array}$ & $\begin{array}{l}\text { Only for maize/C3-cereal, maize/legume } \\
\text { and C3 cereal/legume intercrops }\end{array}$ \\
\hline 6 & $(\mathrm{NE}, \mathrm{CE}, \mathrm{SE})_{i j k}=\beta_{\mathrm{N}} N_{i j k}+a_{i}+b_{i j}+\varepsilon_{j j k}$ & All records with information on $\mathrm{N}$ input \\
\hline 7 & $\begin{array}{l}(\mathrm{NE}, \mathrm{CE})_{i j k}=\beta_{\mathrm{TC}}\left(T C_{i j k}\right)+\beta_{\mathrm{N}}\left(T C_{i j k}\right) N_{i j k}+a_{i}+b_{i j}+ \\
\varepsilon_{i j k}\end{array}$ & $\begin{array}{l}\text { Only for records with information on } \mathrm{N} \\
\text { input concerning maize/C3-cereal, } \\
\text { maize/legume and C3 cereal/legume } \\
\text { intercrops }\end{array}$ \\
\hline 8 & $\mathrm{SE}_{i j k}=\beta_{\mathrm{DV} 2}\left(D V 2_{i j k}\right)+\beta_{\mathrm{N}}\left(D V 2_{i j k}\right) N_{i j k}+a_{i}+b_{i j}+\varepsilon_{i j k}$ & $\begin{array}{l}\text { Only for records with information on } \mathrm{N} \\
\text { input concerning maize/C3-cereal, } \\
\text { maize/legume and C3 cereal/legume } \\
\text { intercrops }\end{array}$ \\
\hline
\end{tabular}

Note: TC (Trait combination) is a categorical variable with three levels representing maize/C3-cereal, maize/legume and C3-cereal/legume intercrops. The intercept $\beta_{\mathrm{TC}}\left(T C_{i j k}\right)$ can take three values, depending on species combinations such as maize/C3-cereal, maize/legume, C3-cereal/legume. DV1 and DV2 are categorical variables with two levels (dummy variables). DV1 indicates whether the intercrop includes maize: $(0)$ intercrops with maize (maize/C3-cereal and maize/legume); (1) intercrops without maize (C3-cereal/legume). DV2 indicates whether the intercrop includes a legume: (0) with a legume; (1) without a legume. After model selection (Method A8), models 4, 5,7 and 8 were selected to estimate the different responses of three species trait combinations to TND or N input.

We made funnel plots (Duval and Tweedie 2000) for the NE, CE and SE to assess publication bias (Methods S5.7). For each funnel plot, we plotted average NE, CE and SE in each of the 69 studies against the total number of experimental units (replicates) in the study as a proxy for study accuracy. There were 341 out of 426 data records without standard error or standard deviation reported. We therefore did an unweighted analysis in which all studies had an assumed equal variance, consistent with earlier studies on yield advantages in intercropping (Yu et al. 2015; Martin-Guay et al. 2018). 


\subsection{Results}

\subsubsection{Frequency distribution of the net effect and its components}

The average NE of intercropping was $2.14 \pm 0.16 \mathrm{Mg}^{-1}$ grain yield (mean \pm standard error) with a median of $1.86 \mathrm{Mg} \mathrm{ha}^{-1}$ (Fig. 5.2a, model 1). The NE was negative in only $9 \%$ of the data records. Most of the yield gain (90\%) was due to the CE: the average CE was $1.94 \pm 0.15 \mathrm{Mg}$ ha $^{-1}$ with a median of $1.79 \mathrm{Mg} \mathrm{ha}^{-1}$ (Fig. 5.2b). The SE was a minor component (10\%) of the

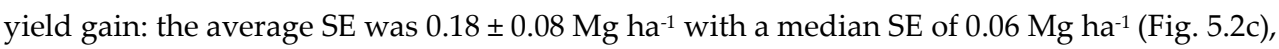
indicating that overyielding of the species with the greater sole crop yield made only a minor contribution to the NE.
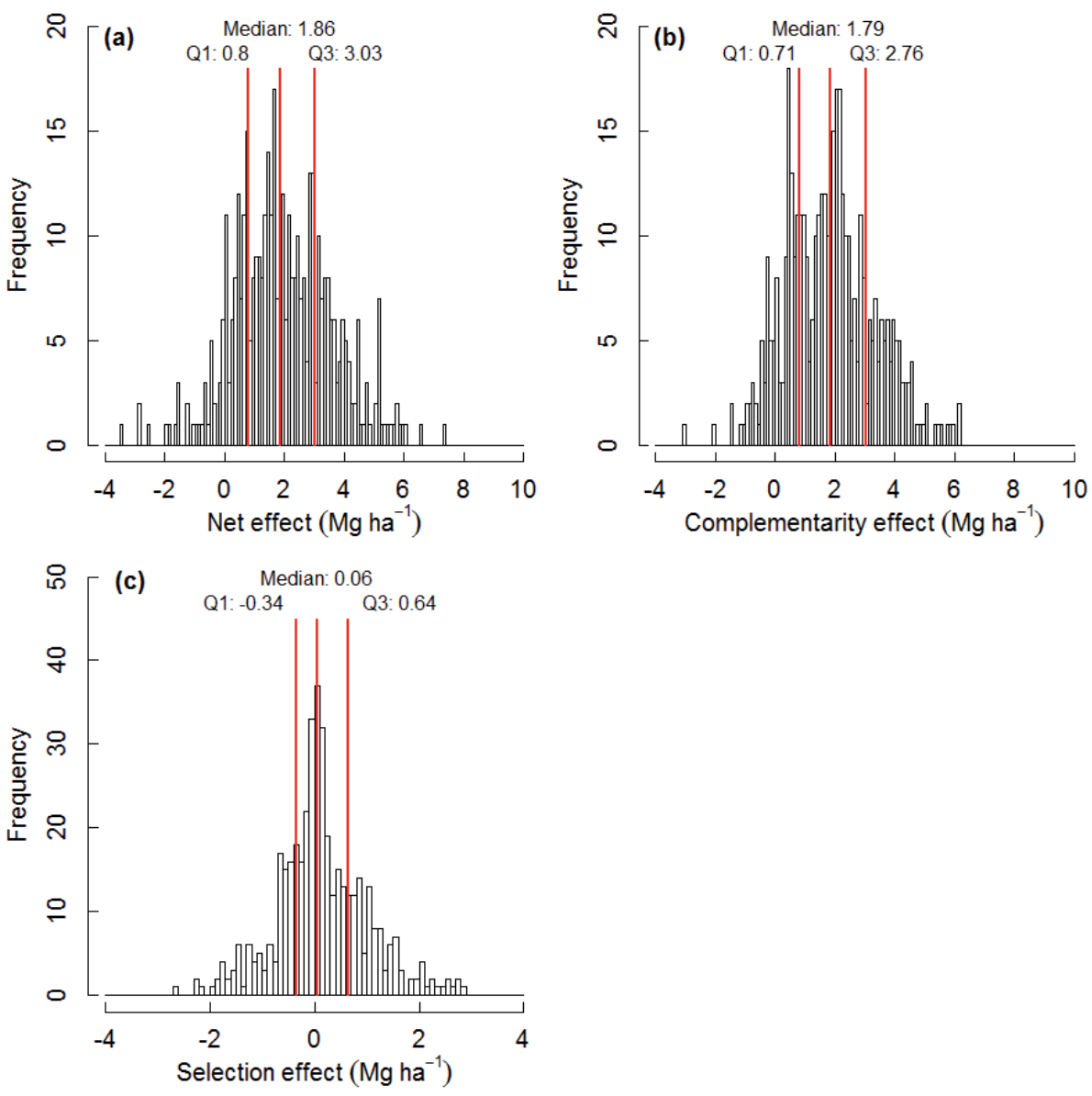

Fig. 5.2 Frequency distribution of (a) the net effect (NE), (b) the complementarity effect (CE) and (c) the selection effect (SE). Vertical red lines in the panels a-c indicate the first quartile (Q1), median and third (Q3) quartile of the NE, CE and SE. 


\subsubsection{Effects of species trait complementarity on the net effect and its components}

The NEs of maize/C3-cereal and maize/legume intercrops were similar: $2.25 \pm 0.22 \mathrm{Mg}^{-1}$ and $2.43 \pm 0.18 \mathrm{Mg} \mathrm{ha}^{-1}(P=0.44$, Fig. 5.3a), respectively. The NE in C3-cereal/legume intercrops was $0.44 \pm 0.40 \mathrm{Mg} \mathrm{ha}^{-1}$, not significantly different from zero, and significantly lower than in mixtures containing maize and another cereal or a legume (both $P<0.001$ ). There was no difference in CE whether maize was intercropped with a C3-cereal $(2.27 \pm 0.20$ $\left.\mathrm{Mg} \mathrm{ha}^{-1}\right)$ or a legume $\left(2.08 \pm 0.16 \mathrm{Mg} \mathrm{ha}^{-1}\right)$. The CE in C3-cereal/legume intercrops was $0.14 \pm$ $0.35 \mathrm{Mg} \mathrm{ha}^{-1}$, not significantly different from zero, and significantly lower than in mixtures containing maize and another cereal or a legume (both $P<0.001$ ). When maize was intercropped with a legume, the SE was higher than when intercropped with a C3 cereal (difference in SE $=0.47 \pm 0.13 \mathrm{Mg} \mathrm{ha}^{-1}$, model 2, $P<0.001$, Fig. 5.3b). Summarizing, the NEs and CEs of intercrops with maize were substantially higher than those of intercrops without maize, while the SE was slightly greater when maize was intercropped with a legume than when it was intercropped with a C3 cereal.
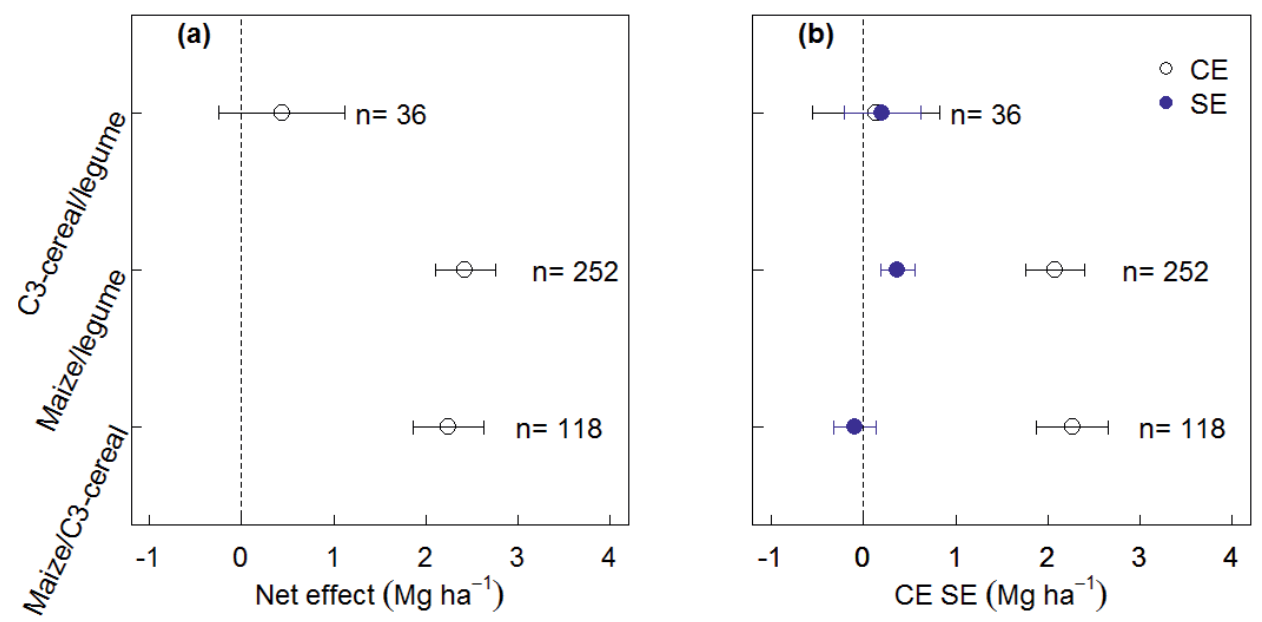

Fig. 5.3 The net effect (a), complementarity effect (CE) and selection effect (SE) (b) of intercropping for maize/C3-cereal, maize/legume and C3-cereal/legume combinations. The horizontal bars represent $95 \%$ confidence intervals; $n=$ number of entries.

\subsubsection{Effect of temporal niche differentiation on the net effect and its components, and the interaction with species combinations}

When using the full dataset, the NE increased $0.81 \pm 0.40 \mathrm{Mg} \mathrm{ha}^{-1}$ per unit of TND (model 3, $P$ $=0.04$, Fig. 5.4a). The CE increased with $2.65 \pm 0.33 \mathrm{Mg}$ ha-1 $^{-1}$ per unit TND $(P<0.001$, Fig. 5.4c $)$ while the SE decreased $1.73 \pm 0.22 \mathrm{Mg} \mathrm{ha}^{-1}$ per unit TND $(P<0.001$, Fig. $5.4 \mathrm{e})$, but the decrease of SE was smaller than the increase of CE, the NE therefore increased per unit of TND. When 
only using data for the subsets of maize/C3-cereal, maize/legume and C3-cereal/legume, we did, however, not identify a significant positive relationship between TND and NE (model 4, Fig. 5.4b). Only the CE of maize/legume intercrops increased with TND $\left(2.51 \pm 0.36 \mathrm{Mg} \mathrm{ha}^{-1}, P\right.$ $<0.001$, Fig. 5.4d), but the CEs of the other two species combinations were independent of TND. The presence of maize in intercropping was associated with a decrease in SE with greater TND. The SE of intercrops with maize decreased with TND but the SE of intercrops without maize was independent of TND (Fig. 5.4f). The results indicate that in maize/legume intercrops, the SE had a slightly larger contribution to the net effect at low TND (high overlap in time between species) whereas the contribution of CE was bigger at higher TND.

\subsubsection{Effect of $\mathbf{N}$ input on the net effect and its components, and the interaction with species combinations}

We hypothesized that the NE and CE might show quadratic responses to N fertilizer input, however, in model selection (Methods S5.6), the linear models were better than the quadratic models (Table A2). Both the NE and CE increased with $\mathrm{N}$ fertilizer input (model $6, P<0.001$, Fig. 5.5a, c). The NE increased $2.75 \pm 1.33 \mathrm{~kg} \mathrm{ha}^{-1}$ per $\mathrm{kg}$ of $\mathrm{N}$ fertilizer per ha, and the CE increased $2.66 \pm 0.58 \mathrm{~kg} \mathrm{ha}^{-1}$ per $\mathrm{kg}$ of $\mathrm{N}$ fertilizer per ha. The SE was independent of $\mathrm{N}$ input (model 6, $P=0.77$, Fig. 5.5e). Thus, the yield gain and competitive relaxation of intercrops depend on $\mathrm{N}$ fertilizer input. $\mathrm{N}$ fertilizer input had no influence on the SE.

The NE of maize/C3-cereal intercrops increased $7.33 \pm 0.88 \mathrm{~kg} \mathrm{ha}^{-1}$ per $\mathrm{kg}$ of $\mathrm{N}$ fertilizer per ha (model 7, $P<0.001$, Fig. 5.5b), and the CE of maize/C3-cereal intercrops increased $5.79 \pm 0.83$ $\mathrm{kg} \mathrm{ha}^{-1}$ per kg of $\mathrm{N}$ fertilizer per ha (model $7, P<0.001$, Fig. $5.5 \mathrm{~d}$ ), but $\mathrm{NE}$ and CE of intercrops with legumes did not respond to $\mathrm{N}$ input. The SE of maize/C3-cereal intercrops was close to zero and slightly increased with $\mathrm{N}$ input (model $8, P<0.01$; Fig. 5.5f). However, there were no significant responses of $\mathrm{SE}$ to $\mathrm{N}$ fertilizer input in intercrops with legumes (i.e., maize/legume and C3-cereal/legume). 

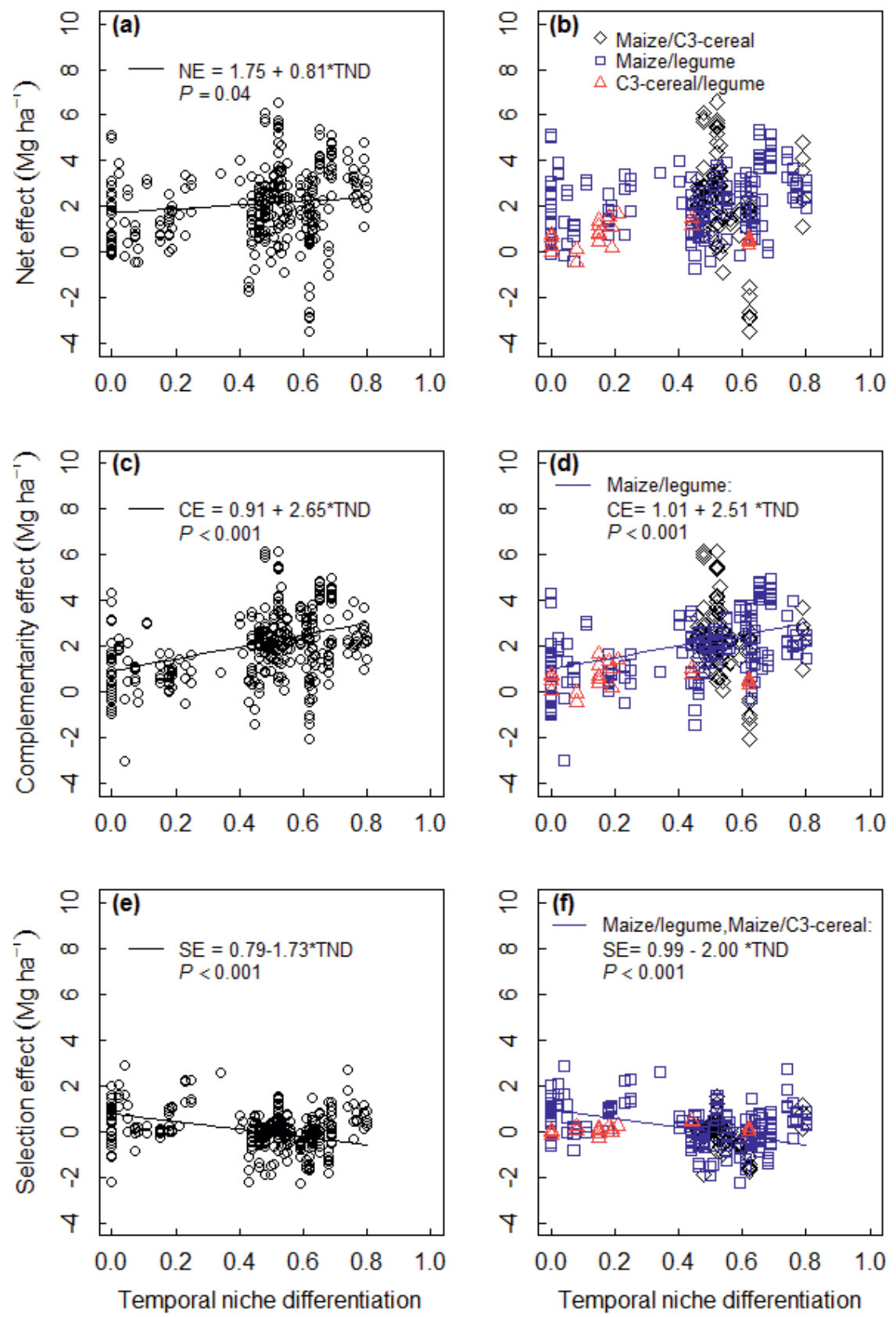

Fig. 5.4 Relationship between (a) the net effect, (c) complementarity effect (CE) and (d) selection effect (SE) and temporal niche differentiation (TND) for all intercrops, and relationship between (b) the NE, (e) $\mathrm{CE}$, (f) SE and TND for maize/C3-cereal, maize/legume and C3-cereal/legume intercrops. Only regressions with $P<0.05$ are presented in the panels. 

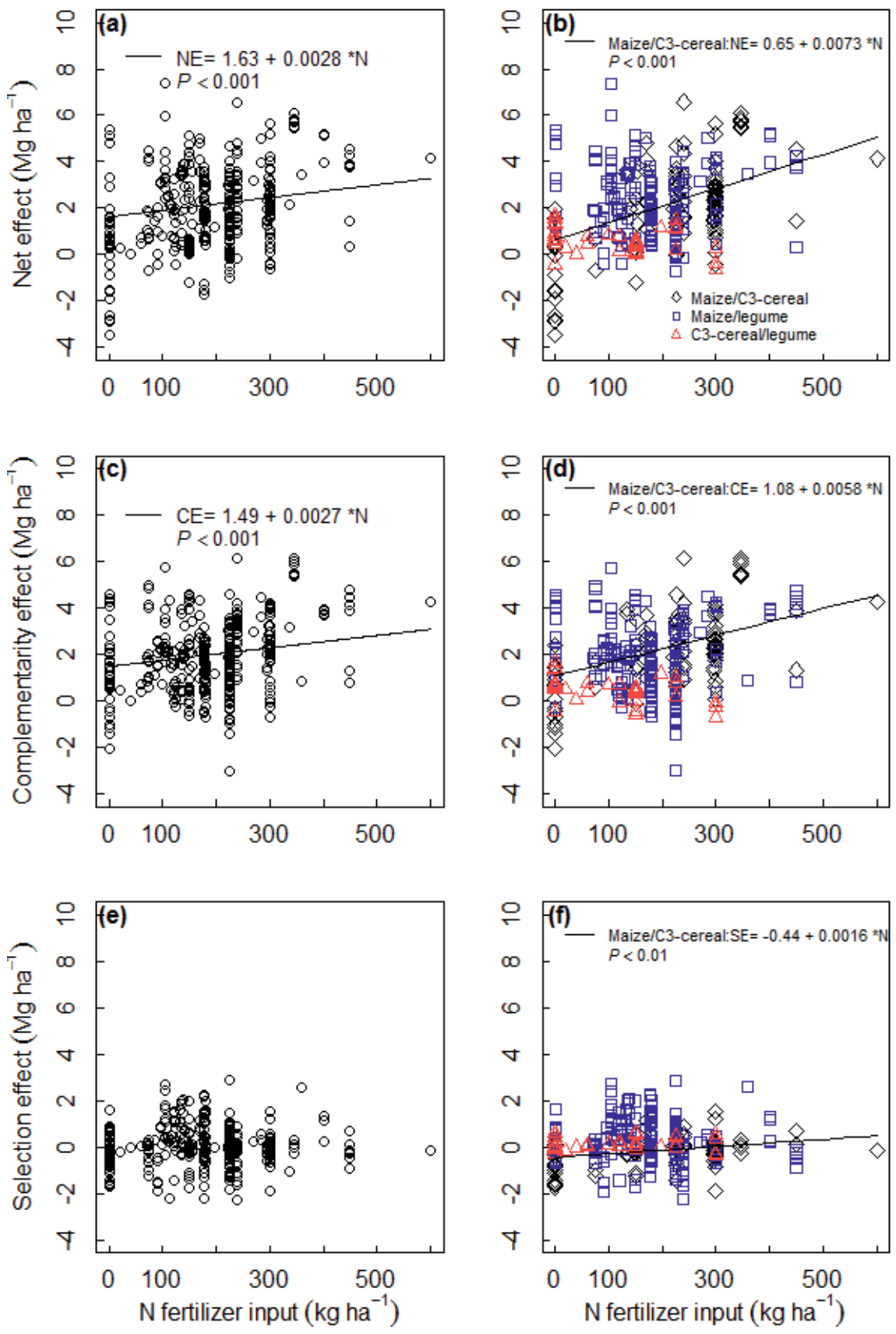

Fig 5.5 Relationship between (a) the net effect, (c) complementarity effect (CE) and (d) selection effect (SE) and $\mathrm{N}$ input for all intercrops, and relationship between (b) the NE, (e) CE, (f) SE and N input for maize/C3-cereal, maize/legume and C3-cereal/legume intercrops. Only regressions with $P<0.05$ are presented in the panels. 


\subsubsection{Effect of $P$ input on the net effect and its components, and the interaction with species combinations}

The NE and its components did not respond to $P$ fertilizer input, and regressions for different functional intercrop groups did not identify any significant relationships (Fig. S5.1, Appendix D).

\subsection{Discussion}

Our study showed that the yield gain of intercropping in the present dataset was $2.14 \mathrm{Mg}$ grain per hectare. This yield gain was largely due to the $\mathrm{CE}$, with a small contribution from the SE. Temporal niche differentiation increased the yield gain by increasing the contribution of $\mathrm{CE}$ to the net effect and decreased the contribution of SE. A greater yield gain and CE were found in intercrops with maize (e.g., maize/C3-cereal or maize/legume) compared to intercrops without maize (e.g., C3-cereal/legume). The SE was significantly positive in maize/legume intercrops. The yield gain increased with $\mathrm{N}$ input in maize/C3-cereal intercrops but not in cereal/legume intercrops. This increase in yield gain was largely due to the positive response of maize to $\mathrm{N}$ input in relay strip intercropping. The $\mathrm{NE}$ and its components were independent of $\mathrm{P}$ input.

\subsubsection{Using absolute gains to better appreciate the yield benefit of intercropping}

The choice of indicators is essential to appreciate the yield benefit of intercropping (Bedoussac and Justes 2011). This is the first meta-analysis using the net effect of intercropping to analyze yield advantage. The advantage of net effect is that it expresses intercropping benefit in real terms of $\mathrm{Mg} \mathrm{ha}^{-1}$. The information provided by $\mathrm{NE}$ and its components is complementary to that provided by LER. Where LER characterizes the land use efficiency of intercropping, the NE indicates how much more yield is obtained per unit area than expected from the sole crop yields and species land shares. Relative yield can be high if the absolute yields in the intercrop and the sole crop(s) are low, but in the case of NE, the value is not likely to be substantial at low yield levels. Partitioning the net yield gain of intercrops into complementarity and selection effects with additive partitioning method helps to analyze the drivers of yield gain of intercropping. In particular, additive partitioning helps to ascertain whether intercropping advantage is predominantly due to overyielding of the species with the highest sole crop yield (in many studies maize) or due to overall functional complementarity between the species, such that the sum of relative benefits is greater than zero $(\Delta R Y>0)$. Our analysis shows that $90 \%$ of the intercropping advantage is due to complementarity as captured by CE. Furthermore, the effect size of more than 2 tons of grain per ha is substantial and of great agronomic relevance. 


\subsubsection{Components of net yield gain in different intercropping groups}

In line with our first hypothesis, the $\mathrm{NE}$ and $\mathrm{CE}$ were greater in $\mathrm{C} 3 / \mathrm{C} 4$ intercrops (mainly maize with a C3-cereal or legume) than in intercrops with only C3 species, predominantly C3-cereal/legume mixtures (Fig. 5.3). This might be explained by differences in functional traits and temporal niche differentiation between maize and C3 species. Large differences in growing period and contrasting temperature responses between maize and C3 species allow greater complementarity in resource capture (light, water and nutrients) to be achieved over a growing season, particularly if sowing of the species is staggered in time. The larger TND of intercrops with maize (Fig. S5.2) also explained the higher NE and CE of intercrops with maize than without maize. As a C4 species, maize is more adapted to high temperatures than C3 species, enabling niche differentiation between species in crop mixtures over time, resulting in better exploitation of seasonal patterns in light and temperature (Anten and Hirose 1999).

The hypothesis that the SE would be greater in intercrops with maize, was not confirmed. The $\mathrm{SE}$ of maize/C3-cereal intercrops was not significantly different from 0 . In this dataset, maize/C3-cereal intercrops included maize/wheat and maize/barley (Fig. S5.3), and these intercrops had high TND (Fig. S5.2) because maize, which is the better competitor, was always sown later than wheat and barley. We infer that due to this temporal differentiation, maize was not strongly competitive to its companion species, and hence, SE was zero.

Contrary to the second hypothesis, we found no differences in NE and CE between maize intercropped with a C3 cereal or a legume (Fig. 5.3b). This was unexpected because the literature assigns a great importance to the complementary uptake of $\mathrm{N}$ by cereals and legumes (e.g., Lithourgidis et al. (2011b)). It is possible that the potential synergy between cereals and legumes did not reach its full potential in the dataset due to high fertilization levels (Fig. S5.4) (Hauggaard-Nielsen and Jensen 2001). It would have been interesting to compare C3-cereal/C3-cereal and C3-cereal/legume intercrops, but there was no data on C3-cereal/C3-cereal intercrops in the dataset (Table 5.2). The comparatively larger SE of maize/legume intercrops as compared to maize/C3-cereal intercrops (Fig. 5.3b) is in line with the well-established low competitiveness of legumes with respect to cereals ( $\mathrm{Yu}$ et al. 2016). With stronger competitiveness of maize towards legumes than to other cereals, a larger SE was expected in mixtures with legumes, and the analysis confirmed this. Maize plants are generally tall (though there is high genotypic variability for this) resulting in severe shading of legumes in mixtures if these are sown at the same time as maize. This highlights the subordinate role that legumes have in mixtures with maize as a result of competition for light (Liu et al. 2017; Liu et al. 2018). 


\subsubsection{Temporal niche differentiation as a mechanism underlying the complementarity and selection effects}

We obtained confirmation of the third hypothesis that CE increases with TND (Fig. 5.4). If two species are sown and harvested at the same time $(\mathrm{TND}=0)$, taller species can outcompete shorter species, since competition for light between species is size asymmetric (Weiner 1990; DeMalach et al. 2016; Huang et al. 2017). With less overlap in time between the two species (high TND), temporal and spatial complementarity in light interception becomes more important. Similarly, the shorter co-growth period allows species to acquire water and nutrients at different times. The later species may also benefit from $\mathrm{N}$ mineralization from decomposing roots of the earlier species. In relay intercropping (high TND), crops can take up $\mathrm{N}$ over a longer period of time. The relatively low density of species during the time that they are growing without the companion species relaxes competition for both aboveground and belowground resources, resulting in increased CE with greater TND (Fig. 5.4c). Since the NE was greatly contributed by the CE which was positively related to TND, the NE therefore increased with greater TND.

The CE increased with TND in maize/legume intercrops (Fig. 5.4d) but the yield gain and component effects were independent of TND in C3-cereal/legume intercrops (Fig. 5.4b, d, f). The range of TND in maize/legume intercrops (0-0.80) was larger than in the other two groups (Fig. 5.4). While TND is evidently a factor contributing positively to $\mathrm{CE}$ in maize/legume intercrops, other factors may be involved, such as the higher temperature optimum for growth in maize, or the possibility of a more favorable light distribution in the co-growth stage when mixing plants with different architecture and temporal complementarity. Further work is needed to elucidate the role of different plant traits in the complementarity in maize/legume systems with temporal niche differentiation.

\subsubsection{Complementarity effect and selection effect in relation to $\mathrm{N}$ and $\mathrm{P}$ input}

Contrary to our last hypothesis, we found a linear response rather than a quadratic response of the NE or CE of maize/C3-cereal intercrops to the $\mathrm{N}$ fertilizer input (Fig. 5.5b, d). The positive response of $\mathrm{NE}$ to $\mathrm{N}$ input in maize/C3-cereal intercropping systems is likely due to the positive response of maize in relay intercropping systems to sufficient $\mathrm{N}$ availability during its recovery after harvest of the C3-cereal (e.g., Li et al. 2001a; Gou et al. 2016).

We found that the NE and CE of intercrops with legumes (i.e., maize/legume, C3-cereal/legume intercrops) were independent of $\mathrm{N}$ fertilizer input. Similarly, the LER of cereal/legume intercrops was independent of $\mathrm{N}$ fertilizer input in other meta-analysis studies (Pelzer et al. 2014). However, results of Yu et al. (2015); Yu et al. (2016) indicate that LER in simultaneous cereal/legume intercrops decreases with $\mathrm{N}$ input. While we had hypothesized a quadratic response to $\mathrm{N}$ input in cereal/legume intercrop, we found in our meta-analysis no 
significant response at all. This is not contradicting our initial reasoning. On the one hand, we expected that $\mathrm{N}$ input would tend to increase yield level, and thereby $\mathrm{NE}$, which was confirmed (Fig. S5.5). On the other hand, the complementarity between cereals and legumes for $\mathrm{N}$ acquisition would diminish in importance as $\mathrm{N}$ input increased, shown as lower LER (also confirmed, Fig. S5.5), which would tend to decrease NE. The overall effect was no effect of $\mathrm{N}$ input on $\mathrm{NE}$ in cereal/legume intercropping. On the other hand, $\mathrm{N}$ input increased both yield level and LER in maize/C3-cereal intercropping (Fig. S5.8). Hence the effect of N input on NE in maize/C3-cereal intercrops was positive.

Available $\mathrm{N}$ is not entirely driven by fertilizer as $\mathrm{N}$ can also be mineralized from soil organic matter. We conducted an additional analysis using as an explanatory variable the total $\mathrm{N}$ supply calculated as the sum of $\mathrm{N}$ derived from fertilizer (accounting for recovery fraction) and $\mathrm{N}$ from soil organic matter (Methods S5.8; (Sattari et al. 2014)). This analysis indeed yielded a curvilinear response of NE to N supply (Fig. S5.6, S5.7). However, the response of $\mathrm{CE}$ to $\mathrm{N}$ supply was linear while SE showed no response to $\mathrm{N}$ supply, which is inconsistent with the curvilinear response of NE. We consider this analysis of the influence of $\mathrm{N}$ supply less robust than the analysis of $\mathrm{N}$ input because (1) the analysis of the effect of $\mathrm{N}$ supply was based on unverified assumptions in the calculation of supply (e.g., the recovery fraction) and (2) the dataset was considerably (37\%) smaller than the full dataset used for the analysis of $\mathrm{N}$ input. All in all, both analyses show that a trade-off exists between the effects on yield level and intercropping advantage of $\mathrm{N}$ input and soil $\mathrm{N}$ supply; on the one hand, $\mathrm{N}$ input increased $\mathrm{N}$ availability and yield level, but on the other hand, higher levels of soil $\mathrm{N}$ decrease relative intercropping advantage due to $\mathrm{N}$ capture complementarity in cereal/legume mixtures. In maize/C3-cereal mixtures, both the yield level and the relative intercropping advantage increased with $\mathrm{N}$ input.

SE was independent of $\mathrm{N}$ input in cereal/legume intercrops (Fig. 5.5f). This contradicts our hypothesis and several empirical studies showing that application of $\mathrm{N}$ fertilizer in cereal/legume intercrops increases the competitiveness of cereals thereby increasing the competitive inequality between cereals and legumes (Bedoussac and Justes 2010; Andersen et al. 2014; Pelzer et al. 2014; Yu et al. 2016). A possible explanation is that most of the intercropping systems in our database were strip intercropping systems. In these systems, the competitive interactions between species are less intense than in the row intercropping or completely mixed intercropping systems that were conducted in Europe or worldwide. Both experiments and simulations with plant models have shown that competitive dominance effects are aggravated if the strips are narrow or consist of single rows (Yu 2016).

Contrary to our expectation and the stress gradient hypothesis, yield gain and its component effects were independent of $\mathrm{P}$ input. The reason may be that soil P levels in the synthesized 
studies were not limiting yield. The average Olsen-P in the studies in this dataset was $12.3 \pm$ $2.5 \mathrm{mg} \mathrm{kg}^{-1}$ (Fig. S5.8), which was in the range of soil Olsen-P for optimal crop yield (10.9 mg $\mathrm{kg}^{-1}$ to $21.4 \mathrm{mg} \mathrm{kg}^{-1}$ ) (Bai et al. 2013). Accordingly, there was no response of maize yield in sole crop to the P input of sole maize in the dataset (Fig. S5.9b) (382 out of 426 data records include maize in the intercrop). Similar to our results, Li et al. (2018) did not find any consistent effect of $\mathrm{P}$ input on $\mathrm{CE}$ across four species combinations in intercropping. Positive interactions between intercrops that involve P-mobilizing exudates require root proximity (Hinsinger et al. 2011), but our dataset mostly comprised data on strip intercropping. Altogether, this meta-analysis gives no support for the notion that the level of $\mathrm{P}$ input is an important factor driving yield advantages in Chinese intercropping.

\subsection{Conclusions}

Our study highlights that net effects of Chinese intercropping on yield are highly dependent on the presence of maize and that temporal niche differentiation is key to competitive relaxation through an increase of the complementarity effect. The results indicate that yield gain by intercropping is sustained under high nutrient availability. Yield gains are similar regardless whether maize is intercropped with a C3 cereal or a legume. The yield gains of maize/C3-cereal intercrops depend on $\mathrm{N}$ input, while the yield gains in cereal/legume intercrops were independent of $\mathrm{N}$ input.

The results confirm that intercropping is a promising pathway for ecological intensification of agriculture (Lithourgidis et al. 2011a; Brooker et al. 2015) which demands for design of optimized cropping systems that are highly productive and resource use efficient (Malezieux et al. 2009; Gaba et al. 2015). Our findings indicate that these systems might be conceived with high yielding $\mathrm{C} 4$ species such as maize that are tall, fast-growing during the later growing season and can recover from early competition with an earlier sown species.

\section{Acknowledgements}

The authors gratefully acknowledge funding from Chinese National Basic Research Program (2015CB150400), and National Key R\&D Program of China (grant number: 2017YFD0200200/2017YFD0200207). Projects of International Cooperation and Exchanges NSFC (31210103906), and the Innovative Group Grant of the National Natural Science Foundation of China (31421092). The financial support of the Wageningen University Sandwich Scholarship is gratefully acknowledged. The authors acknowledge funding from the European Union's Horizon 2020 Programme for Research \& Innovation under grant agreement $n^{\circ} 727217$ (www.remix-intercrops.eu)" . We thank three anonymous reviewers for constructive comments on this manuscript. 



\section{Chapter 6 Syndromes of production in intercropping impact yield gains}

Chunjie Li, Ellis Hoffland, Thomas W. Kuyper, Yang Yu, Chaochun Zhang, Haigang Li,

Fusuo Zhang, Wopke van der Werf

This chapter is published as:.

Li C, Hoffland E, Kuyper TW, Yu Y, Zhang C, Li H, Zhang F, van der Werf W (2020) Syndromes of production in intercropping impact yield gains. Nature Plants 6: 653-660. https://doi.org/10.1038/s41477-020-0680-9 


\begin{abstract}
Intercropping, the simultaneous production of multiple crops on the same field, provides opportunities for sustainable intensification of agriculture if it can provide greater yield per unit land and fertilizer than sole crops. The worldwide absolute yield gain of intercropping as compared to sole crops has to date not been analyzed. We therefore performed a global meta-analysis to quantify the effect of intercropping on the yield gain, exploring the effect of crop species combinations, temporal and spatial arrangement and fertilizer input. We found that the absolute yield gains, compared to monocultures, were greatest for mixtures of maize with short grain cereals or legumes that had substantial temporal niche differentiation from maize, when grown with high nutrient inputs, and using multi-row strips of each species. This approach, commonly practiced in China, provided yield gains that were in an absolute sense about four times as large as those in another, low-input, intercropping strategy, commonly practiced outside China. The alternative intercropping strategy consisted in growing mixtures of short stature crop species, often as full mixtures, with the same growing period, and with low to moderate nutrient inputs. Both the low and high yield intercropping strategies saved 16-29\% land and 19-36\% fertilizer compared to monocultures grown under the same management as the intercrop. The two syndromes of production in intercropping uncovered by this meta-analysis show that intercropping offers opportunities for the sustainable intensification of both high and low input agriculture.
\end{abstract}

Keywords: meta-analysis, intercropping, syndromes of production, maize, temporal niche differentiation, nutrient input 


\subsection{Introduction}

With the ongoing increase in the global population and demand for food, improving crop productivity is a pressing challenge (Tilman et al. 2011). Intensive agriculture provides high yields but comes with serious environmental impacts (Matson et al. 1997; Cassman 1999; Tilman et al. 2001). Intercropping (i.e., the mixed cultivation of crop species on the same field (Vandermeer 1989; Willey 1990)) is a sustainable way to develop productive agriculture (Vandermeer 1989; Ren et al. 2014; Martin-Guay et al. 2018): It offers ecological mechanisms for weed suppression (Liebman and Dyck 1993), pest and disease control (Trenbath 1993; Zhu et al. 2000), efficient use of light (Zhang et al. 2008) and water (Yang et al. 2011; Mao et al. 2012; Tan et al. 2020a), conservation of soil resources (Jensen 1996; Hauggaard-Nielsen et al. 2009; Cong et al. 2015) and yield increase ( $\mathrm{Li}$ et al. 2007; Li et al. 2009; Bedoussac et al. 2015). The most obvious advantage of intercropping is land sparing, which is usually quantified by the land equivalent ratio (LER). The LER is defined as the ratio of the area under sole cropping to the area under intercropping needed to give the same yields (Mead and Willey 1980). An LER greater than one means that intercropping saves land. Previous meta-analyses showed that the LER of intercropping averages $1.22 \pm 0.02$ (Yu et al. 2015) or $1.30 \pm 0.01$ (Martin-Guay et al. 2018), depending on the studies selected for meta-analysis. However, the LER is a dimensionless indicator of relative yields in intercropping compared to monocultures. It does not provide information on the yield increase per unit area achieved by intercropping.

The absolute yield gain of species mixtures can be assessed by the net effect of species mixtures on the yield per unit area (Loreau and Hector 2001). The net effect (NE) is defined as the difference in yield or biomass between the mixture and the average of the sole crops (Loreau and Hector 2001). The information provided by NE and LER is complementary. Both metrics are relevant for assessing the benefit of intercropping. The LER evaluates the comparative land use efficiency of intercropping while the NE indicates how much more yield is produced per unit area than expected based on sole crop yields and species proportions. Relative yield can be high at low yield levels, but the net effect is not likely to be substantial at low yield levels. When issues of global food security are at stake, it is important to not focus solely on the land use efficiency (LER), but also pay attention to the NE, i.e., the absolute yield gain. The absolute yield gain of intercropping at a global scale is unknown.

Intercropping is an ancient cropping system, practiced all around the world (Lithourgidis et al. 2011a; Li et al. 2013) (Fig. S6.1, Appendix E). Various crop combinations have been recognized and utilized in Africa, Asia, Europe and the Americas for centuries and are still prevalent (Hong et al. 2017). Crop species may be grown simultaneously or partly so, and in no distinct row arrangement (mixed) or in alternate rows or strips on the same field (Li et al. 2013) (Fig. 6.1). In strip intercropping, the strips are wide enough to permit independent 
cultivation but narrow enough to allow beneficial interspecific interactions (Vandermeer 1989) (Fig. 6.1a, b, e-g). Maize (Zea mays) is a frequently used species in intercropping. This high-yielding species can be sown in strips of several rows, alternating with several rows of a C3 species, e.g., small grains such as wheat (Triticum aestivum) (Gou et al. 2017) or a legume such as soybean (Glycine max) (Xu et al. 2020). Maize has a late and long growing season and is usually harvested after the C3 species in a system known as relay strip intercropping (Lithourgidis et al. 2011a; Li et al. 2013; Brooker et al. 2015) (Fig. 6.1b).

Maize and other cereals can also be sown in alternate rows or mixed in a more or less random pattern with other small grains or legumes (Fig. 6.1c, d). Alternate-row and mixed intercropping are popular in organic farming with low input in Europe (Hauggaard-Nielsen et al. 2009; Voisin et al. 2014; Barbieri et al. 2017). Here, mixtures of a legume and a C3 cereal species are the most popular combination (Fig. 6.1h-j). These intercropping systems have low nitrogen $(\mathrm{N})$ fertilizer input but realize an acceptable protein content in cereal grain due to $\mathrm{N}_{2}$ fixation by legumes. These systems have an advantage of low input and low emissions (Lithourgidis et al. 2006; Bedoussac et al. 2014). However, due to lower inputs, they are also comparatively low yielding. In these systems, the intercropped species are mostly sown in full mixtures that are harvested at the same time (Bedoussac et al. 2015), i.e., without temporal niche differentiation.

We previously found that intercrops with maize in China have greater yield gain than intercrops without maize (Chapter 5). The LER was increased at greater temporal niche differentiation (Yu et al. 2015) and at lower N input (Hauggaard-Nielsen and Jensen 2001). However, the effect of these management factors on the net effect of intercropping on yield has not been studied at a global scale. We therefore investigate here the effect of species combinations, temporal and spatial arrangement, and fertilizer input on the yield gain and ask the question how different management affects yield gain.

We present here a global meta-analysis to quantify the yield gain for grain-producing intercropping systems with different species combinations (with or without maize), temporal and spatial arrangement, and fertilizer input. We also evaluated whether intercropping can save land and fertilizer. The land and fertilizer savings were quantified with relative metrics (Yu et al. 2015; Martin-Guay et al. 2018; Xu et al. 2020) while yield gain was assessed with an absolute yield metric (Loreau and Hector 2001). We show that the greatest absolute yield gains are achieved when management factors are coordinated in a high input - high output syndrome of production (Andow and Hidaka 1989; Vandermeer 1997) in intercropping, with substantial input of fertilizer, inclusion of maize in the mixture, cultivation in strips, and use of relay intercropping. Substantially smaller yield gains, but still considerable land and fertilizer savings compared to sole crops under the same management, are obtained in a low 
input - low output intercropping strategy, without maize, and with fully mixed intercrops without temporal niche differentiation.

(a)

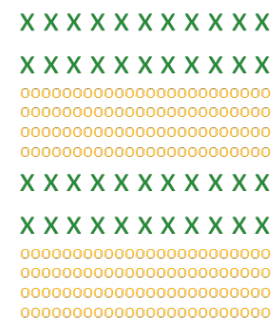

(b)

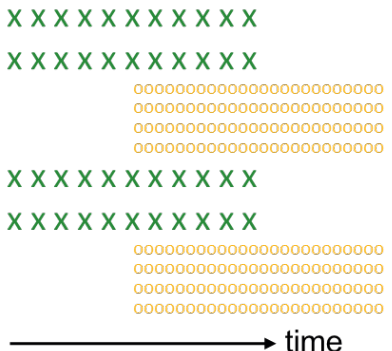

(c)

$x \times x \times x \times x \times x$ 00000000000 $\mathrm{X} \times \mathrm{XXXX \times \times} \times$ 000000000000 $\mathrm{X} \times \mathrm{X} \times \mathrm{X} \times \mathrm{X} \times \mathrm{X} \times \mathrm{X}$ 000000000000 $\mathrm{X} \times \mathrm{X} \times \mathrm{X} \times \mathrm{X} \times \mathrm{X} \times \mathrm{X}$ 000000000000 $\mathrm{X} \times \mathrm{X} \times \mathrm{X} \times \mathrm{XXXX}$ 000000000000 $\mathrm{x} \times \mathrm{x} \times \mathrm{x} \times \mathrm{x} \times \mathrm{x}$ 000000000000 $X X X X X X X X X$ (d)

$x \times O x \circ O x \circ x$

$0 \circ x \in O x \circ x \circ$

OXXOXXOX

$x \circ x \circ O x \circ x x$

oxxoxoxox

$\mathrm{XOX} O \mathrm{XOX} \mathrm{XOX}$

OXXOXOXOO

$x \times 00 x x 0 x x$

$0 \mathrm{XOOX} O \mathrm{XXO}$

$\mathrm{XXOX} \mathrm{X} \mathrm{X} O \mathrm{XX}$

$0 x 00 x O x O 0$

$x \times O x O x O O X$

$x \circ O X X O X X 0$
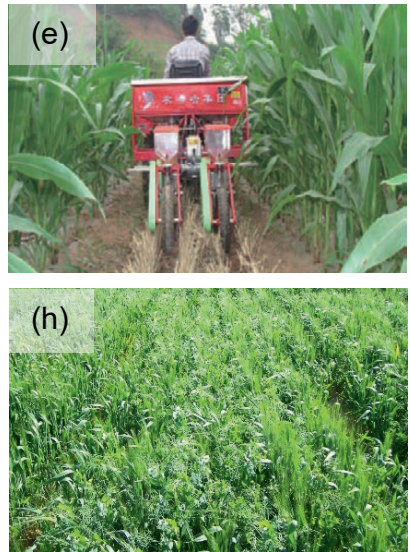
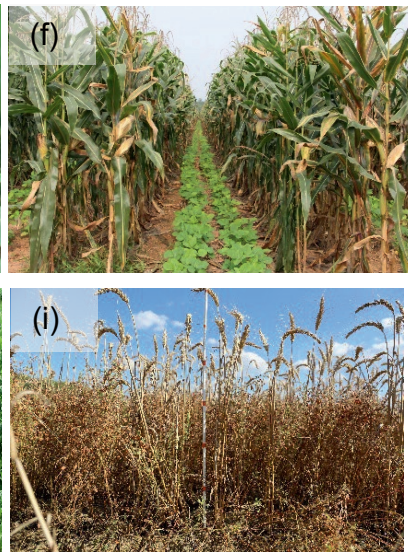
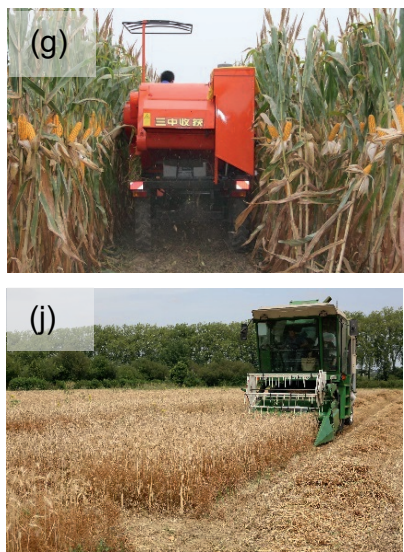

Fig. 6.1 Schematic illustration and examples of alternative intercropping strategies. (a) Strip intercropping, with both species grown simultaneously, (b) relay strip intercropping, with one species sown and harvested later than the other, (c) alternate-row intercropping, (d) mixed intercropping, (e) a mini-tractor sowing soybean and applying fertilizer in maize/soybean relay strip intercropping, (f) relay strip intercropping of maize and soybean, $(\mathrm{g})$ a soybean harvester working in a soybean strip in Southwest China (Images by Junbo Du), (h) alternate-row intercropping of durum wheat and winter pea in France (Image by Laurent Bedoussac), (i) mixed lentil/spring wheat intercropping at harvest, (j) mechanical harvest of mixed lentil/spring wheat intercropping in France (Images by Loïc Viguier).

\subsection{Materials and Methods}

\subsubsection{Data selection}

The data set was built by combining a database built by Yu et al. (2015) and the database in Chapter 5. From the original database of Yu et al. (2015), all data records of grain-producing intercrops (e.g., cereals, legumes, oilseed crops) that provided data on species densities were extracted (539). We removed the duplicate data records (9 publications and 31 data records) in the two datasets. All intercrops in the resulting database were grain-producing intercrops. 
The data set included variables such as the publication title, year and author, and the yield of both sole crops and intercrops, species combination, planting density, row distance, fertilizer input, sowing dates and harvest dates. Most of the studies did not report the irrigation frequency and volumes in the different treatments. Therefore, irrigation amount was not included in the data set. The data set included 934 data records, representing data from 226 experiments described in 132 publications. "Experiment" was defined as a unique combination of site and year. Within experiments, data records were defined by treatment, including species combination, sowing and harvest dates and fertilizer input.

\subsubsection{Response and explanatory variables}

In the analysis, the response variables are net effect (NE), land equivalent ratio (LER), $N$ fertilizer equivalent ratio (NFER), $\mathrm{P}$ fertilizer equivalent ratio (PFER), rate of $\mathrm{N}$ (and $\mathrm{P}$ ) fertilizer input in intercrops $\left(\mathrm{kg} \mathrm{ha}^{-1}\right)$, observed (and expected) yield ( $\left.\mathrm{Mg} \mathrm{ha}^{-1}\right)$, temporal niche differentiation (TND, see equation (6.7) below), and explanatory variables are presence of maize in species combinations (categorical; 2 levels: with or without), spatial arrangement (categorical; 3 levels: strip, row, mixed), the origin of data (categorical; 2 levels: from China, outside China), TND, and the rate of $\mathrm{N}$ (and P) fertilizer input in intercrops (kg ha-1).

\subsubsection{Net effect}

The net effect (NE) is defined as the difference between the observed yield and the expected yield (Loreau and Hector 2001).

$\mathrm{NE}=\left(Y_{1}+Y_{2}\right)-\left(E Y_{1}+E Y_{2}\right)$

Where $Y_{1}$ and $Y_{2}$ are the observed yields of species 1 and 2 in intercrop, $E Y_{1}$ and $E Y_{2}$ are the expected yields (EY) of two species, which were calculated as the product of monoculture yield and land share (Chapter 5).

$E Y_{1}=M_{1} \times L S_{1}$

$E Y_{2}=M_{2} \times L S_{2}$

Where $M_{1}, M_{2}$ are the yields (per unit area of the respective sole crop) of species 1 and 2 in monoculture. $L S_{1}, L S_{2}$ are the land shares of species 1 and 2 in intercropping. This land share was calculated on the basis of the densities of a species in the intercrop and the sole crop or on the basis of row or plant arrangement (Chapter 5).

\subsubsection{Land equivalent ratio (LER)}

Land equivalent ratio (LER) is defined as the sum of partial LERs (relative yields) per species ( $\mathrm{pLER}_{1}$ and $\mathrm{pLER}$ ):

$\mathrm{LER}=\mathrm{pLER}_{1}+\mathrm{pLER}_{2}=\frac{Y_{1}}{M_{1}}+\frac{Y_{2}}{M_{2}}$ 
Where $Y_{1}, Y_{2}$ are the yields (per unit of total area of the intercrop) of species 1 and 2 in intercropping, $M_{1}, M_{2}$ are the yields of species 1 and 2 in monoculture (same as above).

\subsubsection{NFER and PFER}

Because no $\mathrm{N}$ was applied to many of the legumes in some of the selected studies, we could not compare the $\mathrm{N}$ use efficiency of sole crops and intercrops. As an alternative, we used relative indicators. In analogy with the land equivalent ratio (LER) and water equivalent ratio (WER) (Mao et al. 2012), we defined NFER and PFER as the amount of N and P fertilizer used in sole cropping to produce the same yields as obtained in intercropping.

$\mathrm{NFER}=\frac{N \text { ert }_{1} \times \frac{Y_{1}}{M_{1}}+N \text { ert }_{2} \times \frac{Y_{2}}{M_{2}}}{N \text { fert }_{\mathrm{IC}}}=$ pLER $_{1} \times \frac{N \text { ert }_{1}}{N \text { fert }_{\mathrm{IC}}}+$ pLER $_{2} \times \frac{N \text { ert }_{2}}{N \text { ert }_{\mathrm{IC}}}$

PFER $=\frac{\text { Pfert }_{1} \times \frac{Y_{1}}{M_{1}}+\text { Pfert }_{2} \times \frac{Y_{2}}{M_{2}}}{P f e r t_{\mathrm{IC}}}=$ pLER $_{1} \times \frac{\text { Pfert }_{1}}{\text { Pfert }_{\mathrm{IC}}}+$ pLER $_{2} \times \frac{\text { Pfert }_{2}}{\text { Pfert }_{\mathrm{IC}}}$

where Nfertic, Pfertic are the $\mathrm{N}$ and $\mathrm{P}$ fertilizer input per unit area (in $\mathrm{kg} \mathrm{ha}^{-1}$ ) of the intercrop (Chapter 5). Nfert 1, Pfert $_{1}$ are the $\mathrm{N}$ and $\mathrm{P}$ fertilizer input per unit area of species 1 in monoculture. Nfert $2, \mathrm{Pfert}_{2}$ are the $\mathrm{N}$ and $\mathrm{P}$ fertilizer input of species 2 in monoculture. NFER or PFER express the relative amount of $\mathrm{N}$ or $\mathrm{P}$ fertilizer that would be required if sole crops would be used to achieve the same yields as a unit area of intercrop. Values of NFER and PFER larger than 1 indicate fertilizer savings in intercropping. NFER and PFER equal to LER indicate that the nutrient use efficiency gains of intercropping are primarily due to concentrating production on less land (Xu et al. 2020). If the fertilizer amount in the intercrop is intermediate between that in sole crops, NFER and PFER will tend to be larger than LER. If the fertilizer input in the intercrop is higher than that in sole crops, NFER and PFER will tend to be smaller than LER.

\subsubsection{Temporal niche differentiation (TND)}

An index for temporal niche differentiation (TND) was used to express the proportion of the total growing period of an intercropping system that species are growing alone. TND was calculated using sowing and harvest dates of each species in the intercrop (Yu et al. 2015):

$\mathrm{TND}=\frac{P_{\text {system }}-P_{\text {overlap }}}{P_{\text {system }}}=1-\frac{P_{\text {overlap }}}{P_{\text {system }}}$

where $P_{\text {overlap }}$ represents the period of overlap between the growing periods of the intercropped species, while $P_{\text {system }}$ represents the duration of the whole intercrop from sowing of the first crop till harvest of the last crop. TND $=0$ means full overlap of two species (species are sown and harvested at the same time). TND $=1$ means no overlap, which refers to double 
cropping (the second species is sown after the first is harvested). Double cropping was not included in our analysis.

\subsubsection{Statistical analysis}

Linear regression with mixed-effects models (function lme in R package nlme) (R Core Team 2014) was used to estimate the average values of NE, observed and expected yields, N and $P$ fertilizer input, TND, LER, NFER, PFER and to compare differences in these parameters between intercrops with and without maize, and the differences in NE between intercrops with different spatial arrangements, and the relationship between NE and TND or fertilizer input. We used publication and experiment within publications as random effects to account for differences among the studies (publications) and the experiments (sites * years) within studies. A variance model (function varIdent in $\mathrm{R}$ package $n l m e$ ) was used to account for the heterogeneity of variance (Zuur et al. 2009) between intercrops with and without maize. The associations between the NE of intercrops and the variables such as N input, P input, TND, observed and expected yields, species combinations with and without maize, spatial arrangement and the origin of intercrops were furthermore visualized with principal component analysis (PCA), using the vegan package in R (Oksanen 2017).

\subsection{Results}

\subsubsection{Yield benefits of intercropping}

The overall yield gain (net effect) in intercropping was $1.5 \pm 0.1 \mathrm{Mg}^{\mathrm{a}}{ }^{-1}$ (mean \pm standard error) in this global dataset. The NE was positive in $87 \%$ of the data records (Fig. 6.2a). The yield gains differed between intercrops with or without maize and between intercrops in different spatial arrangements. The NE was $2.1 \pm 0.1 \mathrm{Mg}^{-1}$ in intercrops with maize, approximately four times as high as in intercrops without maize $\left(0.5 \pm 0.1 \mathrm{Mg} \mathrm{ha}^{-1}\right)$ (Fig. 6.2b, Fig. S6.3). When the NE was compared between intercrops with or without maize receiving $\mathrm{N}$ input less than the median value of $75 \mathrm{~kg} \mathrm{~N} \mathrm{ha}^{-1}$ in the dataset, or at least this amount, the overall effect of $\mathrm{N}$ input was non-significant $(P=0.32)$, but there was a significant interaction $(P=0.01)$, indicating contrasting responses to $\mathrm{N}$ input in intercrops with or without maize (Fig. 6.2b). The NEs were similar in strip and alternate-row intercrops (1.5 \pm 0.1 and $1.4 \pm 0.1$ $\mathrm{Mg} \mathrm{ha}^{-1}$, respectively, Fig. 6.2c), but the NEs were significantly greater in these two spatial arrangements than in fully mixed intercrops $\left(1.0 \pm 0.2 \mathrm{Mg} \mathrm{ha}^{-1}\right)$. The spatial arrangement effects were confounded with those of the maize presence and the fertilizer input and the use of relay intercropping. 


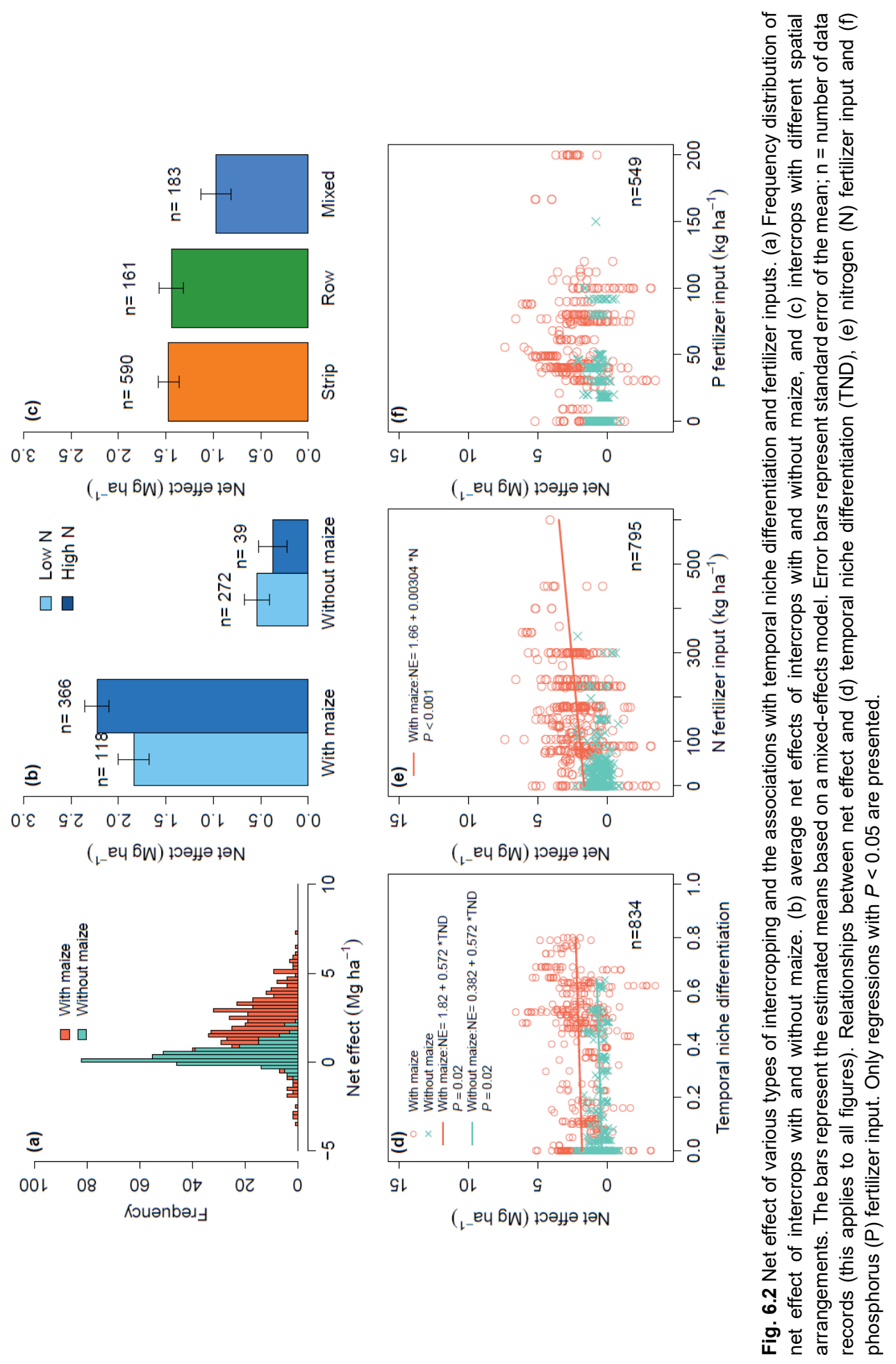


We used an index for TND to characterize complementarity in growing period between the intercropped species. TND quantifies the total period of non-overlap as a proportion of the total growing period of the two species on a scale of 0 (simultaneous growth) to 1 (the first species is harvested before the second is sown(Yu et al. 2015)). The NE increased $0.6 \pm 0.2 \mathrm{Mg}$ ha $^{-1}$ per unit of TND $(P=0.02$, Fig. 6.2d) in both intercrops with and without maize. The NE of intercrops with maize increased $3.0 \pm 0.5 \mathrm{~kg} \mathrm{ha}^{-1}$ per $\mathrm{kg}$ of $\mathrm{N}$ fertilizer per ha, but the NE of intercrops without maize was independent of $\mathrm{N}$ fertilizer input. There was no response of the NE to $P$ fertilizer input, irrespective of whether maize was included in the intercrop or not.

\subsubsection{Temporal and spatial arrangements, fertilizer inputs and species selection in different intercropping systems}

TND was significantly larger $(P<0.001)$ in intercrops with maize $(0.3 \pm 0.03)$ than in intercrops without maize $(0.1 \pm 0.03$; Fig. 6.3 a) $)$ i.e., the relative co-growth period of crop species was shorter in intercropping systems with maize than in systems without maize.

Nitrogen fertilizer input was three times as high in intercrops with maize (155 $\left.\pm 10 \mathrm{~kg} \mathrm{ha}^{-1}\right)$ as in intercrops without maize $\left(46 \pm 10 \mathrm{~kg} \mathrm{ha}^{-1}\right)$ (Fig. 6.3b; $\left.P<0.001\right)$. The $\mathrm{P}$ fertilizer rate was similar in intercrops with and without maize $(P=0.08$, Fig. $6.3 \mathrm{~b})$.

The observed yield of intercrops with maize $\left(8.9 \pm 0.3 \mathrm{Mg} \mathrm{ha}^{-1}\right)$ was $5.5 \mathrm{Mg}^{-1}$ higher $(P<$ 0.001 ) than the observed yield of intercrops without maize (3.4 $\pm 0.3 \mathrm{Mg} \mathrm{ha}^{-1}$, Fig. 6.3c). The expected yield (calculated as the product of monoculture yield and land share of component species in intercropping) of intercrops with maize $\left(6.7 \pm 0.2 \mathrm{Mg} \mathrm{ha}^{-1}\right)$ was $3.7 \mathrm{Mg} \mathrm{ha}^{-1}$ higher than the expected yield of intercrops without maize $\left(3.0 \pm 0.2 \mathrm{Mg}^{-1}\right.$, Fig. 6.3c). 

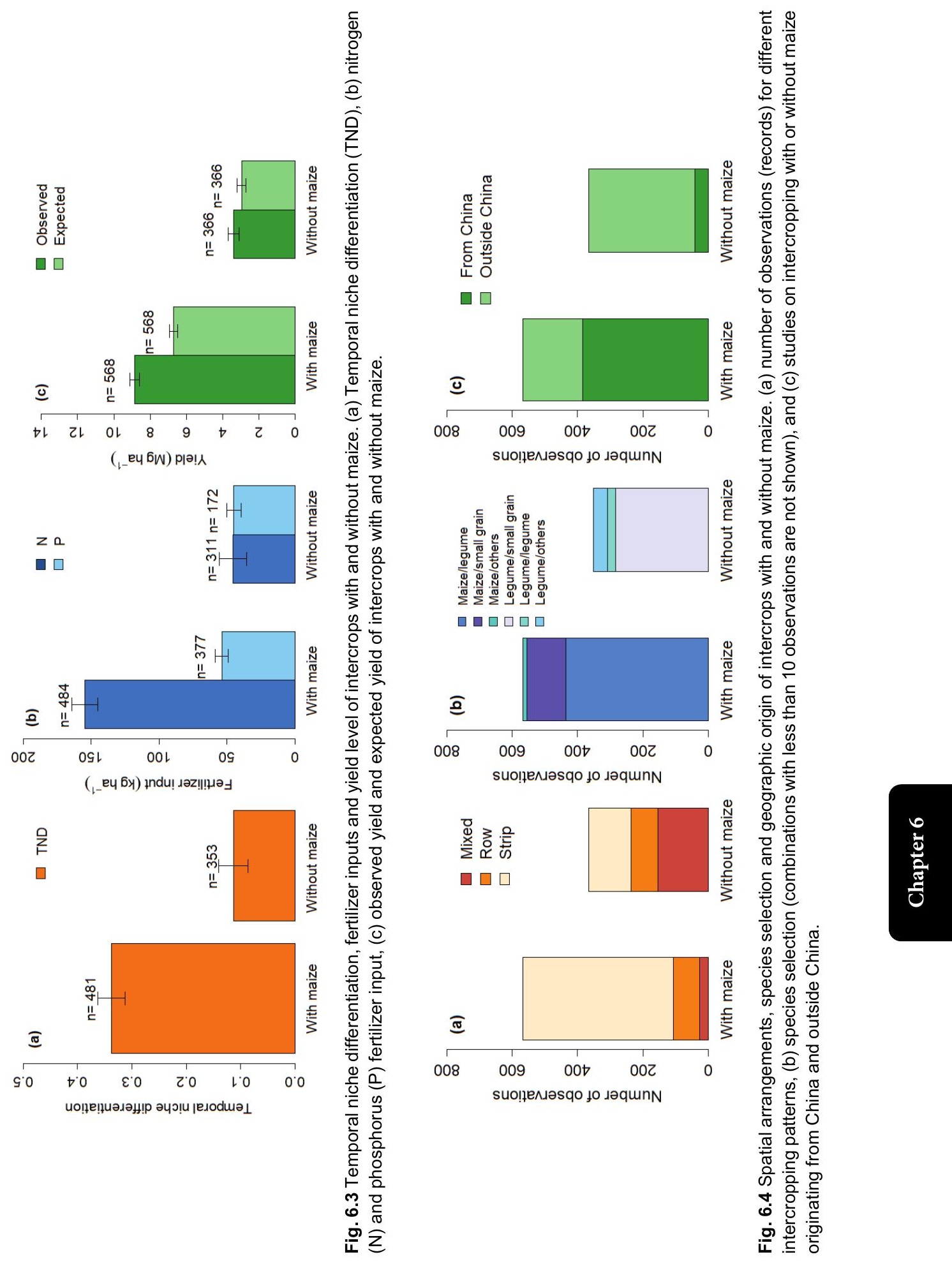
There were marked differences in spatial arrangement and companion species between intercropping systems with and without maize. Most of the intercrops with maize were arranged in strips (461 out of 568 records, Fig. 6.4a), and much fewer records represented intercrops with maize grown in alternate rows (79 out of 568) or fully mixed with the companion species (28 out of 568). Of the intercrops without maize, 155 of 366 records were mixed intercropping, 82 records were alternate-row intercropping and 129 records were strip intercropping (Fig. 6.4a). Legumes such as pea (Pisum sativum), faba bean (Vicia faba), soybean, and peanut (Arachis hypogaea), were the most common companion species in intercrops with maize (436 records, Fig. 6.4b, Table S6.1). There was also a substantial number of observations (120 records) on maize intercropped with small grains, e.g., wheat or barley (Hordeum vulgare) (Fig. S6.2). Intercrops without maize were dominated by legume-based intercrops (352 out of 366 records, Fig. 6.4b), e.g., mixtures of legumes with small grains (wheat, barley, oats (Avena sativa), rice (Oryza sativa), 284 records), another legume species (25 records), or another species (43 records), e.g., oilseed rape (Brassica napus) or sesame (Sesamum indicum). Only 14 records of intercrops without maize included a non-legume species (Table S6.1).

On a total of 426 records originating from China 384 records concerned intercropping with maize, whereas a smaller proportion of records originating from studies outside China (184 out of 508 records) concerned intercropping with maize (Fig. 6.4c). A majority of data records (324 out of 508 records) originating from studies outside China concerned intercropping without maize. These studies originated from Europe (44\%), Asia (32\%) and Africa (17\%) (Fig. S6.4). 


\subsubsection{Syndromes of crop production in intercropping}

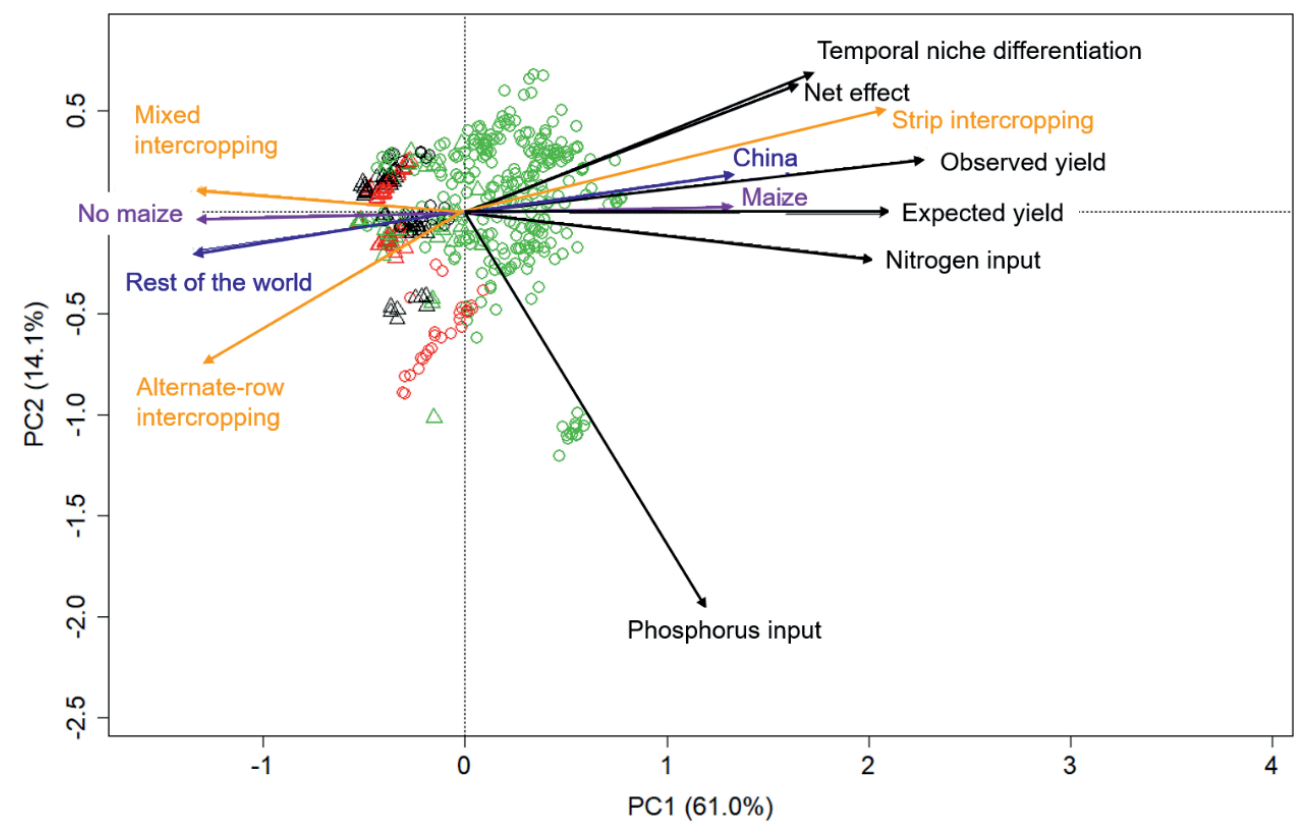

Fig. 6.5 Principal component analysis of associations between yield gain and intercropping design and management. Symbols represent mixed intercropping with maize (black circles) or without maize (black triangles), alternate-row intercropping with maize (red circles) or without maize (red triangles), and strip intercropping with maize (green circles) or without maize (green triangles). Arrows represent continuous variables (black) and categorical variables (colored). Factor loadings are given in Table S6.2.

Results of principal component analysis illustrate the existence of two contrasting syndromes of production in intercropping (Fig. 6.5). On the one hand, there are systems with maize with high yield levels, high $\mathrm{N}$ input, and strip intercropping with temporal niche differentiation (high loadings on principal component 1 (PC1), Table S6.2). On the other hand, there are systems without maize with substantially lower yield levels, lower $\mathrm{N}$ input, and often in simultaneous alternate-row or mixed intercropping. Studies representing the high yield intercropping syndrome with maize mostly originated from China while studies representing the lower yield intercropping syndrome without maize mostly originated outside China. 


\subsubsection{Both low and high yield intercropping strategies save land and fertilizer}

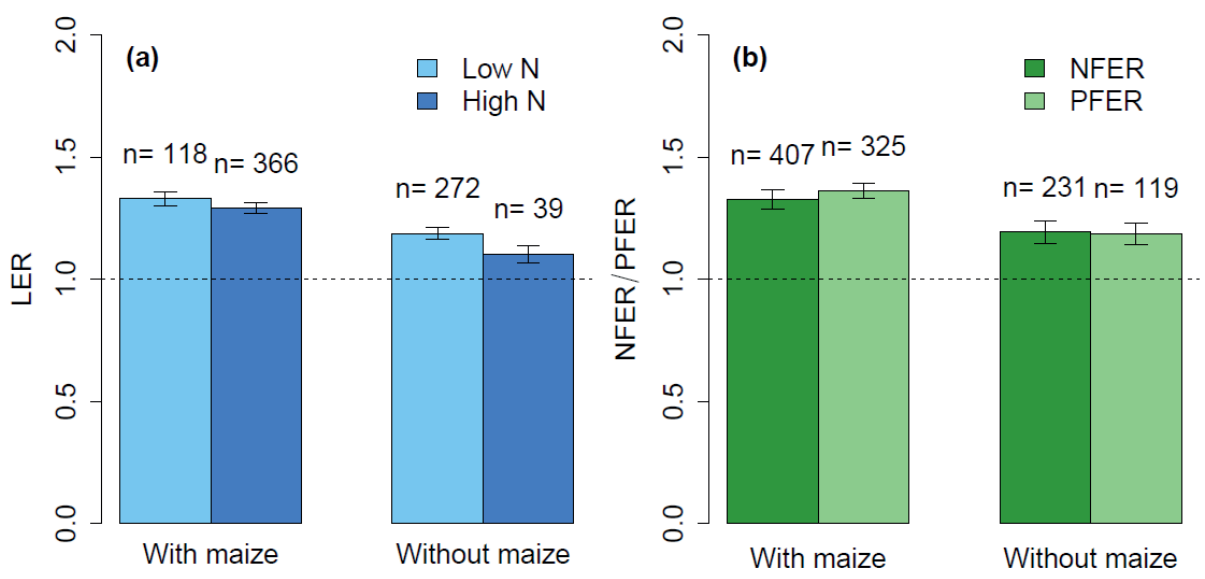

Fig. 6.6 Land and fertilizer savings of intercropping. (a) Land equivalent ratio (LER) and (b) nitrogen fertilizer equivalent ratio (NFER) and phosphorus fertilizer equivalent ratio (PFER) of intercrops with and without maize. The dashed lines represent LER (or NFER, PFER) equal to 1.

Relative metrics, LER, NFER, and PFER, were calculated to characterize the relative use efficiency of land (LER), N fertilizer (NFER) and P fertilizer (PFER) in intercropping. The LERs of intercrops with and without maize were both significantly larger than 1, but the LER of intercrops with maize $(1.29 \pm 0.02)$ was significantly greater than the LER of intercrops without maize $(1.16 \pm 0.02)(P<0.001$, Fig. 6.6a, Fig. S6.5). Averaged over levels of $N$ input, the land savings in intercrops with maize were $13 \%$ larger than in intercrops without maize. When $\mathrm{N}$ input was added as a categorical variable in this analysis, the effect of maize presence was still highly significant, but in addition there was a small but significant decrease of LER (by $0.05 \pm 0.02$ units, $P=0.004$ ) with higher $\mathrm{N}$ input. There was no significant interaction between $\mathrm{N}$ input and maize presence $(P=0.23)$ (Fig. 6.6a).

The NFER and PFER indicate the ratio of the fertilizer amounts used in sole cropping to the fertilizer used under intercropping to produce equal amounts of yield. The NFERs of intercrops with and without maize were $1.33 \pm 0.04$ and $1.19 \pm 0.05$, respectively (Fig. 6.6b). So, to achieve the same yield as intercrops, the sole crops used 19-33\% more $\mathrm{N}$ fertilizer than the intercrop, indicating increased $\mathrm{N}$ use efficiency in intercropping if nutrient use efficiency is expressed as fertilizer used per unit yield produced. The NFER of intercrops with maize was higher $(P=0.01)$ than that of intercrops without maize, indicating that intercrops with maize save more $\mathrm{N}$ fertilizer as compared to sole crops than intercrops without maize. Similarly, the PFER of intercrops with maize $(1.36 \pm 0.03)$ was larger than the PFER of intercrops without 
maize $(1.19 \pm 0.04)(P<0.001$, Fig. $6.6 \mathrm{~b})$, indicating that, while both types of intercrops save $\mathrm{P}$ fertilizer compared to sole crops, the savings are greater in intercrops with maize than in intercrops without maize.

\subsection{Discussion}

This paper presents a previously undescribed dichotomy in strategies for intercropping that could be regarded as two syndromes of production (Andow and Hidaka 1989; Vandermeer 1997). These different strategies have likely been developed to address different production objectives. On the one hand, systems with maize, commonly used in China, represent a strategy of intercropping based on high inputs, high outputs, and a comparatively large intercropping advantage in terms of absolute yields per hectare. These systems are based on strip intercropping with narrow strips (usually in the order of 1-2 m wide), and a relay sequence in the sowing and harvesting of the intercropped species. Due to this relay sequence, the total duration of the intercropping system exceeds that of both component crops, providing opportunity for increased capture of light, water and nutrient resources, and limiting the period of co-growth, during which species compete for resources. These relay systems obtain the greatest possible grain yield under land and resource constraints (Li et al. 2001b; Gou et al. 2017; Hong et al. 2019).

On the other hand, systems without maize were often cultivated with low inputs, and they had substantially lower intercropping benefits in terms of absolute yield per hectare. These intercropping systems were usually grown as simultaneous intercrops, with simultaneous sowing and harvesting of the two species, and with the species grown most often in alternate rows or completely mixed, but rarely in strips. These systems without maize aimed to develop an agricultural system that exploits species complementarities to drastically lower inputs, but they had lower outputs than the systems with maize. Due to the simultaneous sowing and harvesting, these systems are easier to mechanize than systems with maize that are usually relay systems. Furthermore, due to the lower inputs, these systems without maize are expected to have lower nutrient losses per hectare than systems managed according to the high yield syndrome.

Land and fertilizer equivalent ratios were well above one (in the range of 1.16 to 1.36) in both syndromes of production, indicating that compared to sole crops, both strategies of intercropping resulted in considerable savings of land and nutrient resources. The relative efficiencies of intercrops as compared to sole crops (LER, NFER, PFER) were greater in the case of the high input-high output syndrome than in the case of the low input-low output syndrome, leading to the unexpected finding that the benefits of diversifying agriculture are at least as high under high input as under low input conditions. 
Large intercropping benefits in production systems with high inputs contrast with the established opinion that the stress gradient hypothesis is a key explanation for intercropping benefits (Brooker et al. 2015). This hypothesis is based on the idea that under stressful conditions, facilitative and complementary species traits support the functioning of mixtures. While there is no doubt that this hypothesis explains many cases of overyielding in intercrops at low input levels, the current analysis shows that benefits may be even greater if stresses are relieved, and intercropping is exploited to enhance resource capture and mitigate nutrient losses at higher input levels. The findings show that intercropping can be adapted to both low input and high input agriculture, based on different production situations and socio-economic conditions with associated constraints and objectives, resulting in two syndromes characterized by a coordinated set of management practices.

In this analysis, we cannot disentangle the effect of maize from the effects of strip intercropping, relay intercropping or nutrient inputs. Most of the maize intercrops were tall/short combinations, so intercrops were often sown in strips to reduce interspecific competition for light ( $\mathrm{Li}$ et al. 2001b; Liu et al. 2018) and to permit management by hand in smallholder farming. Maize is better adapted to high temperatures than C3 species, which makes a $\mathrm{C} 3 / \mathrm{C} 4$ mixture amenable to temporal niche differentiation between component species. The spatial and temporal niche differentiation and the differences in plant height, photosynthesis mechanisms (Anten and Hirose 2003), rooting patterns and phenology (Anten and Hirose 1999) between maize and C3 species allow complementary use of light, water and nutrient resources in intercropping. Legume-based intercrops were especially favored in low-input (organic) agriculture to compensate for low external input and make use of biological $\mathrm{N}_{2}$ fixation by legumes to maintain yield (Fujita et al. 1992; Voisin et al. 2014).

The existence of these syndromes of production suggests different production orientation in different regions: high yield and high land use efficiency in China, and reduced inputs and low nutrient emissions outside China. In China, to achieve stable food supply with limited land and resources, Chinese farmers developed and practiced intercropping for thousands of years (Knörzer et al. 2009). However, to maximize grain yields, fertilizer inputs have been strongly increased over the last decades in most regions in China (Knörzer et al. 2009; Du et al. 2018), contrasting with traditional and circular patterns of low input and low output (Li et al. 2013). Tightened environmental policies may reduce inputs in China in the future, both in intercropping and sole crops, in order to diminish nutrient losses per hectare (Ju et al. 2009).

The high NFER and PFER of intercropping indicate that 19\% (without maize) to 35\% (with maize) reduction in total fertilizer input may be achieved in intercropping as compared to sole crops while achieving the same amount of product output. The lower input of nutrients required per unit product in intercropping provides the potential to save fertilizer $(\mathrm{Xu}$ et al. 
2020) and reduce losses to the environment (Whitmore and Schröder 2007; Li et al. 2011a) compared to monocultures that receive high inputs in China (Ju et al. 2009). Nevertheless, despite the greater NFER and PFER (relative input per unit product), the high input-high output syndrome may still have higher nutrient emissions per hectare than the low input-low output syndrome. Further research is needed to assess the environmental benefits of the high-input intercropping strategy as compared to sole cropping or reduced-input intercropping. Possibly, may be found between the low and high input strategy, combining strengths of both strategies, but this will require a further analysis of trade-offs.

Intercropping is not currently a part of modern industrialized high-input and high-yield agriculture in western nations. However, intercropping is gaining increasing interest in the context of sustainable agriculture in the west and innovative farmers are experimenting with it, often using legumes to reduce fertilizer inputs. Legume-based intercrops are in organic farming to produce high-quality grain and forage at low $\mathrm{N}$ input (Bedoussac et al. 2015), to reduce nitrate leaching (Whitmore and Schröder 2007), and improve overall resilience by reducing pest and disease incidence (Trenbath 1993), weed pressure (Liebman and Dyck 1993), and risk of crop failure associated with drought or erratic rainfall (Rusinamhodzi et al. 2012). Those intercrops are mostly fully-mixed to adapt to sowing and harvesting with machinery in the countries with a high level of mechanization (Bedoussac et al. 2015). Mixed intercropping is also practiced by smallholder farmers in shifting cultivation systems with limited use of fertilizer and machinery (Vandermeer 1989; Rusinamhodzi et al. 2012). Combining traits of both syndromes of production in intercropping may enable high food production with lower environmental footprint than is realized in the currently existing high input-high output syndrome.

Our study suggests that intercropping strategies with maize provide an opportunity to design intercropping systems with large temporal niche differentiation to adapt to extended growing seasons and higher temperatures due to global warming (Menzel and Fabian 1999; Peñuelas and Filella 2001). Furthermore, the temporal arrangement in relay strip intercropping allows better timing of fertilizer application to save fertilizer input. For instance, reduced $\mathrm{N}$ fertilizer input at early co-growth stage in maize/pea intercropping improves $\mathrm{N}_{2}$ fixation of intercropped pea, and $\mathrm{N}$ fertilization at late co-growth stage increases the recovery growth of intercropped maize (Hu et al. 2016; Hu et al. 2017). The relatively high and stable crop productivity and economic benefits of intercropping are attractive to farmers (Ngwira et al. 2012; Pelzer et al. 2012; Viguier et al. 2018). However, management of two crops in one field is more complex than that of a single crop, and markets may require high purity standards for harvested product that may be difficult to achieve if crops are harvested simultaneously with existing machinery (Bedoussac et al. 2015; Viguier et al. 2018). Strip relay 
intercropping may be a greater challenge for mechanization than simultaneous intercropping. Limited work on these challenges has been done, and work is currently ongoing to overcome these challenges (Du et al. 2018; Iqbal et al. 2018) and make mechanized intercropping possible (Fletcher et al. 2017). The remarkable advantages of intercropping, and the possibility to apply intercropping under high yield conditions, as shown here, should provide the incentive for stakeholders and policy makers to work on solving current constraints, and introduce much needed diversity in agricultural systems (Tilman et al. 2001; Tilman et al. 2002; Wezel et al. 2014).

The current analysis did not consider water use in intercropping. In many production situations with high inputs and outputs, irrigation water is used. Relay intercropping increases the length of the growing season and thus increases total crop evaporation (Tan et al. 2020a). Therefore, intercrops need greater amount of irrigation water than sole crops (Yang et al. 2011). Nevertheless, previous work has shown that the increased water consumption in intercropping systems is more than offset by higher productivity, such that the overall effect of intercropping is still an increase in water use efficiency, calculated per unit product, when compared to sole crops (Mao et al. 2012; Chai et al. 2014; Tan et al. 2020a). We did not include water use efficiency in the current analysis, because the literature searches were not tailored to this. New systematic literature review and data retrieval is needed to analyze the worldwide water footprint of intercropping. Based on current knowledge, the likely outcome is that the high water use efficiency of intercropping can help to alleviate water constraints in agriculture (Stomph et al. 2020). This is primarily due to species complementarities with respect to the location (soil depth) and timing (during the season) of water extraction (Yang et al. 2011; Mao et al. 2012).

In conclusion, this meta-analysis presents two diverging syndromes of agricultural production by intercropping and suggests that these allow harvesting $16 \%$ to $29 \%$ more grain per hectare while using $19 \%$ to $36 \%$ less fertilizer per unit output than conventionally done in the monocrops of modern industrialized agriculture. Higher yield and lower inputs might mean greater profit to farmers (Ngwira et al. 2012; Pelzer et al. 2012; Viguier et al. 2018), lowered environmental impacts (Whitmore and Schröder 2007; Pelzer et al. 2012) and a more stable and secure food supply (Rusinamhodzi et al. 2012; Raseduzzaman and Jensen 2017). This meta-analysis shows how these advantages may be realized by intercropping in both high and low input agriculture. Therefore, intercropping provides an important principle for advancing the sustainable intensification of agriculture. 


\section{Acknowledgements}

The authors gratefully acknowledge funding from Chinese National Basic Research Program (2015CB150400), and National Key R\&D Program of China (grant number: 2017YFD0200200/2017YFD0200207). The financial support of the Wageningen University Sandwich Scholarship is gratefully acknowledged. The authors acknowledge funding from the European Union's Horizon 2020 Programme for Research \& Innovation under grant agreement n`727217 (www.remix-intercrops.eu)" 

Chapter 7 General discussion 


\subsection{Main questions and main findings of this thesis}

Species diversity tends to increase the productivity of natural ecosystems (Tilman et al. 2014). In agricultural ecosystems, intercropping (i.e., cultivation of two or more crop species on the same field) is more productive than sole crop cultivation (Willey 1979; Vandermeer 1989; Zhang and Li 2003). Previous studies showed that intercropping increases productivity on low phosphorus (P) soils (Li et al. 2007; Mei et al. 2012; Latati et al. 2016). The ecological mechanisms underlying these benefits mainly include complementarity and facilitation with respect to resource acquisition (Fridley 2001; Li et al. 2014; Xue et al. 2016). Complementarity refers to a decrease in competition through resource partitioning (e.g., temporal, spatial and chemical partitioning of resources) (Fridley 2001). In intercropping systems, facilitation involves belowground processes where a nutrient-mobilizing species increases the nutrient availability both for itself and for its non-mobilizing companion (Li et al. 2014). Competition can also produce overyielding in some cases, as strong competitors will tend to overyield in mixtures and weak competitors will tend to underyield (Atwater and Callaway 2015).

Species have developed various $\mathrm{P}$ mobilizing strategies (e.g., root exudates) to access sparingly soluble organic or inorganic P (Vance et al. 2003). Different plant strategies, reflecting variations in plant functional traits, are commonly hypothesized to underlie reduced competition through resource partitioning and to promote complementarity and facilitation with respect to resource use (Fridley 2001). A well-demonstrated example is resource partitioning for nitrogen $(\mathrm{N})$ between legumes and other plant species, where both species compete for soil N, but only legumes can fix N2 (Hauggaard-Nielsen and Jensen 2001; Corre-Hellou et al. 2006; Kahmen et al. 2006). Resource partitioning for P has also been hypothesized to occur. Turner (2008) hypothesized that partitioning for different forms of soil organic P would alleviate competition for P among plant species. Hinsinger (2011) extended this hypothesis to intercropping systems, in which two component species would tap into distinct soil P pools. However, there is a shortage of empirical evidence for this hypothesis.

The land equivalent ratio (LER) is a commonly used index to assess yield advantages of intercrops. It is numerically the same as the relative yield total (RYT; De Wit (1960)). From previous meta-analyses, LER of intercropping averages $1.22 \pm 0.02$ (Yu et al. 2015) or $1.30 \pm$ 0.01 (Martin-Guay et al. 2018), depending on the selected studies. A value of LER larger than one means intercrops save land compared to sole crops. However, the LER is a dimensionless indicator and does not provide information on the absolute yield increase of intercrops. Loreau and Hector (2001) proposed additive partitioning as a statistical method to analyze productivity benefits in plant species mixtures. This method defines the net effect (NE) as the difference in yield or biomass between the mixture and the (weighted) average of the sole crops, and partitions the NE into two components: a complementarity effect (CE) and a 
selection effect (SE). The CE is the overall gain in relative yield in a mixture (RYT-1) multiplied by the average yield or biomass of the sole crops (Loreau and Hector 2001). The SE measures the association between sole crop yield of species and their change in relative yield in the mixture (Loreau and Hector 2001). It is a measure for how much of the yield gain is due to overyielding of component species with high versus low sole crop yield. No meta-analysis has been done to quantify the yield gain (NE) of intercrops and to determine the drivers of yield gain (CE, SE), and the effects of management on yield gain.

Based on the above, this thesis aimed to answer the following questions:

- Does dissimilarity in species' capabilities to access different P sources lead to enhanced P uptake and yield of intercrops;

- How large is the absolute yield gain of intercrops and what are the drivers of yield gain;

- How do agronomic practices (e.g., selection of species, temporal and spatial arrangement, and fertilizer input) impact species interactions and yield gain of intercrops?

To answer the above questions, I conducted empirical studies and meta-analyses. In the empirical studies, I tested for complementarity in $\mathrm{P}$ acquisition from different sources in species mixtures based on the hypothesis of resource partitioning for P (Turner 2008; Hinsinger et al. 2011) in pot experiments with quartz sand (an inert substrate) and soil (Chapters 2 and 3). Then, I determined the role of complementarity in P acquisition from different sources in overyielding by intercropping in the field (Chapter 4 ). In the empirical studies, complementarity and facilitation with respect to P uptake represent the mechanisms, i.e., complementarity in $\mathrm{P}$ acquisition from different sources and facilitation of $\mathrm{P}$ uptake involving root exudates and potentially mobilized $\mathrm{P}$ sources taken up by species mixture. Many field studies on intercropping for grain production have been done in China over the past thirty years. This has resulted in ample data on intercropping from China. In the first meta-analysis, I quantified the absolute yield gain (NE) and the drivers of yield gain (CE, SE) of Chinese grain intercrops with the additive partitioning method (Loreau and Hector 2001) (Chapter 5). Subsequently I investigated how agronomic practices affect species interactions and yield gain of intercrops on a global scale (Chapter 6). The complementarity effect and selection effect are mathematical derivations, which represent the outcomes of species interactions in intercrops. The main findings are as follows.

Chapters 2 and 3: There was slight evidence for complementarity in $P$ acquisition from different sources in pot experiments with quartz sand but not with soil. In the pot experiments, dissimilarity in species' capabilities to access different $P$ sources was not essential to achieve greater $P$ uptake in a species mixture compared to monocultures. Species dominance led to increased P acquisition by species mixtures, even if species' abilities to access $P$ sources were similar. 
Chapter 4: In the field experiment, complementarity in or facilitation of P uptake was not the main driver for overyielding by a relay strip intercropping.

- Chapter 2 provided an experimental test for the P resource partitioning hypothesis, which assumes that dissimilarity in $\mathrm{P}$ acquisition from different $\mathrm{P}$ sources among species leads to enhanced $\mathrm{P}$ uptake by species mixtures compared to their sole species. Two pot experiments with quartz sand were conducted. Experiment 1 tested for the capabilities of twelve species to access the sparingly soluble calcium-bound $\mathrm{P}(\mathrm{CaP})$, phytate $\mathrm{P}(\mathrm{PhyP})$ and P-coated Fe(hydr)oxide (FeP). Species combinations with dissimilar (millet/chickpea; cabbage/faba bean) and similar traits (wheat/maize) were selected for Experiment 2. Complementarity in $\mathrm{P}$ acquisition from different sources was confirmed in a millet/chickpea combination: there was enhanced $\mathrm{P}$ uptake by this species mixture on mixed $\mathrm{CaP}$ and PhyP compared to the average $\mathrm{P}$ uptake by this species mixture on sole $\mathrm{P}$ sources. There was no enhanced $\mathrm{P}$ uptake by cabbage/faba bean combination, because their abilities to access PhyP and FeP were similar in Experiment 2, which was not consistent with the results of Experiment 1. Furthermore, there was increased P uptake in wheat/maize mixture despite similar abilities of these two species to access $\mathrm{CaP}$ and PhyP. In this mixture, the increase of $\mathrm{P}$ acquisition of wheat was larger than the decrease of $\mathrm{P}$ acquisition of maize. The results suggest differences in $\mathrm{P}$ uptake traits were not required to achieve greater than expected $P$ uptake by a species mixture.

- With the same species combinations in Chapter 2, Chapter 3 presented a pot experiment with low P soils containing a mixture of organic and inorganic P sources. Moreover, in Chapter 3, I provided a modified framework based on Hinsinger's framework of competition, facilitation, and complementarity. This framework highlights competition for ortho-P (the only P form that is available for uptake by plants) in species mixtures. It describes the mechanisms involving root exudates and potentially mobilized $\mathrm{P}$ sources and the outcomes (species' $\mathrm{P}$ uptake and biomass) depending on species' competitive ability to acquire P. Facilitation of $\mathrm{P}$ uptake by millet was observed but without overyielding of $\mathrm{P}$ uptake by millet/chickpea mixture. No complementarity in acquiring $\mathrm{P}$ from different sources was found in the other species mixtures. Similar to the results of Chapter 2, increased P uptake was observed in wheat/maize mixtures compared to the average $\mathrm{P}$ uptake by sole species. The results provide no evidence for the hypothesis on complementarity in $\mathrm{P}$ acquisition from different sources in the soil.

- Based on the above selection of species combination and the corresponding mixed P sources, Chapter 4 tested the complementarity in P acquisition from different sources on a low $\mathrm{P}$ soil under field conditions. Millet and chickpea showed differences in phosphatase activities and carboxylates in the rhizosphere during the co-growth period, but $\mathrm{P}$ uptake by plants was similar in different rows in intercropping strips. There was increased $\mathrm{P}$ 
uptake in intercropping compared to the expected P uptake, based on sole crops at a low P level, but the extra P uptake was not associated with yield increase. At a high P level, there was a yield increase of intercrops even though the $\mathrm{P}$ limitation was relieved by applying $\mathrm{P}$ fertilizer, demonstrating the relevance of other mechanisms than complementarity in $\mathrm{P}$ acquisition from different sources.

Chapter 5: From the meta-analysis, yield gain of intercrops in field studies was mainly due to the complementarity effect, an outcome of any mechanism reducing competition; The underlying drivers of yield gain were related to the presence of maize and temporal complementarity in resource acquisition, and there was no strong evidence for the selection effect.

- Chapter 5 presented a meta-analysis on the field studies on intercropping conducted in China. The total yield in intercrops exceeded the expected yield, estimated based on sole crop yields, by $2.14 \pm 0.16 \mathrm{Mg} \mathrm{ha}^{-1}$. Ninety percent of this yield gain was due to a positive complementarity effect (CE) while the remaining $10 \%$ was due to selection effect (SE). The $\mathrm{CE}$ increased and the SE decreased with temporal niche differentiation, which is the proportion of the total growing period of the crop mixture during which species grow alone. Inclusion of maize in the intercrop was a key factor contributing to yield gain, but intercrops with or without legumes had similar yield gains. Intercrops without legumes responded to $\mathrm{N}$ input with greater yield gain, $\mathrm{CE}$ and $\mathrm{SE}$, but the yield gain, $\mathrm{CE}$ and $\mathrm{SE}$ of intercrops with legumes did not respond to $\mathrm{N}$ input. Yield gain, $\mathrm{CE}$ and $\mathrm{SE}$ of intercrops were independent of $P$ fertilizer input.

Chapter 6: On a global level, there was a set of management factors rather than a single factor that drove the yield gain of intercrops, resulting in two contrasting syndromes of production in intercropping.

- Chapter 6 showed a previously undescribed dichotomy in intercropping systems that could be regarded as two syndromes of production, i.e., a two coherent sets of management factors aiming at optimal performance under certain production objectives and constraints. On the one hand, systems with maize, commonly practiced in China, represented a strategy of intercropping based on high inputs, high outputs, and a comparatively large intercropping advantage in terms of absolute yields per hectare. These systems were based on strip intercropping with narrow strips (usually in the order of 1-2 m wide), and a relay sequence in the sowing and harvesting of the intercropped species. On the other hand, systems without maize were often cultivated with low inputs and had substantially lower absolute yield gain per hectare. These intercropping systems were usually grown and harvested simultaneously, and often in alternate rows or completely mixed. Both the low and high yield intercropping strategies saved 16-29\% land and $19-36 \%$ fertilizer compared to their monocultures. 


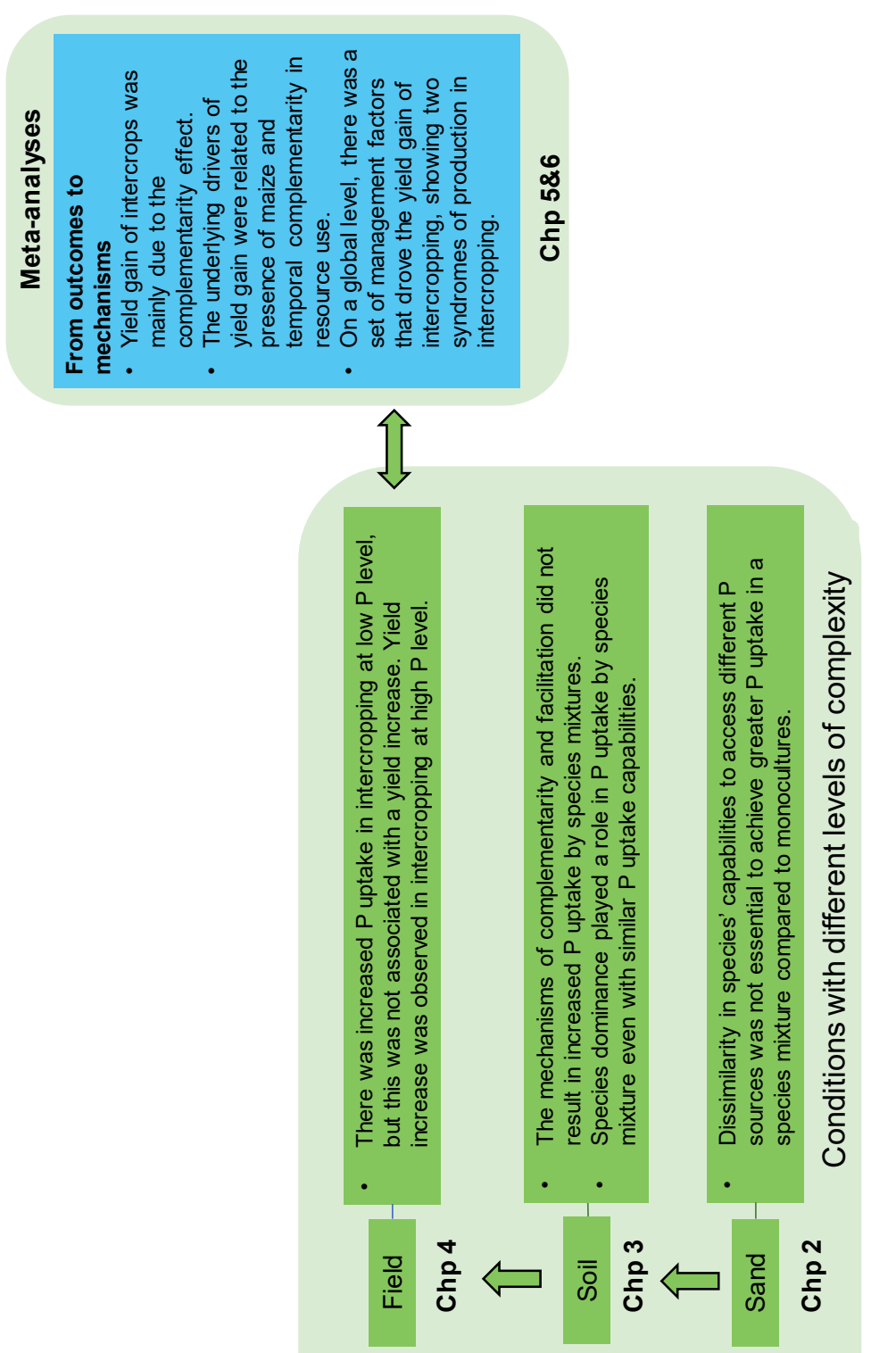

资

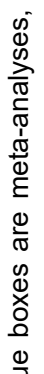

응

竞

을

(1)

कั

ब

ญ

O

$\frac{\dot{\omega}}{w}$

올

.

은

㐫

ర్

4

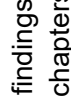

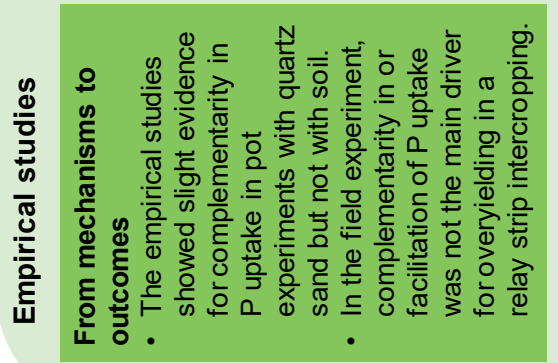

들

ह

$\stackrel{0}{ \pm}$

党点

๖े

ร.

운 흔 
In this chapter, I will discuss the main findings of this thesis (Fig. 7.1) in a broader context and discuss how the findings can improve our understanding of species interactions, contribute to the productivity of intercropping, and suggest for designing intercropping systems.

\subsection{Does dissimilarity in species $\mathbf{P}$ uptake traits lead to enhanced $\mathbf{P}$ uptake and yield of intercrops?}

\subsubsection{There was no evidence for complementarity in $P$ acquisition from different sources by species mixtures in soil in both pot and field experiments}

To test for Turner's and Hinsinger's hypotheses (i.e., dissimilarity in $\mathrm{P}$ acquisition from different $\mathrm{P}$ sources among species leads to enhanced $\mathrm{P}$ uptake by species mixtures compared to their sole species), four criteria should be fulfilled within the experimental design (Chapter 2): 1) $\mathrm{P}$ is the unique limiting factor for plant growth; 2) the species have different capabilities to access different $\mathrm{P}$ sources (trait dissimilarity); 3) there is overyielding by the species combination, i.e., the total $\mathrm{P}$ uptake by the plant species combination is higher than the mean P uptake by the sole species; 4 ) there is overyielding by the plant species combination on the mixed P sources compared to the single P sources, i.e., the total P uptake by the plant species combination from the mixed $\mathrm{P}$ sources is higher than the mean P uptake from the two single $\mathrm{P}$ sources. The overyielding by species mixture on sole P sources or mixed P sources (criterion 3) can be due to any interaction in the species mixture, including complementarity in time of $\mathrm{P}$ acquisition and location of $\mathrm{P}$ uptake, complementarity in $\mathrm{P}$ pools, facilitation of $\mathrm{P}$ uptake. Thus the criterion 3 does not provide sufficient evidence for complementarity in $\mathrm{P}$ acquisition from different sources. A comparison of species mixtures on both single and mixed P sources (criterion 4) is the ultimate test and provides conclusive evidence for complementarity in $\mathrm{P}$ acquisition from different sources in species mixture. Soils always contain a mixture of multiple P sources, so to separate the addition of pure sole P source, pot experiments were conducted with quartz sand. Quartz sand is an inert substrate with no interaction (adsorption, desorption, precipitation) between $\mathrm{P}$ sources and the mineral matrix. There are nine treatments needed for each species combination in the experimental design (Chapter 2), i.e., each sole crop species and their mixture were grown on each sole $\mathrm{P}$ source and a mixture of two P sources.

The design in Chapter 2 avoided some problems of previous studies that claimed to confirm the resource partitioning for $\mathrm{P}$. Some studies investigated species' performance in monoculture but not in mixture on sole P source compared to that on the mixed P sources (Steidinger et al. 2015; Ceulemans et al. 2017). Phoenix et al. (2020) compared P uptake by species mixture and monocultures on different sole P sources but there were no treatments of mixed P sources. These studies therefore only provided the conditions but no conclusive 
evidence for complementarity in $\mathrm{P}$ uptake from different sources by species mixture. Ahmad-Ramli et al. (2013) compared both sole species and species mixture on sole and mixed P sources, however, the experimental condition was not P-limited. An alternative method to demonstrate complementarity in $\mathrm{P}$ acquisition from different sources is investigating the depletion of different $\mathrm{P}$ pools by species mixtures. For instance, $\mathrm{Cu}$ et al. (2005) reported that sole white lupin selectively depleted the citric acid leachable $\mathrm{P}$ and wheat depleted water-leachable P, whereas their mixtures depleted both P pools. However, white lupin did not take up any $\mathrm{P}$ from the substrate, because the total $\mathrm{P}$ content of lupin was less than the seed P. This reasoning also applies to another pot study by Li et al. (2008), who investigated the depletion of soil $\mathrm{P}$ fractions by sole common bean, sole durum wheat, and their mixtures and demonstrated significant differences in various soil $\mathrm{P}$ pools after plant growth. However, only the biomass but not the P uptake by mixed wheat was increased compared to sole wheat, which could be due to $\mathrm{P}$ dilution effects rather than tapping into different $\mathrm{P}$ pools.

With the design in Chapter 2, however, complementarity in $\mathrm{P}$ acquisition from different sources was observed in only one of the tested species combinations. Millet/chickpea mixture increased P uptake from the mixed P sources compared to the average P uptake from sole P sources. There was no increased P uptake in the other species combination (cabbage/faba bean) on mixed P sources compared to that on sole P sources because of the two species' similar capabilities to access P sources. Chapter 3 tested for complementarity in P acquisition from different sources in a subsequent pot experiment with low P soil mixed with organic and inorganic $\mathrm{P}$ sources, where complementarity and facilitation with respect to $\mathrm{P}$ uptake can occur simultaneously. The results showed that there was no complementarity in P acquisition from different sources by millet/chickpea mixture. Instead, chickpea facilitated P uptake by millet in the mixture. For instance, on one low P soil, both the carboxylate concentration and acid phosphatase activity of chickpea were higher than that of millet, and P uptake of mixed millet was increased by mixing with chickpea. Organic $\mathrm{P}$ is less available for enzymatic hydrolysis in the soil because of the adsorption of organic $\mathrm{P}$, and especially phytate (the most abundant form of organic P), to the soil surface (Richardson et al. 2011). So, species need to exude both carboxylates and phosphatases to desorb organic $\mathrm{P}$ in the soil by carboxylates before hydrolysis by phosphatases (Hayes et al. 2000; Tinker and Nye 2000; George et al. 2004). These overlapped species traits of root exudates growing in the soil complicated the conditions for complementarity in accessing different $\mathrm{P}$ sources. These results showed that there was no evidence for complementarity in $\mathrm{P}$ acquisition from different sources in soil by species mixtures.

Though theoretically attractive, there is no empirical support for complementarity in $\mathrm{P}$ acquisition from different sources in soil. In Chapter 3, I therefore proposed a modified 
framework based on Hinsinger's framework of competition, facilitation, and complementarity. The modified framework helps to understand why complementarity in $\mathrm{P}$ acquisition from different sources is hardly supported by empirical studies. Hinsinger's framework of complementarity in tapping into different resource pools properly applies to complementarity in $\mathrm{N}$ use because plant species have different mechanisms to acquire ammonium, nitrate, organic $\mathrm{N}$ or atmospheric $\mathrm{N}_{2}$. However, for soil $\mathrm{P}$, the only available $\mathrm{P}$ form for plants is ortho-P. There is always competition for the available ortho-P because all mobilized P ends up into the same pool. The increased ortho-P pool can equalize competitive ability or can lead to competitive inequality. The outcome of these species interactions can be overyielding or underyielding of $\mathrm{P}$ uptake and growth, depending on relative $\mathrm{P}$ acquisition gains by one species and $\mathrm{P}$ acquisition losses by the other. The framework separated the mechanisms of belowground process involved root exudates and mobilized $\mathrm{P}$ sources from the outcomes of P uptake and biomass of species mixture (Barry et al. 2019): the mechanisms of complementarity and facilitation with respect to $\mathrm{P}$ uptake did not necessarily result in overyielding of $\mathrm{P}$ uptake. The framework is useful to explain rhizosphere modifications of species in the absence of increased $\mathrm{P}$ uptake by species mixture in previous studies (Li et al. 2008; Li et al. 2010; Dissanayaka et al. 2015).

\subsubsection{Species dominance plays a role in $\mathbf{P}$ uptake by species mixture in pot experiments}

Species' trait dissimilarities can result in complementarity or competitive dominance in species mixtures (Wagg et al. 2017). When designing genotype mixtures based on resource-use complementarity, Montazeaud et al. (2018) found that the dominant genotype gained more than the inferior genotype lost, leading to overyielding by the mixture in a pot experiment. There were similar dominance of one species over the other species in species mixtures in the Chapters 2 and 3. In the wheat/maize mixture growing on quartz sand (Chapter 2) and one calcareous soil (Chapter 3), sole wheat and sole maize had similar abilities to access P sources, but wheat was more competitive than maize due to its high root length density and phenotypic plasticity (Li et al. 2001b; Liu et al. 2015). Wheat took up more $\mathrm{P}$ than maize lost $\mathrm{P}$ acquisition in the mixture when supplied with mixed $\mathrm{P}$ sources in quartz sand and soil. This resulted in higher P uptake by a wheat/maize mixture than expected from sole species. Therefore, species dominance can also lead to enhanced P acquisition by species mixtures, although species' P uptake abilities are similar.

Under field conditions, Sun et al. (2019b) showed that the dominance of alfalfa significantly improved $\mathrm{P}$ acquisition by maize/alfalfa intercropping. However, the meta-analysis on the intercrops in China showed that competitive dominance only played a small role in absolute yield gain (Chapter 5). Most of the Chinese intercrops are relay strip intercrops with large temporal niche differentiation (TND, the proportion of the total growing period of the crop 
mixture during which species grow alone (Yu et al. 2015)). Therefore, the interspecific competition for resources during co-growth period is reduced. These results suggest that species dominance is the main contributor to the overyielding of $\mathrm{P}$ uptake by species mixtures with roots mostly overlap in pot experiments.

The stress gradient hypothesis proposes that competitive interactions are more frequent in more productive environments, but competition gives way to facilitation as environmental stress increases (e.g., reduced nutrient or water availability) (Bertness and Callaway 1994; Maestre et al. 2009; He et al. 2013a). One may thus expect facilitation of P uptake and overyielding by intercropping to occur under low $\mathrm{P}$ conditions. The field experiment with millet/chickpea intercropping showed overyielding of the aboveground $\mathrm{P}$ content of intercrops at a low P level (Chapter 4). This outcome suggests the mechanisms of relaxing interspecific competition occurred in this relay strip intercropping at a low P level. However, the increased P uptake did not lead to overyielding of yield, suggesting the mechanisms of complementarity or facilitation of $\mathrm{P}$ uptake was not the main driver for overyielding. There was overyielding of grain yield at high P level, refuting the stress gradient hypothesis. In previous field studies, increased P uptake (quantified with LER) by intercrops was also reported to be independent of $\mathrm{P}$ fertilization rate (Mei et al. 2012; Xia et al. 2013; Tang et al. 2016; Li et al. 2018), i.e., relative yield gain was found in intercropping at both low and high $\mathrm{P}$ fertilization rates. The meta-analyses in Chapters 5 and 6 showed that the absolute yield gain of intercrops was also independent of $P$ fertilization rate. The lack of $P$ fertilizer effect on yield gain of intercrops is related to the currently high available soil $\mathrm{P}$ levels in most of the agroecological regions of China ( $\mathrm{Li}$ et al. 2011b). The increased P uptake of relay strip intercrops at high $\mathrm{P}$ soil is more likely due to temporal and spatial complementarity in resource use (e.g., light, nutrients or water).

Only a few studies have investigated rhizosphere modifications in intercropping under field conditions (Latati et al. 2014; Sun et al. 2019a). In the field experiment, I simultaneously determined root exudates and aboveground $\mathrm{P}$ content and biomass of intercrops during the co-growth period (Chapter 4). This allowed for determining whether the mechanisms of complementarity and facilitation with respect to $\mathrm{P}$ uptake directly lead to the corresponding outcomes of crop performance quantified by P uptake, biomass and yield. The results showed that the aboveground $\mathrm{P}$ content and biomass were similar in intercropping and monoculture for both millet and chickpea during the co-growth period at both low and high P levels. However, the mechanisms of complementarity and facilitation with respect to P uptake could occur during the co-growth stage according to the framework in Chapter 3 . The phosphatase activity of chickpea was higher than millet and the carboxylate concentration of millet was higher than chickpea during the co-growth stage. Furthermore, there was overyielding of $\mathrm{P}$ 
uptake at low P level and overyielding of grain yield at high P level, based on the final harvest of each species. This indicates that overyielding could be related to the recovery growth of intercropped millet after chickpea harvest in this relay strip intercropping in addition to the rhizosphere modifications during the co-growth period. That result was consistent with the meta-analysis on intercropping, where temporal complementarity in using resources drove the yield gain of intercropping at field level. Thus, the mechanisms of complementarity and facilitation with respect to P uptake occurred in intercropping, but they were not the key drivers of overyielding by relay strip millet/chickpea intercropping under the conditions investigated in this thesis.

\subsubsection{How large is the absolute yield gain of intercrops and what are the drivers of yield gain?}

To quantify the absolute yield gain of intercrops, I conducted meta-analyses on field studies on grain intercrops with the additive partitioning method. The absolute yield gain (NE) indicates how much more yield is obtained per unit area than expected from the sole crop yields and species' land shares. This metric expresses intercropping benefits in terms of $\mathrm{Mg}$ $\mathrm{ha}^{-1}$, which is of agronomic relevance. Partitioning the net yield gain of intercrops into complementarity and selection effects with the additive partitioning method helps to analyze the drivers of yield gain of intercrops. For instance, partitioning helps to determine whether the intercropping advantage is predominantly due to overyielding of the species with the highest sole crop yield or due to overall functional complementarity between the species. The information provided by the net effect and its components is complementary to that provided by LER, which characterizes the land-use efficiency of intercropping. Relative yield can be high if the absolute yields of the intercrop and the sole crop(s) are low, but in the case of NE, the value is not likely to be substantial at low yield levels.

The meta-analysis showed that the yield gain of intercrops (mostly in strips) was mainly (90\%) due to a positive complementarity effect. The absolute yield gain of intercrops increased with TND. That was similar to Yu et al. (2015), who showed that a greater LER increased with greater TND. The complementarity effect also increased with TND, but the selection effect decreased with TND. This suggests that temporal complementarity in using resources alleviates the competition between intercrops and drives the yield gain of intercrops. However, whether this temporal complementarity is mostly for light (aboveground) or nutrient/water (belowground) could be a topic for future research. Moreover, as a relative term, TND stays the same if the co-growth period and the duration of the whole intercropping system are fixed and regardless of the sequence of each species. However, in terms of plant interactions, species sequence makes a difference. Future analyses are needed to have an estimate of TND from both an aboveground and a belowground perspective. 


\subsection{How do agronomic management factors impact yield gain?}

The relative yield gain (LER) is affected by species traits of intercrops, temporal niche differentiation, and $\mathrm{N}$ fertilizer input (Yu 2016). The global meta-analysis investigated the interactive effects of these management factors and showed a previously undescribed dichotomy in intercropping systems (Chapter 6). That could be regarded as two syndromes of production (Andow and Hidaka 1989; Vandermeer 1997) (Fig. 7.2). On the one hand, the intercrops with maize were arranged in strips, based on high fertilizer inputs and with large TND, and were mostly practiced in China. On the other hand, the intercrops without maize were often arranged in fully mixed or alternate rows, and applied with low fertilizer input as well as small TND, and were mostly practiced outside China. These findings help us to realize that intercropping can save land and resources under both low and high input conditions. That contrasts with the opinion that yield benefit of intercropping is pronounced mostly under infertile conditions based on the stress gradient hypothesis ( $\mathrm{Li}$ et al. 2007; Brooker et al. 2015).

Both intercropping syndromes resulted in considerable savings of land and fertilizers to produce equal amounts of yield compared to sole crops. The fertilizer savings of intercrops were quantified by the relative metrics of $\mathrm{N}$ (or P) fertilizer equivalent ratio (NFER and PFER) (Xu et al. 2020), which is in analogy with the LER and water equivalent ratio (WER) (Mao et al. 2012). The NFER and PFER represent the relative amounts of $N$ and $P$ fertilizer that are given in sole crops compared to those given in intercrops to get the same total product output.

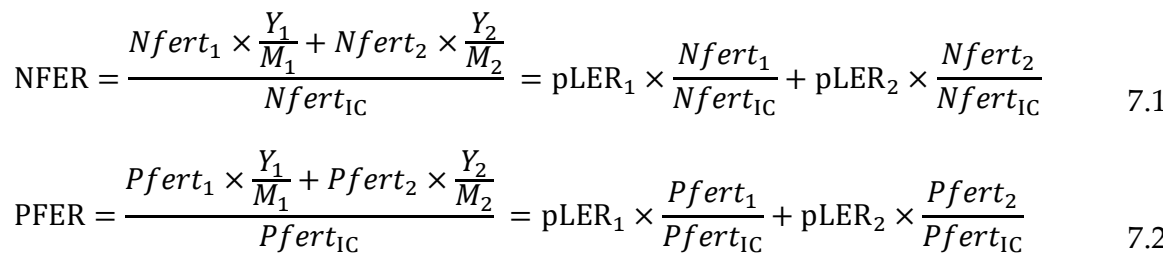

where Nfertıc, Pfertic are the $\mathrm{N}$ and $\mathrm{P}$ fertilizer input per unit area (in $\mathrm{kg} \mathrm{ha}^{-1}$ ) of the intercrop (Chapter 5). Nfert 1, Pfert 1 are the $\mathrm{N}$ and $\mathrm{P}$ fertilizer input per unit area of species 1 in monoculture. Nfert2, Pfert 2 are the $\mathrm{N}$ and $\mathrm{P}$ fertilizer input of species 2 in monoculture. If NFER and PFER are $>1$, less fertilizer is used in intercrop than in sole crops to achieve the same product output. If the fertilizer amount in the intercrop is intermediate between that in sole crops, NFER and PFER will tend to be larger than LER. If the fertilizer amount in the intercrop is higher than that in sole crops, NFER and PFER will tend to be smaller than LER. 
I found that the values of NFER and PFER were well above one: NFER of intercrops with and without maize was $1.33 \pm 0.04$ and $1.19 \pm 0.05$, respectively; PFER of intercrops with and without maize was $1.36 \pm 0.03$ and $1.19 \pm 0.04$, respectively. These ratios represent $19 \%$ (without maize) to $35 \%$ (with maize) reduction in fertilizer input in intercropping as compared to sole crops to achieve the same amount of product output. The NFER and PFER were larger than the LER (1.29 \pm 0.02 with maize, $1.16 \pm 0.02$ without maize), indicating that the fertilizer used in intercrops was intermediate between that in sole crops and higher relative nutrient use efficiency of intercrops than sole crops. This also suggests there are fertilizer savings in addition to land savings in intercropping. The potential mechanisms that allow these additional fertilizer savings deserve future research.

The global meta-analysis (Chapter 6) helps to realize that intercropping strategies are context-dependent, which reflects different production situations and objectives. To ensure food supply in China, intercropping has been transformed into a pattern of high input and high output, which contrasts with the traditional pattern of low input and low output (Li et al. 2013). However, Chapter 6 showed that intercropping saved fertilizer input compared to the monocultures that are often applied with high fertilizer input in China (Ju et al. 2009). The high input - high output intercropping syndrome may have higher nutrient losses to the environment than the low input - low output syndrome. Further research is needed to address the environmental issues in the high-input intercropping systems. The low-input intercropping strategy was mostly practiced in organic agriculture in western countries and low-input agriculture in Asia and Africa in the global data set (Chapter 6). This low-input intercropping often produces low grain yield but reduces nitrate leaching and controls pests and diseases (Bedoussac et al. 2015). These findings suggest that a set of management are needed to design intercropping rather than manipulating one management factor. The two syndromes of intercropping exemplify a trade-off between yield and environmental cost. However, I think that convergence between both syndromes is desirable. For instance, future intercropping systems could be more intensive than the current systems in Africa, but the future intercropping systems could be less intensive than the current systems in China. These possibilities in combining traits of both syndromes of production in intercropping could achieve high food production with low environmental costs (Fig. 7.2). However, the transformations of high-input or low-input syndromes of production depend on stakeholders such as farmers and consumers through the market, and are very much under the control of governments who can set standards and limits to inputs in the public interest. 


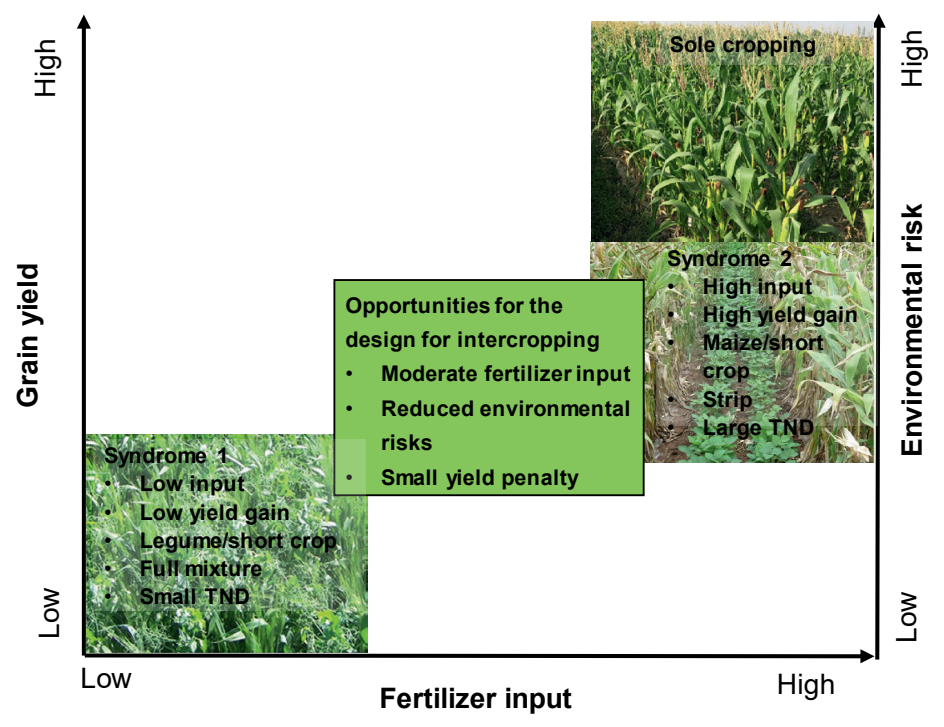

Fig. 7.2 A schematic pattern of syndromes of production in intercropping, and the grain yield, fertilizer input and environmental risk of the two syndromes compared to sole cropping, and the opportunities for the design for intercropping in the future.

\subsection{Novelties and limitations of this thesis}

In this thesis, to avoid confusion, complementarity and facilitation with respect to $\mathrm{P}$ uptake were referred to as mechanisms, i.e., complementarity in P uptake means complementary $\mathrm{P}$ acquisition from different sources by two species in species mixture, and facilitation of $\mathrm{P}$ uptake means one species facilitate the P uptake by its neighbor through root exudates. These mechanisms are different from the outcomes such as increased P content and biomass. In current literature, complementarity is often used as both a cause of enhanced ecosystem functioning in diverse communities and a consequence of some community processes (Barry et al. 2019). The complementarity effect and other measures such as the net effect, LER or RYT represent the consequence but not the underlying mechanisms. However, these measures are often interpreted as evidence for complementarity, resource partitioning or facilitation. This thesis studied both approaches from mechanisms to outcomes of species interactions in empirical studies (Chapters 2-4) and an approach from outcomes to mechanisms with the meta-analyses (Chapters 5, 6). The results showed that the potential causes and hypothesized mechanisms of species interaction can be used to explain the outcomes of crop performance as measured by relative or absolute terms. However, it is difficult to predict the outcomes based on dissimilarities in species traits and the assumed mechanisms of species interactions. 
The reasons could be that one mechanism alone does not necessarily lead to overyielding by species mixtures (Barry et al. 2019). Several kinds of species interactions often occur simultaneously and result in enhanced resource use and yield gain of intercrops. LER calculated with yield or P content is often used to demonstrate overyielding, and facilitation of $\mathrm{P}$ uptake is often interpreted as evidence for overyielding of $\mathrm{P}$ uptake. That could overrate the contribution of the facilitation of $\mathrm{P}$ uptake to overyielding, since several other causes also drive overyielding, including temporal and spatial complementarity in P uptake.

The design (Chapter 2) and modified conceptual framework (Chapter 3) in this thesis provide a tool to determine the occurrence of complementarity, facilitation, or competition for $\mathrm{P}$ uptake in species mixtures. The framework on complementarity highlights the competition for the ortho-P pool between species and that plants can mobilize both sparingly soluble $\mathrm{P}$ sources to some extent, although they have different abilities to mobilize different $\mathrm{P}$ sources. That helps to understand why there is limited evidence for the resource partitioning hypothesis for $\mathrm{P}$ compared to $\mathrm{N}$ from literature.

In the empirical studies, I focused on the physiological P uptake traits of species (root exudates), but not on root morphological traits. Root architecture traits such as crown root surface area and lateral root volume of plants had a greater effect on P uptake compared to root exudates in maize/alfalfa intercropping (Sun et al. 2019a). Greater root length density and root relative growth rate provide a species with a competitive advantage in capturing soil nutrients over neighboring species (Ravenek et al. 2016; Wagg et al. 2017). This competitive inequality between species allows for species dominance, which can also contribute to increased P uptake and growth of species mixture compared to sole species. Legumes appear to promote mycorrhiza colonization and a network of mycorrhiza between species (Duchene et al. 2017). The common mycorrhizal networks between millet and chickpea promoted enhanced $\mathrm{P}$ uptake by millet/chickpea mixture in an unpublished study that I executed. Future research is needed to investigate root physiological, morphological and mycorrhizal traits of species' P uptake in species mixture.

In the meta-analyses, I focused on the yield gain of intercropping and the efficiency of land and fertilizer use but not on water use in intercropping. Most of the maize-based intercrops in China are irrigated because the annual precipitation, for instance, in Northwest China $(<160$ $\mathrm{mm}$ ), is not enough for crop growth (Yang et al. 2011; Chai et al. 2014). Previous studies have shown improved water use efficiency of relay intercropping compared to sole crops (Yang et al. 2011; Chai et al. 2014; Tan et al. 2020a). Analyzing the water use efficiency of intercropping would be a worthwhile topic for future work. 


\subsection{Implications for designing intercropping systems}

In this thesis, I applied theories and methods from ecology to agriculture such as the resource partitioning hypothesis, stress gradient hypothesis and additive partitioning method. The results of testing resource partitioning for $\mathrm{P}$ suggest that species complementarity in physiological P uptake traits was not a sufficient criterion to select species combinations for intercropping systems. The absolute yield gain can be achieved under both low and high levels of fertilizer input, contrasting with the stress gradient hypothesis. The additive partitioning method helps to determine the drivers of yield gain of intercropping. The results suggest that including maize and short co-growth period of intercrops are relevant for designing for productive intercropping systems. These intercropping systems with temporal niche differentiation can adapt to extended growing seasons and higher temperatures due to global warming (Menzel and Fabian 1999; Peñuelas and Filella 2001).

In agricultural systems, crop species are generally selected and bred for fast growth and rapid nutrient acquisition (Mariotte et al. 2018). With a high nutrient level in most of the soils in China (Chapters 5 and 6), aboveground competition for light will be prominent in intercropping. The design for intercropping in the current fertile soils could focus on how to reduce competition for light in intercropping, such as investigating proper strip width, selecting species with high plant plasticity, proper time management, better timing of fertilization and the legacy effect of earlier sown species' roots in relay intercropping to improve nutrient acquisition efficiency.

Crop diversification is a plausible strategy for ecological intensification (Bommarco et al. 2013). This thesis contributes to understanding the influence of species interactions on nutrient acquisition efficiency and yield, which is critical for strengthening the ecological foundations of sustainable agriculture. The syndromes of production in intercropping provide options for applying different intercropping strategies in different regions within a country. The Chinese government could adjust the policy of fertilizer subsidies to reduce the current overuse in high-input systems, and the other governments (e.g., African government) can support fertilizer use in the systems with limited use of fertilizer, depending on socio-economic and environmental objectives.

\subsection{Conclusions}

The empirical studies in this thesis showed no evidence for complementarity in P acquisition from different sources in the soil in both pot and field experiments. In field experiments, there was overyielding by millet/chickpea relay strip intercropping, but it was not driven by the complementarity in $\mathrm{P}$ acquisition from different sources or facilitation of $\mathrm{P}$ uptake. The meta-analyses in this thesis provided the quantification of the absolute yield gain, which 
reflects the productivity of intercrops. The presence of maize and temporal complementarity in using resources (e.g., light, water, $\mathrm{N}$ and $\mathrm{P}$ ) played an important role in competitive relaxation and hence yield gain of intercrops in the field studies. At a global level, there was a set of coordinated management factors rather than a single factor that drove the yield gain of intercrops, resulting in two contrasting syndromes of production in intercropping. These findings are relevant for the design of intercropping systems. Designing intercropping systems for improved $\mathrm{P}$ acquisition cannot be through the mechanisms of complementarity in $\mathrm{P}$ acquisition from different sources. Further research on designing intercropping systems could consider a set of management strategies such as using strip intercropping, a relatively short co-growth period of the two crop species, and including species with high productivity (e.g., maize). I hope all these will provide a contribution to exploring the opportunities that intercropping can meet the demand for food while reducing the environmental impacts of agriculture. 



\section{References}

Adler PB, Fajardo A, Kleinhesselink AR, Kraft NJB (2013) Trait-based tests of coexistence mechanisms. Ecology Letters 16:1294-1306.

Ae N, Arihara J, Okada K, Yoshihara T, Johansen C (1990) Phosphorus uptake by pigeon pea and its role in cropping systems of the Indian subcontinent. Science 248:477-480.

Ahmad-Ramli MF, Cornulier T, Johnson D (2013) Partitioning of soil phosphorus regulates competition between Vaccinium vitis-idaea and Deschampsia cespitosa. Ecology and Evolution 3:4243-4252.

Andersen SN, Dresboll DB, Thorup-Kristensen K (2014) Root interactions between intercropped legumes and non-legumes-a competition study of red clover and red beet at different nitrogen levels. Plant and Soil 378:59-72.

Andow DA, Hidaka K (1989) Experimental natural history of sustainable agriculture: syndromes of production. Agriculture, Ecosystems \& Environment 27:447-462.

Anten NPR, Hirose T (1999) Interspecific differences in above-ground growth patterns result in spatial and temporal partitioning of light among species in a tall-grass meadow. Journal of Ecology 87:583-597.

Anten NPR, Hirose T (2003) Shoot structure,leaf physiology, and daily carbon gain of plant species in a tallgrass meadow. Ecology 84:955-968.

Atwater DZ, Callaway RM (2015) Testing the mechanisms of diversity-dependent overyielding in a grass species. Ecology 96:3332-3342.

Bai ZH, Li HG, Yang XY, Zhou BK, Shi XJ, Wang BR, Li DC, Shen JB, Chen Q, Qin W, Oenema O, Zhang FS (2013) The critical soil P levels for crop yield, soil fertility and environmental safety in different soil types. Plant and Soil 372:27-37.

Bais HP, Weir TL, Perry LG, Gilroy S, Vivanco JM (2006) The role of root exudates in rhizosphere interations with plants and other organisms. Annual Review of Plant Biology 57:233-266.

Banik P, Midya A, Sarkar BK, Ghose SS (2006) Wheat and chickpea intercropping systems in an additive series experiment: Advantages and weed smothering. European Journal of Agronomy 24:325-332.

Barbieri P, Pellerin S, Nesme T (2017) Comparing crop rotations between organic and conventional farming. Scientific Reports 7:13761.

Barot S, Allard V, Cantarel A, Enjalbert J, Gauffreteau A, Goldringer I, Lata J-C, Le Roux X, Niboyet A, Porcher E (2017) Designing mixtures of varieties for multifunctional agriculture with the help of ecology. A review. Agronomy for Sustainable Development 37:13.

Barry KE, Mommer L, van Ruijven J, Wirth C, Wright AJ, Bai Y, Connolly J, De Deyn GB, de Kroon H, Isbell F, Milcu A, Roscher C, Scherer-Lorenzen M, Schmid B, Weigelt A (2019) The Future of Complementarity: Disentangling Causes from Consequences. Trends in Ecology \& Evolution 34:167-180.

Bedoussac L, Journet É-P, Hauggaard-Nielsen H, Naudin C, Corre-Hellou G, Prieur L, Jensen ES, Justes E (2014) Eco-functional intensification by cereal-grain legume intercropping in organic farming systems for increased yields, reduced weeds and improved grain protein concentration. In: Organic Farming, Prototype for Sustainable Agricultures. Springer, pp 47-63.

Bedoussac L, Journet EP, Hauggaard-Nielsen H, Naudin C, Corre-Hellou G, Jensen E, Prieur L, Justes E (2015) Ecological principles underlying the increase of productivity achieved by cereal-grain legume intercrops in organic farming. A review. Agronomy for Sustainable Development 35:911-935.

Bedoussac L, Justes E (2010) Dynamic analysis of competition and complementarity for light and N use to understand the yield and the protein content of a durum wheat-winter pea intercrop. Plant and Soil 330:37-54. 
Bedoussac L, Justes E (2011) A comparison of commonly used indices for evaluating species interactions and intercrop efficiency: Application to durum wheat-winter pea intercrops. Field Crops Research 124:25-36.

Bertness MD, Callaway R (1994) Positive interactions in communities. Trends in Ecology \& Evolution 9:191-193.

Betencourt E, Duputel M, Colomb B, Desclaux D, Hinsinger P (2012) Intercropping promotes the ability of durum wheat and chickpea to increase rhizosphere phosphorus availability in a low $\mathrm{P}$ soil. Soil Biology and Biochemistry 46:181-190.

Bolker BM (2008) Ecological Models and Data in R. Princeton. Princeton, NJ, Princeton University Press Bommarco R, Kleijn D, Potts SG (2013) Ecological intensification: harnessing ecosystem services for food security. Trends in Ecology \& Evolution 28:230-238.

Bommarco R, Vico G, Hallin S (2018) Exploiting ecosystem services in agriculture for increased food security. Global Food Security 17:57-63.

Brooker RW, Bennett AE, Cong W-F, Daniell TJ, George TS, Hallett PD, Hawes C, Iannetta PPM, Jones HG, Karley AJ, Li L, McKenzie BM, Pakeman RJ, Paterson E, Schöb C, Shen J, Squire G, Watson CA, Zhang C, Zhang F, Zhang J, White PJ (2015) Improving intercropping: a synthesis of research in agronomy, plant physiology and ecology. New Phytologist 206:106-117.

Brooker RW, Karley AJ, Newton AC, Pakeman RJ, Schöb C (2016) Facilitation and sustainable agriculture: a mechanistic approach to reconciling crop production and conservation. Functional Ecology 30:98-107.

Callaway RM (1995) Positive interactions among plants. Botanical Review 61:306-349.

Callaway RM, Brooker RW, Choler P, Kikvidze Z, Lortie CJ, Michalet R, Paolini L, Pugnaire FI, Newingham B, Aschehoug ET, Armas C, Kikodze D, Cook BJ (2002) Positive interactions among alpine plants increase with stress. Nature 417:844-848.

Cardinale BJ, Wright JP, Cadotte MW, Carroll IT, Hector A, Srivastava DS, Loreau M, Weis JJ (2007) Impacts of plant diversity on biomass production increase through time because of species complementarity. Proceedings of the National Academy of Sciences of the United States of America 104:18123-18128.

Cassman KG (1999) Ecological intensification of cereal production systems: yield potential, soil quality, and precision agriculture. Proceedings of the National Academy of Sciences 96:5952-5959.

Ceulemans T, Bode S, Bollyn J, Harpole S, Coorevits K, Peeters G, Van Acker K, Smolders E, Boeckx P, Honnay O (2017) Phosphorus resource partitioning shapes phosphorus acquisition and plant species abundance in grasslands. Nature Plants 3:16224.

Chai Q, Qin AZ, Gan YT, Yu AZ (2014) Higher yield and lower carbon emission by intercropping maize with rape, pea, and wheat in arid irrigation areas. Agronomy for Sustainable Development 34:535-543.

Chardon WJ, Groenenberg JE, Temminghoff EJM, Koopmans GF (2012) Use of reactive materials to bind phosphorus. J Environ Qual 41:636-646.

Chimonyo VGP, Modi AT, Mabhaudhi T (2015) Perspective on crop modelling in the management of intercropping systems. Archives of Agronomy and Soil Science 61:1511-1529.

Cong WF, Hoffland E, Li L, Six J, Sun JH, Bao XG, Zhang FS, van der Werf W (2015) Intercropping enhances soil carbon and nitrogen. Global Change Biology 21:1715-1726.

Corre-Hellou G, Fustec J, Crozat Y (2006) Interspecific competition for soil N and its interaction with $\mathrm{N}-2$ fixation, leaf expansion and crop growth in pea-barley intercrops. Plant and Soil 282:195-208.

Crème A, Rumpel C, Gastal F, de la Luz Mora Gil M, Chabbi A (2016) Effects of grasses and a legume grown in monoculture or mixture on soil organic matter and phosphorus forms. Plant and Soil 402:117-128.

Cu STT, Hutson J, Schuller KA (2005) Mixed culture of wheat (Triticum aestivum L.) with white lupiu (Lupinus albus L.) improves the growth and phosphorus nutrition of the wheat. Plant and Soil 272:143-151. 
De Wit CT (1960) On competition. Verslagen landbouwkundige onderzoekingen 66.8 Pudoc, Centrum voor landbouwpublikaties en landbouwdocumentatie, Wageningen, The Netherlands.

Dechassa N, Schenk MK (2004) Exudation of organic anions by roots of cabbage, carrot, and potato as influenced by environmental factors and plant age. Journal of Plant Nutrition and Soil Science 167:623-629.

DeMalach N, Zaady E, Weiner J, Kadmon R (2016) Size asymmetry of resource competition and the structure of plant communities. Journal of Ecology 104:899-910.

Dissanayaka DMSB, Maruyama H, Masuda G, Wasaki J (2015) Interspecific facilitation of P acquisition in intercropping of maize with white lupin in two contrasting soils as influenced by different rates and forms of P supply. Plant and Soil 390:223-236.

Dissanayaka DMSB, Maruyama H, Nishida S, Tawaraya K, Wasaki J (2016) Landrace of japonica rice, Akamai exhibits enhanced root growth and efficient leaf phosphorus remobilization in response to limited phosphorus availability. Plant and Soil:1-12.

Du JB, Han TF, Gai JY, Yong TW, Sun X, Wang XC, Yang F, Liu J, Shu K, Liu WG, Yang WY (2018) Maize-soybean strip intercropping: Achieved a balance between high productivity and sustainability. Journal of Integrative Agriculture 17:747-754.

Duchene O, Vian JF, Celette F (2017) Intercropping with legume for agroecological cropping systems: Complementarity and facilitation processes and the importance of soil microorganisms. A review. Agriculture Ecosystems \& Environment 240:148-161.

Duval S, Tweedie R (2000) Trim and Fill: A Simple Funnel-Plot-Based Method of Testing and Adjusting for Publication Bias in Meta-Analysis. Biometrics 56:455-463.

Evers JB, van der Werf W, Stomph TJ, Bastiaans L, Anten NPR (2018) Understanding and optimizing species mixtures using functional-structural plant modelling. Journal of Experimental Botany 70:2381-2388.

Fan FL, Zhang FS, Song YN, Sun JH, Bao XG, Guo TW, Li L (2006) Nitrogen fixation of faba bean (Vicia $f a b a \mathrm{~L}$.) interacting with a non-legume in two contrasting intercropping systems. Plant and Soil 283:275-286.

Fargione J, Tilman D (2005) Niche differences in phenology and rooting depth promote coexistence with a dominant $\mathrm{C}_{4}$ bunchgrass. Oecologia 143:598-606.

Faucon M-P, Houben D, Lambers H (2017) Plant functional traits: soil and ecosystem services. Trends in Plant Science 22:385-394.

Faucon MP, Houben D, Reynoird JP, Mercadal-Dulaurent AM, Armand R, Lambers H (2015) Advances and Perspectives to Improve the Phosphorus Availability in Cropping Systems for Agroecological Phosphorus Management. In: Sparks DL (ed) Advances in Agronomy, Vol 134, vol 134. Advances in Agronomy. pp 51-79.

Fletcher AL, Kirkegaard JA, Peoples MB, Robertson MJ, Whish J, Swan AD (2017) Prospects to utilise intercrops and crop variety mixtures in mechanised, rain-fed, temperate cropping systems. Crop and Pasture Science 67:1252-1267.

Foley JA, Ramankutty N, Brauman KA, Cassidy ES, Gerber JS, Johnston M, Mueller ND, O'Connell C, Ray DK, West PC (2011) Solutions for a cultivated planet. Nature 478:337-342.

Fridley JD (2001) The influence of species diversity on ecosystem productivity: how, where, and why? Oikos 93:514-526.

Fujita K, Ofosubudu KG, Ogata S (1992) Biological nitrogen-fixation in mixed legume-cereal cropping systems. Plant and Soil 141:155-175.

Gaba S, Lescourret F, Boudsocq S, Enjalbert J, Hinsinger P, Journet EP, Navas ML, Wery J, Louarn G, Malezieux E, Pelzer E, Prudent M, Ozier-Lafontaine H (2015) Multiple cropping systems as drivers for providing multiple ecosystem services: from concepts to design. Agronomy for Sustainable Development 35:607-623.

Gao XP, Kuyper TW, Zou CQ, Zhang FS, Hoffland E (2007) Mycorrhizal responsiveness of aerobic rice genotypes is negatively correlated with their zinc uptake when nonmycorrhizal. Plant and Soil 290:283-291. 
Garnier E, Navas ML, Grigulis K (2016) Plant Functional Diversity Organism traits, community structure, and ecosystem properties. Oxford University Press, Oxford.

Geertsema W, Rossing WAH, Landis DA, Bianchi FJJA, van Rijn PCJ, Schaminee JHJ, Tscharntke T, van der Werf W (2016) Actionable knowledge for ecological intensification of agriculture. Frontiers in Ecology and the Environment 14:209-216.

George TS, Hinsinger P, Turner BL (2016) Phosphorus in soils and plants - facing phosphorus scarcity. Plant and Soil 401:1-6.

George TS, Richardson AE, Hadobas PA, Simpson RJ (2004) Characterization of transgenic Trifolium subterraneum L. which expresses phy A and releases extracellular phytase: growth and $\mathrm{P}$ nutrition in laboratory media and soil. Plant, cell \& environment 27:1351-1361.

George TS, Richardson AE, Simpson RJ (2005) Behaviour of plant - derived extracellular phytase upon addition to soil. Soil Biology and Biochemistry 37:977-988.

Gerke J (2015) The acquisition of phosphate by higher plants: Effect of carboxylate release by the roots. A critical review. Journal of Plant Nutrition and Soil Science 178:351-364.

Giles CD, George TS, Brown LK, Mezeli MM, Richardson AE, Shand CA, Wendler R, Darch T, Menezes-Blackburn D, Cooper P, Stutter MI, Lumsdon DG, Blackwell MSA, Wearing C, Zhang H, Haygarth PM (2016) Does the combination of citrate and phytase exudation in Nicotiana tabacum promote the acquisition of endogenous soil organic phosphorus? Plant and Soil 412:43-59.

Godfray HCJ, Beddington JR, Crute IR, Haddad L, Lawrence D, Muir JF, Pretty J, Robinson S, Thomas SM, Toulmin C (2010) Food security: the challenge of feeding 9 billion people. Science 327:812-818.

Gou F, van Ittersum MK, Wang G, van der Putten PE, van der Werf W (2016) Yield and yield components of wheat and maize in wheat-maize intercropping in the Netherlands. European Journal of Agronomy 76:17-27.

Gou F, Yin W, Hong Y, Werf WVD, Chai Q, Heerink N, Ittersum MKV (2017) On yield gaps and yield gains in intercropping: Opportunities for increasing grain production in northwest China. Agricultural Systems 151:96-105.

Grime JP (2006) Trait convergence and trait divergence in herbaceous plant communities: Mechanisms and consequences. Journal of Vegetation Science 17:255-260.

Hauggaard-Nielsen H, Ambus P, Jensen ES (2001) Interspecific competition, N use and interference with weeds in pea-barley intercropping. Field Crops Research 70:101-109.

Hauggaard-Nielsen H, Gooding M, Ambus P, Corre-Hellou G, Crozat Y, Dahlmann C, Dibet A, von Fragstein P, Pristeri A, Monti M, Jensen ES (2009) Pea-barley intercropping for efficient symbiotic $\mathrm{N}_{2}$-fixation, soil $\mathrm{N}$ acquisition and use of other nutrients in European organic cropping systems. Field Crops Research 113:64-71.

Hauggaard-Nielsen H, Jensen ES (2001) Evaluating pea and barley cultivars for complementarity in intercropping at different levels of soil $\mathrm{N}$ availability. Field Crops Research 72:185-196.

Hayes JE, Richardson AE, Simpson RJ (1999) Phytase and acid phosphatase activities in extracts from roots of temperate pasture grass and legume seedlings. Australian Journal of Plant Physiology 26:801-809.

Hayes JE, Richardson AE, Simpson RJ (2000) Components of organic phosphorus in soil extracts that are hydrolysed by phytase and acid phosphatase. Biology and Fertility of Soils 32:279-286.

He Q, Bertness MD, Altieri AH (2013a) Global shifts towards positive species interactions with increasing environmental stress. Ecology Letters 16:695-706.

He Y, Ding N, Shi J, Wu M, Liao H, Xu J (2013b) Profiling of microbial PLFAs: Implications for interspecific interactions due to intercropping which increase phosphorus uptake in phosphorus limited acidic soils. Soil Biology and Biochemistry 57:625-634.

Hinsinger P (2001) Bioavailability of soil inorganic P in the rhizosphere as affected by root-induced chemical changes: a review. Plant and Soil 237:173-195. 
Hinsinger P, Betencourt E, Bernard L, Brauman A, Plassard C, Shen JB, Tang XY, Zhang FS (2011) P for two, sharing a scarce resource: soil phosphorus acquisition in the rhizosphere of intercropped species. Plant Physiology 156:1078-1086.

Hoffland E, Findenegg GR, Nelemans JA (1989) Solubilization of rock phosphate by rape .2. local root exudation of organic-acids as a response to P-starvation. Plant and Soil 113:161-165.

Holford ICR (1997) Soil phosphorus: Its measurement, and its uptake by plants. Australian Journal of Soil Research 35:227-239.

Holmgren M, Scheffer M, Huston MA (1997) The interplay of facilitation and competition in plant communities. Ecology 78:1966-1975.

Hong Y, Heerink N, Jin S, Berentsen P, Zhang L, van der Werf W (2017) Intercropping and agroforestry in China - Current state and trends. Agriculture, Ecosystems \& Environment 244:52-61.

Hong Y, Heerink N, Zhao M, van der Werf W (2019) Intercropping contributes to a higher technical efficiency in smallholder farming: Evidence from a case study in Gaotai County, China. Agricultural Systems 173:317-324.

Hooper DU, Vitousek PM (1998) Effects of plant composition and diversity on nutrient cycling. Ecological Monographs 68:121-149.

Hu F, Gan Y, Chai Q, Feng F, Zhao C, Yu A, Mu Y, Zhang Y (2016) Boosting system productivity through the improved coordination of interspecific competition in maize/pea strip intercropping. Field Crops Research 198:50-60.

Hu FL, Zhao C, Feng FX, Chai Q, Mu YP, Zhang Y (2017) Improving N management through intercropping alleviates the inhibitory effect of mineral $\mathrm{N}$ on nodulation in pea. Plant and Soil 412:235-251.

Huang C, Liu Q, Gou F, Li X, Zhang C, van der Werf W, Zhang F (2017) Plant growth patterns in a tripartite strip relay intercrop are shaped by asymmetric aboveground competition. Field Crops Research 201:41-51.

Iqbal N, Hussain S, Ahmed Z, Yang F, Wang X, Liu W, Yong T, Du J, Shu K, Yang W, Liu J (2018) Comparative analysis of maize-soybean strip intercropping systems: a review. Plant Production Science:1-12.

Janssen BH, Guiking FCT, van der Eijk D, Smaling EMA, Wolf J, van Reuler H (1990) A system for quantitative evaluation of the fertility of tropical soils (QUEFTS). Geoderma 46:299-318.

Jensen ES (1996) Grain yield, symbiotic $\mathrm{N}_{2}$ fixation and interspecific competition for inorganic $\mathrm{N}$ in pea-barley intercrops. Plant and Soil 182:25-38.

Jesch A, Barry KE, Ravenek JM, Bachmann D, Strecker T, Weigelt A, Buchmann N, de Kroon H, Gessler A, Mommer L, Roscher C, Scherer-Lorenzen M (2018) Below-ground resource partitioning alone cannot explain the biodiversity-ecosystem function relationship: A field test using multiple tracers. Journal of Ecology 106:2002-2018.

Ju XT, Xing GX, Chen XP, Zhang SL, Zhang LJ, Liu XJ, Cui ZL, Yin B, Christie P, Zhu ZL, Zhang FS (2009) Reducing environmental risk by improving $N$ management in intensive Chinese agricultural systems. Proceedings of the National Academy of Sciences of the United States of America 106:3041-3046.

Kahmen A, Renker C, Unsicker SB, Buchmann N (2006) Niche complementarity for nitrogen: An explanation for the biodiversity and ecosystem functioning relationship? Ecology 87:1244-1255.

Knörzer H, Graeff-Hönninger S, Guo B, Wang P, Claupein W (2009) The Rediscovery of Intercropping in China: A Traditional Cropping System for Future Chinese Agriculture - A Review. In: Lichtfouse E (ed) Climate Change, Intercropping, Pest Control and Beneficial Microorganisms. Springer Netherlands, Dordrecht, pp 13-44.

Lambers H, Raven JA, Shaver GR, Smith SE (2008) Plant nutrient-acquisition strategies change with soil age. Trends in Ecology \& Evolution 23:95-103.

Latati M, Bargaz A, Belarbi B, Lazali M, Benlahrech S, Tellah S, Kaci G, Drevon JJ, Ounane SM (2016) The intercropping common bean with maize improves the rhizobial efficiency, resource use and grain yield under low phosphorus availability. European Journal of Agronomy 72:80-90. 
Latati M, Blavet D, Alkama N, Laoufi H, Drevon J, Gérard F, Pansu M, Ounane S (2014) The intercropping cowpea-maize improves soil phosphorus availability and maize yields in an alkaline soil. Plant and Soil 385:181-191.

Li C, He X, Zhu S, Zhou H, Wang Y, Li Y, Yang J, Fan J, Yang J, Wang G, Long Y, Xu J, Tang Y, Zhao G, Yang J, Liu L, Sun Y, Xie Y, Wang H, Zhu Y (2009) Crop Diversity for Yield Increase. Plos One 4:e8049.

Li CJ, Dong Y, Li HG, Shen JB, Zhang FS (2016) Shift from complementarity to facilitation on P uptake by intercropped wheat neighboring with faba bean when available soil $\mathrm{P}$ is depleted. Scientific Reports 6:18663.

Li CJ, Li YY, Yu CB, Sun JH, Christie P, An M, Zhang FS, Li L (2011a) Crop nitrogen use and soil mineral nitrogen accumulation under different crop combinations and patterns of strip intercropping in northwest China. Plant and Soil 342:221-231.

Li H, Huang G, Meng Q, Ma L, Yuan L, Wang F, Zhang W, Cui Z, Shen J, Chen X, Jiang R, Zhang F (2011b) Integrated soil and plant phosphorus management for crop and environment in China. A review. Plant and Soil 349:157-167.

Li H, Shen J, Zhang F, Clairotte M, Drevon JJ, Le Cadre E, Hinsinger P (2008) Dynamics of phosphorus fractions in the rhizosphere of common bean (Phaseolus vulgaris L.) and durum wheat (Triticum turgidum durum L.) grown in monocropping and intercropping systems. Plant and Soil 312:139-150.

Li HG, Shen JB, Zhang FS, Marschner P, Cawthray G, Rengel Z (2010) Phosphorus uptake and rhizosphere properties of intercropped and monocropped maize, faba bean, and white lupin in acidic soil. Biology and Fertility of Soils 46:79-91.

Li L, Li SM, Sun JH, Zhou LL, Bao XG, Zhang HG, Zhang FS (2007) Diversity enhances agricultural productivity via rhizosphere phosphorus facilitation on phosphorus-deficient soils. Proceedings of the National Academy of Sciences of the United States of America 104:11192-11196.

Li L, Sun J, Zhang F, Li X, Rengel Z, Yang S (2001a) Wheat/maize or wheat/soybean strip intercropping : II. Recovery or compensation of maize and soybean after wheat harvesting. Field Crops Research 71:173-181.

Li L, Sun JH, Zhang FS, Guo TW, Bao XG, Smith FA, Smith SE (2006) Root distribution and interactions between intercropped species. Oecologia 147:280-290.

Li L, Sun JH, Zhang FS, Li XL, Yang SC, Rengel Z (2001b) Wheat/maize or wheat/soybean strip intercropping I. Yield advantage and interspecific interactions on nutrients. Field Crops Research 71:123-137.

Li L, Tang CX, Rengel Z, Zhang FS (2003a) Chickpea facilitates phosphorus uptake by intercropped wheat from an organic phosphorus source. Plant and Soil 248:297-303.

Li L, Tilman D, Lambers H, Zhang FS (2014) Plant diversity and overyielding: insights from belowground facilitation of intercropping in agriculture. New Phytologist 203:63-69.

Li L, Yang SC, Li XL, Zhang FS, Christie P (1999) Interspecific complementary and competitive interactions between intercropped maize and faba bean. Plant and Soil 212:105-114.

Li L, Zhang FS, Li XL, Christie P, Sun JH, Yang SC, Tang CX (2003b) Interspecific facilitation of nutrient uptake by intercropped maize and faba bean. Nutrient Cycling in Agroecosystems 65:61-71.

Li L, Zhang L, Zhang F (2013) Crop Mixtures and the mechanisms of overyielding. Encyclopedia of Biodiversity, 2nd edn (ed Levin SA):382-395.

Li MR (1993) Leaf photosynthetic nitrogen-use efficiency of C3 and C4 Cyperus species. Photosynthetica 29:117-130.

Li QZ, Sun JH, Wei XJ, Christie P, Zhang FS, Li L (2011c) Overyielding and interspecific interactions mediated by nitrogen fertilization in strip intercropping of maize with faba bean, wheat and barley. Plant and Soil 339:147-161.

Li SM, Li L, Zhang FS, Tang C (2004) Acid phosphatase role in chickpea/maize intercropping. Annals of Botany 94:297-303. 
Li XF, Wang CB, Zhang WP, Wang LH, Tian XL, Yang SC, Jiang WL, van Ruijven J, Li L (2018) The role of complementarity and selection effects in $\mathrm{P}$ acquisition of intercropping systems. Plant and Soil 422:479-493.

Liao D, Zhang C, Li H, Lambers H, Zhang F (2020) Changes in soil phosphorus fractions following sole cropped and intercropped maize and faba bean grown on calcareous soil. Plant and Soil 448:587-601.

Liebman M, Dyck E (1993) Crop rotation and intercropping strategies for weed management. Ecological Applications 3:92-122.

Lithourgidis A, Dordas C, Damalas CA, Vlachostergios D (2011a) Annual intercrops: an alternative pathway for sustainable agriculture. Australian Journal of Crop Science 5:396.

Lithourgidis AS, Vasilakoglou IB, Dhima KV, Dordas CA, Yiakoulaki MD (2006) Forage yield and quality of common vetch mixtures with oat and triticale in two seeding ratios. Field Crops Research 99:106-113.

Lithourgidis AS, Vlachostergios DN, Dordas CA, Damalas CA (2011b) Dry matter yield, nitrogen content, and competition in pea-cereal intercropping systems. European Journal of Agronomy 34:287-294.

Liu X, Rahman T, Song C, Su B, Yang F, Yong T, Wu Y, Zhang C, Yang W (2017) Changes in light environment, morphology, growth and yield of soybean in maize-soybean intercropping systems. Field Crops Research 200:38-46.

Liu X, Rahman T, Song C, Yang F, Su B, Cui L, Bu W, Yang W (2018) Relationships among light distribution, radiation use efficiency and land equivalent ratio in maize-soybean strip intercropping. Field Crops Research 224:91-101.

Liu YX, Zhang WP, Sun JH, Li XF, Christie P, Li L (2015) High morphological and physiological plasticity of wheat roots is conducive to higher competitive ability of wheat than maize in intercropping systems. Plant and Soil 397:387-399.

Loreau M, Hector A (2001) Partitioning selection and complementarity in biodiversity experiments. Nature 412:72-76.

Loreau M, Naeem S, Inchausti P, Bengtsson J, Grime JP, Hector A, Hooper DU, Huston MA, Raffaelli D, Schmid B, Tilman D, Wardle DA (2001) Ecology - Biodiversity and ecosystem functioning: Current knowledge and future challenges. Science 294:804-808.

Loreau M, Sapijanskas J, Isbell F, Hector A (2012) Niche and fitness differences relate the maintenance of diversity to ecosystem function: comment. Ecology 93:1482-1487.

Machado S (2009) Does intercropping have a role in modern agriculture? Journal of soil and water conservation 64:55A-57A.

Maestre FT, Callaway RM, Valladares F, Lortie CJ (2009) Refining the stress-gradient hypothesis for competition and facilitation in plant communities. Journal of Ecology 97:199-205.

Malezieux E, Crozat Y, Dupraz C, Laurans M, Makowski D, Ozier-Lafontaine H, Rapidel B, de Tourdonnet S, Valantin-Morison M (2009) Mixing plant species in cropping systems: concepts, tools and models. A review. Agronomy for Sustainable Development 29:43-62.

Mao LL, Zhang LZ, Li WQ, van der Werf W, Sun JH, Spiertz H, Li L (2012) Yield advantage and water saving in maize/pea intercrop. Field Crops Research 138:11-20.

Mariotte P, Mehrabi Z, Bezemer TM, De Deyn GB, Kulmatiski A, Drigo B, Veen GF, van der Heijden MGA, Kardol P (2018) Plant-Soil Feedback: Bridging Natural and Agricultural Sciences. Trends in Ecology \& Evolution 33:129-142.

Marquard E, Weigelt A, Temperton VM, Roscher C, Schumacher J, Buchmann N, Fischer M, Weisser WW, Schmid B (2009) Plant species richness and functional composition drive overyielding in a six-year grassland experiment. Ecology 90:3290-3302.

Martin-Guay MO, Paquette A, Dupras J, Rivest D (2018) The new Green Revolution: Sustainable intensification of agriculture by intercropping. Science of the Total Environment 615:767-772.

Matson PA, Parton WJ, Power AG, Swift MJ (1997) Agricultural Intensification and Ecosystem Properties. Science 277:504-509. 
McKane RB, Johnson LC, Shaver GR, Nadelhoffer KJ, Rastetter EB, Fry B, Giblin AE, Kielland K, Kwiatkowski BL, Laundre JA, Murray G (2002) Resource-based niches provide a basis for plant species diversity and dominance in arctic tundra. Nature 415:68-71.

Mead R, Willey R (1980) The concept of a 'land equivalent ratio'and advantages in yields from intercropping. Experimental Agriculture 16:217-228.

Mei PP, Gui LG, Wang P, Huang JC, Long HY, Christie P, Li L (2012) Maize/faba bean intercropping with rhizobia inoculation enhances productivity and recovery of fertilizer $\mathrm{P}$ in a reclaimed desert soil. Field Crops Research 130:19-27.

Menzel A, Fabian P (1999) Growing season extended in Europe. Nature 397:659-659.

Michalet R, Brooker RW, Cavieres LA, Kikvidze Z, Lortie CJ, Pugnaire FI, Valientebanuet A, Callaway RM (2006) Do biotic interactions shape both sides of the humped-back model of species richness in plant communities? Ecology Letters 9:767-773.

Mimmo T, Hann S, Jaitz L, Cesco S, Gessa CE, Puschenreiter M (2011) Time and substrate dependent exudation of carboxylates by Lupinus albus L. and Brassica napus L. Plant Physiology and Biochemistry 49:1272-1278.

Montazeaud G, Violle C, Fréville H, Luquet D, Ahmadi N, Courtois B, Bouhaba I, Fort F (2018) Crop mixtures: does niche complementarity hold for belowground resources? An experimental test using rice genotypic pairs. Plant and Soil 424:187-202.

Morris RA, Garrity DP (1993) Resource capture and utilization in intercropping: water. Field Crops Research 34:303-317.

Muler AL, Oliveira RS, Lambers H, Veneklaas EJ (2014) Does cluster-root activity benefit nutrient uptake and growth of co-existing species? Oecologia 174:23-31.

Murphy J, Riley JP (1962) A modified single solution method for the determination of phosphate in natural waters. Analytica Chimica Acta 27:31-36.

Nasto MK, Osborne BB, Lekberg Y, Asner GP, Balzotti CS, Porder S, Taylor PG, Townsend AR, Cleveland CCC (2017) Nutrient acquisition, soil phosphorus partitioning and competition among trees in a lowland tropical rain forest. New Phytologist 214:1506-1517.

Neumann G (2006) Quantitative determination of acid phosphatase activity in the rhizosphere and on the root surface. Handbook of Methods used in Rhizosphere Research:536.

Neumann G, Romheld V (1999) Root excretion of carboxylic acids and protons in phosphorus-deficient plants. Plant and Soil 211:121-130.

Ngwira AR, Aune JB, Mkwinda S (2012) On-farm evaluation of yield and economic benefit of short term maize legume intercropping systems under conservation agriculture in Malawi. Field Crops Research 132:149-157.

O'Brien MJ, Pugnaire FI, Armas C, Rodríguez - Echeverría S, Schöb C (2017) The shift from plant plant facilitation to competition under severe water deficit is spatially explicit. Ecology and Evolution 7:2441-2448.

Oksanen J, Blanchet, F. G., Friendly, M., Kindt, R., Legendre, P., McGlinn, D., Minchin, P.R., O'Hara, R. B., Simpson, G.L., Peter Solymos, P., H. Stevens, M. H., Eduard Szoecs, E., Wagner, H. (2017) vegan: Community Ecology Package. R package version 2.4-3.

Pearse SJ, Veneklaas EJ, Cawthray G, Bolland MDA, Lambers H (2007) Carboxylate composition of root exudates does not relate consistently to a crop species' ability to use phosphorus from aluminium, iron or calcium phosphate sources. New Phytologist 173:181-190.

Pearse SJ, Veneklaas EJ, Cawthray GR, Bolland MDA, Lambers H (2006) Carboxylate release of wheat, canola and 11 grain legume species as affected by phosphorus status. Plant and Soil 288:127-139.

Pelzer E, Bazot M, Makowski D, Corre-Hellou G, Naudin C, Al Rifai M, Baranger E, Bedoussac L, Biarnes V, Boucheny P, Carrouee B, Dorvillez D, Foissy D, Gaillard B, Guichard L, Mansard MC, Omon B, Prieur L, Yvergniaux M, Justes E, Jeuffroy MH (2012) Pea-wheat intercrops in low-input conditions combine high economic performances and low environmental impacts. European Journal of Agronomy 40:39-53. 
Pelzer E, Hombert N, Jeuffroy M-H, Makowski D (2014) Meta-analysis of the effect of nitrogen fertilization on annual cereal-legume intercrop production. Agronomy Journal 106:1775-1786.

Peñuelas J, Filella I (2001) Responses to a warming world. Science 294:793-795.

Phoenix GK, Johnson DA, Muddimer SP, Leake JR, Cameron DD (2020) Niche differentiation and plasticity in soil phosphorus acquisition among co-occurring plants. Nature Plants 1-6

Preece C, Peñuelas J (2020) A return to the wild: root exudates and food security. Trends in Plant Science 25:14-21.

R Core Team (2014) R: a language and environment for statistical computing. $R$ foundation for statistical computing, Vienna, Austria.

Raseduzzaman M, Jensen ES (2017) Does intercropping enhance yield stability in arable crop production? A meta-analysis. European Journal of Agronomy 91:25-33.

Ravenek JM, Mommer L, Visser EJW, van Ruijven J, van der Paauw JW, Smit-Tiekstra A, de Caluwe H, de Kroon H (2016) Linking root traits and competitive success in grassland species. Plant and Soil 407:39-53.

Ren WZ, Hu LL, Zhang J, Sun CP, Tang JJ, Yuan YG, Chen X (2014) Can positive interactions between cultivated species help to sustain modern agriculture? Frontiers in Ecology and the Environment 12:507-514.

Renard D, Tilman D (2019) National food production stabilized by crop diversity. Nature 571:257-260.

Richardson AE, Hadobas PA, Hayes JE (2000) Acid phosphomonoesterase and phytase activities of wheat (Triticum aestivum L.) roots and utilization of organic phosphorus substrates by seedlings grown in sterile culture. Plant Cell and Environment 23:397-405.

Richardson AE, Hocking PJ, Simpson RJ, George TS (2009) Plant mechanisms to optimise access to soil phosphorus. Crop and Pasture Science 60:124-143.

Richardson AE, Lynch JP, Ryan PR, Delhaize E, Smith FA, Smith SE, Harvey PR, Ryan MH, Veneklaas EJ, Lambers H, Oberson A, Culvenor RA, Simpson RJ (2011) Plant and microbial strategies to improve the phosphorus efficiency of agriculture. Plant and Soil 349:121-156.

Roscher C, Schmid B, Kolle O, Schulze E-D (2016) Complementarity among four highly productive grassland species depends on resource availability. Oecologia 181:571-582.

Rostamza M, Richards RA, Watt M (2013) Response of millet and sorghum to a varying water supply around the primary and nodal roots. Annals of Botany 112:439-446.

Rusinamhodzi L, Corbeels M, Nyamangara J, Giller KE (2012) Maize-grain legume intercropping is an attractive option for ecological intensification that reduces climatic risk for smallholder farmers in central Mozambique. Field Crops Research 136:12-22.

Ryan MH, Tibbett M, Edmonds-Tibbett T, Suriyagoda LDB, Lambers H, Cawthray GR, Pang J (2012) Carbon trading for phosphorus gain: the balance between rhizosphere carboxylates and arbuscular mycorrhizal symbiosis in plant phosphorus acquisition. Plant Cell and Environment 35:2170-2180.

Sattari SZ, Bouwman AF, Giller KE, van Ittersum MK (2012) Residual soil phosphorus as the missing piece in the global phosphorus crisis puzzle. Proceedings of the National Academy of Sciences of the United States of America 109:6348-6353.

Sattari SZ, van Ittersum MK, Bouwman AF, Smit AL, Janssen BH (2014) Crop yield response to soil fertility and N, P, K inputs in different environments: Testing and improving the QUEFTS model. Field Crops Research 157:35-46.

Shenoy VV, Kalagudi GM (2005) Enhancing plant phosphorus use efficiency for sustainable cropping. Biotechnology Advances 23:501-513.

Shipley B, De Bello F, Cornelissen JHC, Laliberté E, Laughlin DC, Reich PB (2016) Reinforcing loose foundation stones in trait-based plant ecology. Oecologia 180:923-931.

Song YN, Zhang FS, Marschner P, Fan FL, Gao HM, Bao XG, Sun JH, Li L (2007) Effect of intercropping on crop yield and chemical and microbiological properties in rhizosphere of wheat (Triticum aestivum L.), maize (Zea mays L.), and faba bean (Vicia faba L.). Biology and Fertility of Soils 43:565-574. 
Steidinger BS, Turner BL, Corrales A, Dalling JW (2015) Variability in potential to exploit different soil organic phosphorus compounds among tropical montane tree species. Functional Ecology 29:121-130.

Stomph T, Dordas C, Baranger A, de Rijk J, Dong B, Evers J, Gu C, Li L, Simon J, Jensen ES, Wang Q, Wang Y, Wang Z, Xu H, Zhang C, Zhang L, Zhang W-P, Bedoussac L, van der Werf W (2020) Designing intercrops for high yield, yield stability and efficient use of resources: Are there principles? In: Sparks DL (ed) Advances in Agronomy, vol 160. Academic Press, pp 1-50.

Stutter MI, Shand CA, George TS, Blackwell MSA, Dixon L, Bol R, MacKay RL, Richardson AE, Condron LM, Haygarth PM (2015) Land use and soil factors affecting accumulation of phosphorus species in temperate soils. Geoderma 257:29-39.

Sun B, Gao Y, Wu X, Ma H, Zheng C, Wang X, Zhang H, Li Z, Yang H (2019a) The relative contributions of $\mathrm{pH}$, organic anions, and phosphatase to rhizosphere soil phosphorus mobilization and crop phosphorus uptake in maize/alfalfa polyculture. Plant and Soil:1-17.

Sun BR, Gao YZ, Yang HJ, Zhang W, Li ZJ (2019b) Performance of alfalfa rather than maize stimulates system phosphorus uptake and overyielding of maize/alfalfa intercropping via changes in soil water balance and root morphology and distribution in a light chernozemic soil. Plant and Soil 439:145-161.

Tadano T, Ozawa K, Sakai H, Osaki M, Matsui H (1993) Secretion of acid-phosphatase by the roots of crop plants under phosphorus-deficient conditions and some properties of the enzyme secreted by lupin roots. Plant and Soil 155:95-98.

Tadano T, Sakai H (1991) Secretion of Acid-Phosphatase by the Roots of Several Crop Species under Phosphorus-Deficient Conditions. Soil Science and Plant Nutrition 37:129-140.

Tan M, Gou F, Stomph TJ, Wang J, Yin W, Zhang L, Chai Q, van der Werf W (2020a) Dynamic process-based modelling of crop growth and competitive water extraction in relay strip intercropping: Model development and application to wheat-maize intercropping. Field Crops Research 246:107613.

Tan Y, Hu F, Chai Q, Li G, Coulter JA, Zhao C, Yu A, Fan Z, Yin W (2020b) Expanding row ratio with lowered nitrogen fertilization improves system productivity of maize/pea strip intercropping. European Journal of Agronomy 113:125986.

Tang X, Placella SA, Daydé F, Bernard L, Robin A, Journet EP, Justes E, Hinsinger P (2016) Phosphorus availability and microbial community in the rhizosphere of intercropped cereal and legume along a P-fertilizer gradient. Plant and Soil:1-16.

Tiessen H, Moir JO (1993) Characterization of available P by sequential extraction. In: Carter MR (ed) Soil sampling and methods of analysis.75-86.

Tilman D, Balzer C, Hill J, Befort BL (2011) Global food demand and the sustainable intensification of agriculture. Proceedings of the National Academy of Sciences 108:20260-20264.

Tilman D, Cassman KG, Matson PA, Naylor R, Polasky S (2002) Agricultural sustainability and intensive production practices. Nature 418:671-677.

Tilman D, Isbell F, Cowles JM (2014) Biodiversity and ecosystem functioning. Annual Review of Ecology, Evolution, and Systematics 45:471-493.

Tilman D, Reich PB, Knops J, Wedin D, Mielke T, Lehman C (2001) Diversity and productivity in a long-term grassland experiment. Science 294:843-845.

Tinker PB, Nye PH (2000) Solute movement in the rhizosphere. Oxford University Press.

Trenbath B (1993) Intercropping for the management of pests and diseases. Field Crops Research 34:381-405.

Turnbull LA, Levine JM, Loreau M, Hector A (2013) Coexistence, niches and biodiversity effects on ecosystem functioning. Ecology Letters 16:116-127.

Turner BL (2008) Resource partitioning for soil phosphorus: a hypothesis. Journal of Ecology 96:698-702.

Vance CP, Uhde-Stone C, Allan DL (2003) Phosphorus acquisition and use: critical adaptations by plants for securing a nonrenewable resource. New Phytologist 157:423-447. 
Vandermeer J (1997) Syndromes of production: an emergent property of simple agroecosystem dynamics. Journal of Environmental Management 51:59-72.

Vandermeer JH (1989) The Ecology of Intercropping. Cambridge University Press.

Vengavasi K, Pandey R (2018) Root exudation potential in contrasting soybean genotypes in response to low soil phosphorus availability is determined by photo-biochemical processes. Plant Physiology and Biochemistry 124:1-9.

Viguier L, Bedoussac L, Journet E-P, Justes E (2018) Yield gap analysis extended to marketable grain reveals the profitability of organic lentil-spring wheat intercrops. Agronomy for Sustainable Development 38:39.

Violle C, Navas ML, Vile D, Kazakou E, Fortunel C, Hummel I, Garnier E (2007) Let the concept of trait be functional! Oikos 116:882-892.

Vogan PJ, Sage RF (2011) Water-use efficiency and nitrogen-use efficiency of C3-C4 intermediate species of Flaveria Juss. (Asteraceae). Plant, cell \& environment 34:1415-1430.

Voisin AS, Gueguen J, Huyghe C, Jeuffroy MH, Magrini MB, Meynard JM, Mougel C, Pellerin S, Pelzer E (2014) Legumes for feed, food, biomaterials and bioenergy in Europe: a review. Agronomy for Sustainable Development 34:361-380.

Wagg C, Ebeling A, Roscher C, Ravenek J, Bachmann D, Eisenhauer N, Mommer L, Buchmann N, Hillebrand H, Schmid B, Weisser WW (2017) Functional trait dissimilarity drives both species complementarity and competitive disparity. Functional Ecology 31:2320-2329.

Wang D, Marschner P, Solaiman Z, Rengel Z (2007) Growth, P uptake and rhizosphere properties of intercropped wheat and chickpea in soil amended with iron phosphate or phytate. Soil Biology and Biochemistry 39:249-256.

Wang X, Deng X, Pu T, Song C, Yong T, Yang F, Sun X, Liu W, Yan Y, Du J (2017) Contribution of interspecific interactions and phosphorus application to increasing soil phosphorus availability in relay intercropping systems. Field Crops Research 204:12-22.

Wang Y, Lambers H (2019) Root-released organic anions in response to low phosphorus availability: recent progress, challenges and future perspectives. Plant and Soil:1-22.

Watt M, Evans JR (2003) Phosphorus acquisition from soil by white lupin (Lupinus albus L.) and soybean (Glycine $\max$ L.), species with contrasting root development. Plant and Soil 248:271-283.

Weiner J (1990) Asymmetric Competition in Plant-Populations. Trends in Ecology \& Evolution 5:360-364.

Wen Z, Li H, Shen J, Rengel Z (2017) Maize responds to low shoot P concentration by altering root morphology rather than increasing root exudation. Plant and Soil 416:377-389.

Westerman RL (1990) Soil testing and plant analysis. Soil Science Society of America, Inc

Wezel A, Casagrande M, Celette F, Vian JF, Ferrer A, Peigne J (2014) Agroecological practices for sustainable agriculture. A review. Agronomy for Sustainable Development 34:1-20.

Whitmore AP, Schröder JJ (2007) Intercropping reduces nitrate leaching from under field crops without loss of yield: A modelling study. European Journal of Agronomy 27:81-88.

Willey RW (1979) Intercropping, its importance and research need I. Competition and yield advantage. Field Crops Abstracts 32:1-10.

Willey RW (1990) Resource Use in Intercropping Systems. Agricultural Water Management 17:215-231.

Xia HY, Wang ZG, Zhao JH, Sun JH, Bao XG, Christie P, Zhang FS, Li L (2013) Contribution of interspecific interactions and phosphorus application to sustainable and productive intercropping systems. Field Crops Research 154:53-64.

Xu Z, Li C, Zhang C, Yu Y, van der Werf W, Zhang F (2020) Intercropping maize and soybean increases efficiency of land and fertilizer nitrogen use; A meta-analysis. Field Crops Research 246:107661.

Xue Y, Xia H, Christie P, Zhang Z, Li L, Tang C (2016) Crop acquisition of phosphorus, iron and zinc from soil in cereal/legume intercropping systems: a critical review. Annals of Botany 117:363-377. 
Yan YH, Gong WZ, Yang WY, Wan Y, Chen XL, Chen ZQ, Wang LY (2010) Seed treatment with uniconazole powder improves soybean seedling growth under shading by corn in relay strip intercropping system. Plant Production Science 13:367-374.

Yan YH, Wan Y, Liu WG, Wang XC, Yong TW, Yang WY, Zhao LL (2015) Influence of seed treatment with uniconazole powder on soybean growth, photosynthesis, dry matter accumulation after flowering and yield in relay strip intercropping system. Plant Production Science 18:295-301.

Yang C, Huang G, Chai Q, Luo Z (2011) Water use and yield of wheat/maize intercropping under alternate irrigation in the oasis field of northwest China. Field Crops Research 124:426-432.

Yu Y (2016) Crop yields in intercropping: meta-analysis and virtual plant modelling. Wageningen University, Wageningen

Yu Y, Stomph T-J, Makowski D, van der Werf W (2015) Temporal niche differentiation increases the land equivalent ratio of annual intercrops: A meta-analysis. Field Crops Research 184:133-144.

Yu Y, Stomph TJ, Makowski D, Zhang LZ, van der Werf W (2016) A meta-analysis of relative crop yields in cereal/legume mixtures suggests options for management. Field Crops Research 198:269-279.

Zemunik G, Turner BL, Lambers H, Laliberte E (2015) Diversity of plant nutrient-acquisition strategies increases during long-term ecosystem development. Nature Plants 1:1-4.

Zhang C, Dong Y, Tang L, Zheng Y, Makowski D, Yu Y, Zhang F, van der Werf W (2019) Intercropping cereals with faba bean reduces plant disease incidence regardless of fertilizer input; a meta-analysis. European Journal of Plant Pathology:1-12.

Zhang CC, Postma JA, York LM, Lynch JP (2014) Root foraging elicits niche complementarity-dependent yield advantage in the ancient 'three sisters' (maize/bean/squash) polyculture. Annals of Botany 114:1719-1733.

Zhang D, Zhang C, Tang X, Li H, Zhang F, Rengel Z, Whalley WR, Davies WJ, Shen J (2016) Increased soil phosphorus availability induced by faba bean root exudation stimulates root growth and phosphorus uptake in neighbouring maize. New Phytologist 209:823-831.

Zhang FS, Li L (2003) Using competitive and facilitative interactions in intercropping systems enhances crop productivity and nutrient-use efficiency. Plant and Soil 248:305-312.

Zhang FS, Shen JB, Zhang JL, Zuo YM, Li L, Chen XP (2010) Rhizosphere processes and management for improving nutrient use efficiency and crop productivity: implications for China. Advances in agronomy 107:1-32.

Zhang L, van der Werf W, Bastiaans L, Zhang S, Li B, Spiertz JHJ (2008) Light interception and utilization in relay intercrops of wheat and cotton. Field Crops Research 107:29-42.

Zhou LL, Cao J, Zhang FS, Li L (2009) Rhizosphere acidification of faba bean, soybean and maize. Science of the Total Environment 407:4356-4362.

Zhu J, van der Werf W, Anten NPR, Vos J, Evers JBC (2015) The contribution of phenotypic plasticity to complementary light capture in plant mixtures. New Phytologist 207:1213-1222.

Zhu Y, Chen H, Fan J, Wang Y, Li Y, Chen J, Fan J, Yang S, Hu L, Leung H (2000) Genetic diversity and disease control in rice. Nature 406:718-722.

Zuo Y, Zhang F, Li X, Cao Y (2000) Studies on the improvement in iron nutrition of peanut by intercropping with maize on a calcareous soil. Plant and Soil 220:13-25.

Zuur A, Ieno E, Walker N, Saveliev A, Smith G (2009) Mixed effects models and extensions in ecology with R. Gail M, Krickeberg K, Samet JM, Tsiatis A, Wong W, editors. New York, NY: Spring Science and Business Media 


\section{Appendix A}
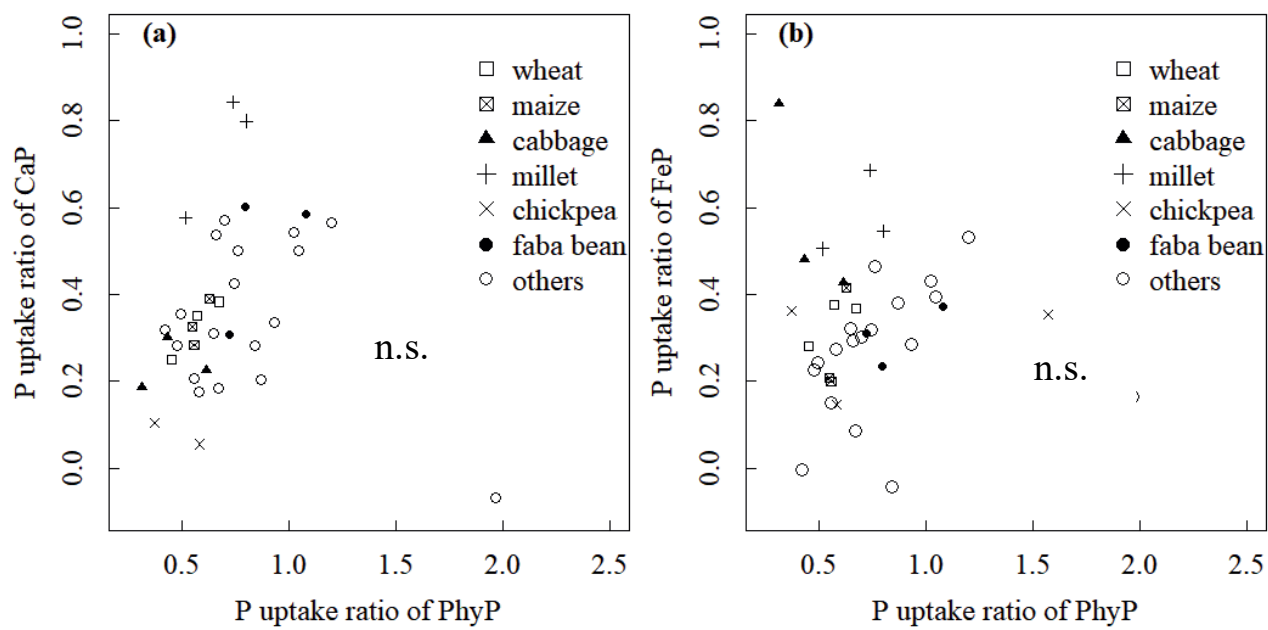

Fig. S2.1 The correlation between the $\mathrm{P}$ uptake ratio of species supplied with $\mathrm{CaP}$ vs $\mathrm{PhyP}(\mathrm{a}, r=0.10$, $P=0.54$ ); FeP vs PhyP (b, $r=-0.04, P=0.81$ ). The different shapes of symbols indicate the six selected species for Experiment 2. The data points in each panel represent individual replicates. n.s. represents a non-significant correlation (Tukey's HSD, $P=0.05$ ). 


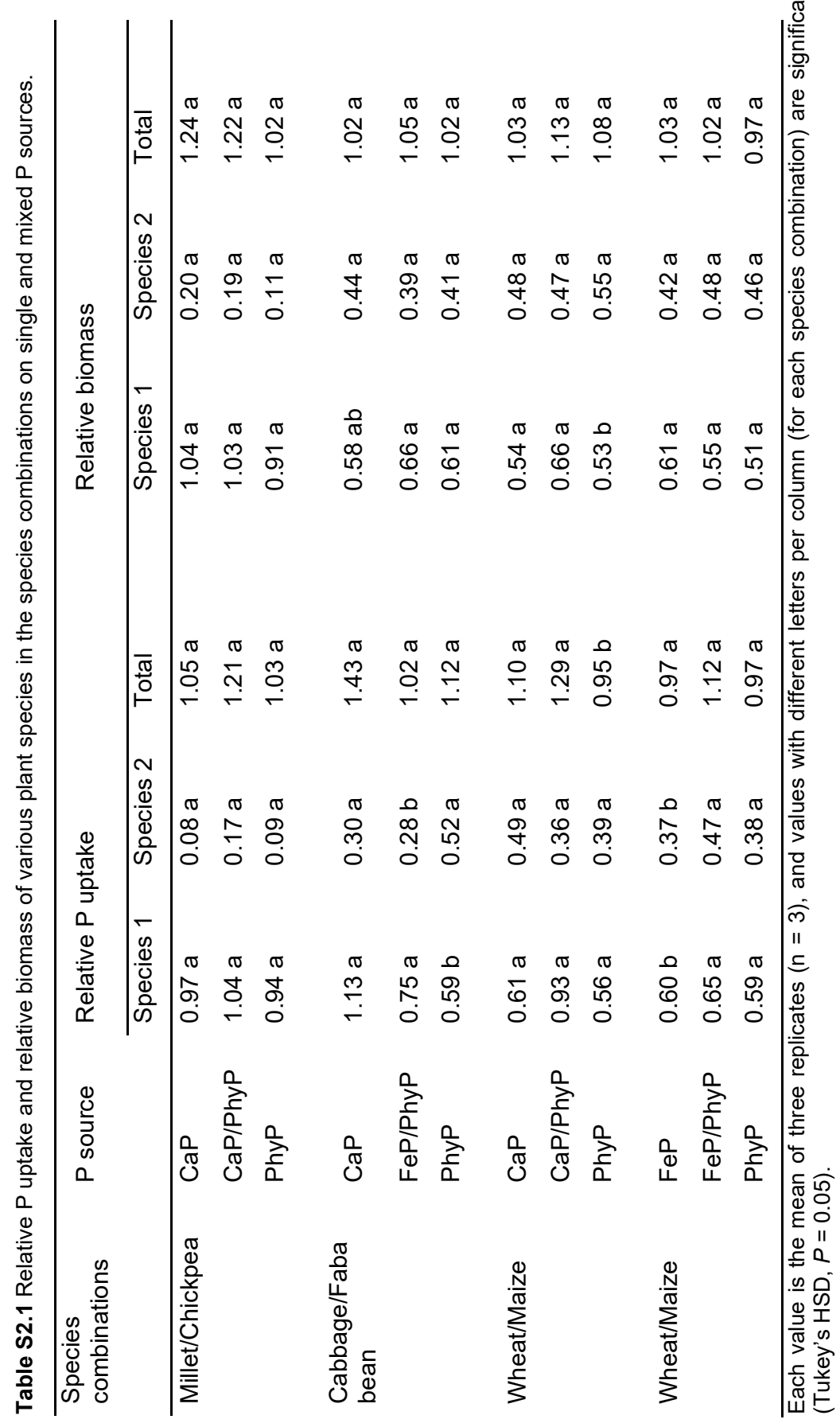




\section{Appendix B}

\section{Methods S3.1 The method to determine soil $P$ fractions}

The P pools of each soil were determined using the method described by Tiessen and Moir (1993). Briefly, $0.5 \mathrm{~g}$ of soil was weighed and sequentially extracted by shaking for $16 \mathrm{~h}$ with a solution. (1) First, the soil sample was shaken for $16 \mathrm{~h}$ with $30 \mathrm{~mL}$ deionized water with two anionic resin strip (25×62.5 mm, Xue Jiete Science and Technology Ltd, Beijing) which had been saturated overnight with bicarbonate ions, $\mathrm{NaHCO}_{3} 0.5 \mathrm{M}, \mathrm{pH} 8.5$, then the resin trip was placed in a clean $50 \mathrm{~mL}$ tube and shaken with $20 \mathrm{~mL} 0.5 \mathrm{M} \mathrm{HCl}$ for $16 \mathrm{~h}$ (Resin-P). (2) Second, $30 \mathrm{~mL}$ of $0.5 \mathrm{M} \mathrm{NaHCO}_{3}$ was used after adjustment to $\mathrm{pH} 8.5$ ( $\left.\mathrm{NaHCO}_{3}-\mathrm{P}\right)$. (3) Third, $30 \mathrm{~mL}$ of $0.1 \mathrm{M} \mathrm{NaOH}$ was used (NaOH-P). (4) Subsequently, $30 \mathrm{~mL}$ of $1 \mathrm{M} \mathrm{HCl}$ was used (1 M HCl-P). Then the soil residue was heated with 10 $\mathrm{mL}$ of concentrated $\mathrm{HCl}$ at $80^{\circ} \mathrm{C}$ in a water bath for $10 \mathrm{~min}$ and $5 \mathrm{~mL}$ of concentrated $\mathrm{HCl}$ were added afterwards, prior to making the volume to $50 \mathrm{~mL}$ with deionized water (conc. HCl-P). Finally, the soil residue was mineralized with concentrated $\mathrm{H}_{2} \mathrm{SO}_{4}(300 \mu \mathrm{L}$ per $30 \mathrm{mg}$ soil residue subsample) at $350{ }^{\circ} \mathrm{C}$ for $3 \mathrm{~h}$ (Residue-P). The supernatant solution was filtered with $0.45 \mu \mathrm{m}$ cellulose nitrate filters and filters were washed with the extractant of the following step to recover extra soil particles. At each step, the inorganic $\mathrm{P}\left(\mathrm{P}_{\mathrm{i}}\right)$ concentration in all extracts was determined within $24 \mathrm{~h}$ using the molybdenum blue method (Murphy and Reley 1962). The total $\mathrm{P}\left(\mathrm{P}_{\mathrm{t}}\right)$ in $\mathrm{NaHCO}_{3}, \mathrm{NaOH}$ and conc. HCl-P fractions were measured by digestion of the extract with $0.5 \mathrm{~g}$,

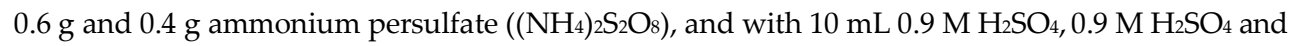
deionized water, respectively. Organic $\mathrm{P}\left(\mathrm{P}_{\mathrm{o}}\right)$ in these fractions was calculated by subtracting the $\mathrm{P}_{\mathrm{i}}$ from $P_{t}$.

\section{Methods S3.2 Determination of soil buffering capacity}

The soil buffering capacity of carboxylate was determined by extracting the citrate from soil with a series of water soil ratios (5:1, 10:1, 20:1, 50:1, 100:1, 200:1). $25 \mathrm{~g}$ air dry soils (Changping, Zhangye soil: $25 \mathrm{~g}$; Guangzhou, Kunming soil: $16.67 \mathrm{~g}$ soil+8.33 g sand) were added with $4.25 \mathrm{~mL}$ sodium citrate solution $\left(4 \mathrm{~g} \mathrm{~L}^{-1}\right)$. The final water content of the soil was $17 \%$, which was consistent with the soil water content of soil in the pot experiment. The soils were put in the fridge for 24 hours prior to citrate extraction.

A series of wet soils 11.7, 5.85, 2.93, 1.17, 0.59, $0.29 \mathrm{~g}$ (the weight of dry soils + the water content) were sampled to be in a beaker and added $50 \mathrm{~mL}$ of $\mathrm{CaCl}_{2}$ solution. After shaking the beaker for 1 $\mathrm{min}$, about $6 \mathrm{~mL}$ of the soil solutions were sampled to a centrifuge tube and added two drops of concentrated phosphoric acid to prevent micro-degradation of the citrate. Then the solutions were stored at $-20^{\circ} \mathrm{C}$ before analysis. Then the supernatants were filtered $(0.45 \mu \mathrm{m})$ into the centrifuge tubes before the enzymatic analysis. Then we tried different correlations between the determined citrate concentration in the extract and solution soil ratios to estimate the citrate concentration in the soil. 

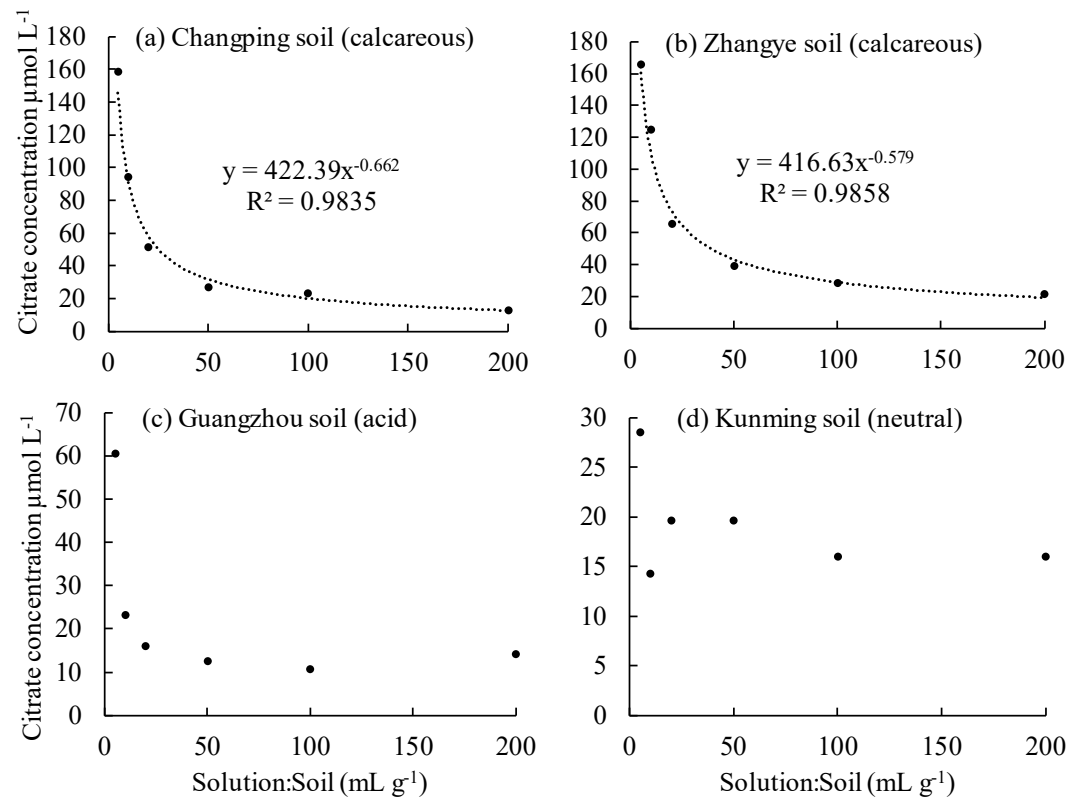

Figure in Methods S3.2 The relationship between citrate concentration determined in the solution and solution soil ratio.

\section{Methods S3.3 Preliminary experiment about sole millet and sole chickpea on Changping soil with different levels of potassium phosphorus (KP).}

One preliminary pot experiment with $1 \mathrm{~kg}$ of soil supplied with $0,10,25,50,100,200 \mathrm{mg} \mathrm{kg}^{-1} \mathrm{P}$ in form of KP. Four plants of millet and four chickpea plants were grown in each pot. Millet was harvested at 38 days after sowing, chickpea was harvested at 60 days after sowing.

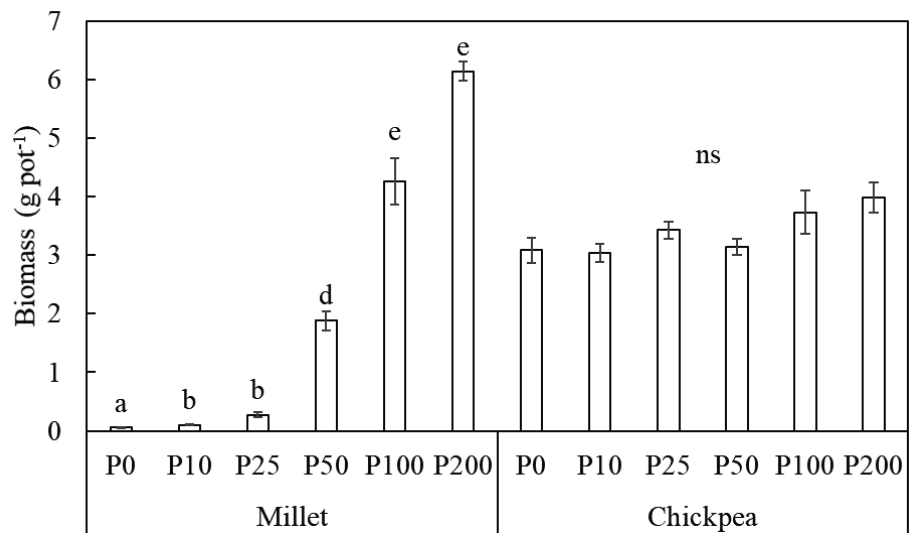

Figure in Methods S3.3 Biomass of millet and chickpea with different levels of potassium phosphorus (KP) supply. P0, P10, P25, P50, P100 and P200 represent treatments with 0, 10, 25, 50, 100, $200 \mathrm{mg} \mathrm{kg}^{-1} \mathrm{P}$ supply in form of KP. Different letters denote significant difference between KP levels $(P<0.05)$, ns denotes no significant difference between KP levels. 


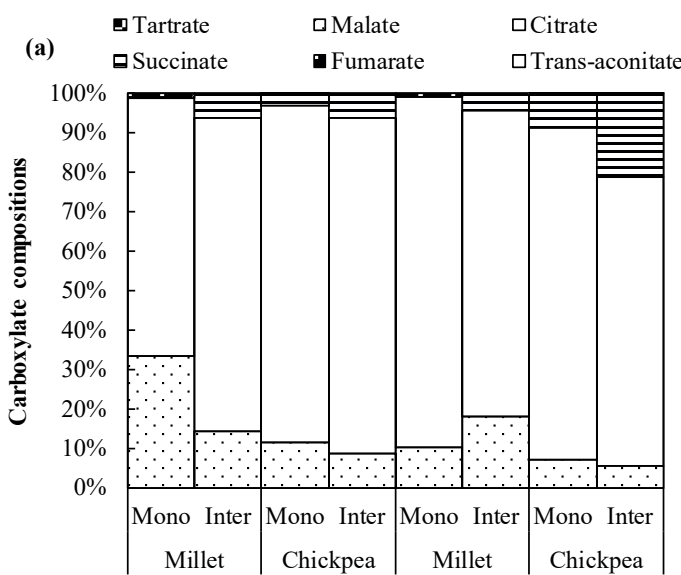

(c)

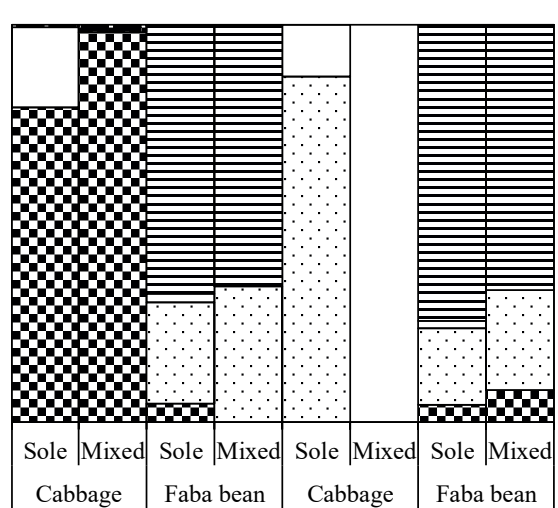

(d)
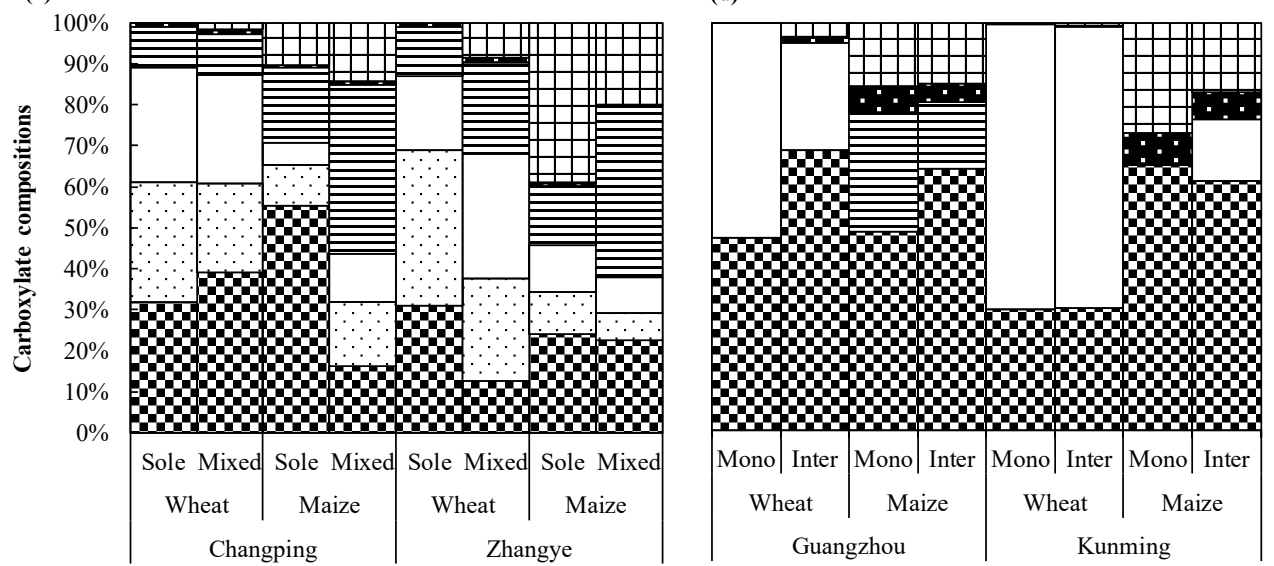

Fig. S3.1 Percentage composition of carboxylates of species in monocultures and mixtures for all the species combinations on Changping, Zhangye, Guangzhou and Kunming soil. (a) millet and chickpea on Changping and Zhangye soil; (b) cabbage and faba bean in Guangzhou and Kunming soil; (c) wheat and maize on Changping and Zhangye soil; (d) wheat and maize on Guangzhou and Kunming soil. 


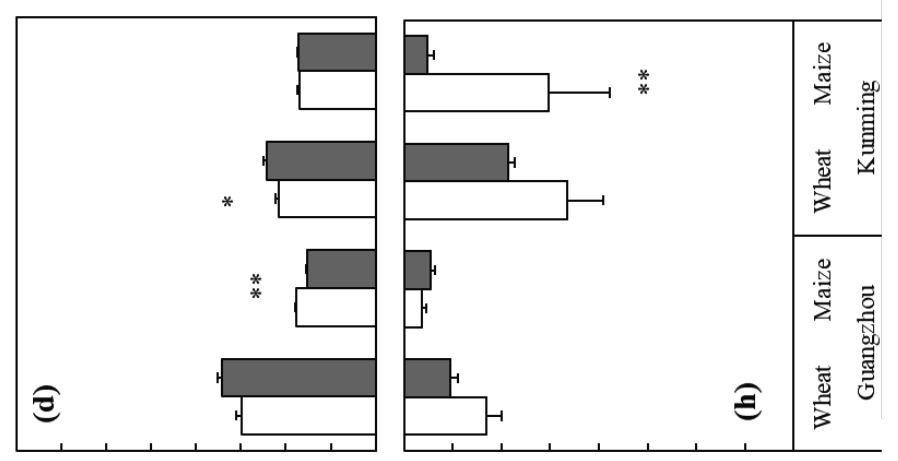

ब.

क्रे क口

त

ó 空

픈

흥 응 은

흔 즌드

U 응

등 오

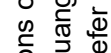

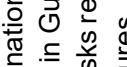

들

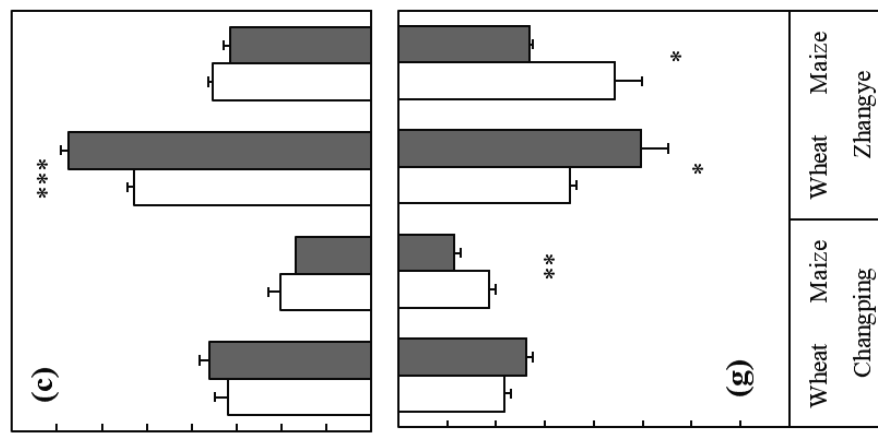

ठ요 क

क $\frac{\pi}{\circ} \frac{1}{\overline{1}}$

잉

응 은 응

क $\frac{\pi}{\varepsilon} .5$

卷

$\overline{\bar{\sigma}} \frac{0}{8}$ 웡

흔 융 휴 के

\%)

定

줄 을

흥

त 0 ठ

๙

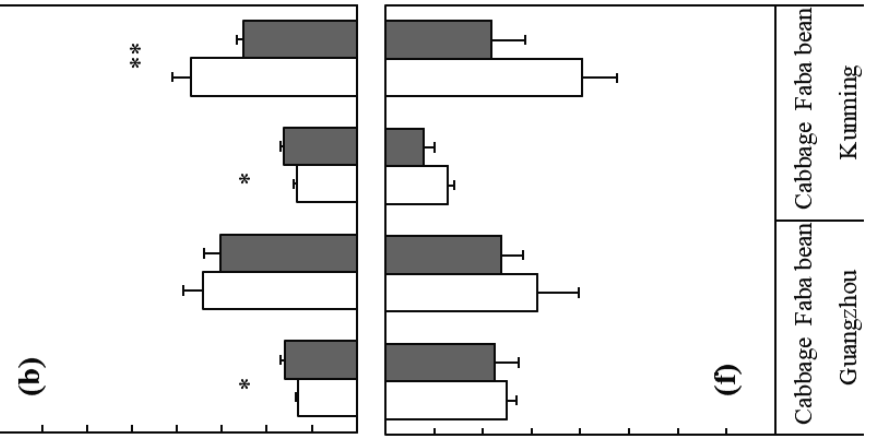

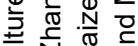

О $\frac{\pi}{0}$

든 응 응

이유

$\subseteq$ 응

क के

\%

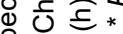

क वे के

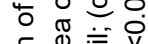

응 음

त्ञ

릉

Ð 둥요

드 तิ $\frac{5}{N}$

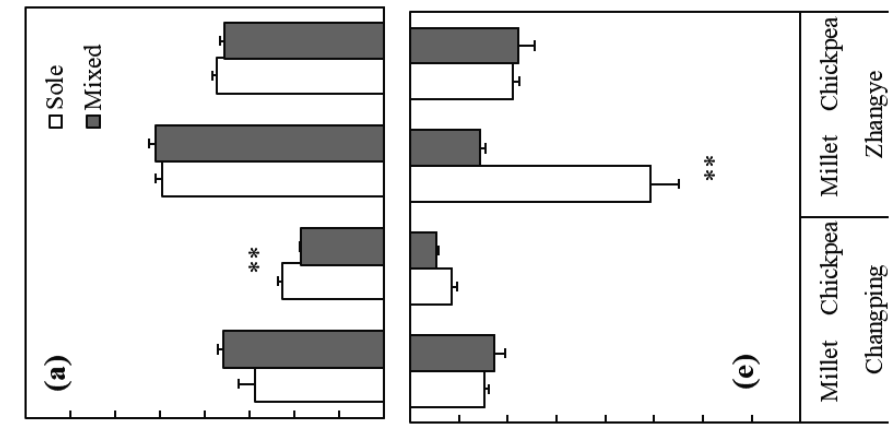

0 t 0

므 产

둥

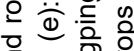

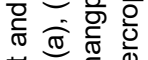

눙

का क

¿

ㄷำ है

क्ष

중

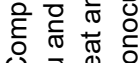

ช ว

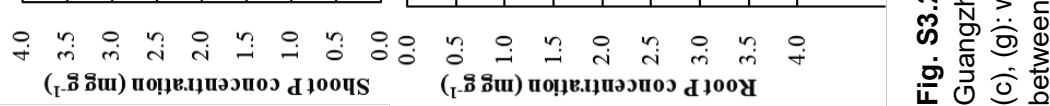




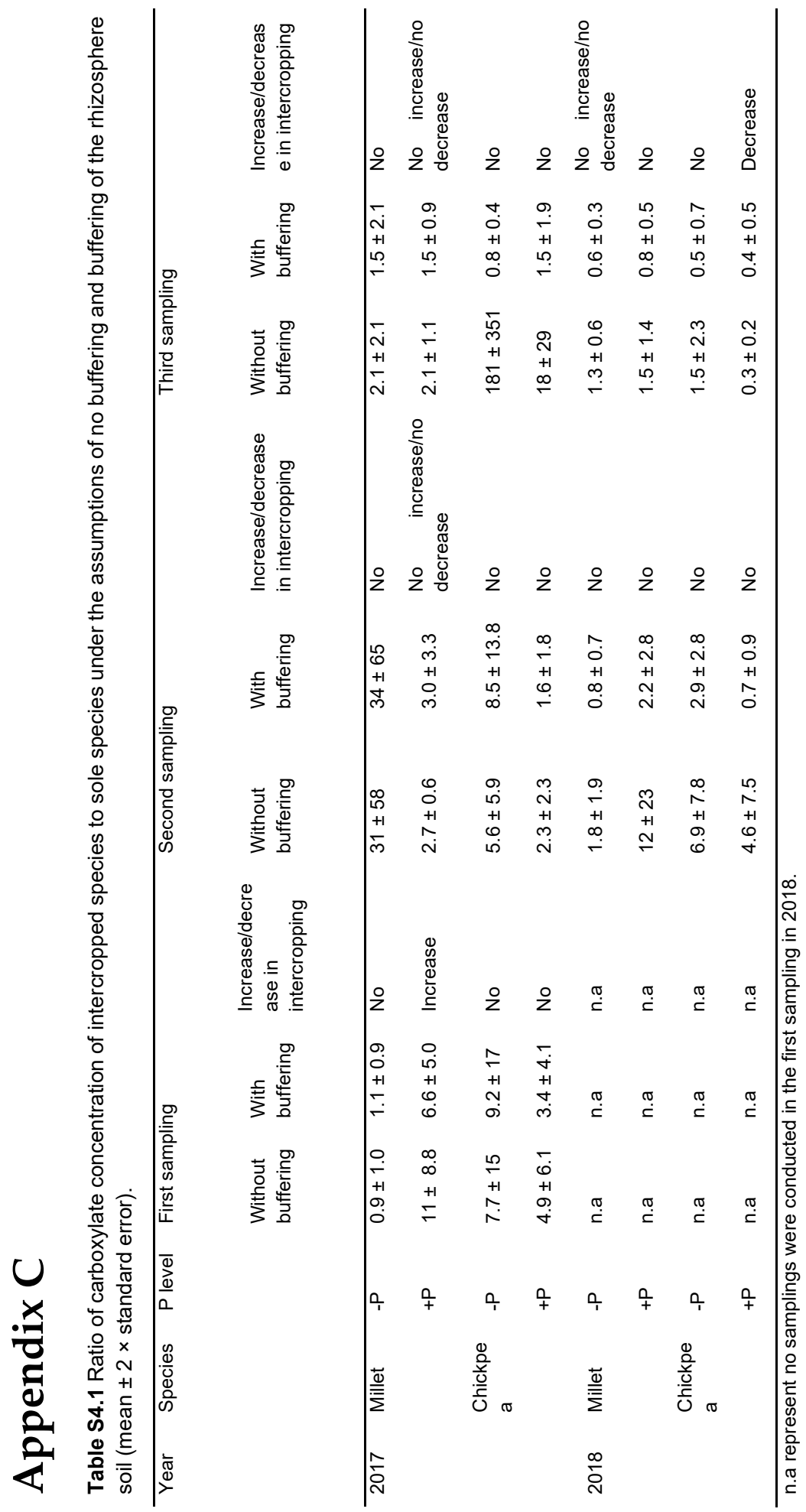


Appendix C

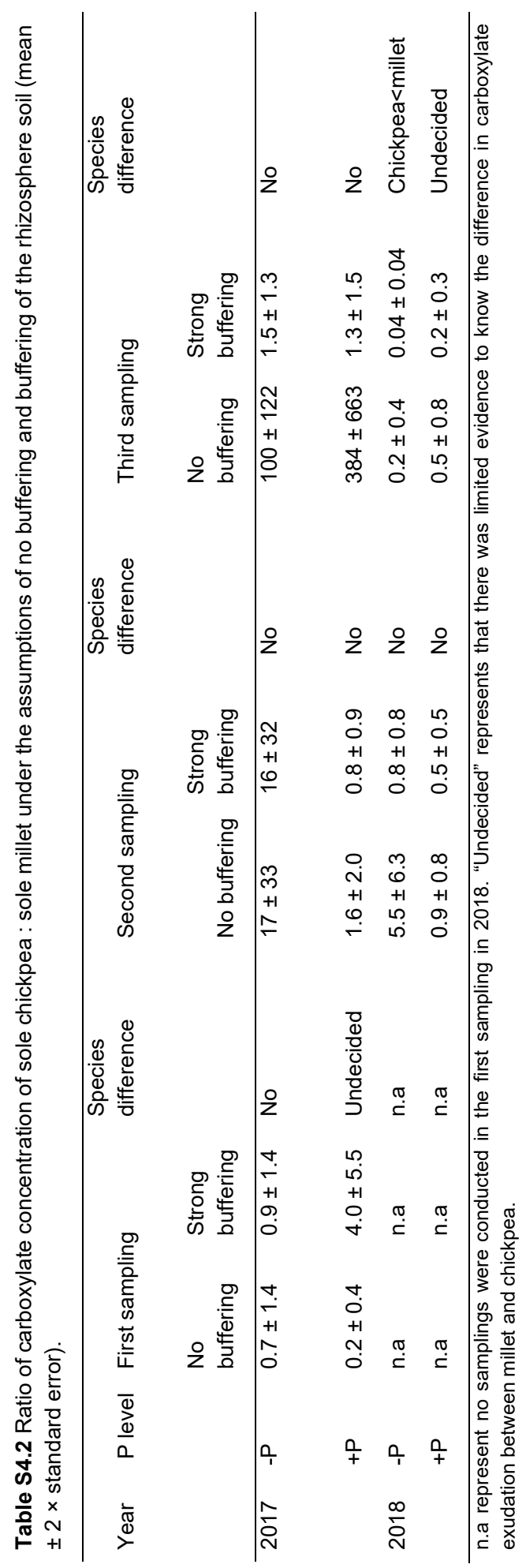


Table S4.3 $P$ values of three-way ANOVA (crop species $\times P$ level $\times$ cropping system) on phytase activity and alkaline activity at the $33^{\text {rd }}$ day and $68^{\text {th }}$ day of co-growth of intercropped millet and chickpea in 2017 and the $62^{\text {nd }}$ and $97^{\text {th }}$ day of co-growth in 2018 .

\begin{tabular}{|c|c|c|c|c|c|c|}
\hline \multirow[b]{2}{*}{ Sampling time } & \multirow[b]{2}{*}{ Factors } & \multicolumn{3}{|l|}{2017} & \multicolumn{2}{|l|}{2018} \\
\hline & & \multicolumn{2}{|c|}{$\begin{array}{l}\text { Phytase } \\
\text { activity }\end{array}$} & $\begin{array}{l}\text { Alkaline } \\
\text { phosphatase } \\
\text { activity }\end{array}$ & $\begin{array}{l}\text { Phytase } \\
\text { activity }\end{array}$ & $\begin{array}{l}\text { Alkaline } \\
\text { phosphatase } \\
\text { activity }\end{array}$ \\
\hline \multirow[t]{7}{*}{$\begin{array}{l}33^{\text {rd }} \text { day } \\
\text { co-growth }\end{array}$} & Species & 0.53 & & $0.03^{*}$ & n.a & n.a \\
\hline & $\mathrm{P}$ & 0.24 & & 0.30 & n.a & n.a \\
\hline & Cropping & $<0.001$ & $1^{* * *}$ & 0.16 & n.a & n.a \\
\hline & Species $\times P$ & 0.59 & & 0.92 & n.a & n.a \\
\hline & $\begin{array}{l}\text { Species } \times \text { cro } \\
\text { pping }\end{array}$ & 0.30 & & 0.71 & n.a & n.a \\
\hline & P×Cropping & 0.37 & & 0.32 & n.a & n.a \\
\hline & $\begin{array}{l}\text { Species } \times \mathrm{P} \times \\
\text { Cropping }\end{array}$ & 0.90 & & 0.92 & n.a & n.a \\
\hline $\begin{array}{l}68^{\text {th }} \text { day of } \\
\text { co-growth }(2017)\end{array}$ & Species & 0.12 & & $<0.001^{\star \star *}$ & 0.50 & $0.001^{* *}$ \\
\hline \multirow[t]{6}{*}{$62^{\text {nd }}(2018)$} & $P$ & $0.02^{*}$ & & 0.09 & 0.73 & 0.98 \\
\hline & Cropping & 0.14 & & 0.13 & 0.10 & $0.03^{*}$ \\
\hline & Species $\times \mathrm{P}$ & 0.99 & & 0.37 & 0.44 & 0.73 \\
\hline & $\begin{array}{l}\text { Species } \times \text { Cro } \\
\text { pping }\end{array}$ & 0.07 & & 0.11 & 0.50 & 0.23 \\
\hline & P×Cropping & 0.58 & & 0.31 & 0.53 & 0.99 \\
\hline & $\begin{array}{l}\text { Species } \times \mathrm{P} \times \\
\text { Cropping }\end{array}$ & 0.32 & & 0.51 & 0.79 & 0.29 \\
\hline $\begin{array}{l}102^{\text {nd }} \text { day of } \\
\text { co-growth }(2017)\end{array}$ & Species & n.a & & n.a & 0.95 & $<0.001^{* * *}$ \\
\hline \multirow[t]{6}{*}{$97^{\text {th }}(2018)$} & $P$ & n.a & & n.a & 0.44 & 0.76 \\
\hline & Cropping & n.a & & n.a & 0.11 & 0.76 \\
\hline & Species $\times P$ & & n.a & n.a & 0.92 & 0.20 \\
\hline & Species $\times$ Crop & ing & n.a & n.a & 0.51 & 0.67 \\
\hline & P×Cropping & & n.a & n.a & 0.50 & 0.30 \\
\hline & Species $\times P \times C$ & opping & n.a & n.a & 0.28 & 0.25 \\
\hline
\end{tabular}




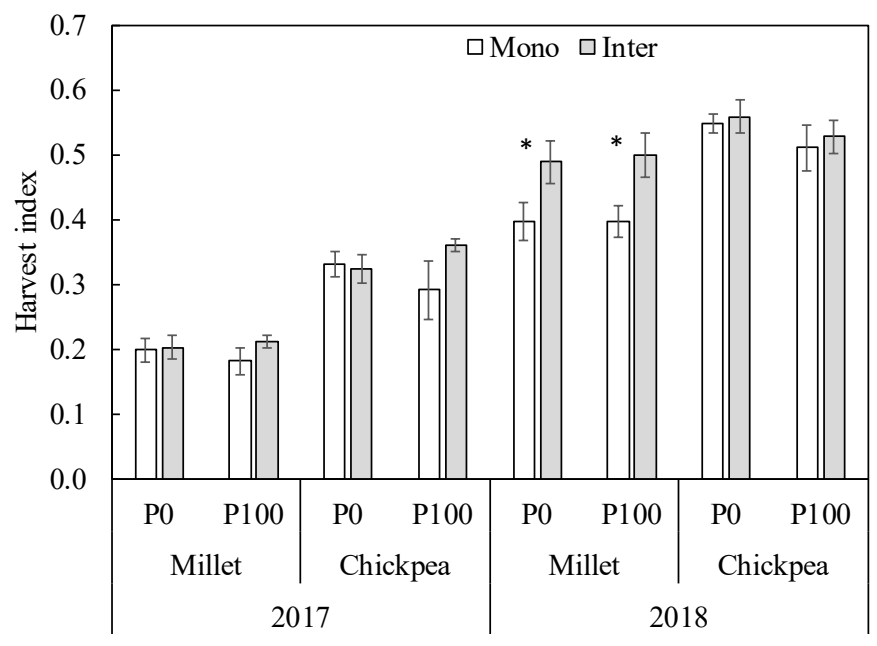

Fig. S4.1 Harvest index (the ratio of harvested grain to total biomass) of millet and chickpea in monoculture (Mono) and intercropping (Inter). Asterisks mean significant difference between monoculture and intercropping under $\mathrm{P} 0$ or $\mathrm{P} 100$ treatments within a year using t-test with unequal variance. 

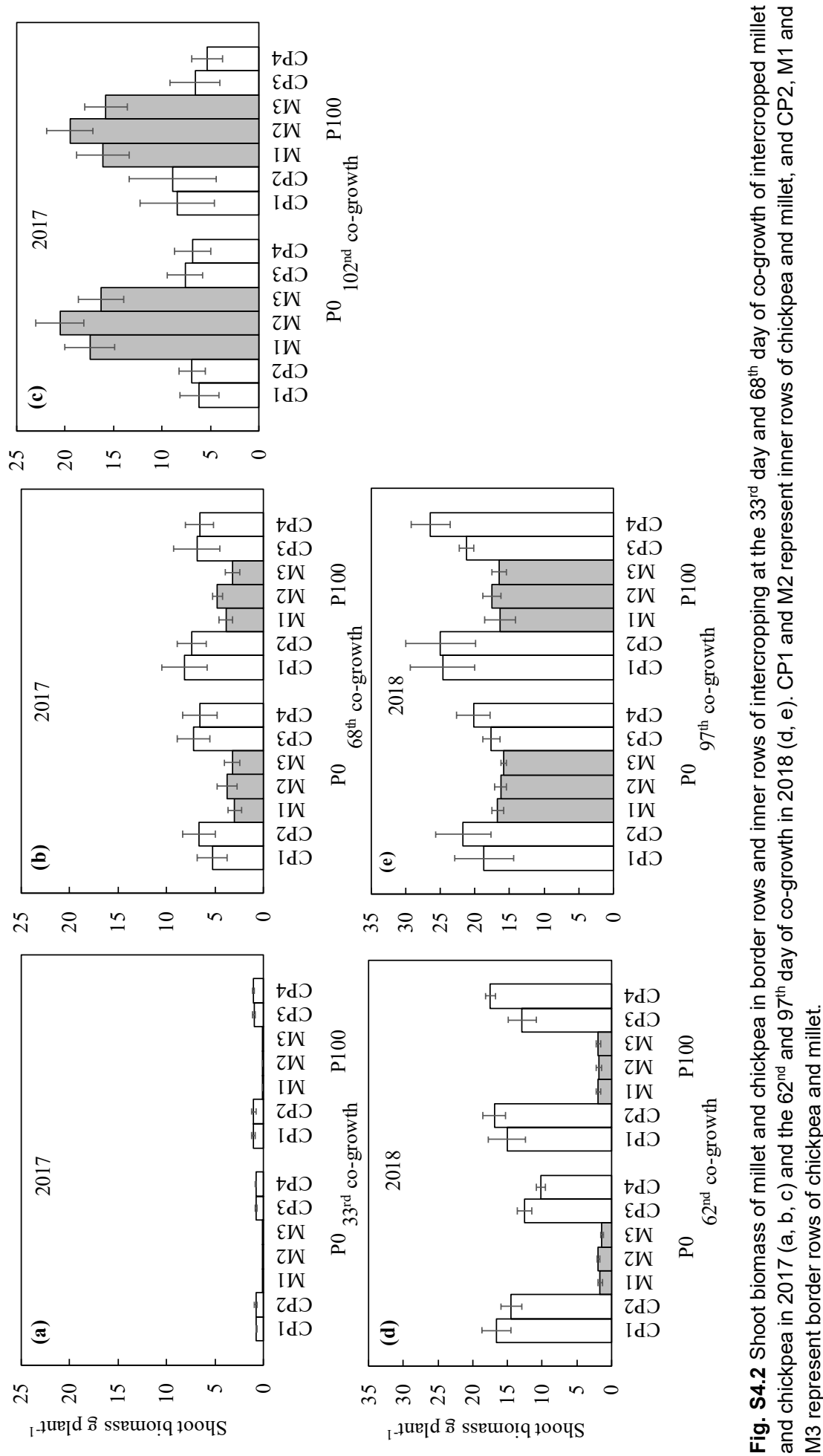

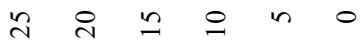

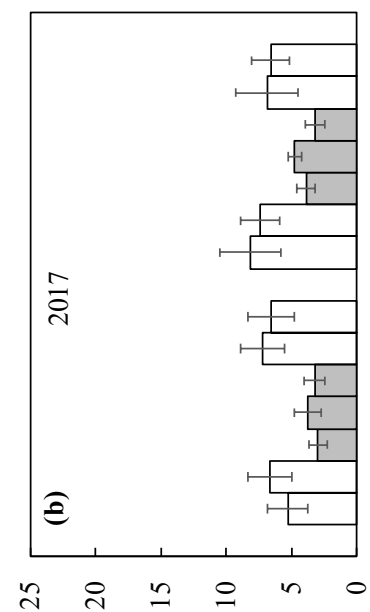

$t d \supset$

$\varepsilon d \supset$

zW 8

IW

Zdว

Id?

$t d \supset$

$\varepsilon \mathrm{d} D$

$\varepsilon W \&$

IW

Zd 2

Id

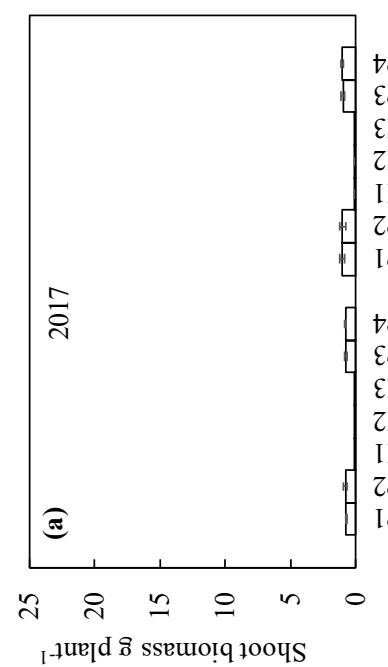

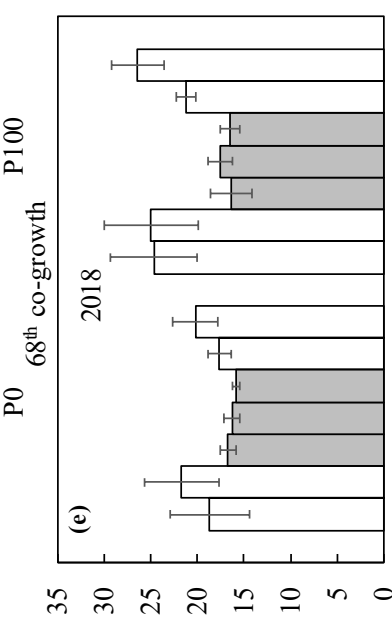

td 2

Ed

EN 8 त

zW $\bar{a}$

IW

Zd $\supset$

Idว

$\downarrow$ dつ

$\varepsilon d \supset$

EW

IW

Zd 2

Id

tdว

$\varepsilon d \supset$

⿰N \& 造宁

IN $a$ 证 둥

Id

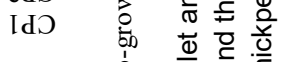

td $\stackrel{0}{\bar{\varepsilon}} \frac{0}{0}$

Ed J पूँ

EW \&

IW

zdว

IdD

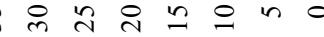

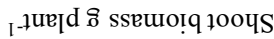



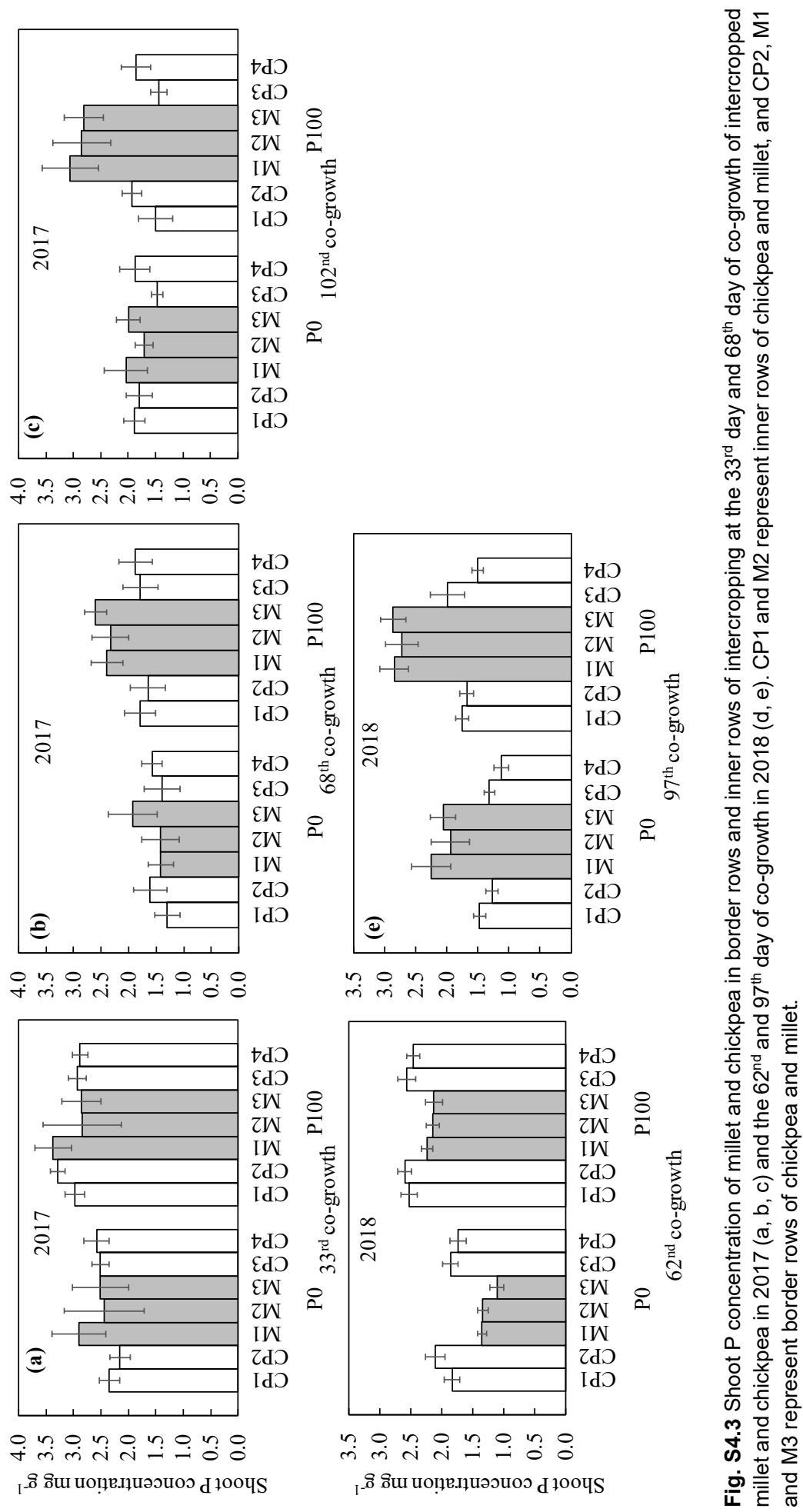

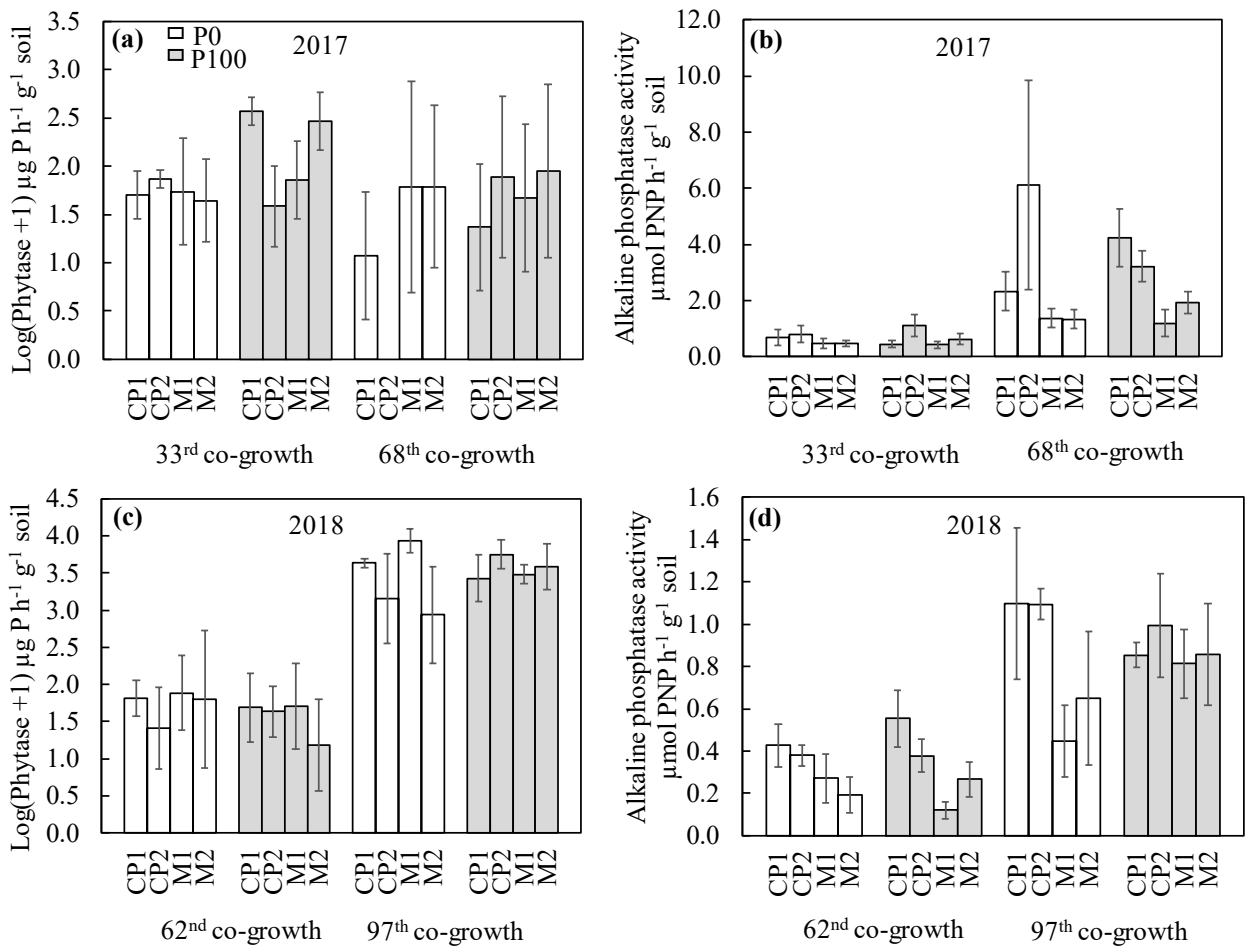

Fig. S4.4 Phytase activity ( $a, c)$ and alkaline phosphatase activity (b, d) of millet and chickpea in border rows (M1, CP2) and inner rows (CP1, M2) of millet/chickpea intercropping in year 2017 and 2018. The legend of " $33^{\text {rd }}$ co-growth" represents the $33^{\text {rd }}$ day of co-growth of intercropped millet and chickpea, with similar meanings for other legends. The legends also apply to other figures. 

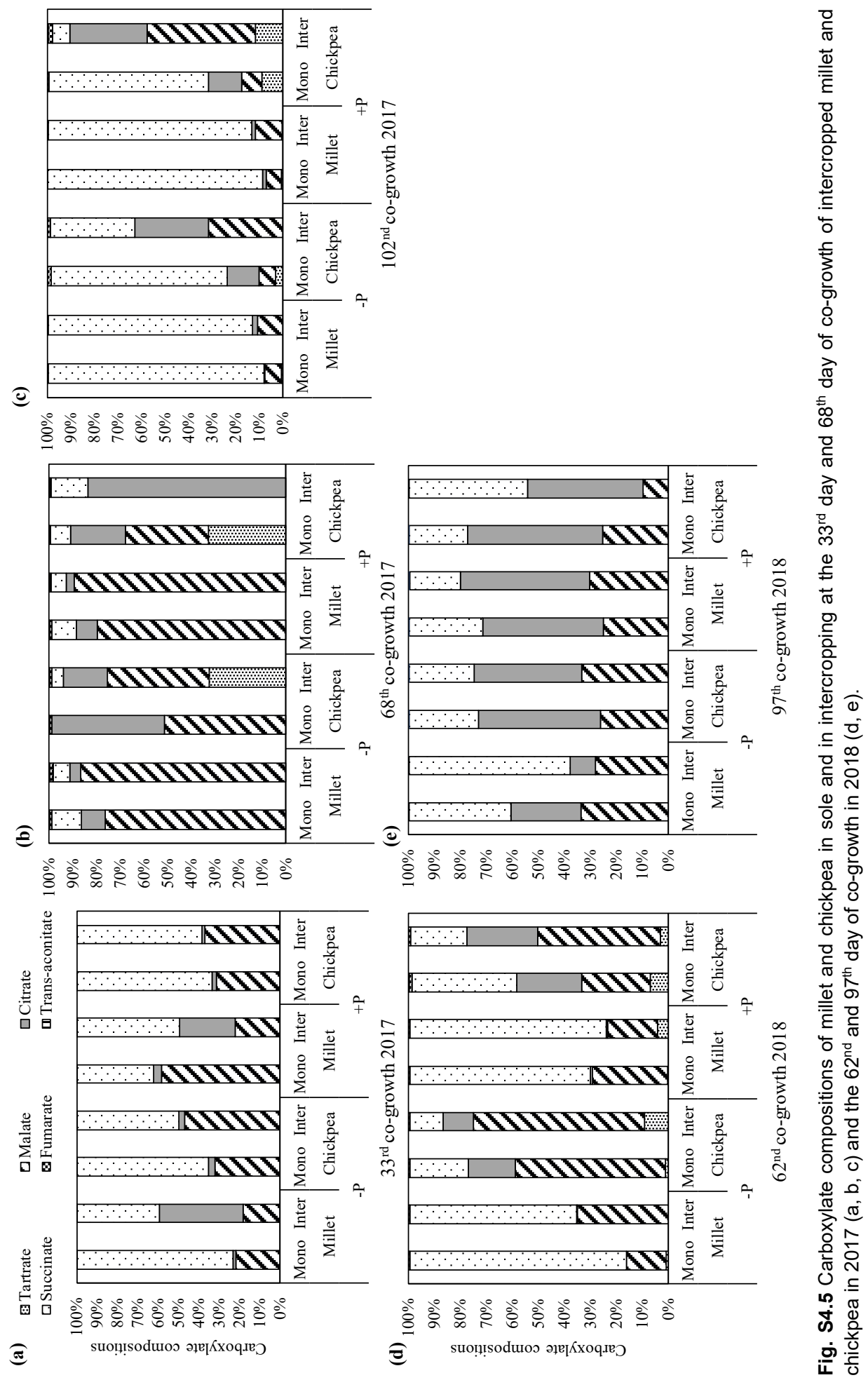


\section{Appendix D}

\section{Methods S5.1 Inclusion criteria, and procedure of paper selection and data extraction}

We selected studies that met the following criteria: (1) field studies were carried out in China, (2) both crop species produced grain and the yield was calculated on the basis of dry kernel weight (crop species included wheat, maize, barley, rice, faba bean, soybean, chickpea, pea, peanut, mungbean, adzuki bean, oilseed rape, oilseed radish, sesame; for the frequencies of each species combination see Fig. 5.1), (2) yield data that are based on aboveground biomass, fiber or tuber mass were not used (e.g. grass, cotton, potato, cabbage, capsicum and sugarcane), (3) grain yields for both intercrops and sole crops were reported, (4) plant density of intercrops was reported or could be calculated from row distance and plant distance. Data records in which the relative density total (RDT) was lower than 1 were excluded (see supplementary methods S4). Some publications did not contain all the data that were needed, e.g. data were missing for input rate of $\mathrm{N}$ and $\mathrm{P}$ fertilizer, or sowing and harvesting dates. Data records with missing values of a variable were excluded only from those analyses that required that variable.

\section{Methods S5.2 Reference list of the 69 publications used in this meta-analysis}

1. Cao, X.D., 2007. Benefits of sesame/peanut intercropping. China Agricultural Information 04. (in Chinese).

2. Chai, Q., Yang. C.H., Huang GB., 2010. Characteristics of crop water consumption of different cropping patterns in an Arid Oasis. Journal of Desert Research. 30, 1153-1159. (in Chinese)

3. Chen, G.P., Yu A.Z., 2014. Response of water use characteristics of maize/pea intercropping to different root partition and irrigation quota. Acta Agriculturae Boreali-occidentalis Sinica 23, 68-73. (in Chinese)

4. Chen, Y.X., 2007. Correlations between interspecies interactions and nitrogen utilization, diseases control and yield production in wheat/faba bean intercropping system. Doctoral thesis, China Agricultural University, Beijing (in Chinese).

5. Cheng, Y.Z., Li, L., Zhou, Q., Guo, N., Xing, H., Jiang, H.D., 2014. Growth and yield formation of maize under different maize/soybean intercropping patterns. Journal of Nanjing Agricultural University 39, 34-39. (in Chinese)

6. Chu, G.X., Shen, Q.R., Cao, J.L., 2004. Nitrogen fixation and $\mathrm{N}$ transfer from peanut to rice cultivated in aerobic soil in an intercropping system and its effect on soil $\mathrm{N}$ fertility. Plant Soil $263,17-27$.

7. Ding, H.B., 2010. The mechanism on enhancing $\mathrm{P}$ acquisition by intercropping between $\mathrm{P}$ efficient species and maize on Fluvo-Aquic soil of Quzhou. Master thesis, China Agricultural University, Beijing (in Chinese).

8. Ding, L., Jin, Y.Z., Li, Y.H., Wang, Y.B., 2014. Spatial pattern and water-saving mechanism of wheat and maize under the condition of strip-ridge intercropping. Acta Agriculturae Boreali-occidentalis Sinica. 23, 56-63. (in Chinese)

9. Fan, F.L., Zhang, F.S., Song, Y.N., Sun, J.H., Bao, X.G., Guo, T.W., Li, L., 2006. Nitrogen fixation of faba bean (Vicia faba L.) interacting with a non-legume in two contrasting intercropping systems. Plant Soil 283, 275-286.

10. Fang, ZG., 2014. Effects of legume/cereal intercropping on N, Fe nutrition and biological 
nitrogen fixation. Doctoral thesis, China Agricultural University, Beijing (in Chinese).

11. Feng, H.C., Chen, F., Zhang, ML., 1995. Luminous effect characters of corn/soybean intercropping. Tillage and Cultivation. 4, 4-6. (in Chinese).

12. Gao, H.M., 2006. The relationship between plant species interaction and root distribution of wheat/faba bean intercropping. Master's thesis, China Agricultural University, Beijing (in Chinese).

13. Gao, Y., Duan, A.W., Liu, Z.G., Sun, J.S., Chen, J.P., Wang, H.Z., 2009. Effect of intercropping patterns on dry matter accumulation and yield components of maize and soybean. Chinese Agricultural Science Bulletin. 25, 214-221. (in Chinese).

14. Gao, Y., Duan, A.W., Qiu, X.Q., Liu, Z.G., Sun, J.S., Zhang, J.P., Wang, H.Z., 2010a. Distribution of roots and root length density in a maize/soybean strip intercropping system. Agric Water Manag 98, 199-212.

15. Gao, Y., Duan, A.W., Qiu, X.Q., Sun, J.S., Zhang, J.P., Liu, H., Wang, H.Z., 2010b. Distribution and Use Efficiency of Photosynthetically Active Radiation in Strip Intercropping of Maize and Soybean. Agron J 102, 1149-1157.

16. Gao, Y., Duan, A.W., Sun, J.S., Li, F.S., Liu, Z.G., Liu, H., Liu, Z.D., 2009. Crop coefficient and water-use efficiency of winter wheat/spring maize strip intercropping. Field Crops Res 111, 65-73.

17. Gao, Y., Wu, P.T., Zhao, X.N., Wang, Z.K., 2014. Growth, yield, and nitrogen use in the wheat/maize intercropping system in an arid region of northwestern China. Field Crops Res 167, 19-30.

18. Gong, M.B., Song, C.Y., Hao, J.J., Wang, S.J., Li, H.W., Li, Z.Q., Zhang, X.Y., 2015. The experimental study of 'the fully mechanical intercropping pattern of summer maize-mung bean'. Chinese Agricultural Science Bulletin 31, 77-81. (in Chinese).

19. Jiao, N.Y., Chen, M.C., Fu, G.Z., Ning, T.Y., Wang, L.M., Li, Z.J., 2007. Studies on photosynthetic product accumulation and leaf area index in a complex population of companion cropping of corn and peanut. Crops 1, 34-35. (in Chinese)

20. Jiao, N.Y., Yang, M.K., Ning, T.Y., Yin, F., Xu, G.W., Fu, G.Z., Li, Y.J., 2013. Effects of maize-peanut intercropping and phosphate fertilizer on photosynthetic characteristics and yield of intercropped peanut plants. Chinese Journal of Plant Ecology. 37, 1010-1017. (in Chinese).

21. Jiao, N.Y., Zhao, C., Ning, T.Y., Hou, L.T., Fu, G.Z., Li Z.J., Chen, M.C., 2008. Effects of maize-peanut intercropping on economic yield and light response of photosynthesis. Chinese Journal of Applied Ecology. 19, 981-985. (in Chinese)

22. Lan, Y.F., Xia, H.Y., Liu, H.L., Yang, S.C., Song, J.G., Li, L. 2010. Yield and inter-specific interactions in maize/chickpea intercrop under different application rates of $\mathrm{P}$ in irrigated sierozem along the Yellow River in Northwest China. Chinese Journal of Eco-Agriculture 18, 917-922. (in Chinese).

23. Li, W.J., Chen, G.P., Chai, Q., 2014. Dry matter accumulation and distribution of alternately irrigated wheat/maize intercropping. Journal of Gansu Agricultural University. 49, 40-46. (in Chinese).

24. Li, L., Sun, J.H., Zhang, F.S., Guo, T.W., Bao, X.G., Smith, F.A., Smith, S.E., 2006. Root distribution and interactions between intercropped species. Oecologia 147, 280-290.

25. Li, L., Sun, J.H., Zhang, F.S., Li, X.L., Yang, S.C., Rengel, Z., 2001. Wheat/maize or wheat/soybean strip intercropping I. Yield advantage and interspecific interactions on nutrients. Field Crops Res 71, 123-137. 
26. Li, L., Yang, S.C., Li, X.L., Zhang, F.S., Christie, P., 1999. Interspecific complementary and competitive interactions between intercropped maize and faba bean. Plant Soil 212, 105-114.

27. Li, Q.Z., Sun, J.H., Wei, X.J., Christie, P., Zhang, F.S., Li, L., 2011. Overyielding and interspecific interactions mediated by nitrogen fertilization in strip intercropping of maize with faba bean, wheat and barley. Plant Soil 339, 147-161.

28. Li, Y.Y., Yu, C.B., Cheng, X., Li, C.J., Sun, J.H., Zhang, F.S., Lambers, H., Li, L., 2009. Intercropping alleviates the inhibitory effect of $\mathrm{N}$ fertilization on nodulation and symbiotic $\mathrm{N}-2$ fixation of faba bean. Plant Soil 323, 295-308.

29. Liang, Q., Yin, Y.P., Yang, T.X., 2004. Preliminary study on maize/soybean intercropping. Tillage and Cultivation. 5, 16-19 and 38. (in Chinese).

30. Liu, G.C., Li, L., Huang, G.B., Sun, J.H., Guo, T.W., Zhang, F.S., 2005. Intercropping advantage and contribution of above-ground and below-ground interactions in the barley-maize intercropping. Scientia Agricultura Sinica 38, 1787-1795. (in Chinese).

31. Liu, G.C., Yang, Q.F., Li, L., Sun, J.B., 2008. intercropping advantage and contribution of above and below ground interactions in wheat/maize intercropping 2, 477-484. Journal of Plant Ecology (Chinese version) (in Chinese).

32. Liu, H.L., 2010. Mechanism of enhanced phosphorus utilization in maize/faba bean and maize/soybean intercropping sierozems and irrigated desert soils. Master thesis. China Agricultural University, Beijing (in Chinese).

33. Liu, J.X., Lu, Y.G., Yuan, H.M., Zhang, Z.Z., Cui, B.W., 2008. The roots of the crop usually absorb and utilize studying to nitrogen under the maize/soybean intercropping condition. Acta Agriculturae Boreali-Sinica 1, 173-175. (in Chinese)

34. Liu, S.M., Huang, P., Chai, Q., Xie, P.X., Peng, Z.K., 2014. Effect of spatial arrangement on aggressivity and grain yield of maize/pea intercropping system. Journal of Gansu Agricultural University. 49, 61-65 and 71. (in Chinese)

35. Luo, L.Y., 2013. Interspecific interaction dynamics in maize/soybean intercropping system and its adjustment to increase system productivity. Master thesis. China Agricultural University, Beijing (in Chinese).

36. Lv, Y., Francis, C., Wu, P., Chen, X., Zhao, X., 2014. Maize-Soybean Intercropping Interactions Above and Below Ground. Crop Science 54, 914-922.

37. Mao, L.L., Zhang, L.Z., Li, W.Q., van der Werf, W., Sun, J.H., Spiertz, H., Li, L., 2012. Yield advantage and water saving in maize/pea intercrop. Field Crops Res 138, 11-20.

38. Mei, P.P., Gui, L.G., Wang, P., Huang, J.C., Long, H.Y., Christie, P., Li, L., 2012. Maize/faba bean intercropping with rhizobia inoculation enhances productivity and recovery of fertilizer $\mathrm{P}$ in a reclaimed desert soil. Field Crops Res 130, 19-27.

39. Mu, Y.P., Chai, Q., Yu, A.H., Yang, C.H., Qi, W.H., Feng, F.X., Kong, X.F., 2013. Performance of Wheat/Maize Intercropping is a Function of Belowground Interspecies Interactions. Crop Science 53, 2186-2194.

40. Qi, W.H., Chai, Q., 2010. Yield response to wheat/maize competitiveness in wheat/maize intercropping system under different root partition patterns. Chinese Journal of Eco-Agriculture. 18, 31-34. (in Chinese)

41. Qin, X.M., 2012. Regulation mechanisms behind rhizosphere interactions between plants in maize/legumes intercropping system under different phosphorus levels. Master thesis. China Agricultural University, Beijing (in Chinese).

42. Qin, A.Z., Huang, G.B., Chai, Q., Yu, A.Z., Huang, P., 2013. Grain yield and soil respiratory 
response to intercropping systems on arid land. Field Crops Res 144, 1-10.

43. Ren, G.H., Chai, Q., 2008. Spatial and temporal distribution of soil moisture and its utilization efficiency in intercropped winter wheat and corn system under limited supplementary irrigation. Bulletin of Soil and Water Conservation. 1, 145-149. (in Chinese).

44. Ren, Y.Y., Wang, Z.L., Wang, X.L., Zhang, S.Q., 2015. The effect and mechanism of intercropping pattern on yield and economic benefit on the Loess Plateau. Acta Ecologica Sinica. 35, 4168-4177. (in Chinese).

45. Shen, Z.H., 2008. Study on crop yield and water use under different intercropping patterns in arid land of Jinzhong. Doctoral thesis, Chinese Academy of Agricultural Sciences, Beijing (in Chinese).

46. Shi, Z.X., Chai, Q., Yang, C.H., Qin, A.Z., 2011. Effects of different nitrogen applications and intercropping stripe compound on yield and WUE under maize/pea intercropping. Journal of Gansu Agricultural University. 46, 39-43. (in Chinese).

47. Shi, Z.S., Chen, H.Y., Ma, Q.Z., Qin, J.G., 2014. Study on different row ratios between spring maize and peanut in North of Guangxi province in China. Modern Agricultural Science and Technology 14, 9-10. (in Chinese).

48. Song, Y.N., Zhang, F.S., Marschner, P., Fan, F.L., Gao, H.M., Bao, X.G., Sun, J.H., Li, L., 2007. Effect of intercropping on crop yield and chemical and microbiological properties in rhizosphere of wheat (Triticum aestivum L.), maize (Zea mays L.), and faba bean (Vicia faba L.). Biol Fert Soils 43 , 565-574.

49. Su, Y.H., Huang, G.Q., Liu, X.Y., Liu, L.W., 2005. Studies on the mechanism of increasing yield and income of the intercropping system with maize and soybean in upland of red soil. Acta Agricultural Universitatis Jiangxiensis 2, 210-213. (in Chinese)

50. Sun, J.H., Li, L., Zhang, F.S., Ma, Z.M., 2007. Influence of nitrogen application on yield and water effect in wheat/maize intercropping system. Chinese Agricultural Science Bulletin 23, 345-348. (in Chinese).

51. Wang, L., Wang, Qi., Zhang, E.H., Liu, Q.L., Yu, H.L., 2014. Effect of nitrogen application on productivity and water use efficiency of wheat/maize intercropping system under straw mulching. Chinese Journal of Eco-Agriculture. 22, 955-964. (in Chinese).

52. Wang, Z.K., Zhao, X.N., Wu, P.T., He, J.Q., Chen, X.L., Gao, Y., Cao, X.C., 2015. Radiation interception and utilization by wheat/maize strip intercropping systems. Agr Forest Meteorol 204, 58-66.

53. Wu, K.S., Song, S.Y., Li, L., Sun, J.H., Zhao, J.H., 2014. Effects of nitrogen fertilizer application and rhizobia inoculation on yield and water use efficiency of pea/maize intercropping system. Chinese Journal of Eco-Agriculture. 22, 1274-1280. (in Chinese).

54. Xia, H.Y., Wang, Z.G., Zhao, J.H., Sun, J.H., Bao, X.G., Christie, P., Zhang, F.S., Li, L., 2013. Contribution of interspecific interactions and phosphorus application to sustainable and productive intercropping systems. Field Crops Res 154, 53-64.

55. Xiao, J.X., Tang, L., Zheng, Y., 2011. Effects of $\mathrm{N}$ fertilization on yield and nutrient absorption in rape and faba bean intercropping system. Plant Nutrition and Fertilizer Science. 17, 1468-1473 (in Chinese).

56. Xiao, Y.B., Duan, Z.Y., Jin, H., Hu, W.L., Chen, S.H., Wei, C.F., 2007. Spared N response and yields advantage of intercropped wheat and faba bean. Plant Nutrition and Fertilizer Science 13, 267-271. (in Chinese).

57. Yang, C., Huang, G., Chai, Q., Luo, Z., 2011. Water use and yield of wheat/maize intercropping 
under alternate irrigation in the oasis field of northwest China. Field Crops Res 124, 426-432.

58. Yang, C.H., Chai, Q., Huang, G.B., 2010. Root distribution and yield responses of wheat/maize intercropping to alternate irrigation in the arid areas of northwest China. Plant, Soil and Environment - UZEI (Czech Republic) 56, 253-262.

59. Yang, F., Wang, X.C., Liao, D.P., Lu, F.Z., Gao, R.C., Liu, W.G., Yong, T.W., Wu, X.L., Du, J.B., Liu, J., Yang, W.Y., 2015. Yield response to different planting geometries in maize soybean relay strip intercropping systems. Agron J 107, 296-304.

60. Ye, Y.L. (2003. Effect of intercropping on nitrogen and water use. Doctoral thesis. China Agricultural University, Beijing (in Chinese).

61. Yin, Wen., Zhao, C., Yu, A.Z., Chai, Q., Hu F.L., Feng, F.X., 2015. Effect of straw returning and reduced tillage on interspecific competition and complementation in wheat/maize intercropping system. 41, 633-641. (in Chinese).

62. Yu, Y.K., 2014. Effects of intercropping for maize and mung bean. Heilongjiang Agricultural Science. 2, 29-31. (in Chinese).

63. Yue, G.G., Wang, E.M., Xu, Y.G., 1995. A study on row-space ratio of corn and soybean in intercropping system and its photosynthetic quantum. Guizhou Agricultural Science 3, 18-22. (in Chinese).

64. Zhang, C.M., Zhang, Y.W., Guo, Z.L., Zhao, X.Y., Yan, H.B., Zhu, H.J., G.W., 2014. Research photosynthetic characteristic of adzuki bean and production efficiency under intercropping patterns. Chinese Agricultural Science Bulletin. 30, 226-231. (in Chinese).

65. Zhang, B.C., Huang, G.B., Feng-Min, L.I., 2007. Effect of Limited Single Irrigation on Yield of Winter Wheat and Spring Maize Relay Intercropping. Pedosphere 17, 529-537.

66. Zhao, J.H., Sun, J.H., Li, L., Li, W.Q., 2012. Effect of maize row spacing on yield of pea/maize intercropping system. Chinese Journal of Eco-Agriculture. 20, 1451-1456. (in Chinese).

67. Zhou, S.M., Ma, S.Q., Li, W., Zhang, S.T., 1998. Analysis of superiority of maize and peanut row intercropping. Acta Agriculturae Universitatis Henanensis 32, 18-23 (in Chinese).

68. Zhou, H.B., Lin, C., Chen, J., Francis, F., Haubruge, E., Yong, L., Bragard, C., Cheng, D.F., 2013. Adaptation of wheat-pea intercropping pattern in China to reduce Sitobion avenae (Hemiptera: Aphididae) occurrence by promoting natural enemies. J Sustain Agr 37, 1001-1016.

69. Zhu, X.T., Chen, J.Q., Tan, C.Y., Yang C.J., 2014. Optimization on plant row and spacing configuration of maize and soybean under 1, 2 intercropping planting model. Soybean Science. 33, 35-40. (in Chinese). 


\section{Methods S5.3 Calculation of $\mathbf{N}$ and $P$ fertilization in intercrops}

If the publication reported the $\mathrm{N}$ and $\mathrm{P}$ fertilizer input of the intercropping system as a whole, we extracted the data directly (368 out of 426 data records). If the $\mathrm{N}$ and $\mathrm{P}$ fertilizer input rate of the intercrop was given separately for each component species, we calculated the total $\mathrm{N}$ and $\mathrm{P}$ input for the intercrop as follows:

$N_{\text {ic }}=N_{\text {ic }, 1} \times S P_{1}+N_{\text {ic }, 2} \times S P_{2}$

$P_{\mathrm{ic}}=P_{\mathrm{ic}, 1} \times S P_{1}+P_{\mathrm{ic}, 2} \times S P_{2}$

Where $N_{\mathrm{ic}}$ and $P_{\mathrm{ic}}$ are the $\mathrm{N}$ and $\mathrm{P}$ fertilizer input of the whole intercropping system, and $N_{\mathrm{ic}, 1}$ and $N_{\mathrm{ic}, 2}$ are the $\mathrm{N}$ fertilizer input of species 1 and 2 in the intercrop, and $P_{\mathrm{ic}, 1}$ and $P_{\mathrm{ic}, 2}$ are the $\mathrm{P}$ fertilizer input of species 1 and 2 in the intercrop. $S P_{1}$ and $S P_{2}$ are the sowing proportion (land share) of species 1 and species 2 in the whole strip of intercrops. The sowing proportion was calculated as follows:

$S P_{1}=\frac{W_{1}}{W_{T}}$

$S P_{2}=\frac{W_{2}}{W_{T}}$

Where $W_{1}$ and $W_{2}$ are the strip width of species 1 and 2 in the intercrop (Methods S5.4), $W_{\mathrm{T}}$ is strip width of the whole intercrop strip width. If one or both of the intercropped species were sown in single rows, above formulas cannot be used. In this case, the relative density was used to calculate sowing proportion (Methods S5.4). If the relative density was also not reported, but the row distances between the rows of the same or different species were all the same, row numbers per meter (and plant numbers per meter within rows) were used to calculate sowing proportion (Methods S5.4). If none of this information was available, the $\mathrm{N}$ input for the intercrops was not included.

\section{Methods S5.4 The calculation of expected species yields in intercrops}

The concept of the land share in strip intercropping

In strip intercropping systems, the expected relative yield can be calculated from the proportions of the area that are sown to the component species. These area proportions or "land shares" as we will call them can be calculated from information on either sowing densities, row or strip configuration or both. Distinction should be made between systems that are a replacement design, in which a certain proportion of one sole crop is replaced by the same proportion of the other species, and other situations (which can be either reductive, augmentative or fully additive). For instance, if maize is grown at a row distance of $75 \mathrm{~cm}$ in the sole crop and mixed with wheat which has a row distance of $12.5 \mathrm{~cm}$ in the sole crop, then each maize row takes the same space as six wheat rows. An intercrop of wheat and maize with 2 maize rows at $75 \mathrm{~cm}$ in each strip, 6 wheat rows at $12.5 \mathrm{~cm}$ in each strip, and 75/2+12.5/2=37.5+ $6.25=43.75 \mathrm{~cm}$ between neighboring wheat and maize rows would be a replacement intercrop. In this intercrop, the expected yield of maize would be two thirds of its monoculture yield (assuming the same yield per plant in the sole crop and the intercrop) and the expected yield of wheat would be one third of its monoculture yield. If however, the space between the two 
species in the intercrop were narrowed to, say, $40 \mathrm{~cm}$, then this would result in an overall increase of plant density. The land share would take into account this density increase by dividing the relative densities by the sum of the two relative densities (RDT: relative density total) and call the resulting fractions the land shares. As a result, we would not expect greater yield as a result of the increase in the density, but the allocation of yield between the species might be slightly changed.

According to the availability of reported data on plant density and row configuration, we calculated the land share and expected relative yield in different situations:

Plant density of both sole crop and intercrop are given in the publication:

1a. Replacement intercrops

1b. Augmentative or fully additive intercrops

1c. Reductive intercrops (reductive intercrops are rare, because if there is complementarity between species in the intercrop, it would make sense to increase density, not decrease it. We excluded reductive intercrops (Methods S5.1).

Plant density of both sole crop and intercrop are not given in the publication:

2a. Replacement intercrops based on row configuration

$2 \mathrm{~b}$. Augmentative or additive intercrops based on row configuration (with the same number of plants per $\mathrm{m}$ row of a species in sole crops and intercrops)

2c. Augmentative or additive intercrops based on row configuration (with a modified number of plants per $\mathrm{m}$ row)

\section{Calculation of land share and expected relative yield based on plant density}

For the publications that reported plant densities of both the sole crop and the intercrop, the relative density of each species was used to calculate the land share of each species in the intercrop. Relative density of a species is calculated as the ratio between the density of that species in the intercrop and the sole crop:

$\left\{\begin{array}{l}R D_{1}=\frac{d_{\mathrm{ic}, 1}}{d_{\mathrm{sc}, 1}} \\ R D_{2}=\frac{d_{\mathrm{ic}, 2}}{d_{\mathrm{sc}, 2}}\end{array}\right.$

Where $d_{\mathrm{ic}, 1}$, and $d_{\mathrm{sc}, 1}$ are densities of species 1 in the intercrop and the sole crop, while $d_{\mathrm{ic}, 2,}$ and $d_{\mathrm{sc}, 2}$ are densities of species 2 in the intercrop and the sole crop, respectively. Density of a species in an intercrop is defined as the number of plants of a species per unit land area of the whole intercrop, i.e. including the area of the strip of the other species (Yu et al. 2016).

1a. Replacement design

For replacement intercrops, the expected relative yield is the same as the relative density.

$\left\{\begin{array}{l}R Y_{1}^{0}=R D_{1} \\ R Y_{2}^{0}=R D_{2}\end{array}\right.$

Where $R Y_{1}^{0}$ and $R Y_{2}^{0}$ represent the expected relative yield of species 1 and 2 . 
This is consistent with the following premises:

1. The absolute yield per plant is for both species the same in the intercrop and the sole crop.

2. Allo-competition (competition from the other species) and auto-competition (competition from the same species) have identical effects on resource capture and yield of a species. So, for replacement intercrops, the relative density is equal to the land share, and equal to the expected relative yield.

1b. Augmentative or fully additive intercrops

For augmentative or fully additive intercrops, premise 1 (equal yield per plant in the sole crop of each species and the intercrop) is not reasonable. In that case, the intercrop is a combination of increased densities of the component species, such that we should expect that the yield per plant is decreased. In this case, a reasonable calculation of the expected yield per species is:

$\left\{\begin{array}{l}R Y_{1}^{0}=\frac{R D_{1}}{R D_{1}+R D_{2}} \\ R Y_{2}^{0}=\frac{R D_{2}}{R D_{1}+R D_{2}}\end{array}\right.$

The expected yield per plant is thus for both species scaled (i.e. multiplied) by a factor $\frac{1}{R D_{1}+R D_{2}}$. This calculation is consistent with the following premises: density increase would not affect the monoculture yields; that is, density increase would be offset by a decrease in yield per plant. So, for augmentative or additive intercrops, the scaled relative density was used to calculate the land share and the expected relative yield.

\section{Calculation of land share and expected relative yield based on row configuration}

In some cases, plant density of both sole crop and intercrop are not available, so the relative density was estimated from the row distance and plant distance.

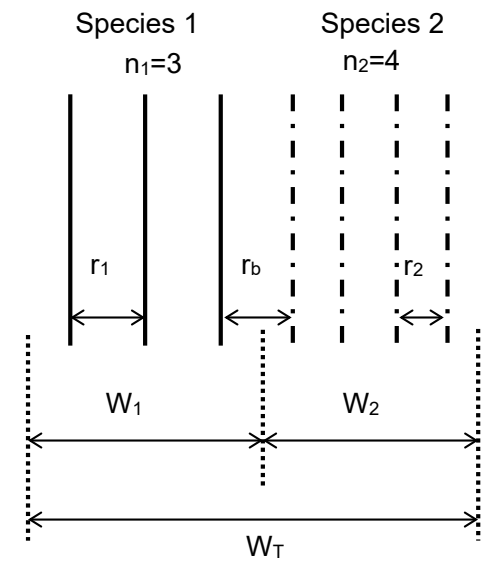

Fig. A1 Schematic configuration of intercropping arranged in strips.

Here we define a species strip as the area occupied by the contiguous rows of a single species plus an appropriate part of the space between the two species. Two adjacent strips of different species in an intercrop form an intercrop strip. First, the strip width for each species is calculated as the width between the inner and outer rows, i.e. $\left(n_{1}-1\right) \times r_{1}$ for species 1 and 
$\left(n_{2}-1\right) \times r_{2}$ for species 2 , plus a proportion of the row distance between the two species strips, $r_{\mathrm{b}}$, such that a proportion $\frac{r_{1}}{r_{1}+r_{2}}$ of $r_{\mathrm{b}}$ is assigned to species 1 and a proportion $\frac{r_{2}}{r_{1}+r_{2}}$ of $r_{\mathrm{b}}$ is assigned to species 2 . Here $n_{1}$ and $n_{2}$ are the number of rows of species 1 and 2 in their species strips. The calculation is built on the premise that species that are planted at a wider row distance have a larger foraging space for resources. For instance, a tall species like maize has a large foraging space for light and it is therefore grown at a large row distance. This formula is well behaved in the sense that it has a meaningful limit if the planting pattern is a replacement design (see below). The resulting formulas for the strip width are:

$\left\{\begin{array}{l}W_{1}=\left(n_{1}-1\right) \times r_{1}+2 \times \frac{r_{1}}{r_{1}+r_{2}} \times r_{\mathrm{b}} \\ W_{2}=\left(n_{2}-1\right) \times r_{2}+2 \times \frac{r_{2}}{r_{1}+r_{2}} \times r_{b}\end{array}\right.$

If the intercrop is a replacement intercrop, the distance between the outer rows of the two strips equals $r_{b}=\frac{r_{1}+r_{2}}{2}$. In this case, the formulas for $W_{1}$ and $W_{2}$ simplify to:

$\left\{W_{1}=n_{1} \times r_{1}\right.$

$\left\{W_{2}=n_{2} \times r_{2}\right.$

The intercrop strip width is calculated as the sum of the two species strip widths.

$W_{T}=W_{1}+W_{2}$

$W_{\mathrm{T}}$ represents the intercrop strip width, i.e. the sum of the strip width of species $1\left(W_{1}\right)$ and the strip width of species $2\left(W_{2} ;\right.$ Fig. A1).

If one or both of the intercropped species were placed in single rows, but the row distances between rows of the same or different species were equal, row numbers per meter (and plant numbers per meter within rows) were used to calculate the relative density or sowing proportion (see the following sections $2 \mathrm{~b}, 2 \mathrm{c}$ ).

2a. Replacement intercrops, based on row configuration

For a replacement design, the relative density of each species is equal to the area proportion, which can be estimated from the species strip width and intercrop strip width.

$\left\{\begin{array}{l}R D_{1}=\frac{W_{1}}{W_{T}} \\ R D_{2}=\frac{W_{2}}{W_{T}}\end{array}\right.$

Then, after calculating the relative density, the expected relative yield of each species was calculated with equation (S6).

2b. Augmentative or additive intercrops, based on row configuration (with the same number of plants per $m$ row)

For non-replacement intercrops with same plant distances in both intercrop and sole crop, the relative density can be estimated from the number of rows per meter (counted perpendicular to the rows): 
$\left\{\begin{array}{l}\text { Rows per meter }{ }_{1}=\frac{n_{1}}{W_{T}} \\ \text { Rows per meter }_{2}=\frac{n_{2}}{W_{\mathrm{T}}}\end{array}\right.$

Relative density is then the ratio of the number of rows per m (RPM) in the intercrop and the number of rows per $\mathrm{m}$ in the sole crop:

$\left\{\begin{array}{l}R D_{1}=\frac{R P M_{\mathrm{ic}, 1}}{R P M_{\mathrm{sc}, 1}} \\ R D_{2}=\frac{R P M_{\mathrm{c}, 2}}{R P M_{\mathrm{sc}, 2}}\end{array}\right.$

Note that rows per meter is the reciprocal of row distance in a sole crop and the "homogenized" or "overall average" row distance for a species (ignoring the other species) in an intercrop.

2c. Augmentative or additive intercrops, based on row configuration (with a modified number of plants per $m$ row)

For non-replacement intercrops with different plant distances in the intercrop and sole crop, plant distances in intercrops and sole crops are considered to calculate the relative density. The relative density is estimated based on the occupied space by plants per meter within rows and across the rows.

$\left\{\begin{array}{l}R D_{1}=\frac{R P M_{\mathrm{ic}, 1}}{R P M_{\mathrm{sc}, 1}} \times \frac{P P M_{\mathrm{ic}, 1}}{P P M_{\mathrm{sc}, 1}} \\ R D_{2}=\frac{R P M_{\mathrm{ic}, 2}}{R P M_{\mathrm{sc}, 2}} \times \frac{P P M_{\mathrm{ic}, 2}}{P P M_{\mathrm{sc}, 2}}\end{array}\right.$

$P P M_{\mathrm{ic}, 1}$, and $P P M_{\mathrm{ic}, 2}$ represent the number of plants of species 1 and 2 per meter row in intercrops while $P P M_{\mathrm{sc}, 1}$, and $P M R_{\mathrm{sc}, 1}$ represent the plants of species 1 and 2 per meter row in sole crops.

Under the above two situations $(2 b, 2 c)$, after calculating the relative density, the expected relative yield of each species was calculated, using the scaled relative density (Equation S7).

\section{Methods S5.5 The calculation of selection effect for intercrops with two species}

We calculated the selection effect (SE) by subtracting from the net effect (NE) the complementarity effect (CE). An equivalent formula that gives more insight is derived from the definition of the selection effect by Loreau \& Hector (2001).

The covariance of the relative yield gain (relative yield minus relative density) and sole crop yield is denoted as:

$$
\begin{gathered}
\operatorname{cov}(\Delta R Y, M)= \\
\frac{1}{N} \sum\left(\Delta R Y_{i}-\overline{\Delta R Y}\right)\left(M_{i}-\bar{M}\right)
\end{gathered}
$$

Where $i$ is an index for species. For intercrops with two species, this becomes:

$$
\operatorname{cov}(\Delta R Y, M)=\frac{1}{2}\left(\left(\Delta R Y_{1}-\overline{\Delta R Y}\right)\left(M_{1}-\bar{M}\right)+\left(\Delta R Y_{2}-\overline{\Delta R Y}\right)\left(M_{2}-\bar{M}\right)\right)
$$

Substitute now in this equation $\overline{\Delta R Y}=\frac{\Delta R Y_{1}+\Delta R Y_{2}}{2}$ and $\bar{M}=\frac{M_{1}+M_{2}}{2}$

Since 


$$
\frac{\Delta R Y_{1}-\Delta R Y_{2}}{2}=\Delta R Y_{1}-\frac{\Delta R Y_{1}+\Delta R Y_{2}}{2}=-\left(\Delta R Y_{2}-\frac{\Delta R Y_{1}+\Delta R Y_{2}}{2}\right)
$$

and

$$
\frac{M_{1}-M_{2}}{2}=M_{1}-\frac{M_{1}+M_{2}}{2}=-\left(M_{2}-\frac{M_{1}+M_{2}}{2}\right)
$$

This simplifies to:

$$
=\frac{1}{4} \times\left(\Delta R Y_{1}-\Delta R Y_{2}\right) \times\left(M_{1}-M_{2}\right)
$$

The selection effect in a two species system is defined as (Loreau \& Hector, 2001):

$$
\begin{gathered}
\mathrm{SE}=2 \times \operatorname{cov}(\Delta R Y, M) \\
\mathrm{SE}=\frac{1}{2} \times\left(\Delta R Y_{1}-\Delta R Y_{2}\right) \times\left(M_{1}-M_{2}\right)
\end{gathered}
$$

\section{Methods S5.6 Model selection methods}

\section{Model selection for estimating the relationship between NE, CE and SE of three species trait combinations and TND, $N$ and $P$ input}

In order to estimate the responses of the three species trait combinations (maize/C3-cereal, maize/legume, C3-cereal/legume) to TND, N and P input, we selected models using a stepwise procedure. The follows were the examples of model selection for the analysis on TND, the model selection method for analysis on $\mathrm{N}$ and $\mathrm{P}$ input were same with the method for analysis on TND. In the first step, we compared four models:

Model (1) the responses of these three groups have common intercept and slope, then there was no categorical variable of species trait combinations. (NE, CE, SE) $i j k=\beta_{\mathrm{TND}} T N D_{i j k}+a_{i}+b_{i j}+\varepsilon i j k$

Model (2) three groups have different intercept and slope, the categorical variable of trait combinations (TC) includes three levels: maize/C3-cereal, maize/legume, C3-cereal/legume. (NE, $\mathrm{CE}, \mathrm{SE})_{i j k}=\beta \mathrm{TC}\left(\mathrm{TC}_{i j k}\right)+\beta_{\mathrm{TND}}\left(T C_{i j k}\right) T N D_{i j k}+a_{i}+b_{i j}+\varepsilon i j k$

Model (3) maize/legume and maize/C3-cereal have the same intercept and slope but this intercept and slope differ from the intercept and slope for C3-cereal/legume intercrops. Then we used a dummy variable (DV1) that has two levels. $D V 1$ indicates whether the intercrop includes maize: (0) intercrops with maize (maize/C3-cereal and maize/legume); (1) intercrops without maize (C3-cereal/legume). (NE, CE, SE) $i_{i j k}=\beta \mathrm{DV} 1\left(D V 1_{i j k}\right)+\beta \mathrm{TND}\left(D V 1_{i j k}\right) T N D_{i j k}+a_{i}+b_{i j}+\varepsilon i j k$

Model (4) maize/legume and C3-cereal/legume have the same intercept and slope but these differ from the intercept and slope of maize/C3-cereal intercrops. Then we used a dummy variable (DV2). $D V 2$ indicates whether the intercrop includes a legume: (0) with a legume; (1) without a legume. $(\mathrm{NE}, \mathrm{CE}, \mathrm{SE}){ }_{i j k}=\beta_{\mathrm{DV} 2}\left(D V 2_{i j k}\right)+\beta_{\mathrm{N}}\left(D V 2_{i j k}\right) N_{i j k}+a_{i}+b_{i j}+\varepsilon i j k$

Model (5) In the second step, if we selected model (2), then we compared it with a model in which the three groups have the same slope but different intercepts: $(\mathrm{NE}, \mathrm{CE}, \mathrm{SE}) i j k=\beta \mathrm{TC}\left(T C_{i j k}\right)+$ $\beta_{\mathrm{TND}} \mathrm{TND}_{i j k}+a_{i}+b_{i j}+\varepsilon_{i j k}$. 
Model (6) If we selected model (3) or (4), we compared this model with a model in which intercrops with maize have the same slope but different intercepts with intercrops without maize $(D V 1)$, or intercrops with legume have the same slope but different intercepts without legume (DV2): $(\mathrm{NE}, \mathrm{CE}, \mathrm{SE})_{i j k}=\beta \mathrm{DV} 1\left(D V 1_{i j k}\right)+\beta_{\mathrm{TND}} T N D_{i j k}+a_{i}+b_{i j}+\varepsilon_{i j k}$ (same model for $\left.D V 2\right)$

The model selection was based on AIC and model parsimony (Bolker 2008, p. 210). If the model with the lowest AIC was less 2 apart from a simpler model $(\triangle \mathrm{AIC}<2)$, then we selected the simpler model of the two models as the best model (Bolker 2008, p. 210).

\section{Model selection on quadratic model or linear model to estimate the relationship between the NE, CE and SE and N or P input}

We hypothesized that the net effect and complementarity effect would have a quadratic response to $\mathrm{N}$ (or $\mathrm{P}$ ) input. Therefore, we compared linear mixed effects models with and without the square of $\mathrm{N}$ (or $\mathrm{P}$ ) input to estimate the relationship of net effect and complementarity effect and $\mathrm{N}$ (or P) input.

Table A2 The AIC of linear mixed effects model and quadratic mixed effects model to estimate the relationship between net effect (NE), complementarity effect (CE) and $\mathrm{N}$ (or P) fertilizer input.

\begin{tabular}{lllll}
\hline \multirow{2}{*}{ Model } & N input & & P input & \\
& NE & CE & NE & CE \\
\hline Linear mixed effects model & 1202.72 & 1109.32 & 1141.18 & 1051.34 \\
Quadratic mixed effects model & 1204.00 & 1111.31 & 1143.04 & 1053.34 \\
\hline
\end{tabular}

Note: the AIC values in bold are the AICs of the selected models. 


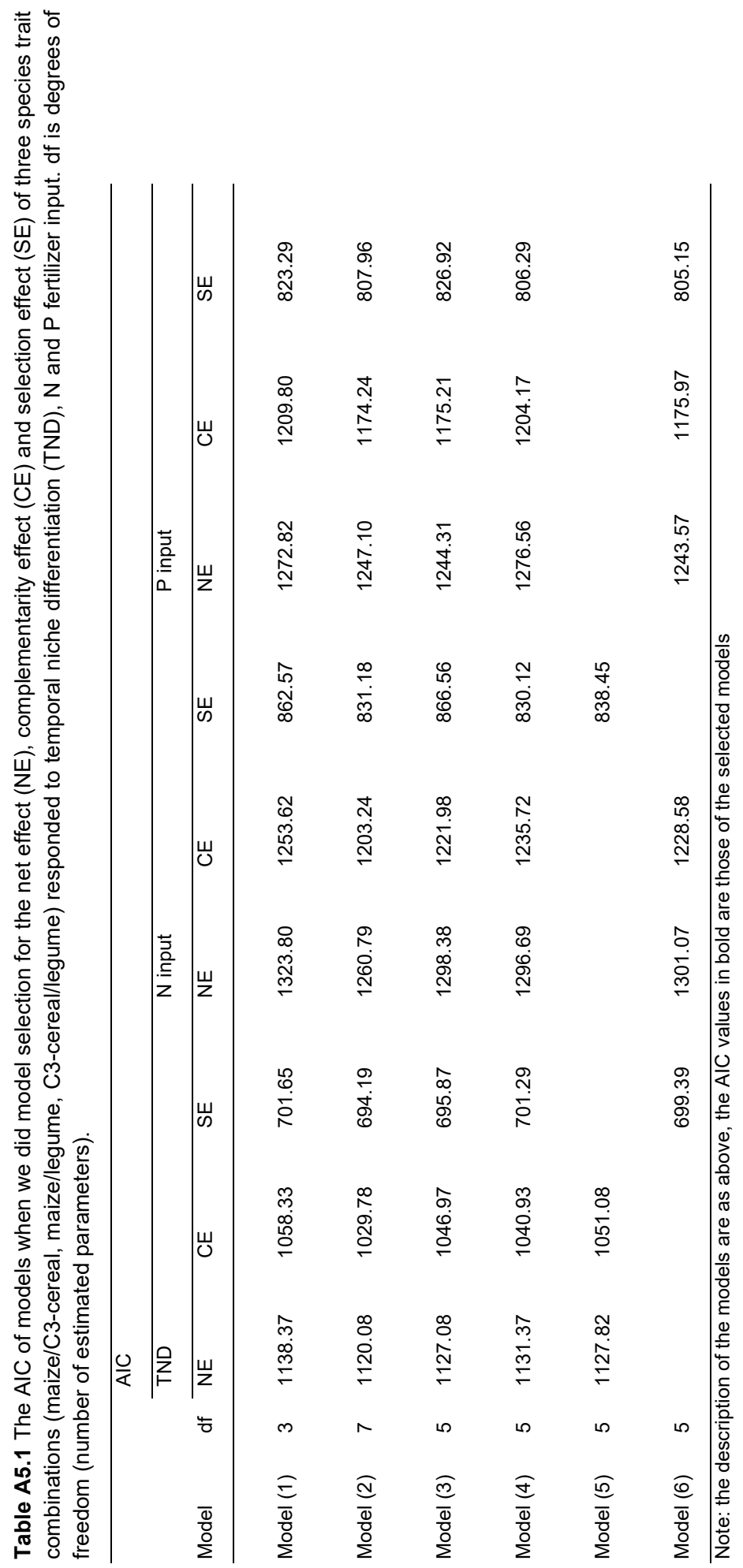




\section{Methods S5.7 Assessment of the possibility of a publication bias}

We used funnel plots to assess publication bias. We plotted average NE, CE and SE in each of the 69 studies against the total number of experimental units (replicates) in the study as a proxy for study accuracy. The funnel plot was very slightly asymmetrical, with absence of data points for negative net effect, negative complementarity effect and negative selection effect if the dataset was small. So there was a very slight publication bias in our dataset. We do not think that this very slight bias critically affects our conclusions.
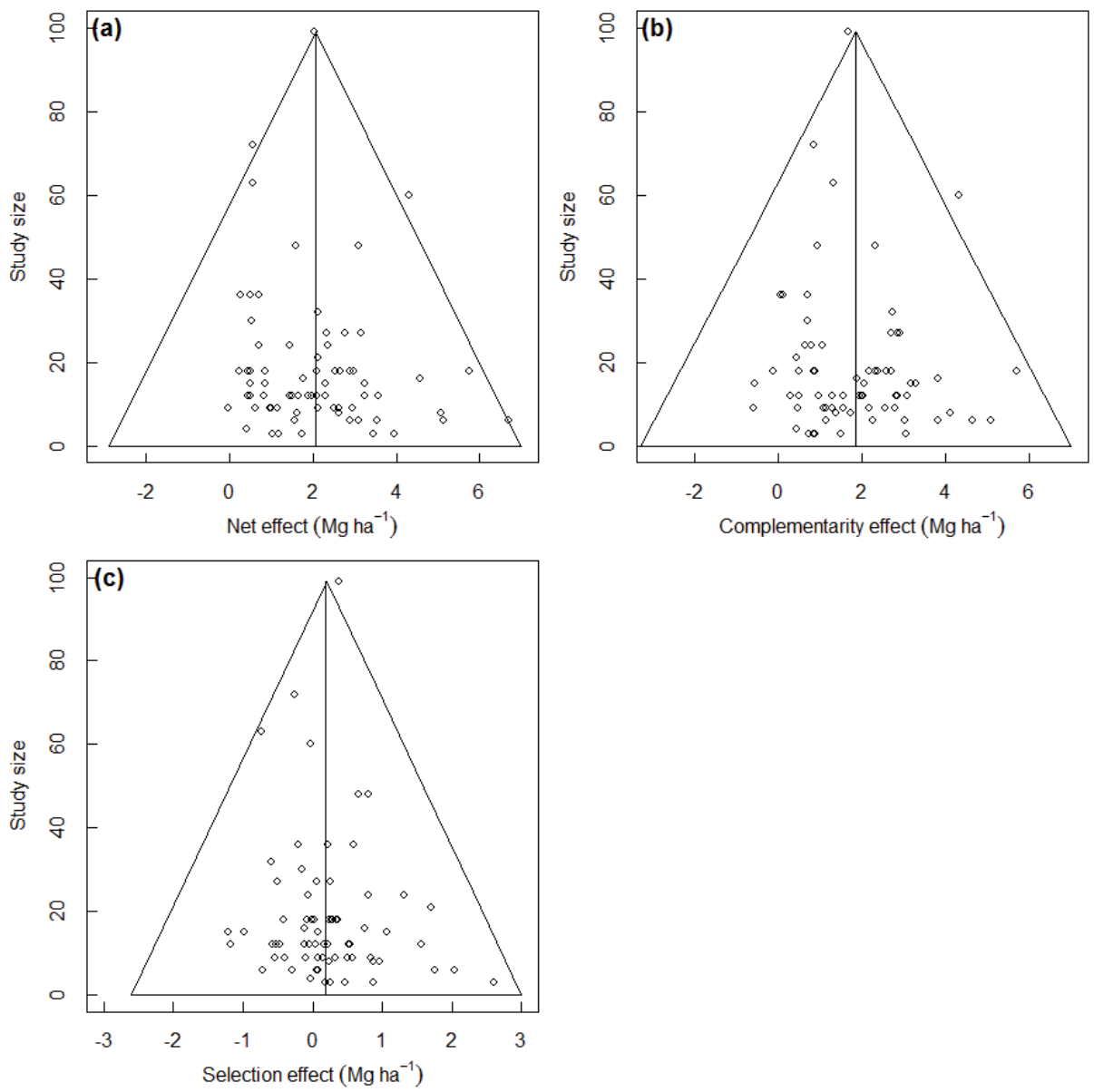

Fig. A2 Funnel plot of study size against (a) net effect, (b) complementarity effect and (c) selection effect. The vertical line in each panel represents the estimated mean of net effect, complementarity effect and selection effect via the mixed effects model. 


\section{Methods S5.8 Calculation of N and P supply}

Crop performance does not only depend on nutrient input but also on the supply of nutrients from the soil, particularly from organic matter. Here we used the QUEFTS model to estimate the total of nutrient supply from fertilizer and from the soil (Sattari et al. 2014). This model uses empirical multiple regression equations to estimate the potential soil supply of $\mathrm{N}$ and $\mathrm{P}$ to a crop in $\mathrm{kg} \mathrm{ha}^{-1}$ per growing season, using commonly available soil parameters ( $\mathrm{pH}$, soil organic $\mathrm{C}$ content, Olsen-P and, optionally, organic $\mathrm{N}$ and total $\mathrm{P}$ content) as independent variables. The $\mathrm{N}$ and $\mathrm{P}$ supply from fertilizer is estimated as the product of the recovery fractions and the application rates. Supplies of N and P were calculated according to Sattari et al. (2014):

$\left\{\begin{array}{c}S_{\mathrm{N}}=\alpha_{\mathrm{N}} \times f_{\mathrm{N}} \times C_{\text {org }}+R_{\mathrm{N}} \times I_{\mathrm{N}} \\ S_{\mathrm{P}}=\alpha_{\mathrm{P}} \times f_{\mathrm{P}} \times C_{\text {org }}+R_{\mathrm{P}} \times I_{\mathrm{P}}+\beta_{\mathrm{P}} \times P_{\text {olsen }}\end{array}\right.$

$S_{\mathrm{N}}$ and $S_{\mathrm{P}}$ represent the total amounts of $\mathrm{N}$ and $\mathrm{P}$ available to a crop during a growing season $\left(\mathrm{kg} \mathrm{ha}^{-1}\right) ; \alpha$ and $\beta$ are empirical parameters $\left(\alpha_{\mathrm{N}}=6.8 ; \alpha_{\mathrm{P}}=0.35 ; \beta_{\mathrm{P}}=0.5\right), f_{\mathrm{N}}$ and $f_{\mathrm{P}}$ are $\mathrm{pH}$-dependent coefficients, $I_{\mathrm{N}}$ and $I_{\mathrm{P}}$ are the $\mathrm{N}$ and $\mathrm{P}$ fertilizer inputs, and $R_{\mathrm{N}}$ and $R_{\mathrm{P}}$ are the recovery fractions of $\mathrm{N}$ and $\mathrm{P}$ fertilizer. We used $R_{\mathrm{N}}=0.5$ and $R_{\mathrm{P}}=0.1$ (Janssen et al. 1990). Corg was calculated as $C_{\text {org }}=0.5 \times O M$, where $O M$ is soil organic matter content $\left(\mathrm{mg} \mathrm{kg}^{-1}\right)$.

The coefficient $f_{\mathrm{N}}$ describes the $\mathrm{pH}$ dependency of mineralization. The following values are used (Sattari et al. 2014):

$f_{\mathrm{N}}=\left\{\begin{array}{cc}0.4 & \text { if } \mathrm{pH}<4.7 \\ 0.25 \times(p H-3) & \text { if } 4.7<\mathrm{pH}<7 \\ 1 & \text { if } \mathrm{pH}>7\end{array}\right.$

The coefficient $f_{\mathrm{P}}$ describes P solubility (Sattari et al., 2014):

$f_{\mathrm{P}}=\left\{\begin{array}{c}0.02 \quad \text { if } \mathrm{pH}<4.7 \\ 1-0.5 \times(\mathrm{pH}-6)^{2} \text { if } 4.7<\mathrm{pH}<6 \\ 1 \quad \text { if } 6<\mathrm{pH}<6.7 \\ 1-0.25 \times(\mathrm{pH}-6.7)^{2} \text { if } 6.7<\mathrm{pH}<8 \\ 0.57 \quad \text { if } \mathrm{pH}>8\end{array}\right.$ 

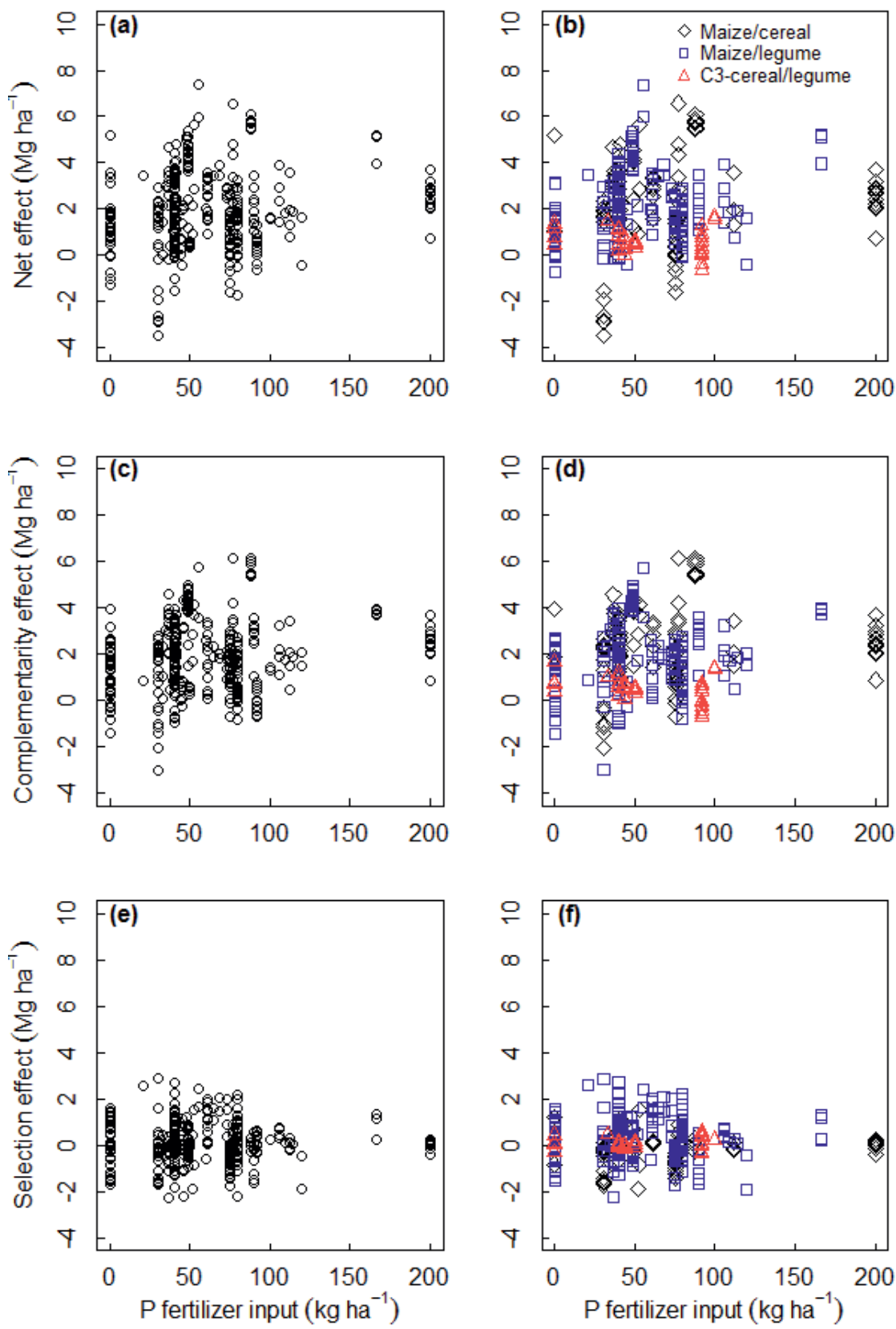

Fig. S5.1 Scatter plots of the net effect (NE), the complementarity effect (CE) and the selection effect (SE) against $\mathrm{P}$ fertilizer input, and the NE, CE and SE of maize/C3-cereal, maize/legume and C3-cereal/legume intercrops against $P$ fertilizer input. Model selection was according to Methods S5.6. (a, c, e) Relationships between NE, CE and SE and $P$ fertilizer input were estimated by model: (NE, CE, SE) $)_{i j k}=\beta_{\mathrm{P}} P_{i j k}+a_{i}+b_{i j}+\varepsilon_{i j k}$. (b, d) Relationship between NE, CE and P input were estimated using model: (NE, CE) $)_{j k}=\beta_{\mathrm{DV} 1}(D V 1)_{i j k}+\beta_{\mathrm{P}} P_{i j k}+a_{i}+$ $b_{i j}+\varepsilon_{i j k}(\mathrm{f})$ Relationships between the SE and $\mathrm{P}$ input were estimated using the model: $\mathrm{SE}_{i j k}=\beta_{\mathrm{DV} 2}(D V 2)_{j k}+\beta_{\mathrm{P}} P_{i j k}$ $+a_{i}+b_{i j}+\varepsilon_{i j k}$. Regression lines were not shown because all of $\mathrm{P}$-values were larger than 0.05 in each panel. 


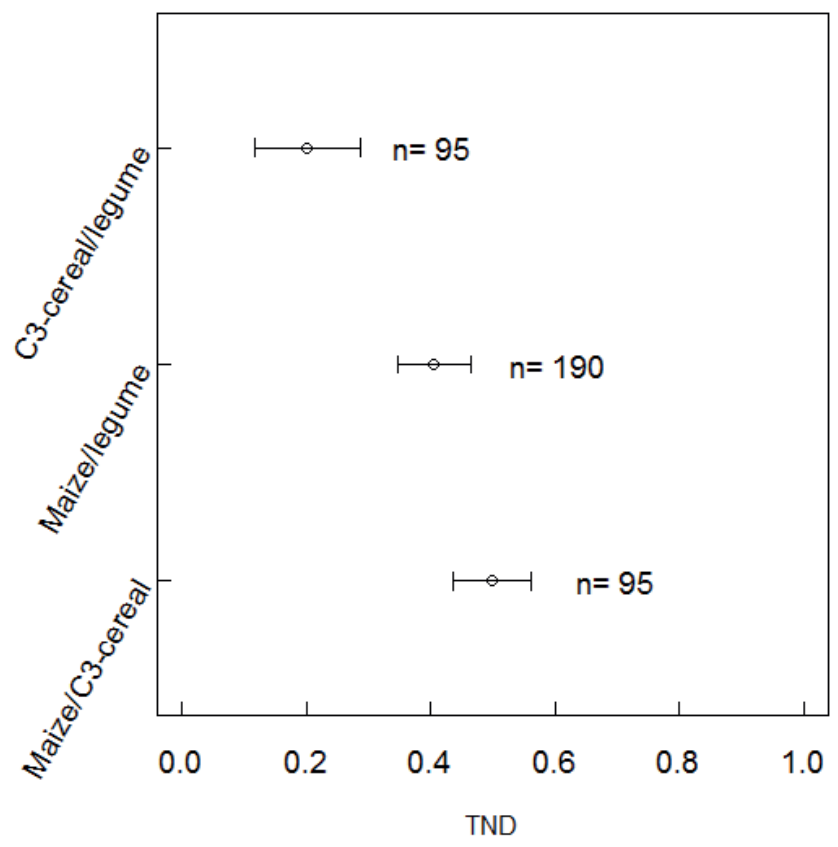

Fig. S5.2 The temporal niche differentiation of C3-cereal/legume, maize/legume and maize/C3-cereal intercrops. The horizontal bars represent $95 \%$ confidence interval of estimations; $\mathrm{n}=$ number of entries. 

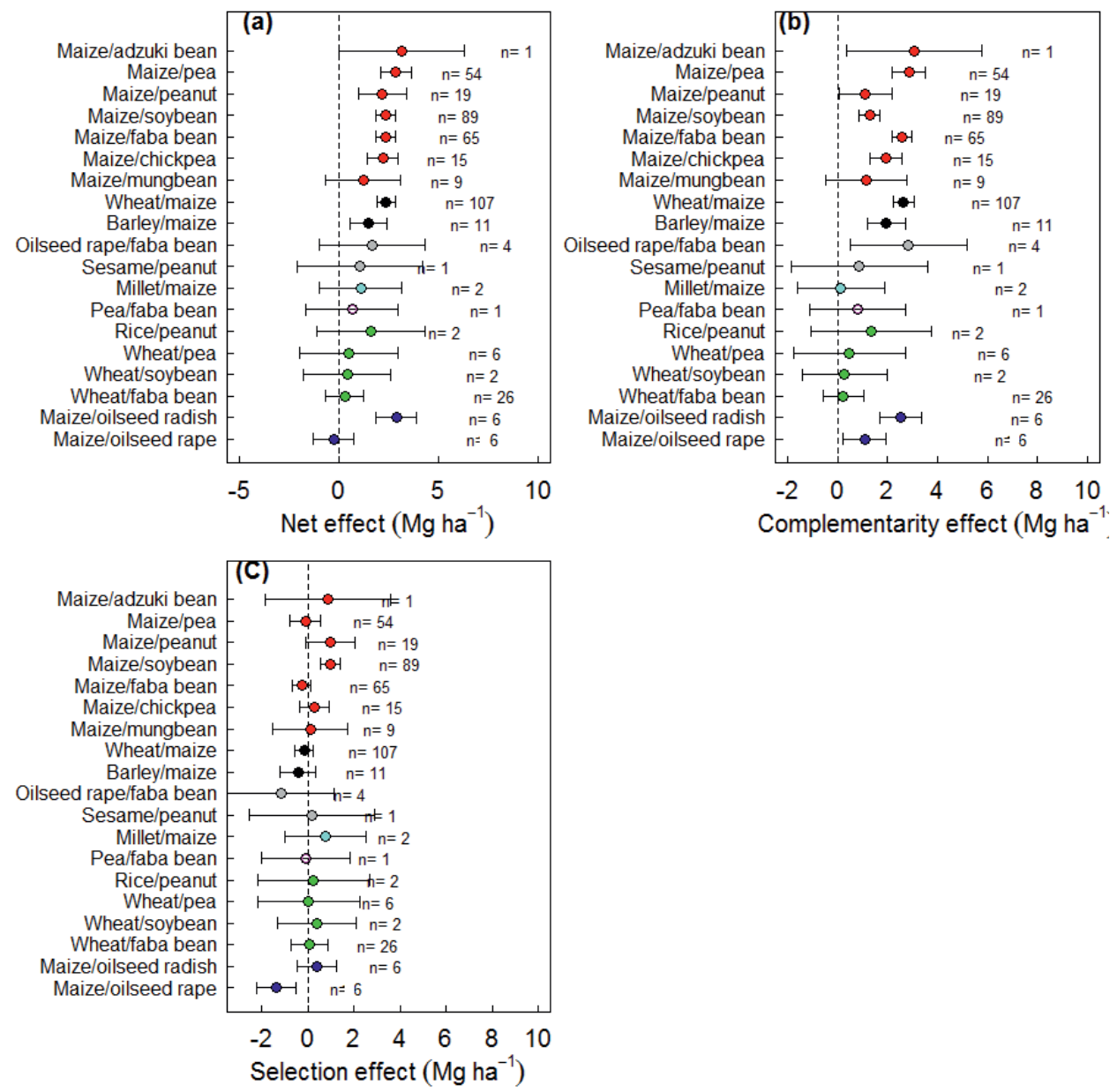

Fig. S5.3 Net effect (NE) (a), complementarity effect (CE) (b) and selection effect (SE) (c) of all species combinations in the dataset. Different colors of points represent different groups of species combinations. Red points represent maize/legume intercrops, black points represent maize/C3-cereal intercrops, grey points represent legume/other species, light blue points represent maize/C4-cereal intercrops, pink circles represent legume/legume intercrops, green points represent C3-cereal/legume intercrops, blue points represent maize/other species. The horizontal bars represent $95 \%$ confidence interval of estimations; $n=$ number of entries. 

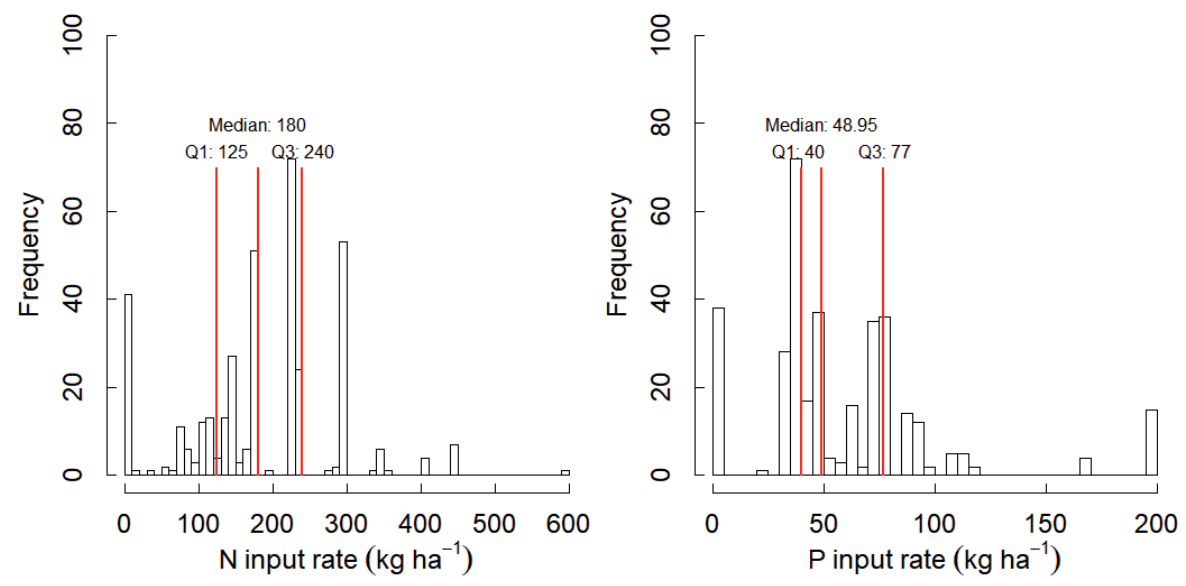

Fig. S5.4 Frequency distribution of $N(a)$ and $P$ fertilizer (b) input rate of intercrops in the dataset. Vertical lines in panels of frequency distribution (a-b) indicate the first quartile (Q1), median and third (Q3) quartile of the $N$ and $P$ input rate.
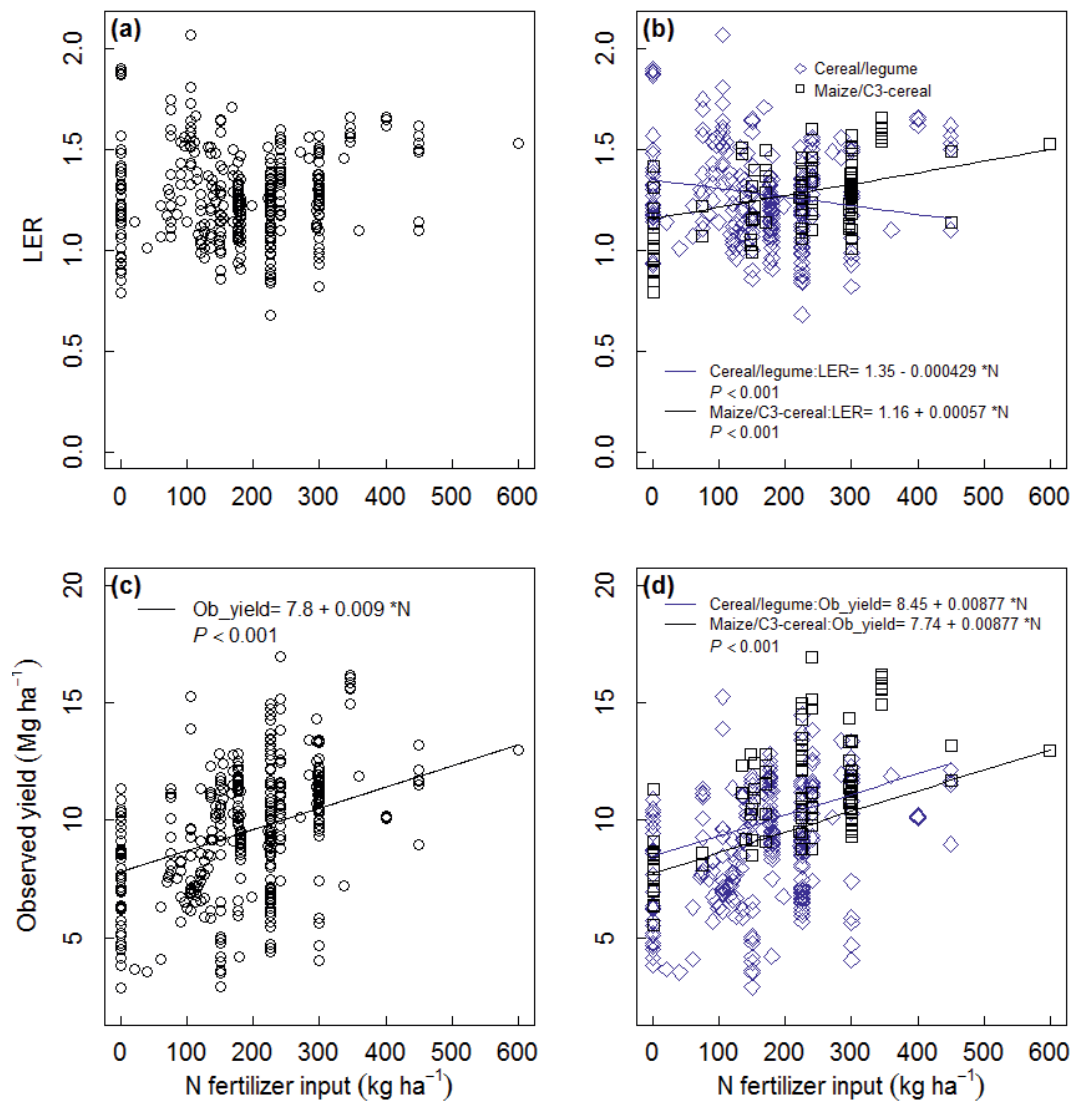

Fig. S5.5 Scatter plots of LER and observed yield against $N$ fertilizer input, and LER, observed yield of cereal/legume, maize/C3-cereal intercrops against $\mathrm{N}$ fertilizer input. Regressions of $P<0.05$ were shown in the panels. 

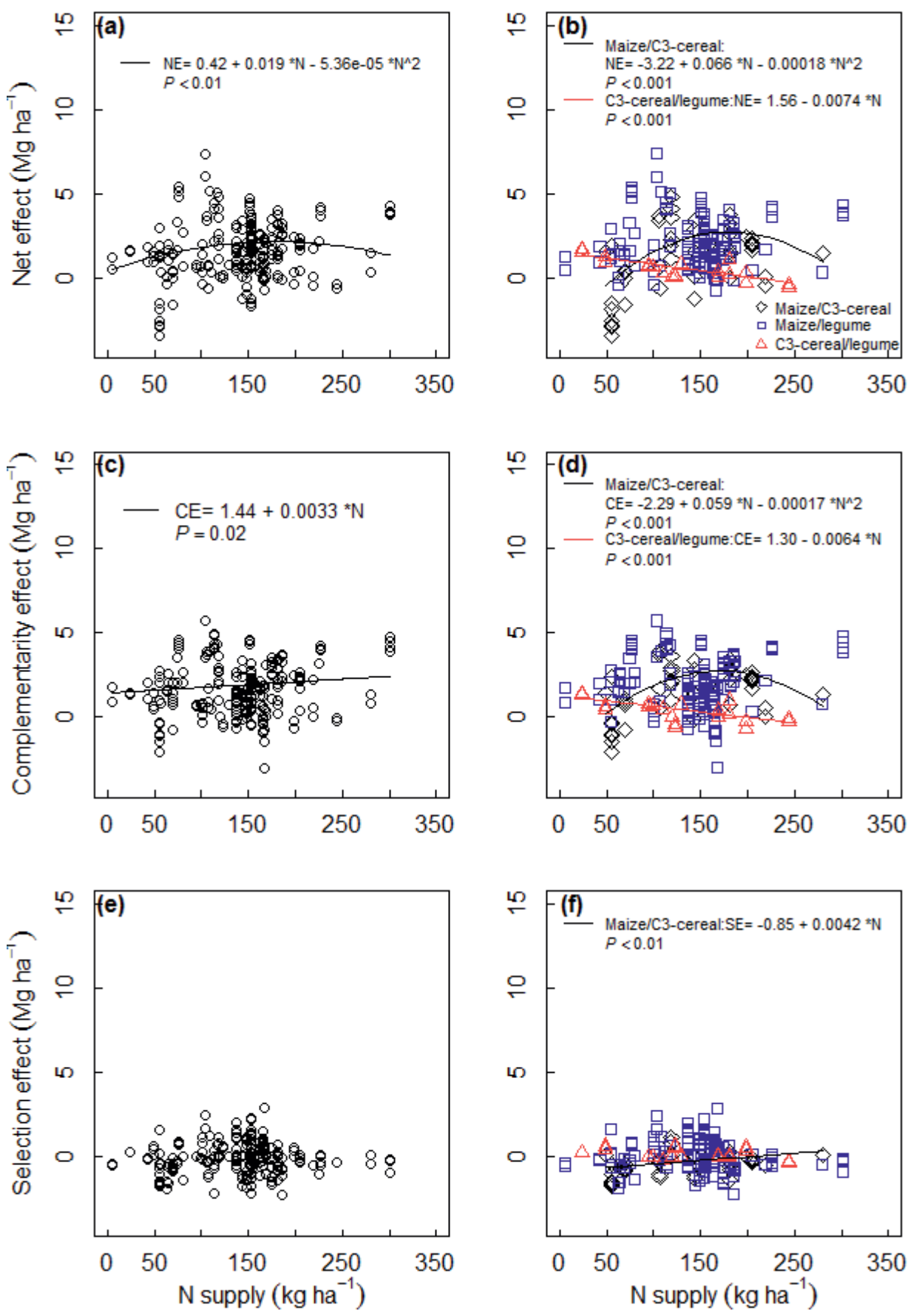

Fig. S5.6 Net effect, complementarity effect and selection effect in response to N supply. (a) net effect (NE), (c) complementarity effect (CE) and (e) selection effect (SE) of intercropping in relation to $\mathrm{N}$ supply, and the NE, CE, $\mathrm{SE}$ against $\mathrm{N}$ supply for maize/C3-cereal, maize/legume and C3-cereal/legume intercrops (b, d, f). N supply was calculated according to Methods S5.6. 

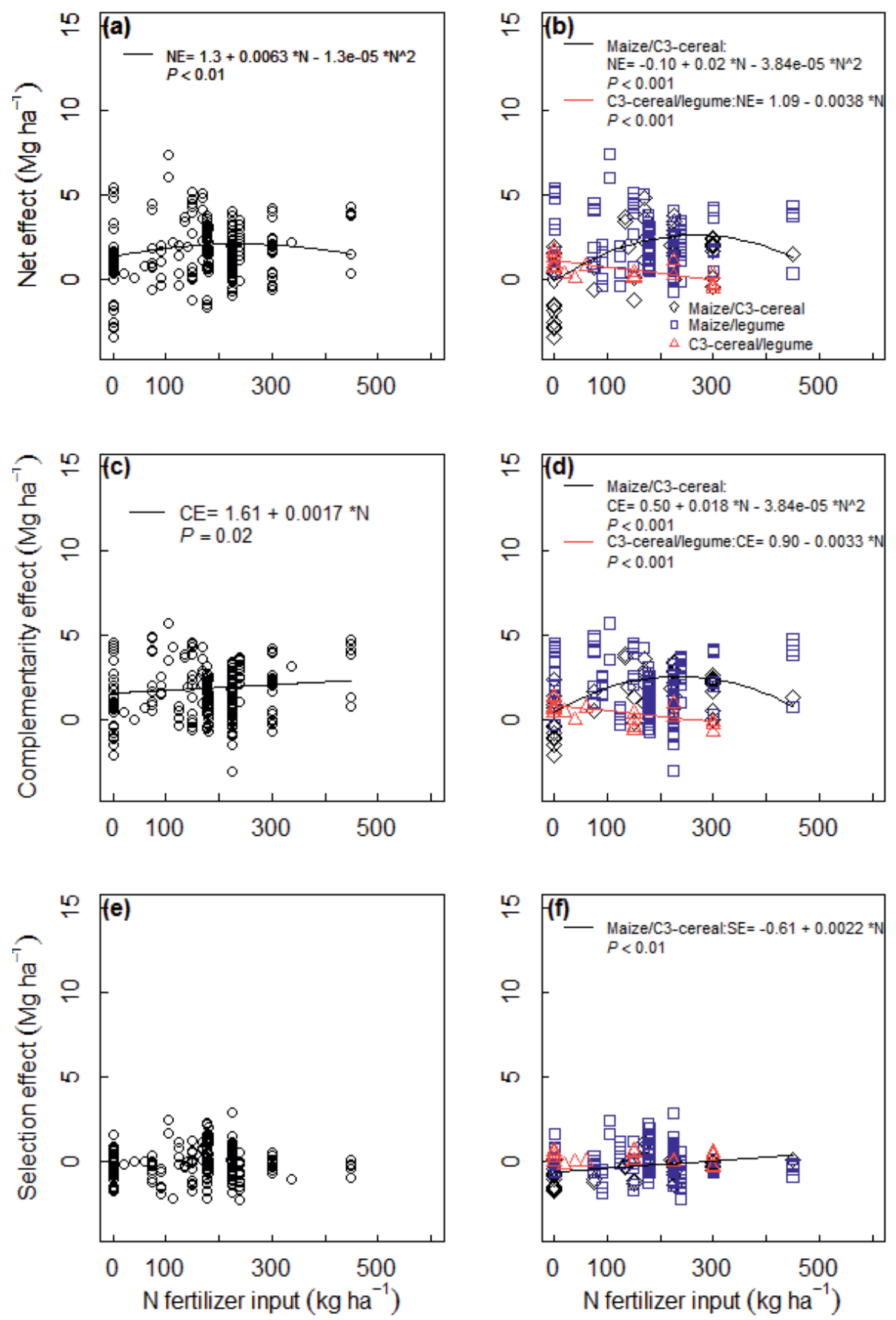

Fig. S5.7 Net effect, complementarity effect and selection effect in response to $\mathrm{N}$ input, when using a subset of the data used also for the analysis of the effect of $\mathrm{N}$ supply (Fig. S5.6). (a) net effect (NE), (c) complementarity effect (CE) and (e) selection effect (SE) of intercropping in relation to $N$ input and the NE, CE, SE against $N$ input for maize/C3-cereal, maize/legume and C3-cereal/legume intercrops (b, $d, f)$. The analysis was based on a subset of available $\mathrm{N}$ supply data. 
When we were analyzing the effect of $\mathrm{N}$ availability on the NE and its components, we compared whether we should use the $\mathrm{N}$ supply as the explanatory variable, since the $\mathrm{N}$ supply includes $\mathrm{N}$ from both soil and fertilizer according to the QUEFTS model (Methods S5.8). Then we compared the results of analysis on the $\mathrm{N}$ supply and $\mathrm{N}$ input. With the same subset of data, the results of analysis on $\mathrm{N}$ input were similar to the analysis on $\mathrm{N}$ supply (Fig. S5.6 vs. Fig. S5.7). The results for the three groups of intercrops were also similar (Fig. S5.6 vs. Fig. S5.7). However, these results for the effect of $\mathrm{N}$ input were very different from those using the full dataset. Thus, the difference in the results of the analysis on $\mathrm{N}$ input and $\mathrm{N}$ supply (Fig. $5.5 \mathrm{vs.}$ Fig. S5.6) was due to using different subsets of data, and not due to the choice of explanatory variable. So, analyzing with different subsets is the main reason for different results of analysis on $\mathrm{N}$ supply and $\mathrm{N}$ input.

We also found that $\mathrm{N}$ supply was a better variable than $\mathrm{N}$ input to explain the relationship between the NE and $\mathrm{N}$ availability ( $\triangle \mathrm{AIC}$ between models estimating the $\mathrm{NE}$ in relation to $\mathrm{N}$ supply and $\mathrm{N}$ input was 4.3). However, the subset of $\mathrm{N}$ supply data had $37 \%$ fewer data records than the subset of $\mathrm{N}$ input data because a considerable number of studies did not report the soil information. The smaller subset with $\mathrm{N}$ supply data than $\mathrm{N}$ input data would lead to less robust results, and there was also contradictory result with a quadratic response for the NE and linear response for the CE (Fig. S5.6) when using $\mathrm{N}$ supply as an explanatory variable. That was inconsistent since the CE accounts for $90 \%$ of the NE. We therefore emphasized the more robust analysis of $\mathrm{N}$ fertilizer input in the main text.

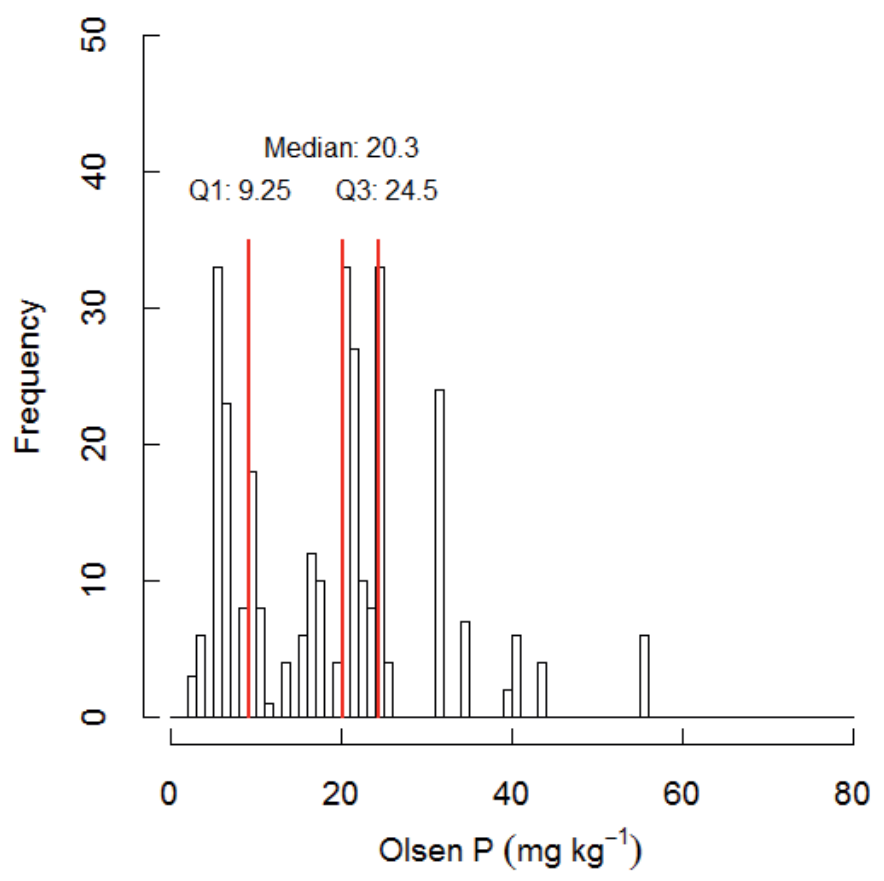

Fig. S5.8 Frequency distribution of Olsen-P in the dataset. Vertical lines in panels of frequency distribution (a-c) indicate the first quartile (Q1), median and third (Q3) quartile of the Olsen-P. 

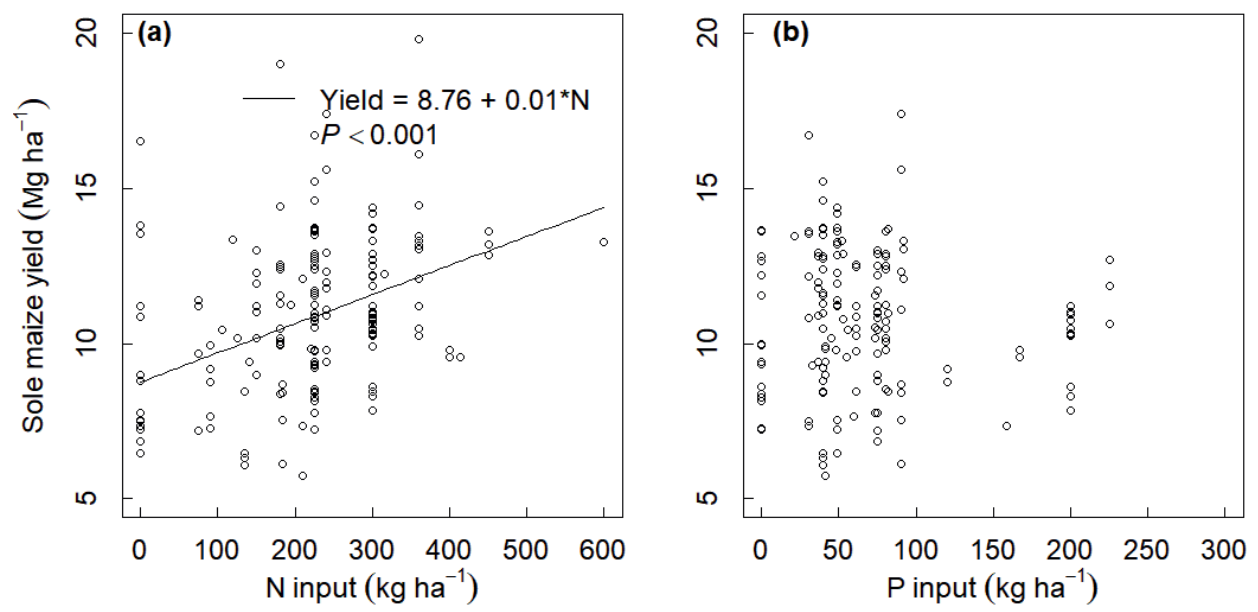

Fig. S5.9 The response of sole maize yield to $N(a)$ and $P(b)$ input in sole maize.

Depending on different subsets, the results of analysis on P supply and P input were slightly different. Considering the similar reasons with the analysis on $\mathrm{N}$ supply, we only discussed the results of analysis on $\mathrm{P}$ input in the main text. 

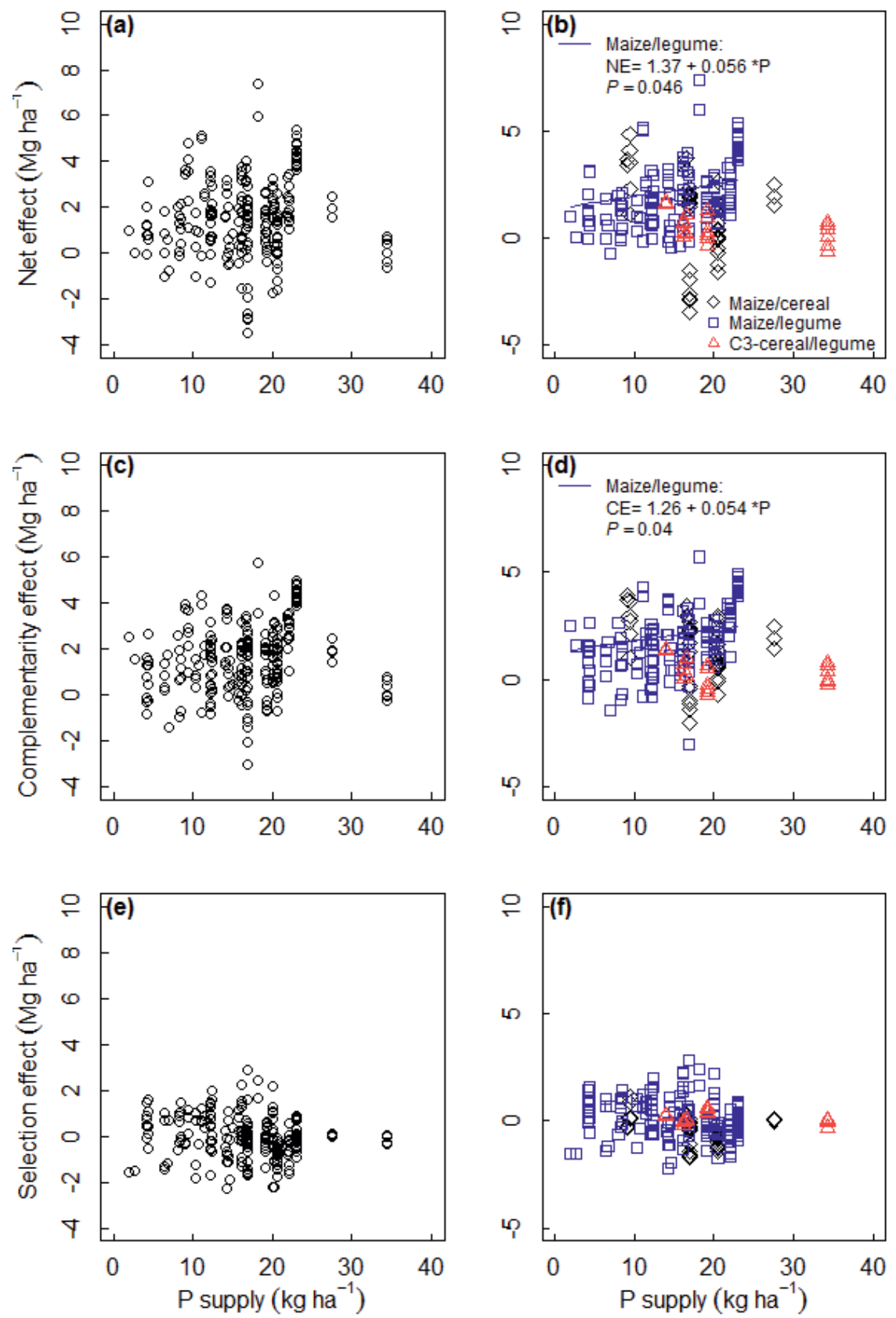

Fig. S5.10 Net effect (NE), complementarity effect (CE) and selection effect (SE) against P supply, and the NE, $\mathrm{CE}$ and $\mathrm{SE}$ of maize/C3-cereal, maize/legume and C3-cereal/legume intercrops against $\mathrm{P}$ supply. Model selection was according to Methods S5.6. P supply was calculated according to Methods S5.8. (a, c, e) Relationships between NE, CE and SE and P supply were estimated by model: (NE, CE, SE) $)_{j k}=\beta_{\mathrm{P}} P_{i j k}+a_{i}+b_{i j}+$ $\varepsilon_{i j k}$. (b, d) Relationship between NE, CE and $P$ supply were estimated using model: $(\mathrm{NE}, \mathrm{CE})_{i j k}=\beta_{\mathrm{TC}}\left(T C_{i j k}\right)+$ $\beta_{\mathrm{P}}\left(T C_{i j k}\right) P_{i j k}+a_{i}+b_{i j}+\varepsilon_{i j k}(\mathrm{f})$ Relationships between the SE and $\mathrm{P}$ input were estimated using the model: $\mathrm{SE}_{i j k}=$ $\beta_{\mathrm{DV} 2}\left(D V 2_{i j k}\right)+\beta_{\mathrm{P}} P_{i j k}+a_{i}+b_{i j}+\varepsilon_{i j k}$. Only regressions of $P<0.05$ were shown in the panels. 


\section{Appendix E}

Table S6.1 Overview of species combinations in the data set

\begin{tabular}{|c|c|c|}
\hline $\begin{array}{l}\text { Groups of species } \\
\text { combinations }\end{array}$ & $\begin{array}{l}\text { Record } \\
\mathrm{s} \text { of } \\
\text { groups }\end{array}$ & Species combination \\
\hline \multirow[t]{10}{*}{ Maize/legume } & \multirow[t]{10}{*}{436} & Maize (Zea mays)/adzuki bean (Vigna angularis) \\
\hline & & Maize (Zea mays)/common bean (Phaseolus vulgaris) \\
\hline & & Maize (Zea mays)/chickpea (Cicer arietinum) \\
\hline & & Maize (Zea mays)/cowpea (Vigna unguiculata) \\
\hline & & Maize (Zea mays)/faba bean (Vicia faba) \\
\hline & & Maize (Zea mays)/white lupin (Lupinus albus) \\
\hline & & Maize (Zea mays)/mung bean (Vigna radiata) \\
\hline & & Maize (Zea mays)/pea (Pisum sativum) \\
\hline & & Maize (Zea mays)/peanut (Arachis hypogaea) \\
\hline & & Maize (Zea mays)/soybean (Glycine max) \\
\hline \multirow[t]{3}{*}{ Maize/small grain } & \multirow[t]{3}{*}{120} & Maize (Zea mays)/wheat (Triticum aestivum) \\
\hline & & Millet (Setaria italica)/maize (Zea mays) \\
\hline & & Maize (Zea mays)/barley (Hordeum vulgare) \\
\hline \multirow[t]{2}{*}{ Maize/others } & \multirow[t]{2}{*}{12} & Maize (Zea mays)/turnip (Brassica campestris) \\
\hline & & Maize (Zea mays)/oilseed rape (Brassica napus) \\
\hline \multirow[t]{12}{*}{ Small grain/legume } & \multirow[t]{12}{*}{284} & Pearl millet (Pennisetum glaucum)/cowpea (Vigna unguiculata) \\
\hline & & Pearl millet (Pennisetum glaucum)/peanut (Arachis hypogaea) \\
\hline & & Oat (Avena sativa)/faba bean (Vicia faba) \\
\hline & & Oat (Avena sativa)/pea (Pisum sativum) \\
\hline & & Rice (Oryza sativa)/mung bean (Vigna radiata) \\
\hline & & Rice (Oryza sativa)/peanut (Arachis hypogaea) \\
\hline & & Sorghum (Sorghum bicolor)/cowpea (Vigna unguiculata) \\
\hline & & Sorghum (Sorghum bicolor)/pigeon pea (Cajanus cajan) \\
\hline & & Triticale (× Triticosecale Wittmack)/pea (Pisum sativum) \\
\hline & & Wheat (Triticum aestivum)/chickpea (Cicer arietinum) \\
\hline & & Wheat (Triticum aestivum)/faba bean (Vicia faba) \\
\hline & & Durum wheat (Triticum turgidum)/lentil (Lens culinaris) \\
\hline
\end{tabular}


Legume/legume

Legume/others

Small grain/small grain

3

7

Wheat (Triticum aestivum)/oilseed rape (Brassica napus)

Barley (Hordeum vulgare)/flax (Linum usitatissimum)

Barley (Hordeum vulgare)/oilseed rape (Brassica napus)

Pea (Pisum sativum)/faba bean (Vicia faba)

Pigeon pea (Cajanus cajan)/peanut (Arachis hypogaea)

Pigeon pea (Cajanus cajan)/soybean (Glycine max)

Mustard (Sinapsis alba)/chickpea (Cicer arietinum)

Mustard (Sinapsis alba)/lentil (Lens culinaris)

Mustard (Sinapsis alba)/pea (Pisum sativum)

Sesame (Sesamum indicum)/mung bean (Vigna radiata)

Sesame (Sesamum indicum)/blackgram (Vigna mungo)

Sesame (Sesamum indicum)/peanut (Arachis hypogaea)

Oilseed rape (Brassica napus)/faba bean (Vicia faba)

Oilseed rape (Brassica napus)/pea (Pisum sativum)

Wheat (Triticum aestivum)/barley (Hordeum vulgare)

Small grain/others
Wheat (Triticum aestivum)/pea (Pisum sativum)

Wheat (Triticum aestivum)/soybean (Glycine max)

Barley (Hordeum vulgare)/faba bean (Vicia faba)

Barley (Hordeum vulgare)/lentil (Lens culinaris)

Barley (Hordeum vulgare)/narrow-leafed lupin (Lupinus angustifolius)

Barley (Hordeum vulgare)/pea (Pisum sativum)

Durum wheat (Triticum turgidum)/pea (Pisum sativum)

Sesame (Sesamum indicum)/sunflower (Helianthus annuus) 
Table S6.2 Factor loadings in the Principal component analysis (PCA)

\begin{tabular}{lcc}
\hline Variables & PC1 & PC2 \\
\hline Temporal niche differentiation & 2.14 & 0.85 \\
Nitrogen input & 2.54 & -0.28 \\
Phosphorus input & 1.50 & -2.46 \\
Observed yield & 2.87 & 0.33 \\
Expected yield & 2.63 & -0.01 \\
Net effect & 2.08 & 0.80 \\
\hline
\end{tabular}

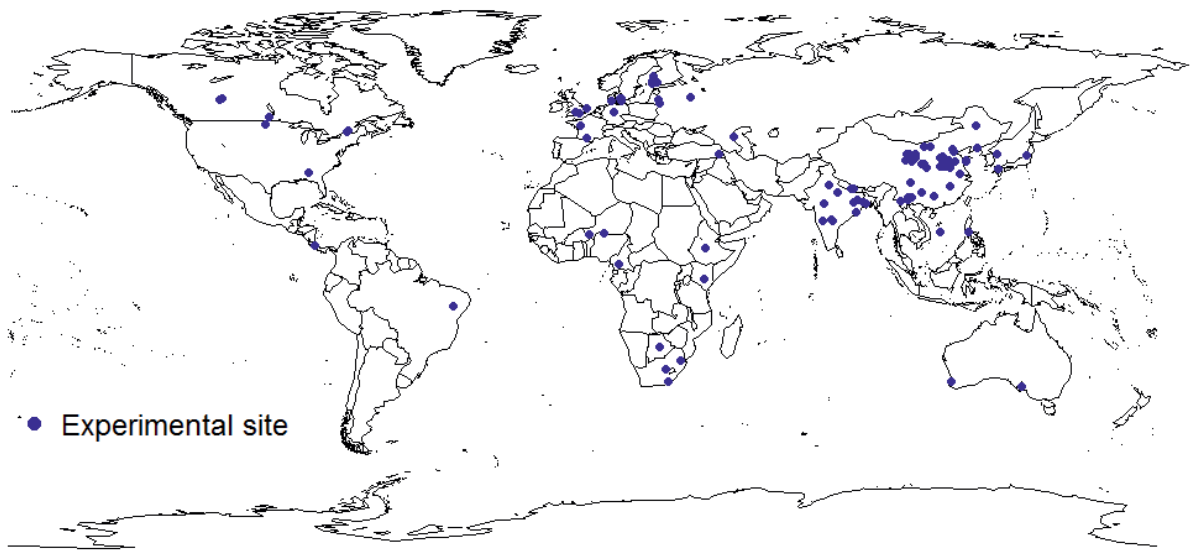

Fig.S6.1 World map with experimental sites. 


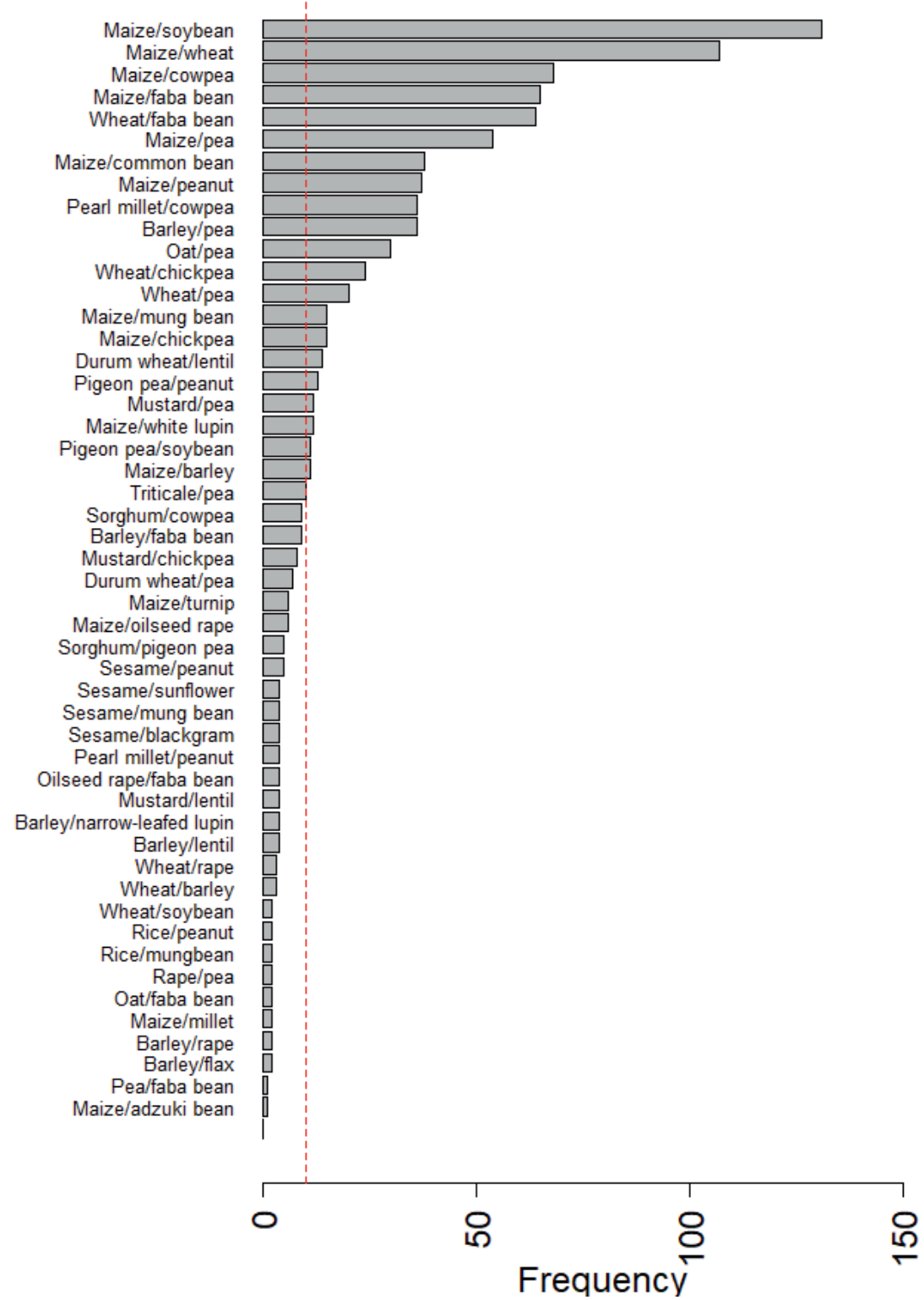

Fig. S6.2 Frequency of species combinations in the dataset. There are 22 species combinations with 10 (red dashed line) or more records in the dataset. 


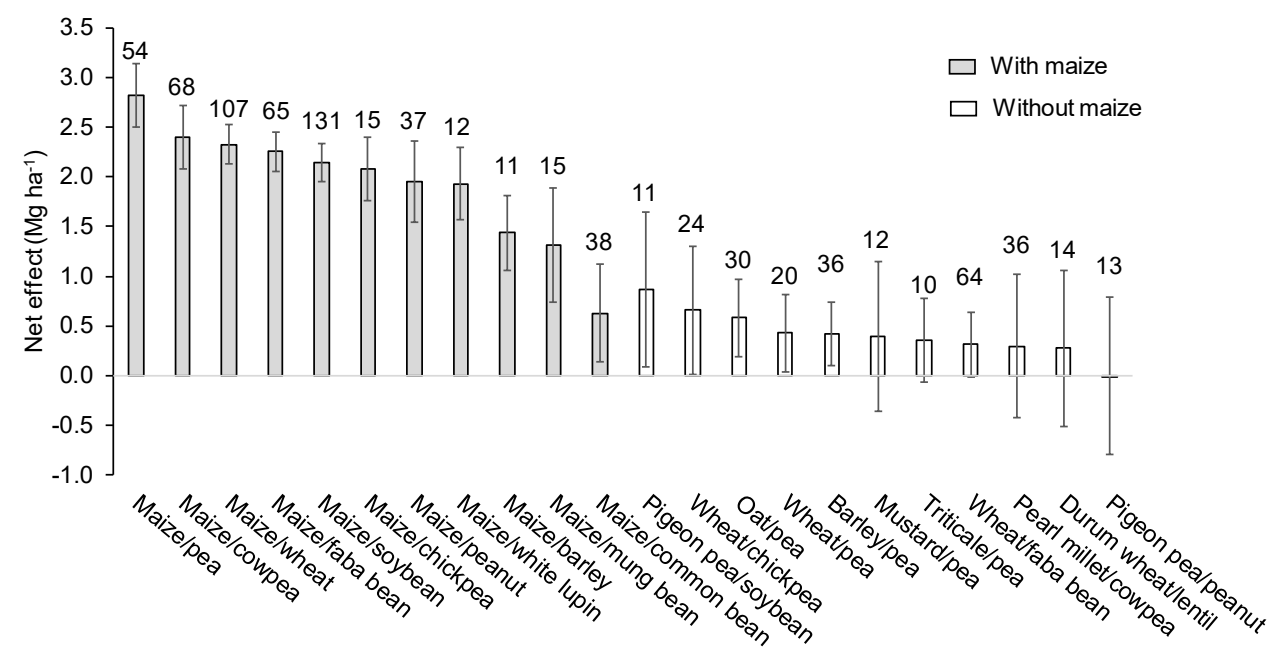

Fig. S6.3 Net effect of species combinations with $\geqslant 10$ data records. The bars represent the estimated mean value based on a mixed-effects model. The error bars represent standard error; number on top of the bar represents the data records.
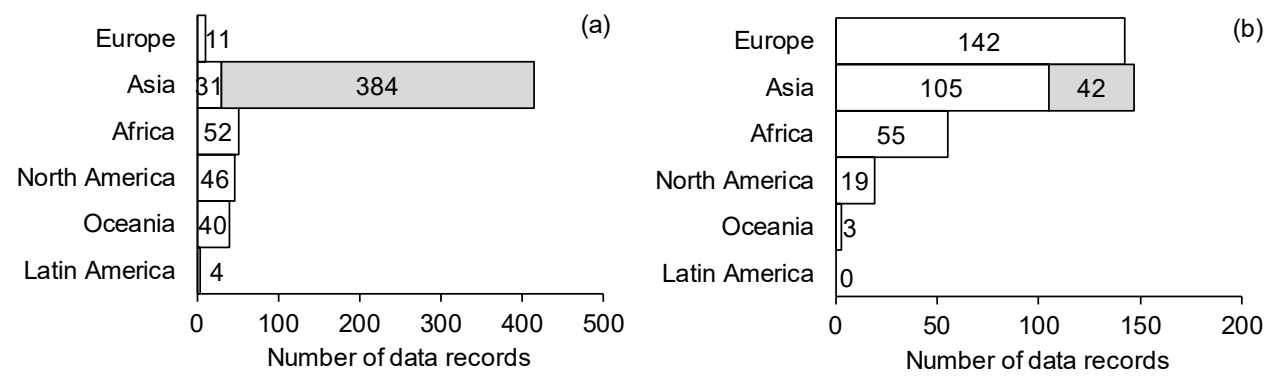

Fig. S6.4 Number of data records of intercrops with (a) and without maize (b) in different continents. Note: the grey part of the bar for Asia represents data from China. 

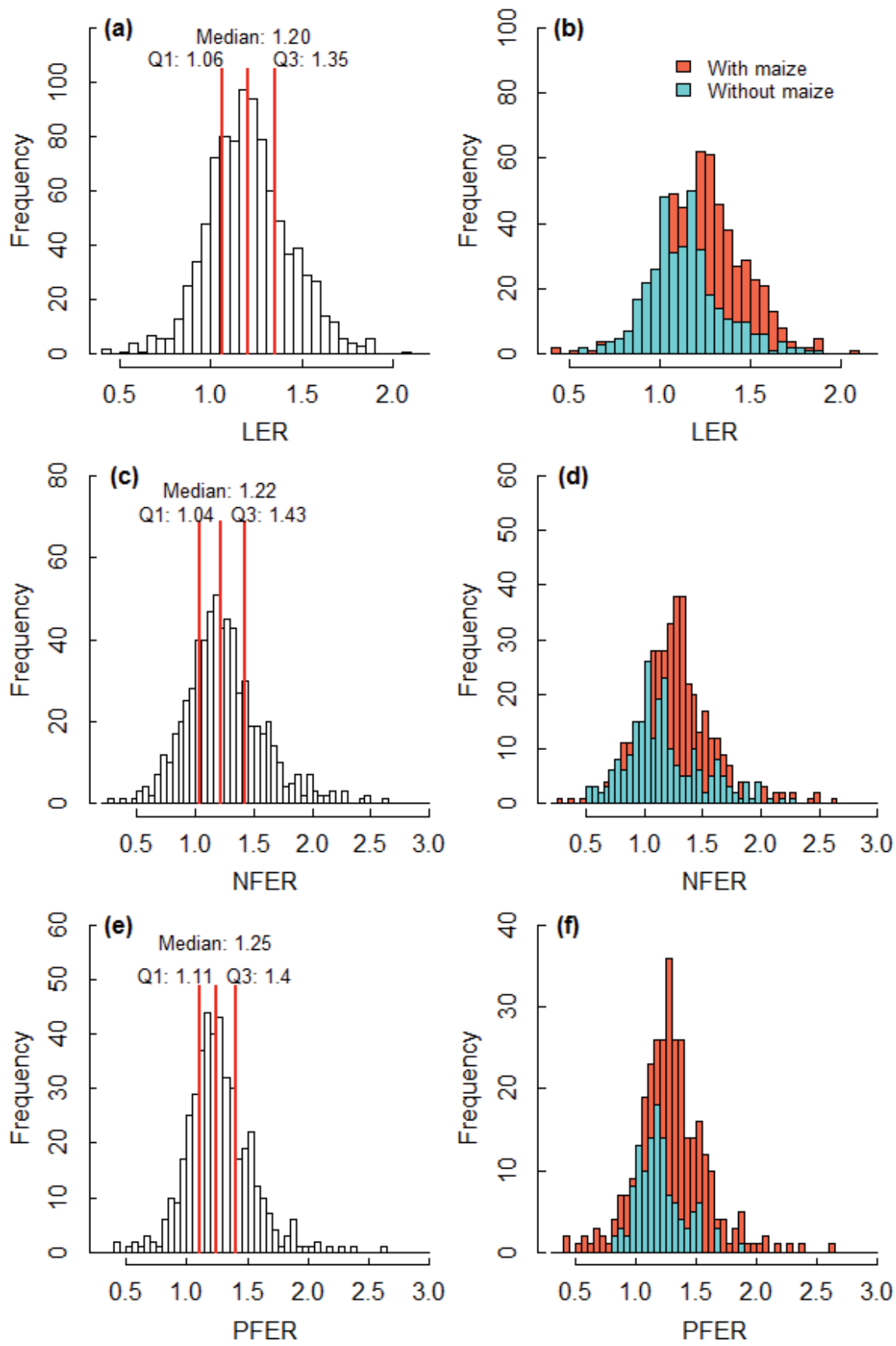

Fig. S6.5 Frequency distribution of the LER, NFER and PFER. (a), (c), (e) LER, NFER, PFER of all intercrops in the data set and (b), (d), (f) LER, NFER, PFER in the subsets of intercrops with and without maize. Vertical red lines in panels a, c and e indicate the first quantile (Q1), median and third quantile (Q3) of the LER, NFER, PFER, respectively. 


\section{Summary (English)}

One of the current challenges facing the world is producing enough food for a rapidly growing global population. Modern intensive agriculture provides high yields but causes substantial environmental risks. Diverse farming systems such as intercropping (i.e., growing two or more crop species in the same field) are an efficient strategy for sustainable agriculture. Intercropping has the potential to increase nutrient acquisition and yield compared to sole crops. The ecological mechanisms underlying these benefits mainly include complementarity in, and facilitation of resource use. Phosphorus $(\mathrm{P})$ is a major nutrient limiting crop yield in many soils. Previous studies have shown that intercropping can increase the yield on soils with low P availability but with various sparingly soluble P sources. Species have developed $\mathrm{P}$ mobilizing strategies (e.g., root exudates) to access the sparingly soluble organic or inorganic $\mathrm{P}$. These variations in plant functional traits are hypothesized to underlie reduced competition for $\mathrm{P}$ through resource partitioning and to promote complementary and facilitative use of these resources. Compared to the well-demonstrated complementary nitrogen $(\mathrm{N})$ use, there is scarce evidence for the hypothesis on resource partitioning of soil $\mathrm{P}$. The advantage of intercropping is commonly quantified by the land equivalent ratio (LER). The LER is the relative area that is required for sole crops to produce the yield that is achieved under intercropping. The LER is a dimensionless indicator and does not provide any information on the absolute yield increase by intercropping. Agronomic practices (e.g., selection of species, sowing and harvest time of component species, spatial arrangement and fertilizer input) impact species interactions in intercropping, but it is still unknown how these factors affect the yield gain of intercrops. Therefore, the objectives of this thesis were:

1) to test for complementarity in P acquisition from different sources by intercrops (Chapter $2-4)$;

2) to quantify the absolute yield gain of intercrops and its drivers (Chapter 5);

3) to study the effect of species choice, temporal and spatial arrangement, and $\mathrm{N}$ and $\mathrm{P}$ fertilizer input on yield gain of intercrops (Chapter 6).

In Chapters 2-4, I carried out a sequence of empirical studies by using quartz sand (an inert substrate without interaction between $P$ ions and the mineral phase), or soil as substrate in pot experiments, or growing a species combination in the field. In Chapter 2, I designed a test for the hypothesis on partitioning of $P$ resources, i.e., to test if species' dissimilar capabilities to access different $\mathrm{P}$ sources reduces the competition for $\mathrm{P}$ in a species mixture. I conducted two pot experiments with quartz sand. Experiment 1 tested for the capabilities of twelve species to access the sparingly soluble calcium-bound $\mathrm{P}(\mathrm{CaP})$, phytate $\mathrm{P}(\mathrm{PhyP})$ and $\mathrm{P}$-coated 
Fe(hydr)oxide (FeP). Species combinations with dissimilar (millet/chickpea; cabbage/faba bean) and similar traits (wheat/maize) were selected for Experiment 2. Complementary P uptake from different sources was confirmed by millet/chickpea combination: there was enhanced $\mathrm{P}$ uptake by this species mixture on mixed CaP and PhyP compared to the expected $\mathrm{P}$ uptake on sole $\mathrm{P}$ sources. There was no enhanced $\mathrm{P}$ uptake by cabbage/faba bean combination, because their abilities to access PhyP and FeP were similar in Experiment 2, which was not consistent with the results of Experiment 1 . There was an unexpected increase in P uptake by the wheat/maize combination with similar abilities to access CaP and PhyP. The results suggested that differences in $\mathrm{P}$ uptake traits were not required to achieve greater than expected P uptake by a species mixture. Species dominance also played a role in increased $\mathrm{P}$ acquisition by species mixture even if species' abilities to access $\mathrm{P}$ sources are similar because the stronger competitive species gains more $\mathrm{P}$ than the weaker competitive species losses.

With the same species combinations in Chapter 2, I conducted a pot experiment with soil to test complementarity in $\mathrm{P}$ acquisition from different resources in Chapter 3. Low P soils were mixed with organic and inorganic P sources, where both complementarity and facilitation with respect to $\mathrm{P}$ uptake could occur simultaneously. To determine the occurrence of the mechanisms of complementarity and facilitation, I proposed a conceptual framework that highlights the competition for ortho-P (the only form $\mathrm{P}$ available to plants) in species mixture. The conceptual framework describes mechanisms related to root exudates and potentially mobilized P sources and outcomes of $\mathrm{P}$ uptake and biomass depending on species' competitive ability to take up $\mathrm{P}$. The analyses of root exudates from the pot experiment suggested facilitation of $\mathrm{P}$ uptake in the millet/chickpea mixture. Complementarity in $\mathrm{P}$ acquisition from different sources was not found in any of the species mixtures. Similar to the results of Chapter 2, species dominance rather than complementarity in $\mathrm{P}$ acquisition from different $\mathrm{P}$ sources or facilitation of $\mathrm{P}$ uptake contributed to the enhance $\mathrm{P}$ uptake in wheat/maize mixtures. Therefore, there was no evidence for complementary use of $P$ sources in the soil.

In Chapter 4, I selected one species combination (millet/chickpea) based on the pot experiments to investigate the occurrence of complementarity in P acquisition from different $\mathrm{P}$ sources and facilitation of $\mathrm{P}$ uptake in a field experiment with low P soil. Complementarity in $\mathrm{P}$ acquisition from different sources and facilitation of $\mathrm{P}$ uptake were expected to contribute to yield gain of intercropping at a low P level rather than a high P level. Millet and chickpea were arranged in strips and with chickpea sown and harvested earlier than millet. Enzyme activities and carboxylates in the rhizospheres of millet and chickpea were different, suggesting complementary use of soil $\mathrm{P}$ pools. But there was no evidence for facilitation of $\mathrm{P}$ 
uptake because the $\mathrm{P}$ content of plants was similar regardless of the neighboring crop species. I observed increased P uptake in intercrops at the low P level, but this was not associated with a yield increase in the intercrop treatment. I also found a yield increase in the intercrop treatment at a high P level. Therefore, I concluded that species' differences in root exudates provided the conditions for complementarity in $\mathrm{P}$ acquisition from different sources or facilitation of $\mathrm{P}$ uptake in millet/chickpea intercropping under field conditions, but such mechanisms did not drive overyielding in this relay strip intercropping, even though soil $\mathrm{P}$ was yield-limiting.

Chapters 5 and 6 analyzed the absolute yield gain of grain intercrops, the drivers of yield gain and the effect of agronomic practices on the yield gain of intercrops. Many field studies on intercropping for grain production have been done in China over the past thirty years. This has resulted in ample data on intercropping from China. Therefore, I quantified the absolute yield gain of grain intercrops conducted in China in Chapter 5 through meta-analysis of data from literature. The drivers of the yield gain of intercrops were estimated using the additive partitioning method. The yield gain was mostly due to a positive complementarity effect $(90 \%)$, while the remaining $10 \%$ was due to a selection effect. The yield gain increased with temporal niche differentiation, which is the proportion of the total growing period of the intercrops during which component species grow alone. The mechanism underlying yield gain shifted from selection effect when there was more overlap in growth period between the two species, to complementarity effect when there was less overlap, while complementarity effect remained the major contributor to yield gain. Inclusion of maize in the intercrop is a key factor contributing to high yield gain, but intercrops with or without legumes have similar yield gains. The yield gain increased with $\mathrm{N}$ input in maize/C3-cereal intercrops but not in cereal/legume intercrops, indicating the ability of legumes to compensate for low $\mathrm{N}$ input. However, yield gain did not respond to $\mathrm{P}$ input, contrasting the stress gradient hypothesis. The results show that complementarity effect is the main contributing factor to yield gain in the investigated Chinese intercropping, which were mostly relay strip intercropping. The underlying drivers of yield gain were related to the presence of maize and temporal complementarity in resource use, but there was no strong contribution of competitive dominance to yield gain of Chinese intercropping.

Chapter 6 presented a meta-analysis of the yield gain of intercropping on a global scale and of the agronomic management factors that impact the yield gain. Yield gain was greatest when maize was intercropped with short-grain cereals or legumes, with temporal niche differentiation and when supplied with high fertilizer inputs in strip intercropping. This strategy was mainly practiced in China. The alternative intercropping strategy was mainly practiced outside China and consisted of intercrops with short stature crop species, often 
simultaneously grown as full mixtures, and supplied with low fertilizer input. Both the low input-low output and high input-high output intercropping strategies saved 16-29\% land and $19-36 \%$ fertilizer compared to their monocultures. These findings distinguish two syndromes of production in intercropping that represent a coherent set of management practices tailored to address different production objectives.

In conclusion, this thesis provided no evidence for complementarity in $\mathrm{P}$ acquisition from different soil $\mathrm{P}$ sources. The presence of maize and temporal complementarity in using resources (e.g., light, water, $\mathrm{N}$ or $\mathrm{P}$ ) played an important role in competitive relaxation and yield gain of intercropping at the field level. On a global level, there was a set of coordinated management factors rather than a single factor that drives the yield gain of intercropping, resulting in two contrasting syndromes of production in intercropping. The present study provides some insights on designing for intercropping with improved resource use efficiency and yield gain. Designing intercropping systems for improved P acquisition cannot be through complementary use of different $\mathrm{P}$ sources. Further research on designing intercropping systems should consider a set of management strategies such as using strip intercropping, a relatively short co-growth period of the two crop species to reduce the intensity of competition for resources, and including species with high productivity (e.g., maize). Hopefully, all these will provide a valuable contribution to exploring the opportunities that intercropping can ensure food production while reducing the environmental impacts of agriculture. 


\section{Summary (Chinese)}

当今世界面临的挑战之一是为迅速增长的全球人口生产足够的粮食。现代集约化农业能提供较 高的粮食产量, 但也带来了巨大的环境风险。多样化的种植体系, 例如间作（即在同一块土地 上种植两种或两种以上的作物）是发展可持续农业的可行策略。与单一种植相比，间作具有提 高养分获取和产量的优势。形成这些优势的生态机制主要包括资源利用的互补作用和促进作用。 磷是限制作物产量的主要土壤养分之一。以往的研究表明, 间作可以提高作物在低磷土壤上的 产量, 低磷土壤中存在多种难溶性的磷源。植物形成了磷的活化策略（例如根分泌物）来获取 难溶性的有机、无机磷源。不同植物物种之间功能性状的差异为通过资源分配来减少对磷的竞 争, 并促进植物对资源利用的互补作用和促进作用提供了假设。这个假设已在植物间对氮素的 互补利用中得到充分证明，与之相比，关于土壤磷资源分配的假设还缺乏验证。

间作优势通常用土地当量比 (LER) 来量化。LER 指生产与间作同等的产量所需要的单作的种 植面积。LER 是一个无量纲指标，不直接体现间作相对于单作在每单位面积上所提高的产量。 农田管理措施（如品种选择、间作作物的播种和收获时间、条带设置和肥料投入等）可影响间 作作物间的相互作用, 但这些因素如何影响间作体系的产量优势仍不清楚。因此, 本博士论文 的研究目的是:

1) 验证间作体系获取不同磷源的互补作用（第 2-4 章）;

2) 量化间作体系的净产量优势及其驱动因素（第 5 章）;

3) 研究品种选择、条带设置、氮肥和磷肥投入对间作体系产量优势的影响（第六章）。

在第 2-4 章中, 我利用石英砂（一种惰性基质且磷离子和矿物相之间无相互作用）、土壤作为 基质进行了盆栽实验, 并利用一个间作体系进行大田试验。在第 2 章中, 我设计了一个验证磷 资源分化利用假设的试验, 即验证不同物种获取不同磷源的能力是否会减少物种间对磷吸收的 竞争。我用石英砂做了两个盆栽试验。试验一明确了 12 种作物获取难溶性钙磷（CaP）、植酸 磷 (PhyP) 和铁氧化物覆盖的 FeP 的能力。选出对这些磷源利用能力不同的物种组合 (谷子/ 鹰嘴豆; 甘蓝/蚕豆) 和对这些磷源利用能力相似的物种组合 (小麦/玉米) 进行了试验二。谷子 /鹰嘴豆组合表现出对不同磷源的互补性吸收：该组合对混合磷源 $(\mathrm{CaP} / \mathrm{PhyP})$ 的吸收量高于 对单种磷源吸收量的平均值。甘蓝/虽豆组合对混合磷源的吸收量与其对单种磷源吸收量的平均 值相似, 因为在试验二中两作物对 $\mathrm{PhyP}$ 和 $\mathrm{FeP}$ 的吸收能力相似, 这与其在试验一中的结果不 一致。小麦/玉米组合对混合磷源 ( CaP/PhyP) 的吸收量明显高于其对单种磷源吸收量的平均 值。结果表明, 物种间不同的吸磷能力并不是提高作物组合相对于单作磷吸收量的必需条件。 即使两作物获取磷源的能力相似, 物种的竞争优势在提高物种组合磷吸收量的过程中也发挥了 作用, 因为竞争较强的物种获得的磷多于竞争较弱的物种失去的磷。

在第 3 章中, 我利用了与第 2 章中相同的物种组合进行了土壤盆栽试验, 目的在于验证物种组 合对土壤中不同磷源吸收的互补作用。试验中所用的低磷土壤与有机、无机磷源混合, 在此条 件下物种组合对磷源吸收的互补作用和促进作用可同时发生。为了明确互补作用和促进作用的 存在, 我提出了一个概念模型, 该模型强调了物种组合对正磷酸盐（植物根系可吸收的唯一磷 
形态）的竞争。这一概念模型描述了与根系分泌物相关的互作机制, 以及潜在磷源的活化吸收 和物种互作结果（磷吸收量和生物量）, 其取决于物种对磷的竞争吸收能力。盆栽试验中根系 分泌物的结果表明, 谷子/鹰嘴豆组合表现出对磷吸收的促进作用。而所有的被试物种组合都没 有表现出对不同磷源的互补性利用。与第 2 章的结果相似, 对磷的竞争优势而非对不同磷源的 互补性利用提高了小麦/玉米组合对磷的吸收量。因此, 在本试验中物种组合对土壤中不同磷源 的互补利用并没有得到验证。

第 4 章在盆栽试验的基础上, 选择了一个物种组合 (谷子/鹰嘴豆), 开展了在低磷土壤上的田 间试验, 研究了对土壤中不同磷源利用的互补作用及促进作用及其对间作体系磷吸收的贡献。 试验假设是间作体系对不同磷源的互补利用和促进作用在低磷水平而非高磷水平下能提高间作 体系的产量。试验中的间作处理是将谷子和鹰嘴豆条带间作种植, 鹰嘴豆早于谷子播种和收获。 结果表明, 谷子和鹰嘴豆的根际磷酸酶活性和有机酸浓度存在差异, 说明两物种对土壤不同磷 库的利用存在潜在的互补性。但间作体系并没有表现对磷吸收的促进作用, 因为间作条带中不 同行中的植物的磷含量相似。在低磷水平下, 我发现间作作物对磷的吸收量相比于单作增加, 但这并没有相应地提高间作体系的产量。我还发现间作体系在高磷水平下的产量相比于单作也 有所提高。因此, 我得出的结论是物种在根分泌物方面的差异为间作体系互补性获取不同的磷 源提供了条件, 但是这种对不同磷源的互补性利用机制并不是大田中谷子/鹰嘴豆条带间套作的 间作优势的主要驱动因子, 即使该试验是在低磷土壤上进行的。

第 5 章和第 6 章分析了粮食作物间作体系的净产量优势及其驱动因素以及农田管理措施对净产 量优势的影响。近三十年来, 我国对以粮食作物为主的间作体系作了大量的田间研究, 这为分 析中国的间作体系提供了充足的数据。因此, 在第 5 章中, 我通过文献资料进行了整合分析, 量化了中国的粮食作物间作体系的净产量优势。利用可加性分配法对间作作物净产量优势的驱 动因素进行了分析和量化。结果表明, 间作体系的净产量优势主要来自于正的补偿效应 $(90 \%)$, 剩余 $10 \%$ 来自于选择效应。净产量优势随时间生态位分化而增加, 时间生态位分化是各间作物 种单独生长的天数占整个间作体系的总生长期天数的比例。当两种作物的共生期较短时, 间作 体系的净产量优势的驱动因素主要为补偿效应, 当两种作物的共生期较长时, 间作体系的净产 量优势的驱动因素主要为选择效应。玉米的存在是间作体系获得较高的净产量优势的关键因素, 而豆科作物的存在与否对间作体系的净产量优势无明显影响。玉米/C3 禾本科作物间作体系的 净产量优势随氮肥的投入而增加, 而禾本科/豆科作物间作体系的净产量优势不依赖于氮肥的投 入, 说明豆科作物对低氮肥投入的补偿作用。然而, 与梯度胁迫假说相反, 净产量优势对磷肥 输入没有响应。结果表明, 间作体系 (条带间套作) 的净产量优势主要来自补偿效应。净产量 优势形成的潜在驱动因素与玉米的存在和资源利用在时间上的互补性有关, 而选择效应对中国 的粮食作物间作体系的净产量优势没有显著的贡献。

第 6 章综合分析了全球范围内粮食作物间作体系的净产量优势和农田管理因素对净产量优势的 影响。当玉米与矮的禾本科或豆科作物间作, 且具有不同的播种时间和收获时间以及较高的养 分投入时, 该间作体系的净产量优势较大。这一间作管理模式广泛用于中国。另一种间作管理 模式主要用于中国以外的地区, 该间作模式主要以矮谷物为主, 通常混合种植、同时播种并同 时收获, 且养分投入低。这两种低投入-低产出和高投入-高产出的间作模式与单作相比, 均节约 
了 16-29\%的土地和 19-36\%的肥料。本章内容揭示了两种为满足不同生产目标而制定的间作生 产的综合管理模式。

综上所述, 本博士论文的研究表明间作体系对土壤中不同磷源的互补性利用缺乏证据。在田间 水平上, 间作体系中玉米的存在以及资源（如光、水、氮、磷）利用在时间上互补性对减弱间 作体系对资源利用的竞争作用和提高净产量优势起着重要作用。在全球尺度上, 推动间作体系 净产量优势形成的因素是一套相协调的管理措施, 而不是单一的管理措施, 从而形成了两种截 然不同的间作生产综合管理模式。本研究为资源高效利用及高产的间作体系的设计提供了思路。 这种间作体系的设计不能仅基于作物对土壤不同磷源的互补性利用机制, 应考虑一套综合的管 理策略, 如采用条带间作、选用高产作物(如玉米)、设置相对较短的共同生长期以减少对资源的 竞争。我希望本论文的研究结果能助力于实现间作体系在减少对环境影响的同时保障粮食生产 的目标。 


\section{Acknowledgements}

I feel very lucky to have this opportunity to do a joint $\mathrm{PhD}$ project. During the past few years, I conducted laboratory and field works in China and in the Netherlands, resulting this PhD thesis. I am really happy to work with so many nice people from all over the world during this long and nice journey. I would like to express my sincere gratitude to those people who have supported and encouraged me. Without you I would never finish this thesis.

Looking back to the time when I started my PhD in 2014, first and foremost, I would like to express my deepest appreciation to Fusuo Zhang at China Agricultural University, and Ellis Hoffland, Thomas W. Kuyper at Wagningen University who promoted this sandwich PhD project and accepted me as a sandwich PhD in Wageningen University. Secondly, I would like to express my earnest thanks to my excellent PhD supervisory team made up of Ellis Hoffland, Thomas W. Kuyper, Wopke van der Werf, Fusuo Zhang, Haigang Li and Junling Zhang. I am very proud to have you involved in my $\mathrm{PhD}$ project.

I am very grateful to my promoter Ellis, for giving me the chance to successfully get the Wageningen sandwich PhD fellowship and accepting me as your PhD student at Wageningen University. Thank you so much for your very careful and thoughtful guidance on the project, and thank you for visiting me to discuss my progress when I was conducting the greenhouse experiments in China. I also thank you for your critical comments and very helpful suggestions on my scientific writing. Whenever I need you inputs to my manuscript, you always gave me very constructive and timely feedbacks. I benefited a lot from your professional supervision and critical commenting on my manuscripts. I appreciate your help on improving my English by lending English books and recommending English movies to me. When I was facing difficulties, you always gave me timely support and suggestions. I especially thank you for the support you gave to me during the corona crisis period.

I am deeply indebted to Thom, for being my second promotor and giving me so many suggestions on my project and constructive and inspiring comments on the manuscripts. You are the most intelligent person I have ever met. You can always come up with special perspectives on the key points in the manuscript. Your valuable and timely feedbacks on the manuscript highly improved the quality of my work. Thanks for your help and encouragements to me when I came across problems. I remember you told me all the problems can be resolved. The discussions and meetings with you were always full of inspirations, laughs and happiness. I am very moved by your passion to science and your optimistic attitude to life.

I would like to express my sincere gratitude to Wopke, my co-promotor. I am so lucky to have you in my $\mathrm{PhD}$ project. You continuously guided me to think by myself and you taught me 
how to articulate research questions and hypothesis, and how to write a good story. Your critical questions and detailed comments often greatly improved the manuscripts. I appreciate your timely replies to my questions by email and your time for our many long and helpful meetings even if during weekends. I also appreciate that you suggested me to take several master courses, which greatly improved my English and scientific skills. All these trainings are very helpful for me in my future career. I am very grateful to your wife, Ms. Saskia Beverloo, for the warmly invitations and nice dinners.

I would like to express my earnest thanks to Fusuo, my co-promotor and also my MSc supervisor. I am very lucky to be your student since 2011. I really appreciate that you recommended me to do a $\mathrm{PhD}$ in Wageningen University. Your wide scientific horizons and innovative perspectives on scientific questions inspired my enthusiasm for science. You are the role model for me. Your encouraging words to me always stimulate me to work hard and to have self-confidence when I meet difficulties. My gratitude to Fusuo is beyond words. I feel very happy that I can continue my work in your group in the future.

I thank Haigang and Junling, who provided many supports on my life in CAU and many careful arrangements for me to do experiments in China. Without your help, I would not finish all the experiments smoothly. I would like to thank Chaochun Zhang, Yang Yu and Jianhao Sun, who are the co-authors of my manuscripts. It is because of your involvement that tremendously helps me about the data collection, data analysis and the establishment and management of the field experiments.

I also would like to thank my colleagues and friends in China. I want to give many thanks to Zhan Xu (徐崭) and Xingchen Yu (于星辰), who are smart students and helped me a lot when I did pot experiments in China. I also thank Zhan to do proofing of my thesis. I am grateful to 张伟娜、马文龙、唐小梅、徐秀、申琪、温智辉, who helped me to fill the pots, wash the sands, wash roots in the greenhouse, or wash the tubes in the lab, or collect the rhizosphere samples in the field. I thank my other colleagues in CAU, 李国华、乔旭、孙东宝、周文利、王男麒、王 光州、吕阳、唐晓燕、金可默、焦小强。I would like to express my sincere thanks to 李欠欠, 张 德闪 for their accompany and encouragements to me during my PhD in China. I am grateful to Yuyun Wang (王宇蕴) for sending the soil from Kunming to me for the pot experiments. I am also grateful to 孙建好、赵建华 and 张浩奇, who helped me to manage the field experiments in Zhangye.

I also would like to thank all the people who made me have an enjoyable time in Wageningen. I am very grateful to my colleagues in Soil Biology Group. My profound appreciation goes to our excellent secretary, Marnella van der Tol. Marnella, thank you very much for your great help and arrangements for my arriving, staying and leaving Wageningen. You also helped me a lot in reading Dutch letters, dealing with the tax affairs, and printing thesis. I express my 
special thanks to your many emails and calls to deal with my flight tickets to China during the corona crisis. I would also like to express my appreciation to all other SBL colleagues, Rachel Creamer, Gerlinde De Deyn, Jan Willem van Groenigen, Ron de Goede, Mirjam Pulleman, Marie Zwetsloot, Gabriel Moinet, Paolo Di Lonardo, Laura Martinez Garcia, Willeke van Tintelen. I also want to mention CSA colleagues, Tjeerd-Jan Stomph, Jochem Evers, Lammert Bastiaans, Niels Anten, for their comments when I joined the lunch seminar in CSA.

I would like to thank many PhD fellows in Wageningen: Franchesca, Kalima, Mart, Natalie, Rima, Meixiu, Carmen, Laura, Peipei, Rocio, Carlos, Giulia, Omotola, Anupol, Hui, Yilina. You brought me great happiness and nice memories in Wageningen. Mirjam and Hannah, my roommates, thanks for your accompany in the office and your invitation for Dutch dinners. Janna, thank you for helping me to move in Wageningen, and thank you for the online drinks with me during corona lock-down. Meixiu and Mirjam, thank you very much for willing to be my paranymphs, although the defence is online. Dear all my colleagues, thanks for sharing your insights and feedbacks during the thesis ring, drinks and the office-chats. I enjoyed the coffee break, cakes, potlucks, dinners, drinks and outdoor activities with you.

I would also like to thank all my Chinese friends in Wageningen. I thank the friends for their help for me when I came to Wageningen at the first time: Yong Hou, Xinxin Wang, Wei Qin, Yang Yu, Fang Gou, Junqi Zhu, Jingmeng Wang, Qian Liu, Zhaohai Bai, Chunxu Song, Dan Yan. Mengru, Zishen, Bei, Qi, Shuangwei, Keli, Qian, Chunfeng, thanks for organizing dinners and drinks, which made my stay in Wageningen pleasant. Zhaojun, I enjoyed doing gardening with you, which relaxed my life in Wageningen. Chunfeng, thank you for designing my thesis cover and I love it very much!

I would like to express my deepest gratitude to my parents, my sisters, and my brother. I could not give you many accompanies because of my long journey of study far away from our home. I am greatly indebted to your understanding and supports throughout my study. Finally, I want to thank my husband Xingxin Wang for sharing the ups and downs during my $\mathrm{PhD}$ study. Your continuous suggestions and encouragements to me stimulated me to pursue my study. It is my greatest happiness to have you with me in the past years, although there were several long periods of separations. We are finally together now and I look forward to all the rest of our life be full of joys and happiness.

\section{Chunjie Li}

Beijing

August 2020 


\section{Publication list}

In this thesis

Li CJ, Hoffland E, Kuyper TW, Yang Y, Li HG, Zhang CC, Zhang FS, Van der Werf W (2020) Yield gain, complementarity and competitive dominance in intercropping in China: A meta-analysis of drivers of yield gain using additive partitioning. European Journal of Agronomy 113:125987.

Li CJ, Kuyper TW, Van der Werf W, Zhang JL, Li HG, Zhang FS, Hoffland E (2019) Testing for complementarity in phosphorus resource use by mixtures of crop species. Plant and Soil 439:163-177.

Li CJ, Hoffland E, Kuyper TW, Yang Y, Zhang CC, Li HG, Zhang FS, Van der Werf W (2020) Syndromes of production in intercropping impact yield gains. Nature Plants 6: 653-660.

Li CJ, Kuyper TW, Van der Werf W, Zhang JL, Li HG, Zhang FS, Hoffland E (2020) A conceptual framework and an empirical test of complementarity and facilitation with respect to $\mathrm{P}$ uptake by species mixtures. Under revision for publication in Pedosphere.

Li CJ, Hoffland E, Van der Werf W, Zhang JL, Li HG, Sun JH, Zhang FS, Kuyper TW (2020) Complementarity and facilitation with respect to $\mathrm{P}$ acquisition do not drive overyielding by intercropping. Submitted.

Other peer-reviewed articles

Xu Z, Li CJ, Zhang CC, Yu Y, Van der Werf W, Zhang F (2020) Intercropping maize and soybean increases efficiency of land and fertilizer nitrogen use; A meta-analysis. Field Crops Research 246:107661.

Li CJ, Dong Y, Li HG, Shen JB, Zhang FS (2016) Shift from complementarity to facilitation on $\mathrm{P}$ uptake by intercropped wheat neighboring with faba bean when available soil $\mathrm{P}$ is depleted. Scientific Reports 6:18663.

Qiao X, Bei SK, Li CJ, Dong Y, Li HG, Christie P, Zhang FS, Zhang JL (2015) Enhancement of faba bean competitive ability by arbuscular mycorrhizal fungi is highly correlated with dynamic nutrient acquisition by competing wheat. Scientific Reports 5:8122.

Li CJ, Dong Y, Li H, Shen J, Zhang F (2014) The dynamic process of interspecific interactions of competitive nitrogen capture between intercropped wheat (Triticum aestivum L.) and faba bean (Vicia faba L.). Plos One 9. 


\section{PE\&RC Training and Education Statement}

With the training and education activities listed below the $\mathrm{PhD}$ candidate has complied with the requirements set by the C.T. de Wit Graduate School for Production Ecology and Resource Conservation (PE\&RC) which comprises of a minimum total of 32 ECTS (= 22 weeks of activities)

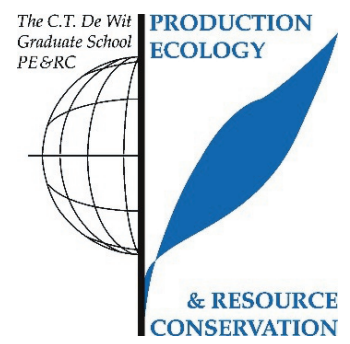

\section{Review of literature (4.5 ECTS)}

- Complementarity between intercropped plants for improving P use efficiency

\section{Writing of project proposal (4.5 ECTS)}

- P4two: Designing for Complementarity in Phosphorus Use in Intercropping

\section{Post-graduate courses (5.6 ECTS)}

- Microbial Ecology; PE\&RC (2015)

- $\quad$ Mixed Effects Model; PE\&RC (2017)

- Soil Ecology; PE\&RC (2018)

- Multivariate Analysis; PE\&RC (2019)

\section{Invited review of (unpublished) journal manuscript (5 ECTS)}

- Annuals of Botany: species' capacity to use sparingly soluble P forms (2015)

- Environmental Science \&Technology: the liberation of P in the rhizosphere (2017)

- Land Degradation \& Development: nitrogen transfer between intercropped maize and alfalfa (2019)

- Field Crops Research: nitrogen transfer between intercropped maize and alfalfa (2019)

- Plos One: facilitation and competition in intercropping (2019)

\section{Deficiency, refresh, brush-up courses (12 ECTS)}

- Functional Diversity for Sustainable Crop Production; CSA (2015)

- Ecological Modelling and Data Analysis in R; CSA (2018)

\section{Competence strengthening / skills courses (3.6 ECTS)}

- PhD Competence Assessment; WGS (2015)

- Project and Time Management; WGS (2015)

- Scientific Writing; WGS (2017)

- The Last Stretch of the PhD Programme; PE\&RC (2019)

- Writing Propositions for Your PhD; PE\&RC (2019) 
PE\&RC Annual meetings, seminars and the PE\&RC weekend (1.2 ECTS)

- PE\&RC Middle Years Weekend (2017)

- PE\&RC Day (2017)

- Plant-Soil Feedback Symposium (2019)

\section{Discussion groups / local seminars / other scientific meetings (4.8 ECTS)}

- Current Themes in Ecology: Biodiversity Research at the Crossroads; Wageningen, the Netherlands (2014)

- PE\&RC Discussion Group, Plant-Soil Interactions; Wageningen, the Netherlands (2017)

- Workshop on Cover Crop Mixtures; Kleve, Germany (2017)

- ReMIX Discussion Group Meeting; Wageningen, the Netherlands (2017)

- Carbon Dilemma; Wageningen, the Netherlands (2018)

- National Conference on Agriculture Green Development; Shijiazhuang, China (2018)

- DISQ Thesis Ring; Wageningen, the Netherlands (2017-2019)

- Intercropping Discussion Group Meeting; Wageningen, the Netherlands (2019)

\section{International symposia, workshops and conferences (9.7 ECTS)}

- The International Workshop of Intercropping for Agronomy and Ecology; oral presentation; Xi'an, China (2015)

- $9^{\text {th }}$ International Phosphorus Workshop (IPW9); oral presentation; Zurich, Switzerland (2019)

- Wageningen Soil Conference; Wageningen, the Netherlands (2019) 


\section{Funding}

The research described in this thesis was financially supported by the Projects of International Cooperation and Exchanges NSFC (31210103906), the National Key R\&D Program of China (2017YFD0200200/2017YFD0200207), the China Scholarship Council (201606350142), and the Wageningen University PhD Fellowship.

Cover design Chunfeng $\mathrm{Gu}$ and Chunjie Li

Printing ProefschriftMaken.nl / Digiforce 



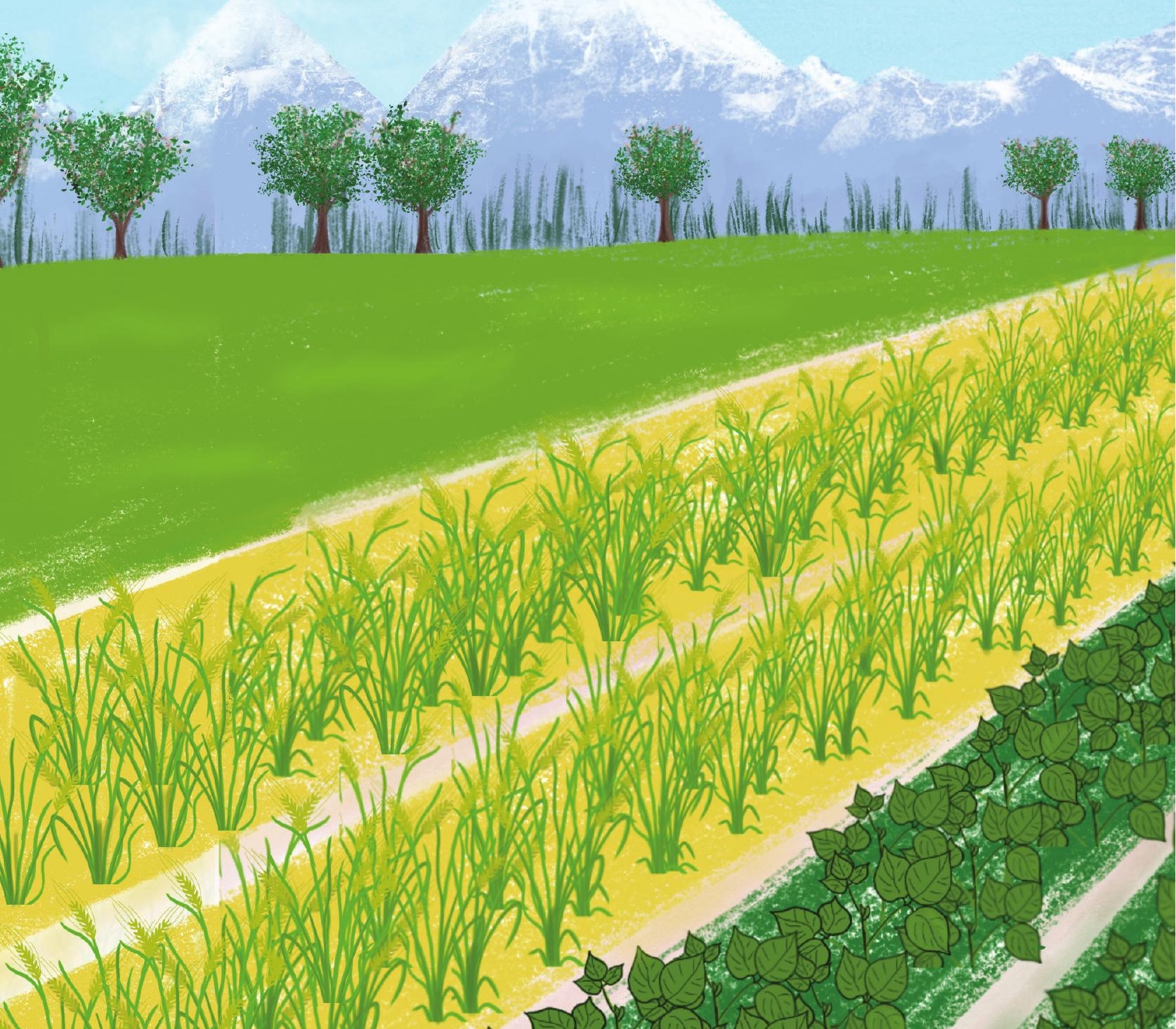

